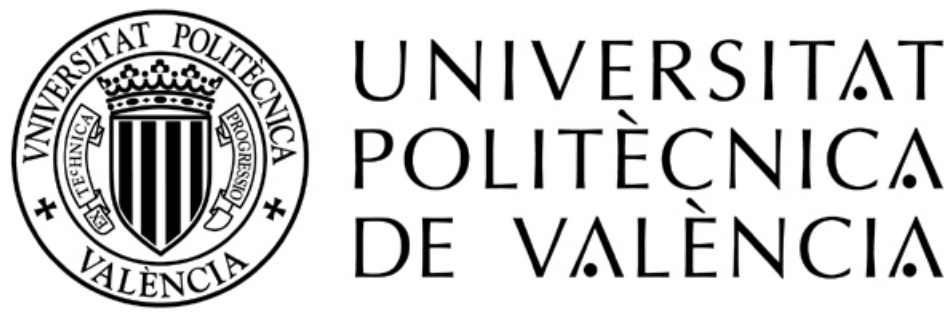

\title{
Acoustics for underwater neutrino telescopes
}

Tesis Doctoral

Manuel Bou Cabo

Enero 2011

Director de tesis

Dr. Miguel Ardid Ramírez
Codirector de tesis

Dr. Víctor Espinosa Roselló 


\section{Contents}

0 Summary of doctoral thesis (in Spanish, English and Catalan).

$1 \quad$ Underwater neutrino telescopes.

1.1 Introduction to underwater neutrino telescopes.

9

1.2 Scientific aims of underwater neutrino telescopes.

1.3 ANTARES.

$1.4 \mathrm{KM} 3 \mathrm{NeT}$.

$2 \quad$ Acoustic positioning system.

2.1 ANTARES positioning system.

2.2 R\&D for the KM3NeT acoustic positioning system.

3 Development of calibration systems for acoustic detection of neutrinos.

$4 \quad$ Publication summaries (in Spanish).

References.

Publications. 


\section{Summary of doctoral thesis.}

\section{Síntesis.}

En esta tesis se tratan diferentes aspectos de la acústica presente en un telescopio submarino de neutrinos, principalmente en dos vertientes: en el sistema de posicionamiento acústico utilizado para la monitorización de las posiciones de los módulos ópticos presentes a lo largo del detector, así como en sistemas para detección acústica de neutrinos, técnica que actualmente está en fase de estudio. Todos los estudios realizados están enmarcados dentro de dos colaboraciones europeas para el diseño, construcción y operación de telescopios submarinos de neutrinos: ANTARES (en fase de operación) y KM3NET (en fase de diseño).

\section{Objetivos.}

Los objetivos de este trabajo pueden resumirse en los siguientes aspectos:

- Estudios y análisis del sistema de posicionamiento acústico de ANTARES. Desarrollo del software para la automatización del procesado de los datos de dicho sistema e incorporación de los resultados en la base de datos del experimento. Análisis de los datos proporcionados por dicho sistema con el fin de validar su correcto funcionamiento.

- Diseño y desarrollo del sistema de posicionamiento acústico para $\mathrm{KM} 3 \mathrm{NeT}$, telescopio unas 20 veces más grande que ANTARES.

- Estudios para la evaluación de la generación acústica paramétrica para el desarrollo de un calibrador compacto capaz de generar señales tipo neutrino útiles en sistemas de detección acústica.

\section{Elementos de la metodología a destacar.}

Cabe destacar aquí que el trabajo se ha desarrollado en el marco de dos colaboraciones internacionales: ANTARES y KM3NeT, financiados con fondos europeos y nacionales. Por su contexto y el carácter de las actividades realizadas ha sido necesaria la formación en distintos campos: telescopios de neutrinos y astropartículas, pero también en otras áreas como la acústica submarina. Además, se ha desarrollado diversas capacidades y destrezas en diversos ámbitos: en instrumentación, en aplicaciones informáticas, en análisis de datos, etc.

Más concretamente, se ha trabajado en aplicaciones informáticas para los desarrollos y análisis en ANTARES. Por otro lado, se ha trabajado en tecnologías de acústica submarina para el desarrollo del sistema de posicionamiento acústico para KM3NeT con los requerimientos impuestos por dicha infraestructura: medio hostil (en el mar a unos $3000 \mathrm{~m}$ de profundidad sometido a altas presiones), alta precisión requerida $(10 \mathrm{~cm}$ en distancias del orden del kilómetro), bajo consumo eléctrico, capacidad de comunicación y configuración, etc. Para el desarrollo del calibrador compacto de señales tipo neutrino se ha conseguido realizar estudios pioneros de generación paramétrica en casos con simetría cilíndrica y señales transitorias y aplicarlos 
para el desarrollo del calibrador capaz de producir una señal bipolar transitoria altamente directiva.

\section{Resultados logrados.}

Los resultados logrados en la realización de esta tesis doctoral pueden resumirse atendiendo a las tres temáticas abordadas, posicionamiento acústico para KM3NeT, colaboración en el proyecto ANTARES y diseño y evaluación de técnicas para detección acústica de neutrinos:

- Dentro de la colaboración en el telescopio de neutrino ANTARES han sido realizados numerosos estudios para comprobar la estabilidad y precisión de los diferentes elementos que componen el sistema de posicionamiento, siendo todos los resultados satisfactorios. También se desarrolló una interfaz (desarrollada en $\mathrm{C}++$ en entorno Linux) que permitió la incorporación de los datos del sistema de posicionamiento acústico en la base de datos y así proporcionar éstos para la posterior reconstrucción de las partículas detectadas.

- Diseño y desarrollo del sistema de posicionamiento acústico para el telescopio de neutrinos $\mathrm{KM} 3 \mathrm{NeT}$. En el marco de este proyecto se ha desarrollado el sistema de transceptores acústicos para un nuevo sistema de posicionamiento que será testeado y validado durante el verano de 2011 en el prototipo NEMO-KM3NeT en el mar a $3500 \mathrm{~m}$ de profundidad cerca de Capo Passero (Sicilia).

- En relación al desarrollo de un calibrador acústico que imita el pulso de la interacción del neutrino, los estudios realizados para la evaluación de la técnica de generación acústica paramétrica con este fin ha tenido resultados satisfactorios y prometedores para la posible construcción de un calibrador compacto, cuyo prototipo se ha empezado a desarrollar.

Todas estas actividades y resultados científico-tecnológicos han sido útiles para el desarrollo del área de los telescopios de neutrinos submarinos, y como tal han sido publicados en revistas científicas internaciones.

\section{Formato de presentación de la tesis.}

Esta tesis se presenta en la modalidad de artículos, es decir, el núcleo central que constituye la tesis es la participación y contribuciones del doctorando en las publicaciones que se adjuntan al final del documento. Con el fin de introducir y contextualizar la labor de investigación, además de este resumen, se presenta también en la memoria una introducción a los telescopios submarinos de neutrinos, a los sistemas de posicionamiento acústico, referidos especialmente a ANTARES y KM3NeT, y a las actividades encaminadas a la detección acústica de neutrinos, principalmente en I+D en calibración para esta técnica. También se adjunta unos resúmenes de los artículos en español. 


\section{Synthesis.}

In this thesis different aspects of acoustics present in an underwater neutrino telescopes are treated, mainly in two topics: the acoustic positioning system used to monitor the positions of the optical modules placed along the detector, and the systems for acoustic neutrino detection technique, which is currently under study. All studies are framed in two European partnerships for the design, construction and operation of undersea neutrino telescope, ANTARES (under operation) and $\mathrm{KM} 3 \mathrm{NeT}$ (design phase).

\section{Objectives.}

The objectives of this study can be summarized in the following aspects:

- Research and analysis of acoustic positioning system of ANTARES. Development of software for the automation of data processing system and incorporating the results into the database of the experiment. Analysis of data from the system in order to validate its correct operation.

- Design and development of the acoustic positioning system for the $\mathrm{KM} 3 \mathrm{NeT}$ telescope, which will be about 20 times larger than ANTARES.

- Studies to evaluate acoustic parametric generation for the development of a compact calibrator capable of generating signals useful to calibrate neutrino acoustic detection systems.

\section{Elements of the methodology to emphasize.}

It should be noted here that the work has been developed within the framework of two international collaborations: ANTARES and KM3NeT, with the support of European and National funds. Due to the context and nature of activities it has been needed training in different fields: astroparticle and neutrino telescopes, but also in other areas such as underwater acoustics. It has also been needed to develop abilities and skills in various areas: instrumentation, applications, data analysis, etc. More specifically, we have worked on software for the development and analysis at ANTARES and in underwater acoustic technologies for the development of KM3NeT acoustic positioning system with the requirements imposed by the infrastructure: hostile environment (in the sea about $3000 \mathrm{~m}$ depth under high pressure), high precision required (10 $\mathrm{cm}$ over distances of the order of kilometers), low power consumption, communication capabilities and configuration, etc. For the development of the compact calibrator to reproduce neutrino like signals, pioneering studies of parametric generation in cases with cylindrical symmetry and transient signals have been achieved and applied in order to develop a device that can produce a highly directive transient bipolar signal.

\section{Results achieved.}

The results achieved in the realization of this thesis can be summarized in response to the three issues under discussion, acoustic positioning $\mathrm{KM} 3 \mathrm{NeT}$, ANTARES project collaboration and design and evaluation of techniques for acoustic detection of neutrinos: 
- Within the collaboration in the ANTARES neutrino telescope, numerous studies have been conducted to verify the stability and accuracy of the various components of the positioning system and of the results. Also an interface (using $\mathrm{C}_{++}$/Oracle in Linux environment) has been done that allows the incorporation of data from the acoustic positioning system in the database and thus provide these for the subsequent reconstruction of particles detected.

- Design and development of acoustic positioning system for KM3NeT neutrino telescope. As part of this project a system of acoustic transceivers for a new positioning system has been developed and will be tested and validated during the summer of 2011 in the NEMO$\mathrm{KM} 3 \mathrm{NeT}$ prototype at $3500 \mathrm{~m}$ deep sea near Capo Passero (Sicily).

- In relation to the development of an acoustic calibrator that mimics the pulse of the neutrino interaction, studies for the evaluation of parametric sound generation technique for this purpose has been done, obtaining successful and promising results for the possible construction of a compact calibrator device, whose prototype is being developed.

These activities and scientific and technological results have been useful for the development in the field of underwater neutrino telescopes, and as such, they have been published in international scientific journals.

\section{Format of the thesis presentation.}

This thesis is presented in the "articles" modality, that is, the central core of the thesis is the participation and contributions of the Doctorate Candidate on the publications attached at the end of the memory. In order to introduce and contextualise the research tasks, in addition to this summary, there are also in the report introductions to underwater neutrino telescopes, to the acoustic positioning systems, referred to ANTARES and KM3NeT, and to the activities related to acoustic detection of neutrinos, mainly in $R \& D$ in calibration for this technique. There is, as well, a summary of the publications in Spanish. 


\section{Síntesi.}

En aquesta tesi es tracten diferents aspectes de l'acústica present en un telescopi submarí de neutrins, principalment en dues vessants: en el sistema de posicionament acústic utilitzat per a la monitorització de les posicions dels mòduls òptics presents al llarg del detector, així com en sistemes per a detecció acústica de neutrins, tècnica que actualment està en fase d'estudi. Tots els estudis realitzats estan emmarcats dins de dos col-laboracions europees per al disseny, construcció i operació de telescopis submarins de neutrins: ANTARES (en fase d'operació) i KM3NET (en fase de disseny).

\section{Objectius.}

Els objectius d'aquest treball es poden resumir en els següents aspectes:

- Estudis $i$ anàlisi del sistema de posicionament acústic d'ANTARES. Desenvolupament dels codis informàtics per a l'automatització del processat de les dades d'aquest sistema i incorporació dels resultats a la base de dades de l'experiment. Anàlisi de les dades proporcionades per aquest sistema per tal de validar el seu correcte funcionament.

- Disseny i desenvolupament del sistema de posicionament acústic per $\mathrm{KM} 3 \mathrm{NeT}$, telescopi unes 20 vegades més gran que ANTARES.

- Estudis per a l'avaluació de la generació acústica paramètrica per al desenvolupament d'un calibrador compacte capaç de generar senyals tipus neutrí útils en sistemes de detecció acústica.

\section{Elements de la metodologia a destacar.}

Cal destacar aquí que el treball s'ha desenvolupat en el marc de dos col-laboracions internacionals: ANTARES i $\mathrm{KM} 3 \mathrm{NeT}$, finançats amb fons europeus i nacionals. Pel context i el caràcter de les activitats realitzades ha estat necessària la formació en diferents camps: telescopis de neutrins $i$ astropartícules, però també en altres àrees com l'acústica submarina. A més, s'ha desenvolupat diverses capacitats i destreses en diversos àmbits: en instrumentació, en aplicacions informàtiques, en anàlisi de dades, etc. Més concretament, s'ha treballat en aplicacions informàtiques per als desenvolupaments $i$ anàlisi en ANTARES. D'altra banda, s'ha treballat en tecnologies d'acústica submarina per al desenvolupament del sistema de posicionament acústic per KM3NeT amb els requeriments imposats per la infraestructura: medi hostil (al mar a uns $3000 \mathrm{~m}$ de profunditat sotmès a altes pressions), alta precisió requerida $(10 \mathrm{~cm}$ en distàncies de l'ordre del quilòmetre), baix consum elèctric, capacitat de comunicació i configuració, etc. Per al desenvolupament del calibrador compacte de senyals tipus neutrí s'ha aconseguit realitzar estudis pioners de generació paramètrica en casos amb simetria cilíndrica i senyals transitòries i aplicar-los per al desenvolupament del calibrador capaç de produir un senyal bipolar transitori altament directiu.

\section{Resultats assolits.}

Els resultats aconseguits en la realització d'aquesta tesi doctoral es poden resumir atenent a les tres temàtiques abordades, posicionament acústic per 
KM3NeT, col-laboració en el projecte ANTARES i disseny i avaluació de tècniques per a detecció acústica de neutrins:

- Dins de la col-laboració en el telescopi de neutrins ANTARES han estat realitzats nombrosos estudis per comprovar l'estabilitat i precisió dels diferents elements que composen el sistema de posicionament, sent tots els resultats satisfactoris. També es va desenvolupar una codi informàtic (desenvolupat en llenguatge $\mathrm{C}++$ en entorn Linux) que va permetre la incorporació de les dades del sistema de posicionament acústic a la base de dades i així ficar a l'abast de tothom aquests dades per a la posterior reconstrucció de les partícules detectades.

- Disseny i desenvolupament del sistema de posicionament acústic per al telescopi de neutrins $\mathrm{KM} 3 \mathrm{NeT}$. En el marc d'aquest projecte s'ha desenvolupat el sistema de transceptors acústics per a un nou sistema de posicionament que serà testejat i validat durant l'estiu de 2011 en el prototip NEMO-KM3NeT al mar a 3500 m de profunditat a prop de Capo Passero (Sicília).

- En relació al desenvolupament d'un calibrador acústic que imita el pols de la interacció del neutrí, els estudis realitzats per a l'avaluació de la tècnica de generació acústica paramètrica, aquest efecte ha tingut resultats satisfactoris i prometedors per a la possible construcció d'un calibrador compacte, el prototip s'ha començat a desenvolupar.

Totes aquestes activitats i resultats científic-tecnològics han estat útils per al desenvolupament de l'àrea dels telescopis de neutrins submarins, i com a tal han estat publicats en revistes científiques internacionals.

\section{Format de presentació de la tesis.}

Aquesta tesi es presenta en la modalitat d'articles, és a dir, el nucli central que constitueix la tesi és la participació i contribucions del doctorand en les publicacions que s'adjunten al final del document. Per tal d'introduir i contextualitzar la tasca d'investigació, a més d'aquest resum, es presenta també en la memòria una introducció als telescopis submarins de neutrins, als sistemes de posicionament acústic, referits especialment a ANTARES i $\mathrm{KM} 3 \mathrm{NeT}$, i a les activitats encaminades a la detecció acústica de neutrins, principalment en $\mathrm{R}+\mathrm{D}$ en calibració per a aquesta tècnica. També s'adjunta uns resums dels articles en espanyol. 


\section{Underwater neutrino telescopes}

\subsection{Introduction to underwater neutrino telescope.}

Observation of high energy ( $10 \mathrm{GeV}-10 \mathrm{PeV})$ neutrinos can be considered as a 'new tool' useful to study astrophysical objects of the Universe such as Active Galactic Nuclei, Gamma Ray Burst, Supernova remnant, or dark matter. It could be very helpful as well in particle physics since it will allow testing astrophysical models through the neutrino interaction cross-sections or by comparing hadronic and electromagnetic processes. In this section we present just a global overview of the interests of the underwater neutrino telescopes; the scientific and technological challenges of this kind of facilities; and the difficulties for building and operating them.

The traditional way to observe and study the Universe has been based on the observation of photons and cosmic rays. These messengers have been very useful during last decades to establish a new 'era' of modern astrophysics observations but they have some drawbacks. Photons interact with matter, infrared radiation and with the cosmic microwave background. Due to these reasons some information that could be brought by photons does not reach the Earth. In its travel through the Universe, protons and nuclei are affected by magnetic fields so directional information can be lost. In addition it is important to consider the interaction that can suffer protons with $\gamma_{C M B}$ originating the 'GZK' cut off for energies higher than $5 \cdot 10^{19} \mathrm{eV}$.

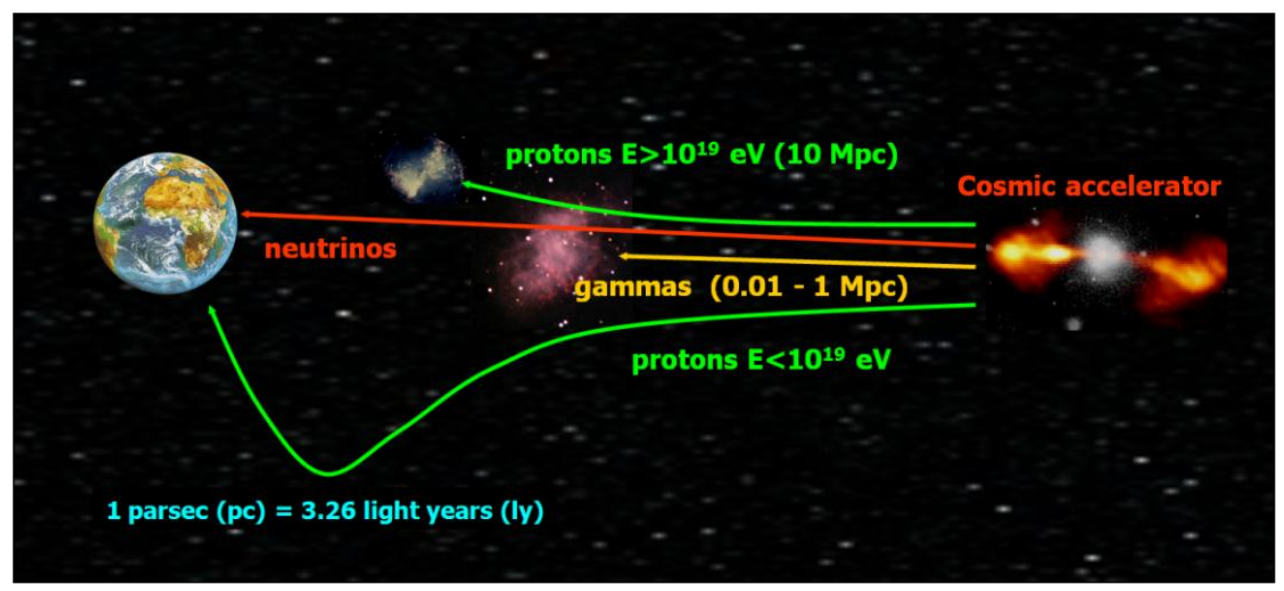

Figure 1.1. Scheme of the different kind of particles that can reach the Earth from astrophysical sources and its possible interaction with the medium along the path.

To obtain a good and complete description of the Universe it would be certainly interesting to observe and understand the internal composition of the astrophysical object, to have observations and measurements in a large energy range and have the possibility of detecting particles from distant sources. All these aspects would be possible if there would be a messenger, which was easily produced in astrophysical sources, with no electrical charge, so it would not be affected by magnetic fields, and with small probability of interaction, so they can escape of dense media and travel long distances. As schematically 
shown in Figure1.1, the only known candidate that verifies the properties exposed is the neutrino.

Neutrino is a sub-atomic fermion particle without electric charge that was proposed by Pauli at the 1930's to explain conservation of energy and linear momentum of $\beta$ decay.

$$
n \rightarrow p+e^{-}+\overline{v_{e}}
$$

Following Pauli's hypothesis, this particle would be massless and would have a very small cross-section $\sigma \sim 10^{-44} \mathrm{~cm}^{2}$. Our knowledge of these particles has improved during decades of study. We know that neutrino has a very little mass but is not zero, and there exists three kinds of neutrinos according to the three leptonic families $\left(v_{e}, v_{\mu}, v_{\tau}\right)$, and its corresponding anti-particles $\left(\bar{v}_{e}, \bar{v}_{\mu}, \bar{v}_{\tau}\right)$. Specific properties of the neutrino particle make it very interesting to do astrophysics.

As it has been pointed before, the interaction probability of the neutrino is very small, meaning that it will not be affected in its trajectory through the Cosmos to the Earth. It can, as well, escape from dense media allowing us to study the inner working mechanism of astrophysical objects. In addition, it is a neutral particle so magnetic fields do not affect the path along its Universe. On the other hand, the low probability of interaction makes difficult to detect them, and therefore, it is essential that neutrino telescopes have necessarily a big detection volume, especially for the case of energetic neutrinos where the fluxes are not so high. Since it is a neutral particle, the detection is based on the observation of secondary particles induced by neutrino interaction [MAR 60]. At present, the more advanced and promising projects of high energy neutrino telescopes (Amanda-Ice-Cube [RAW 07], ANTARES [ASL 99, BOU 09], $\mathrm{KM} 3 \mathrm{NeT}$ [BAG 08, KAT 09, BAG10], Baikal [AYN06]) use the detection of Cherenkov light of the resulting particles, mainly muons, produced on the interaction of a neutrino with nucleus of the natural media, such as ice or water. Ice Cube, an international consortium which main objective is the construction of a neutrino telescope at the South Pole, uses the ice as the active volume of detection. To have an idea of the complexity and technological challenge of these telescopes, we have just to say that Ice Cube is composed of approximately 80 lines, each one with 60 digital optical modules that are placed in deep holes of $2.54 \mathrm{~km}$ made with hot water drills. It is easy to understand the need of having a big volume of detection (of the cubic kilometre order) attending to the cosmic neutrino fluxes predicted $[\mathrm{CHI} \mathrm{10]} \mathrm{to} \mathrm{have,} \mathrm{at} \mathrm{least,} \mathrm{a} \mathrm{few} \mathrm{neutrino}$ events detected per year to test different astrophysical models or for neutrino astronomy.

Concerning ANTARES, it is an international project that has built an undersea neutrino telescope with 12 lines covering an area of $0.1 \mathrm{~km}^{2}$. It is located at 40 $\mathrm{km}$ of the south coast of France. Each line, submerged to a depth of about 2500 $\mathrm{m}$, has a height of approximately $450 \mathrm{~m}$ containing 25 floors with three optical 
modules. A schematic view of an ANTARES line and an artistic impression of Ice Cube can be seen in Figures 1.2 and 1.3 respectively.

On the other hand, KM3NeT is a European project for the design and construction of an undersea neutrino telescope with an effective volume of detection of $1 \mathrm{~km}^{3}$ in the Mediterranean Sea, at present it is under the preparatory phase for the construction. KM3NET involves more than 10 European countries and 40 universities and research institutes, and takes the experience from two important pilot projects NEMO [MIG 08] and NESTOR [RAP 09], and, obviously, from the ANTARES telescope.

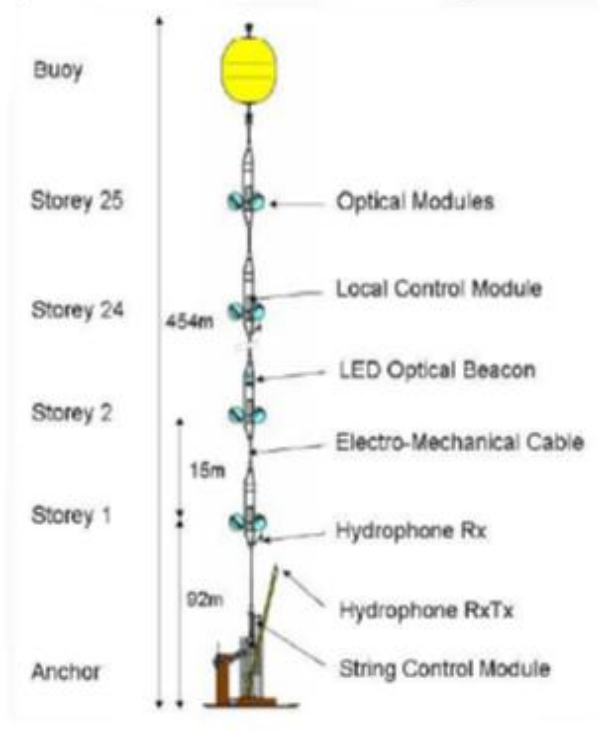

Figure 1.2. Schematic view of an ANTARES line.

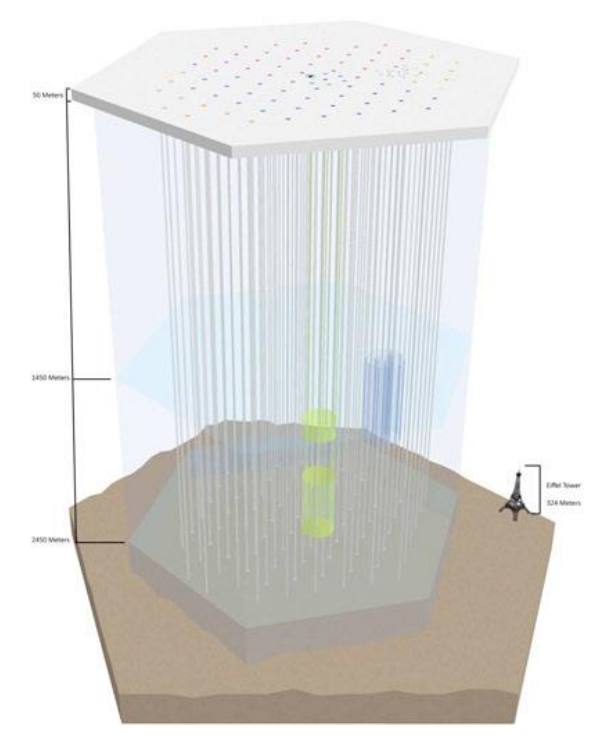

Figure 1.3. Artistic impression of Ice Cube

Array

Undersea neutrino telescopes present the advantage of having a better angular resolution ( $\sim 3^{\circ}$ at $\mathrm{E}>10 \mathrm{Tev}$ for ANTARES [B/G 09]) than those built in ice $\left(\sim 1^{\circ}\right.$ for Ice Cube). Advantages of building a detector in ice are that the deployment could be easier than in the sea and that the optical modules array are not affected by to sea current movements. Among undersea neutrino detection drawbacks, it should be included the radioactive decay of ${ }^{40} \mathrm{~K}$ that produces a high optical background and the bioluminescence, that is, light produced by living organism which depends of the season of the year, the temperature and other environmental factors.

With respect to neutrino interactions with matter, it is necessary to take into account the three different flavours of neutrino (electron, muon, tau) in order to distinguish between the different topologies that can be observed. For each type of neutrino, there exists the corresponding anti-neutrino, but they are usually not distinguishable in a neutrino telescope.

The major type of neutrino reactions (channels) can be summarized as follows:

$$
v_{e}+N \rightarrow e+X
$$


The signature that this reaction has is an electromagnetic shower plus a hadronic shower imposed. These showers can be detected by Cherenkov light if the interaction is inside of the detector. The angular resolution for this kind of events is fair, a few degrees at best.

$$
v_{\mu}+N \rightarrow \mu+X
$$

This kind of reaction produces a hadronic shower (which can be detected if interaction is inside or close of the detector) and a high energy muon which produces a track along the detector volume. The high energy muon is a good signature to detect neutrino interactions even for interactions outside the detector, especially for those directions where the muon could not come directly from cosmic ray showers. Moreover, the angular resolution for high energy muons can be very good, $\sim 0.1$.

$$
v_{\tau}+N \rightarrow \tau+X
$$

This reaction could produce different channels:

$$
\begin{gathered}
\tau \rightarrow v \bar{\nu} \mu \rightarrow v_{\mu}+N \rightarrow \mu+X \\
\tau \rightarrow v \bar{v} e \rightarrow v_{e}+N \rightarrow e+X \\
\tau \rightarrow v+\text { hadrons }
\end{gathered}
$$

Tau events could also produce the characteristic 'double bang' signature, which originates two showers, first comes from the production and then decay of a tau particle and second happens when tau leptons originated at first cascade decays into a tau neutrino.

All these reactions produces hadronic shower. The energy resolution is poor due to the fact that a large fraction of the $v_{\tau}$ energy goes to secondary neutrinos and the direction reconstruction can be good for the first channels but poorer for the rest.

Among the different kinds of neutrino interactions, the muon channel is the most suitable for astroparticle observation and the orientation and depth of the optical modules are selected to optimise the performance of this detection channel. Both, ice and water, neutrino telescopes have been designed taking advantage of the Earth as a shield, which stops all particles except neutrinos (very high energy neutrinos can also be stopped by the Earth). For this reason, we have to be able to detect upward-going muons that come from $v_{\mu}$ interactions and discriminate them from downward atmospheric muons. To reduce the huge amount of atmospheric muon background it is necessary that the neutrino telescope is installed in a deep site (as an example of what means deep site, it should be noted that Antares is installed $2475 \mathrm{~m}$ of depth, the tests performed in different phases of the Nemo project were performed at $3450 \mathrm{~m}$ and studies of Nestor were done at $4100 \mathrm{~m}$ of depth). Additionally to the deep location, the orientation of photomultipliers usually suited for the detection of upward-going muons. This is why in ANTARES the photomultipliers are oriented $45^{\circ}$ below of the horizontal. 
In any case, the detection principle of all these telescopes is based on the collection of the Cherenkov light using a 3D array of optical modules with photomultipliers, distributed inside the detection volume. Cherenkov light emission occurs when a charged particle pass through a medium exceeding light velocity in the medium. The light is emitted in a cone form with an angle $\theta$ which depends of the particle velocity and the refractive index of the medium:

$$
\cos \theta=\frac{1}{n \cdot \beta}
$$

The number of photons produced along a flight path $\mathrm{dx}$ in a wavelength bin $\mathrm{d} \lambda$ for a particle carrying unit charge is:

$$
\frac{d^{2} N}{d \lambda \cdot d x}=\frac{2 \cdot \pi \cdot \alpha}{\lambda^{2}} \cdot \sin ^{2} \theta
$$

Knowing the time ( $1 \mathrm{~ns}$ precision) and the position $(\sim 10 \mathrm{~cm}$ precision) of the illuminated photomultipliers, it is possible to reconstruct the muon trajectory and therefore, the incoming neutrino direction. The amount of light collected, the number of photomultipliers with signals, the number of hits detected by each photomultiplier can in some cases help to estimate the neutrino energy. In order to do so properly time and position calibration systems are needed. For instance, very large underwater neutrino telescopes need real-time measurement of the positions of their optical sensors, since these are attached to some partially-mobile, non-rigid structure. Undersea currents can displace the optical sensors by up to several meters from their nominal positions. Time synchronization is assured using different time calibration systems and techniques: measurements of the different optical module delays in the lab before deployment, using light sources (LED and Laser beacons), studying ${ }^{40} \mathrm{~K}$ coincidences, and looking at time residuals of atmospheric muons.

Considering that underwater neutrino telescopes are based on light detection, the characterization of the site is another essential aspect. In this sense measurements related to deep-sea water optical properties (absorption and scattering) and environmental properties (water temperature, salinity, biological activity, optical background, water currents and sedimentation) are needed. This aspect is very important for $\mathrm{KM} 3 \mathrm{NeT}$ project to select between different candidates the most optimal location to build a future detector with $1 \mathrm{~km}^{3}$ of effective volume of detection. 


\subsection{Scientific aims of the underwater neutrino telescopes.}

The scientific program of the underwater neutrino telescopes is vast, as we will see in this section. Of course, the implications of the observations that could be done using these detectors and the corresponding studies are related to the kind of neutrino sources expected to be observed, and to the understanding of some astrophysical open problems in which the generation and observation of neutrinos could bring some light [CHI 10]. The main goal of underwater neutrino telescopes is the observation of astrophysical objects like Active Galactic Nuclei (AGN), Gamma Ray Bursts (GRBs), Microquasars, or Supernova Remnants. In fact, astrophysical objects that are able to accelerate protons and nuclei in a wide range of energy are possible candidates to be considered as neutrino sources due to a possible interaction of these accelerated cosmic rays with matter or radiation located in the surroundings of the source. Other interesting applications of underwater neutrino telescopes will be the indirect detection of dark matter using neutrinos generated by the annihilation of weakly interacting massive particles (WIMPs) captured by celestial bodies like the Earth, the Sun or even the Galactic Center. Finally, these detectors are also good for the understanding of some particle physics processes involving for example neutrino oscillations or neutrino interaction cross-sections.

In addition, and due to the particular location of underwater neutrino telescopes, these infrastructures offer the possibility to extend the scientific program beyond the astroparticle physics field by including in the facility different sensors for Earth and Sea studies. The continuous monitoring of these sensors in real time is a powerful tool for environmental studies, and to bring some light in the understanding of different multidisciplinary problems such as ocean dynamics, climate change, etc.

As a very general introduction about generation of neutrinos, taking into account that, contrary to what happens with mono-energetic beams generated by machines on Earth, cosmic accelerators produce power law spectra of ions at high energy, $\Phi_{p} \propto E^{-\gamma}$. In general, at cosmic accelerator the dominant mechanism is first order diffusive shock acceleration (first order Fermi mechanism), which will produce a spectrum with $\gamma \sim 2+\varepsilon$, where $\varepsilon$ is a small number.

It is possible to distinguish three types of neutrino spectra that can be produced by cosmic rays:

- Neutrinos produced by cosmic rays at their acceleration sites and following the hard $(\gamma \sim 2.0-2.2)$ cosmic ray source spectra.

- Neutrinos produced by galactic cosmic rays in interaction with interstellar gas. This kind of neutrinos should follow the cosmic ray spectrum up to the highest energies, since all interaction products, including muons, decay.

- Atmospheric neutrinos, which follow a spectrum with $\gamma \sim 2.7$ up to $\sim 100 \mathrm{GeV}$ and the power increases towards $\gamma \sim 3.7$ at higher energies.

At next paragraphs the most interesting sources of neutrino that can be studied by underwater neutrino telescopes will be pointed. 
Neutrino studies.

- Active Galactic Nuclei (AGN)

AGNs are promising candidates as neutrino sources since these astrophysical objects have high neutrino luminosity. AGN models propose that this high neutrino luminosity comes from accretion of matter at a rate of few solar masses per year (onto a massive black hole the accretion rate can be from $10^{6}$ to $10^{10}$ solar masses). Some AGNs also produce highly collimated jets of plasma which transport synchrotron electrons with opening angles of a few degrees or less. The origin of high energy component of emission by AGN can be explained by hadronic model [ACH 06]. Acceleration of protons is assumed to occur by the first order diffusive Fermi mechanism and the shock, resulting in an $E^{-2}$ differential spectrum that extends up to $E_{\max }$. Energy loss processes occur during acceleration, including $p \gamma \rightarrow n \pi$ and $p \gamma \rightarrow p+e^{+}+e^{-}$in the dense radiation fields as well as $p p$ colissions in the gas. All three processes contribute an energetic electromagnetic component, either through $\pi^{0} \rightarrow \gamma \gamma$ or by production of electrons. Both photo-meson production and $p p$ collisions also give rise to neutrinos via $\pi^{ \pm} \rightarrow \mu^{ \pm} \rightarrow e^{ \pm}$, decay chain. An important detail is that photoproduction of charged pions by protons is dominated by $n \pi^{+}$channel [STE 68]. Summarizing the most important reactions can be;

$$
\begin{aligned}
& p \gamma \rightarrow \Delta^{+} \rightarrow n \pi^{+} \\
& p p \rightarrow \pi^{ \pm} N \\
& \pi^{+} \rightarrow \mu^{ \pm} v_{\mu} \rightarrow e^{ \pm} v_{e} v_{\mu} v_{\mu} \\
& \pi^{0} \rightarrow \gamma+\gamma \\
& \pi^{0} \rightarrow e^{+}+e^{-}+\gamma
\end{aligned}
$$

Similar reactions can be considered for neutrons.

There are several objects that are characterized as AGNs. Blazars seem the most promising candidates to be detected as individual neutrino point sources. They have a continuum emission from radio to gamma rays energies. Due to non-thermal processes these astrophysical objects present highly variable fluxes in hours to months. Several blazars have been characterized by the satellite EGRET (Energetic Gamma Ray Experiment Telescope) and FERMI experiments, at an energy range of GeV. Moreover, many other TeV blazars have also been detected and studied by the latest generation of gamma ray Cherenkov telescopes. 
Gamma Ray Bursts are very violent flashes that are related to extremely energetic processes that occur at distant galaxies. Different observations point that these events are caused by cataclysmic stellar collapses producing a fireball with bulk expansion Lorentz factor $\Gamma \sim 10^{2}-10^{3}$ [BAH 00]. Gamma ray bursts have the following characteristics:

- GRBs are very luminous events, typically $L_{\gamma} \sim 10^{51}$ to $10^{54} \mathrm{erg} / \mathrm{s}$ over durations to seconds or tens of seconds.

- The duration of a GRB follows a bimodal distribution with peaks near two seconds, although some GRBs have a duration ranging from milliseconds to 1000 seconds.

- GRBs produce a broken power - law spectrum of gamma rays [BAN 93].

- GRBs are cosmological events. Red shifts exceeding $z=4$ have been measured.

- GRBs are rare phenomenon: the estimation is one burst per galaxy per million years.

Theoretical models predict that the bursts are produced by the dissipation of kinetic energy of a relativistic expanding fireball [PIR 94, MES 95]. Taking into account the dissipation region, protons could be accelerated in these regions at energies $>10^{20} \mathrm{eV}$ [WAX 95 a]. In addition, the spectrum and flux of ultra-high energy cosmic rays $\left(\approx 10^{19} \mathrm{eV}\right)$ agree with the results expected from Fermi acceleration of protons in cosmological GRBs [WAX 95 b]. A possible consequence of the dissipative fireball model of GRBs is the existence of the conversion of a significant fraction of the fireball energy to an accompanying burst of $\approx 10^{14} \mathrm{eV}$ neutrinos, created by photo-meson production of pions in interaction between, fireball gamma rays and accelerated protons. In underwater neutrino telescopes, GRBs offer a very good opportunity to detect a neutrino source with high level of confidence since the time and direction coincidence reduces the background extremely.

- $X$-ray binaries.

Binary system, are composed by a compact object (neutron star, or black hole) and a non-compact companion star. These types of systems are dynamically complicated and involve mass transfer from the companion on the compact object, through an accretion disk. Considering that is known that neutron stars have a very strong $\left(10^{12} \mathrm{G}\right)$ surface magnetic field, taking into account both magnetic fields and plasma flow creates the environment necessary for the formation of strong shocks and corresponding particles acceleration. The companion star itself, the accretion flow or the heavy stellar winds might be targets for inelastic nucleon interaction and neutrino production. The consideration of X-ray binaries as neutrino sources started with measurements related with the detection of UHE $\left(>10^{14} \mathrm{eV}\right) \gamma$ rays from Cygnus X-3. Such $\gamma$ rays would be accompanied by high energy neutrinos. 
Supernova remnants have been considered as the best candidates for the acceleration of galactic cosmic rays. In some cases the residue of supernova is a neutron star, which can be detected as a pulsar. Inside supernova, protons can be accelerated by the first order Fermi acceleration mechanism if the shell is turbulent. If the pulsar is present, there are additional acceleration mechanisms [BER 90]. Particle acceleration in supernova remnants is accompanied by the production of gamma rays and neutrinos due to an interaction of accelerated protons with the matter present in the medium. It is appropriate to consider the work done by Berezinsky and Ptuskin [BER 89] that points that acceleration at the supernova blast wave could also produce an observable signal, even though in this case the accelerated particles are not deep inside the expanding shell.

Due to a gradually slow-down of the shock wave, when a supernova enter into the Sedov phase the maximum energy of the particles that can be confined within the SNR decreases. This causes that the most energetic particles escape from it and the emission of gamma rays and neutrino is suppressed. In spite of this, multi TeV gamma rays and neutrinos can still be generated by the cosmic rays that escape the SNR due to interactions with the molecular cloud surrounding [GAB 07]. The duration of the emission is related to the time of propagation of cosmic rays from the SNR through the cloud.

Observations have been made in $\mathrm{TeV}$ gamma rays with fluxes quite close to theoretical predictions [ESP 96]. However, the gamma ray data do not provide a clear and direct evidence of proton acceleration since they could be produced by inverse Compton scattering of directly accelerated electrons. Those gamma rays coming from possible $\pi^{0}$ decay would be accompanied by neutrinos, and their observation would provide a clear indication of proton acceleration. The disadvantage of young supernova remnants as a potential neutrino sources is that supernova explosions are rare events. H.E.S.S collaboration published recently results obtained of the first detection of very high energy gamma rays from supernova 1006 [ACE 11].

\section{- Neutrino oscillations.}

Undersea neutrino telescopes can offer a good opportunity for measurements of atmospheric neutrinos that could bring some light to clarify questions related to neutrino oscillations. The most interesting candidate for this study is the muon neutrino, but tau neutrino at extremely high energy $(>100 \mathrm{TeV})$ could be interesting as well.

Atmospheric neutrinos are emitted due to the decay of hadrons produced by the interaction of cosmic rays with atmospheric nuclei. Electronic neutrinos or muon neutrinos are generated principally by the following processes;

$$
\pi^{ \pm} \rightarrow \mu^{ \pm}+v_{\mu} / \overline{v_{\mu}} \text { followed by } \mu^{ \pm} \rightarrow e^{ \pm}+\overline{v_{\mu}} / v_{\mu}+v_{e} / \overline{v_{e}} \text {. }
$$


In an infinite medium the ratio between $\bar{v}_{\mu} / \nu_{\mu}$ and $\bar{v}_{e} / v_{e}$ is expected to be two. Since the atmosphere is not an infinite medium, the expected ratio is affected by energy, increasing with the energy of neutrino. Due to that, not all high energy muons can decay before being absorbed. In addition, the magnetic field of the Earth can have some influence on low energy charged particles. Measurements published by some underground experiment [CAS 91, FUK 98, ALL 97] show evidence of $v_{\mu}$ deficit with respect to $v_{e}$. Other experiments, Fréjus [BER 90, DAU 95] and Nusex [AGL 89], have not found anomaly so the problem is still open. Hypothesis about the possibility of neutrinos oscillation can be proposed as an explanation for the low value of the flux for $v_{\mu}$ in front of the expected value.

Considering the hypothesis of two-neutrinos mixing, the oscillation probability is:

$$
P=\sin ^{2} 2 \theta \cdot \sin ^{2}\left(1.27 \cdot \frac{L}{E} \cdot \Delta m^{2}\right)
$$

where $\Delta m^{2}=m^{2}{ }_{j}-m^{2}{ }_{i}$ is the difference of square masses (in $\mathrm{eV}^{2}$ ), $L$ represents the distance travelled by the neutrino (in $\mathrm{km}$ ), $E$ is the energy (in $\mathrm{GeV}$ ) and $\theta$ is the mixing angle. This is still an open problem with several points that need to be clarified. Different regions of $\Delta m^{2}$ have been studied considering solar neutrinos, atmospheric neutrinos, and short baseline beam neutrinos. Up to now, all the measurements done indicate an evidence of a non-zero $\Delta m^{2}$ value. The most interesting zone is located between $1 \cdot 10^{-3} \mathrm{eV}^{2}<\Delta m^{2}<2$. $10^{-2} \mathrm{eV}^{2}$ that corresponds to principal oscillation (first dip).

Considering tau neutrinos, although the contribution of this flavour to the atmospheric flux is negligible, their interaction must be taken into account in order to study neutrino oscillations. If $v_{\mu} \rightarrow v_{\tau}$ oscillation occurs, the charged current conversion can produce charged $\tau$ leptons that could contribute to the signal observed due to a specifically $\tau^{-} \rightarrow \mu^{-} \bar{v}_{\mu} v_{\tau}$. The number of $v_{\tau}$ and $v_{\mu}$ would be equal over the entire atmospheric flux $(\leq 500 \mathrm{GeV}$ ), however the number of $\left(\tau^{+}, \tau^{-}\right)$produced with energies above $10 \mathrm{GeV}$ would only be $53 \%$, whereas it would be $64 \%$ for $\left(\mu^{+}, \mu^{-}\right)$. The contamination of the muon sample due to tau decays would be about $9-11 \%$.

Following the idea exposed in [HAL 98], detection of very high energy neutrinos might be possible taking into account that the Earth is nearly transparent to lowenergy neutrinos, but opaque to neutrinos above $100 \mathrm{TeV}$. Nevertheless, a $\tau$ neutrino with energies above this value can produce a signal in a neutrino telescopes due to a $\tau^{ \pm}$production by $v_{\tau}$ decay before it is absorbed, and producing $v_{\tau}$ with less energy which continue along the original $v_{\tau}$ flight. Therefore, when a $v_{\tau}$ has an energy of $\sim 1 \mathrm{PeV}$, it can penetrate through the Earth, and could produce a very high energy event related to the detection of a $v_{\tau}$. 
Existence of dark matter in the universe was first proposed by Zwicky [ZWI 33] in the 1930s in order to explain the dynamics of clusters of galaxies where the ordinary observable luminous matter was insufficient to provide gravitational stability. Presence of dark matter in galaxies has been confirmed by numerous studies including gravitational lensing. Dark matter is required as well to explain the rotation curves measured for many galaxies, including the milky-way [SOF 01].

Following latest cosmology experiments, the standard picture is that the Universe is composed by the following composition; $70 \%$ of dark energy, $\sim 25 \%$ of dark matter while the ordinary matter (including stars, planets, dust and gas, and radiation in various forms) is only $\sim 5 \%$.

Theoretical studies point that the nature of dark matter is essentially nonbaryonic. No baryonic dark matter models say that it is compatible with a gas of cold and Weakly Interacting Massive Particles (WIMPs). There are no particle candidates in the Standard Model that exhibits these cold dark matter properties, however theories beyond the standard model [SUS 84] propose that candidates for WIMPs come from the super-symmetric and extra dimensional theories. SUper SYmmetry theories (SUSY) propose symmetry between bosons and fermions which is broken at the currently accessible energy scale. The Minimal Super Symmetric Model [MSSM] [DIE 05] points that every fermion has a boson partner in the same way that all known bosons has as partner a fermionic particle and two Higgs doublets. Among the dark matter candidates, two of them have been extensively studied for the last two decades, the lightest of the four neutralinos (which will be referred to as neutralino) and the gravitino.

Neutralino is a linear combination of the Majorana fermionic super partners of the Gauge and Higgs bosons [GOL 83]. Underwater neutrino telescopes can be a key to study neutralino dark matter models. These relic neutralinos could be trapped due to a gravity inside of massive celestial bodies like the Galactic Center, the Sun or the Earth, originating a subsequent accumulation of these particles in a region around the centre of these massive celestial bodies. Neutralinos would annihilate into a fermion antifermion pair or into various twobody combinations of W, Z and Higgs bossons. Direct decay to neutrinos is zero in the non- relativistic limit, but channels through $c$, b and $t$ quarks, $\tau$ lepton, Z, W and Higgs can all produce a significant flux of high energy neutrinos.

The expected energy for the neutrino produced is about $1 / 2$ to $1 / 3$ of the neutralino mass and the expected muon flux depends on the neutralino mass and the assumed MSSM parameters. The Sun can be considered as a source of neutrinos from neutralino annihilation, but it would be more difficult to see them using the Earth due to the low capture rates of neutralinos predicted.

As it has been said, neutralino is the most suited dark matter particle that could be tested in underwater neutrino telescopes. Nevertheless, there are also other 
dark matter models (Kaluza-Klein, super heavy dark matter) that could be tested using these detectors.

\section{Associated sciences.}

Although not directly related to astroparticle or particle physics, underwater neutrino telescopes offer unique possibilities to host sensors for Earth and Sea science studies. The neutrino telescope infrastructure can also be seen as an observatory for deep-sea measurements in the fields of marine biology, oceanography, geology and geophysics.

Traditional observation of deep-sea properties have been done using autonomous measuring systems, deployed in the sea for up to one year, which must be recovered in order to retrieve data for the analysis. This experimental set-up has some limitations, such as duration of batteries or data storage. In a neutrino telescope, sub-sea infrastructure is permanently cabled to shore allowing saving continuous data without interruption over long periods. These types of systems will also provide real time information, and could be used to monitor events such as earthquakes, slope failures or tsunamis.

Therefore, this is a clear example of synergy between two different science communities. Earth and Sea science community gains from having real time monitoring of their sensors, taking advantage of the collaborative efforts and experience on different technologies of the particle physics community. On the other hand, the astroparticle community gains from the understanding of the environment where the detector is (very important for the success of the experiment), and on the experience on marine technologies of Earth-Sea science community. 


\subsection{ANTARES}

The ANTARES (Astronomy with a Neutrino Telescope and Abyss environmental RESearch) Collaboration has built a large effective area water Cherenkov detector in the deep Mediterranean Sea optimised for the detection of muons from high-energy astrophysical neutrinos. It is, at present, the largest neutrino telescope in the northern hemisphere [MON 08] and the largest underwater neutrino telescope in the world. This facility has represented a technological challenge since a large amount of sensors of different kinds had to be deployed and connected in deep sea to become a network of coordinated underwater sensors looking for neutrinos and monitoring the deep sea. ANTARES telescope is located at a depth of $2475 \mathrm{~m}$ in the Mediterranean Sea $\left(42^{\circ} 48^{\prime} \mathrm{N}, 6^{\circ} 10^{\prime} \mathrm{E}\right), 42 \mathrm{~km}$ from the French city of Toulon (France), Figure 1.4. To make this idea feasible a large European Collaboration (with more than 200 people among physicists, engineers and technicians from France, Germany, Italy, The Netherlands, Romania, Russia and Spain) has built, deployed an operated a detector with an effective surface area of about $0.1 \mathrm{~km}^{2}$ composed of 12 vertical lines of about $450 \mathrm{~m}$ height and about $70 \mathrm{~m}$ spacing, holding 885 photomultipliers. Besides the optical module sensors, a set of calibration sensors, a data acquisition system and communication networks are needed. A specific dedicated instrumentation line with multidisciplinary oceanographic equipment and acoustic sensors have been deployed as well. All this configure a large interrelated network of systems of sensors looking for neutrinos and monitoring the deep sea.

ANTARES has the objective to detect and study very high-energy extraterrestrial neutrino sources, allowing us to open a new window to the Universe. Results from the telescope could produce a valuable insight not only in astronomy and astrophysics, but in particle physics, dark matter and cosmology as well. In addition, ANTARES houses instrumentation from other sciences like marine biology and geophysics for long term and on-line monitoring of the deep sea environment.

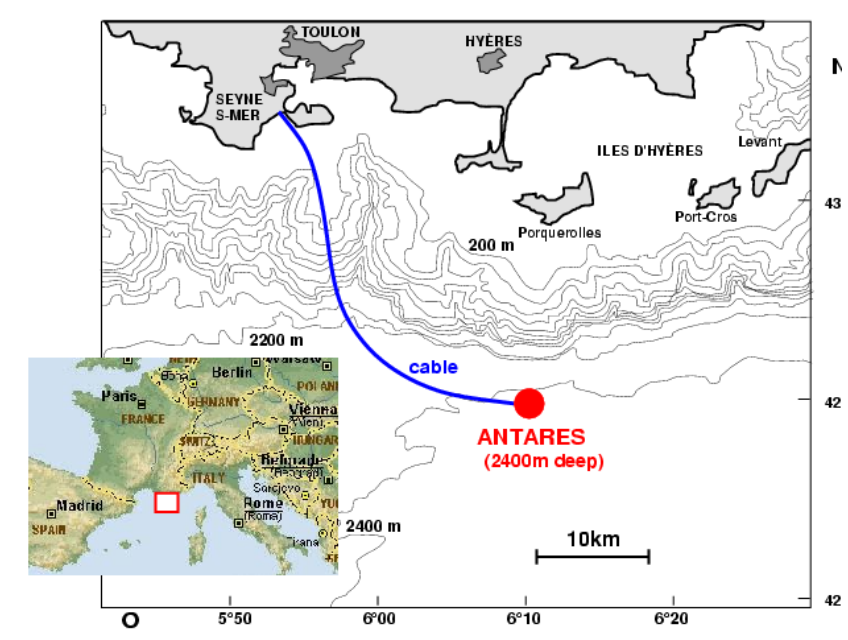

Figure 1.4. Detail of Antares neutrino telescope situation. 


\section{Detector design}

Before describing the ANTARES detector design [ASL 99], it is worthwhile to point out the factors which orientate and constrain it:

- The need to optimise the physics performance of the detector;

- The environmental conditions at the site, which influence the spacing of optical modules, the mechanical structure of detector strings, and the expected background rates;

- The requirement for a high level of reliability;

- The practical experience gained from the design and deployment of the prototype strings and modules performed during several years.

The detector consists of 12 lines (plus the additional instrumentation line) made of mechanically resistant electro-optical cables anchored at the sea bed at distances of about $70 \mathrm{~m}$ one from each other, and tensioned by buoys at the top. Each line has 25 storeys, which could be considered the elemental part of the detector. Each storey contains three optical modules and a local control module for the corresponding electronics. Additionally, there are different kinds of sensors and instrumentation (LED beacons, hydrophones, compasses/tiltmeters) for the timing and position calibration of the optical modules. The first storey is about $100 \mathrm{~m}$ above the sea floor and the vertical distance between adjacent storeys is $14.5 \mathrm{~m}$. That results in a neutrino telescope spread over an area of about $0.1 \mathrm{~km}^{2}$ and with an active height of about $0.3 \mathrm{~km}$. Each line is connected to a Junction Box, which transmits power and sends the data to the ground station. The Junction Box is connected to the onshore station by a $42 \mathrm{~km}$ electro-optical cable. Figure 1.5 shows a schematic view of the detector array indicating the principal components, as well as an artistic view of the detector its.

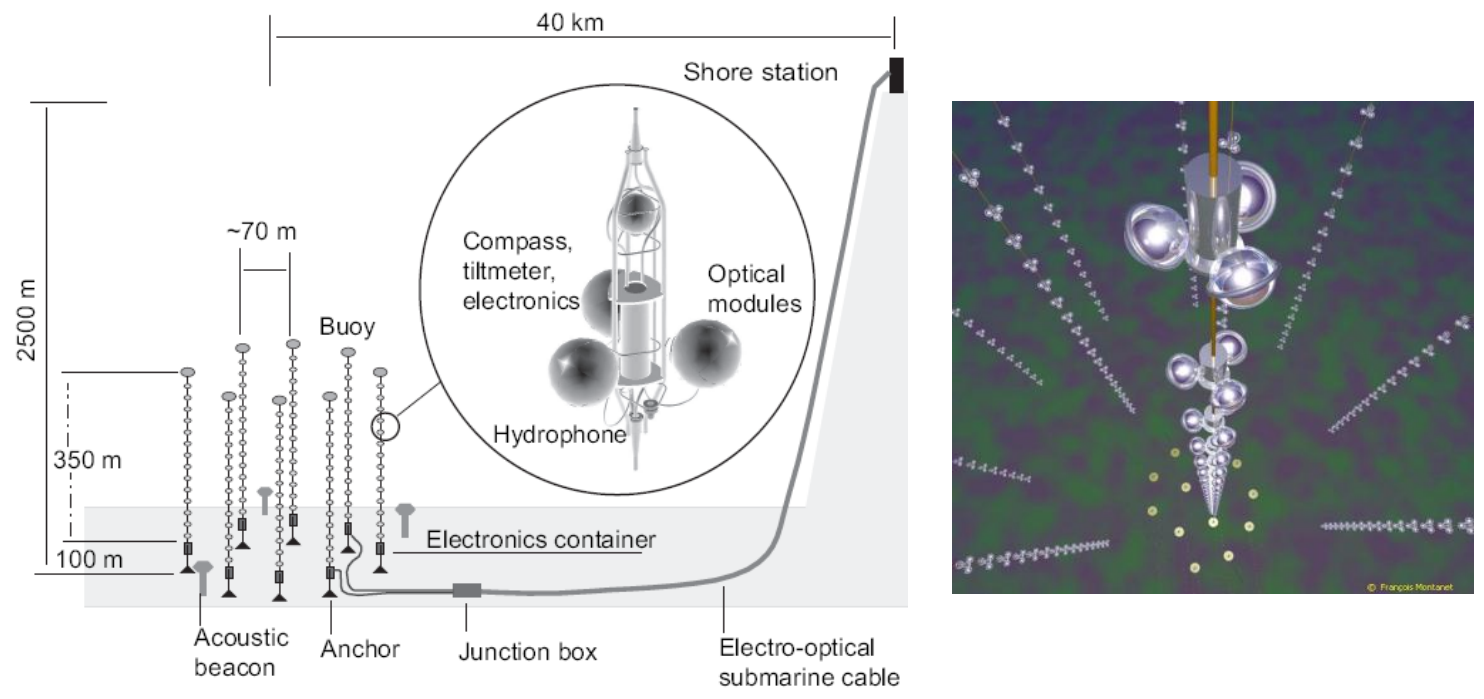

Figure 1.5. Schematic and artistic view of the ANTARES detector 


\section{- Optical Modules}

The basic unit of the detector is the optical module (OM) consisting of a pressure-resistant glass sphere with the instrumentation inside. Its main component is a large area hemispherical photomultiplier (PMT) glued in a pressure resistant glass sphere with optical gel. A $\mu$-metal cage is used to shield the PMT against the Earth's magnetic field. Electronics inside the OM are reduced to a minimum, namely: the PMT high voltage power supply and a LED system used for internal calibration. A more detailed description of these elements can be found in [AMR 02].

The optical modules are grouped together in 'storeys' of three modules and interconnected via an electro-mechanical cable. They are arranged with the axis of the PMTs 45o below the horizontal. A 10" PMT model R7081-20 from Hamamatsu is used. The angular acceptance of the optical modules is broad, falling to half maximum at $\pm 70^{\circ}$ from the axis. This means that the present arrangement of OMs detects light in the lower hemisphere with high efficiency, and has some acceptance for muon directions above the horizontal. In the lower hemisphere there is an overlap in angular acceptance between modules, permitting an event trigger based on coincidences from this overlap.

\section{- Data acquisition and communication systems}

In order to handle all data coming from the underwater sensors of the telescope, intelligent data acquisition (DAQ) and communication systems are required. The DAQ system of ANTARES is extensively described in [AGU 07]. Here, we summarise the main aspects of it. The TTS is a mean transit time spread of $\sim 1.3 \mathrm{~ns}$. The PMT signal is processed by the Analogue Ring Sampler (ARS), an ASIC card which digitizes the arrival time and charge of the pulse [AGU 10 a]. The readout trigger threshold of the ARS is set at about 0.3 photoelectrons. The optical modules deliver their data in real time and can be remotely controlled from the ANTARES shore station through a Gb Ethernet network. Every storey is equipped with a LCM containing the electronic boards for the OM signal processing, the instrument readout, the acoustic positioning, the power system and the data transmission. Every five storeys, in the middle, the Master Local Control Module (MLCM) also contains an Ethernet switch board, which multiplexes the DAQ channels from the other storeys. At the bottom of the line, the BSS is equipped with a String Control Module (SCM) which contains the local readout and DAQ electronics, as well as the power system for the whole line. Each of these containers constitutes a node of the data transmission network, receiving and transmitting data and slow-control commands. The functions supported by the SCM include reading sensors, adjusting slow-control parameters, the trigger, and the distribution of power, master clock and resetting signals to the front-end electronics. Finally, both MCLM and SCM include a Dense Wavelength Division Multiplexing system used for data transmission in order to merge several $1 \mathrm{~Gb} / \mathrm{s}$ Ethernet channels on the same pair of optical fibres, using different laser wavelengths. The individual SCMs are linked to a common junction box (JB) by electro-optical cables which are connected using a manned submarine or a Remote Operated Vehicle (ROV). A standard deep sea telecommunication cable links the junction box with a shore station where the data are filtered and recorded. 
All data, times and pulse amplitudes are stored in memory. In order to provide an efficient transfer of the data, the memory is divided in buffers of $104 \mathrm{~ms}$ length (time slice). The starting times of the buffers on each of the storeys are synchronised. These buffers are transmitted via an Ethernet network to a farm of processors on shore where candidate events are filtered from the continuous data stream for further off line processing. Individual processors in the farm receive and process all buffers from the full detector associated with a single time slice. Following this philosophy, the trigger logic in the sea is planned to be as simple and flexible as possible. In the present scheme, all OMs are continuously read out and sent to shore. Once the OM signal is above the ARS threshold (Level 0 hit), which is set around $1 / 3$ of the single photoelectron level (SPE), then the data filter on-shore farm look for a physics event by searching a set of correlated Level 1 hits, which corresponds either to local coincidences of Level 0 hits within 20ns or for a high amplitude hit (typically $>3$ SPE) on the full detector on a few microseconds window. A minimum of 6 Level 1 hits is typically required. In case of an event is found, all Level 1 and Level 0 hits of the full detector during the few microsecond correlation time window are written on disk, otherwise the hits are thrown away.

\section{- Calibration systems}

ANTARES is expected to achieve very good angular resolution $\left(<0.3^{\circ}\right.$ for muon events above $10 \mathrm{TeV}$ ). The pointing accuracy of the detector is determined largely by the overall timing accuracy of each event. This is a quadratic sum of terms due to:

- the precision with which the spatial positioning and orientation of the optical modules is known;

- the accuracy with which the arrival time of photons at the optical modules is measured;

- the precision with which local timing of individual optical module signals can be synchronised with respect to each other.

In order to determine accurately these parameters positioning and timing calibration systems are needed. The reconstruction of the muon trajectory is based on the differences of the arrival times of the photons between optical modules. As such, it is sensitive to the distances between the optical modules. In order to avoid degrading the reconstruction, it is necessary to monitor the position of each optical module with a precision of about $10 \mathrm{~cm}$ (light travels 22 $\mathrm{cm}$ per ns in water). The reconstruction of the muon trajectory and the determination of its energy also require knowledge of the optical module orientation with a precision of a few degrees. The precise absolute positioning of the whole detector has to be guaranteed in order to point to individual sources.

To attain a suitable precision on the overall positioning accuracy a constant monitoring of the relative positions of the various detector elements with respect to the absolutely positioned acoustic beacons and emitters is necessary [ARD 09 a]. The relative positioning of the detector is obtained from two independent systems: 
- A High Frequency Long BaseLine acoustic system (HFLBL) giving the 3D position of hydrophones placed along the line. These positions are obtained from triangulation from emitters anchored in the base of the line plus autonomous transponders on the sea floor (this system will be described in chapter 2).

- A set of tiltmeter-compass sensors giving the local tilt angles of each OM storey with respect to the horizontal plane (pitch and roll), as well as its orientation with respect to the Earth Magnetic North (heading).

The shape of each string is reconstructed by performing a global fit to the mechanical model of the line based on all this information. Then, the relative positions of the OMs are then deduced from this reconstructed line shape and from the geometry of the Optical Module Frame.

In order to apply the method proposed, we need to know two parameters: the water current flow and the sound velocity in sea water. For this, different oceanographic equipment has been deployed.

On the other hand, the absolute positioning of the detector is performed by acoustic triangulation of low frequency acoustic beacons placed on the string bottom, and a range-meter on a surface ship equipped with the Dynamic Global Positioning System. In order to avoid pointing offsets, a precision of about $1 \mathrm{~m}$ is needed for absolute positioning. This requires of a precise triangulation which necessitates the knowledge of the sound velocity profile from the sea floor to the surface, which can be strongly distorted by thermal effects which depend on the season and current. This has to be measured by using a CTD profiler at the same time than the absolute positioning calibration is performed.

The relative time resolution between OMs is of utmost importance for the muon trajectory reconstruction. It is limited by the transit time spread of the signal in the PMTs (about $1.3 \mathrm{~ns}$ ) and by the scattering and chromatic dispersion of light in sea water (about $1.5 \mathrm{~ns}$ for a light propagation of $40 \mathrm{~m}$ ). The electronics of the ANTARES detector is designed in order to contribute less than $0.5 \mathrm{~ns}$ to the overall time resolution. Time calibration should aim at a precision below the nanosecond level. To this end, several complementary time calibration systems have been implemented in the ANTARES detector in order to measure and monitor the relative times between different components of the detector due to, e.g. cable lengths and electronics delays. These time calibrations are performed by the following systems [AGU $11 \mathrm{a}]$ :

(1) The internal clock calibration system: a very precise time reference clock distribution system has been implemented in the ANTARES detector. It consists of a $20 \mathrm{MHz}$ clock generator on shore, a clock distribution system and a clock signal transceiver board placed in each Local Control Module (LCM), which contains the electronic boards for the OM signal processing, the instrument readout, the acoustic positioning, the power system and the data transmission. A common clock signal is provided to the ARS. Synchronised data commands can be superimposed on the clock signal, in particular start and stop commands, which together with a high precision Time to Digital Converter composed the essential components of the system. This system also includes an echo-based 
time calibration whereby each LCM clock electronics board is able to send back a return signal through the same optical path as the outgoing clock signals. This system enables the time offsets between all LCM clock boards to be measured by recording the propagation delays of the return signals of each storey with respect to the original clock signal emission time. Measurements in real conditions show a resolution of about $0.1 \mathrm{~ns}$, well within the specifications. The system also includes the synchronisation with respect to Universal Time, by assigning the GPS timestamp to the data, with a precision of about $100 \mu \mathrm{s}$, much better than the required precision of $1 \mathrm{~ms}$ in absolute timing in order to look for coincidences between ANTARES and other astrophysical experiments. The clock signals are distributed across all detector components from the shore up to the clock boards. The remaining path between these boards and the PMT photocathodes requires however a different timing calibration mechanism.

(2) The internal Optical Module LEDs: inside each Optical Module there is a blue LED attached to the back of the PMT capable of illuminating the photocathode. The LED is an HLMP-CB15 from Agilent whose light intensity is peaked at around $470 \mathrm{~nm}$ with a FWHM of $15 \mathrm{~nm}$. These LEDs are used to measure the relative variation of the PMT transit time and dedicated runs of this LED calibration system are customarily taken. This system is used to calibrate the path travelled by the signal starting at the PMT photocathode up to the read-out electronics. The effect of the transmission of the light in water is, however, not addressed by this calibration method.

(3) The Optical Beacons [SAL 07]: this system allows the relative time calibration of different OMs to be determined by means of independent and well-controlled pulsed light sources. This system also makes possible to monitor the influence of the water on the light propagation. The Optical Beacon system consists of a series of pulsed light sources distributed throughout the detector. A LED Beacon is composed of several LEDs, pulsed by dedicated electronic circuits. Those beacons are located, more or less, uniformly along every detector line so that their light can illuminate all storeys on the neighbouring lines. The Laser Beacons use a solid state pulsed laser whose light is spread out by a diffuser. Laser Beacons are located at the bottom of a few lines in the so-called Bottom String Socket. The Laser Beacons illuminate mainly the bottom part of the lines and are located in a stationary position.

(4) Several thousands of down-going muon tracks will be detected per day. The hit time residuals of the reconstructed muon tracks can be used to monitor the time offsets of the Optical Modules. This methodology will enable an overall space-time alignment and calibration cross-checks.

\section{- Instrumentation Line and AMADEUS system}

There is an instrumentation line, which has a total height of about $300 \mathrm{~m}$ and comprises 6 storeys with equipment for monitoring the sea. It is worth to mention that three of the storeys of this line, as well as three storeys of the detection line 12, are equipped with hydrophones. With such a configuration, this acoustic system, called AMADEUS, constitutes a basic, but functional, 
prototype array developed to evaluate the feasibility of the acoustic detection of neutrinos in deep sea [AGU 11 b].

\section{Performance and results}

The ANTARES detector is running and taking data for several years, through different configurations: 5 lines, 10 lines, and the final configuration with 12 lines (since the detector were completed in May 2008). Although there have been several problems during the operation, most of them have been solved and the detector is taking valuable data with a high duty cycle [BRU 11]. In this section, some analyses and results are summarized:

\section{- Atmospheric muons}

The main goal of a neutrino telescope is to detect high-energy neutrinos from extraterrestrial sources. However, the signal observed by ANTARES is dominated by muons that are generated in cosmic ray interactions in the atmosphere above the detector and which have sufficient energy to reach the detector at its average installation depth of $2200 \mathrm{~m}$ below sea surface. The muon flux measured at the ANTARES site is an important test beam to study detector systematics and to validate the reconstruction algorithms employed. Two different studies of the depth-intensity relation for muons have been carried out using different techniques [AGE 09, AGU 10 b, BAZ 09]. As shown in Figure 1.6 the results are in a good agreement with previous experiments and with the simulations done.

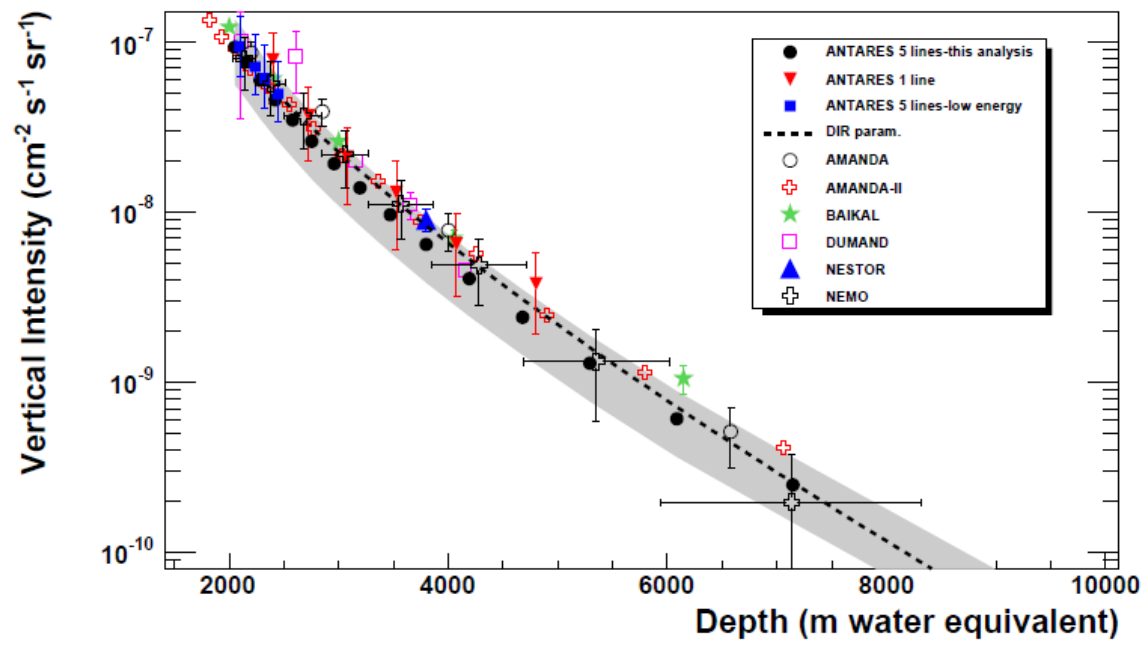

Figure 1.6. Vertical flux of atmospheric muons as a function of the equivalent slant depth (taken from [AGU $10 \mathrm{~b}$ ])

- Diffuse flux of astrophysical neutrinos

ANTARES has made an analysis of the diffuse flux of neutrinos using 20072009 data, and an upper limit for this flux has been derived [AGU $11 \mathrm{c}$ ], shown in Fig. 1.7. The search method for the diffuse neutrino flux exploits the fact that the atmospheric neutrino flux, which constitutes the main background in this search, has been measured to exhibit a $E^{-3.7}$ dependence at high energies. The predicted diffuse flux of cosmic neutrinos, however, is expected to follow the 
much harder energy spectrum of its parent hadron distribution, i.e., approximately $\mathrm{E}^{-2}$. To separate atmospheric and diffuse cosmic neutrino fluxes, a robust energy estimator for high-energy muon neutrino events has been developed for ANTARES.

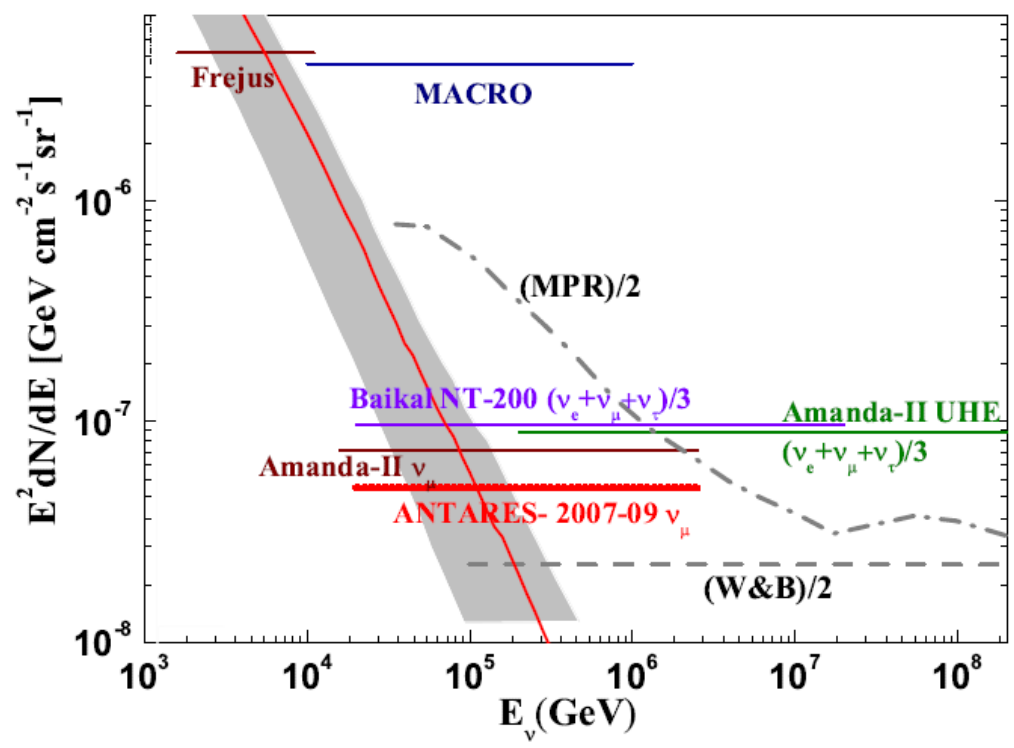

Figure 1.7. The ANTARES upper limit ( $90 \%$ C.L.) for a $E^{-2}$ diffuse high-energy muonic neutrino + antineutrino flux, compared with limits from other experiments and theoretical predictions for transparent sources (taken from [AGU $11 \mathrm{c}$ ], see it for the complete details).

- Other analyses

Several analyses based on the 2007 and 2008 data are completed or close to completion, and some of them are being draft, as for example the search for neutrino point sources. Other analyses, including more data or looking to different topics are ongoing, like the search for relativistic monopoles, indirect search for dark matter, neutrinos from gamma ray bursts, etc. There are as well analyses on sensors for Earth-Sea science studies, as for example, to study the bioluminescence activity or the sea current dynamics. 


\section{4. $\mathrm{KM} 3 \mathrm{NeT}$.}

$\mathrm{KM} 3 \mathrm{NeT}$ is a deep-sea multidisciplinary observatory in the Mediterranean Sea that will provide innovative science opportunities in the fields of Astroparticle Physics and Earth and Sea Science. This idea is based on the synergy of using a common infrastructure allowing for long term continuous operation of a neutrino telescope and marine instrumentation. The consortium KM3NeT is formed by 40 Institutes or University groups from ten European countries: Cyprus, France, Germany, Greece, Ireland, Italy, Netherlands, Romania, Spain and UK. The main goal of this project is to build and operate an underwater neutrino telescope with at least one cubic kilometre of detection volume. $\mathrm{KM} 3 \mathrm{NeT}$ project is currently at design and preparation phase for the construction. Final technical and site decisions are expected by the end of 2011 and a technical proposal will be presented in early 2012. Final prototyping and construction could begin in 2013 and data taking will already start during the construction period of about five years with first science data anticipated in 2014 [BAG 10].

The construction of a deep-sea neutrino telescope is technically highly challenging: the components must withstand the enormous pressure and chemically aggressive sea water whilst being reliable enough to minimize complex maintenance operations (KM3NeT is designed for at least 10 years of operation). The deployment operations must be safe, robust and precise. The design builds on the extensive experience gained in the Mediterranean pilot projects ANTARES, NEMO and NESTOR, as well as on deep-sea know-how from other fields of science and industry. A major step forward has been the ultimate proof of feasibility for a deep-sea neutrino telescope provided by the successful installation and operation of the ANTARES experiment.

The scientific aims of $\mathrm{KM} 3 \mathrm{NeT}$, as an underwater neutrino telescope, have been summarised in section 1.2, and the detection principle, as well as, the general structure is very similar to that presented for ANTARES, in section 1.3. Naturally, since KM3NeT is going to be at least 20 times larger than ANTARES, it cannot be a scaled version of ANTARES, so that new technological solutions are needed. These solutions have been (and are being) studied within the Design Study and Preparation Phase Projects funded by the European Union, $6^{\text {th }}$ and $7^{\text {th }}$ Framework Program, respectively.

The principle of operation of the KM3NeT neutrino telescope is to detect the Cherenkov light produced after a neutrino interaction and to be able to reconstruct the track direction. For this, approximately ten thousand optical modules distributed in a 3D array covering at least $1 \mathrm{~km}^{3}$ of detection volume are foreseen. The optical modules consist of one or several photomultiplier tubes contained in glass spheres that are designed to resist the hydrostatic pressure of the deep sea environment. They are kept suspended in the sea by vertical structures, which are anchored to the seafloor by a dead-weight and kept close to vertical with a buoy at their top. These structures together with their optical modules are called detection units. 
Additionally, a calibration system is implemented to determine the positions of the optical modules and to provide timing synchronisation of the photomultiplier signals with accuracies of about $40 \mathrm{~cm}$ and $2 \mathrm{~ns}$, respectively [TOS 09, SAL 10].

The power required for the photomultipliers and electronics located underwater is fed via a single cable from shore to a primary junction box. From there it is distributed via a seafloor cable network that branches via secondary junction boxes to the detection units. Inside the detection units the power is distributed further to the optical modules via a vertical backbone cable. The same cable network via a fibre optic is used for the configuration of the different elements of the telescope, as well as to retrieve the digitised data from the photomultipliers (time and amplitude). Finally, a shore station receives the data and is used to control the operation of the detector. It also houses computing facilities to filter and store the data from the telescope, before transferring them to remote nodes for analysis. The connection to the local power grid is also housed here. Figure 1.8 shows schematically all these ideas. A more distributed layout is foreseen for the Earth and Sea Sciences instrumentation, as shown in Figure 1.9. This facility will be used to take data continuously of parameters such as sea current velocity, bioluminescence, etc., or used even as warning detectors for earthquakes and tsunamis.

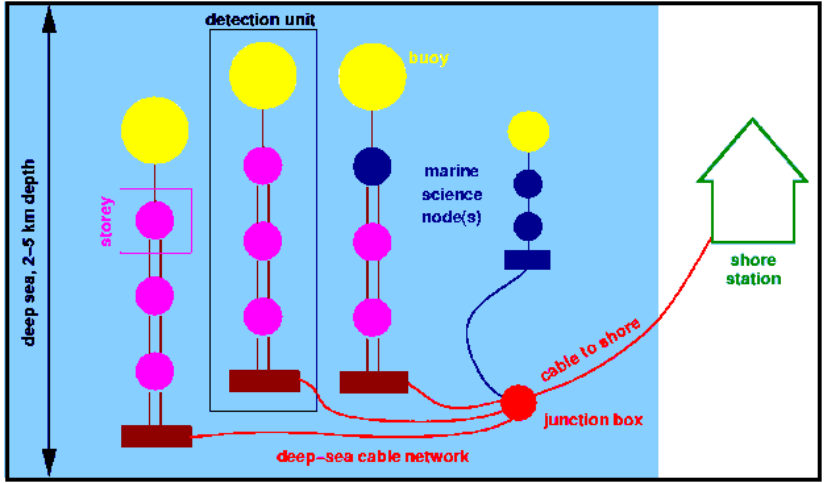

Figure 1.7 : Schema that shows the basic ideas about KM3NeT neutrino telescope

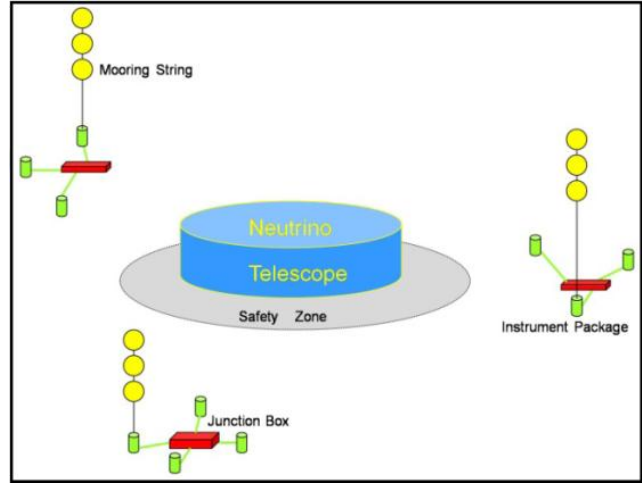

Figure 1.8: Possible location for marine science instrumentation.

$\mathrm{KM} 3 \mathrm{NeT}$ telescope is in its final stage of design, implying that the technical implementation of particular solutions for the different systems described above should be demonstrated and a final decision taken soon. Another open question is the site location. Three candidate sites, shown in Figure 1.9, have been proposed, associated to the three projects: Nemo $\left(36^{\circ} 16^{\prime} \mathrm{N} 16^{\circ} 06^{\prime} \mathrm{E}\right.$, depth:

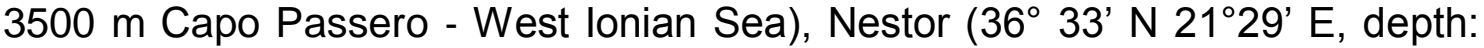
$4550 \mathrm{~m}$ Pylos - East Ionian Sea) and ANTARES (42 48' N 06¹0' E, depth: $2475 \mathrm{~m}$ Toulon - Ligurian Sea). Sites under study have common characteristics:

- Place must be near to the coast in order to minimize difficulties at deployment process.

- Location should have enough depth in order to minimize the background generated by cosmic rays.

- Optimal properties of light transmission in water, that allows a good behaviour at the range of $350 \mathrm{~nm}-550 \mathrm{~nm}$. 
- Low level of bioluminescence and biofouling.

- Low value for current velocity.

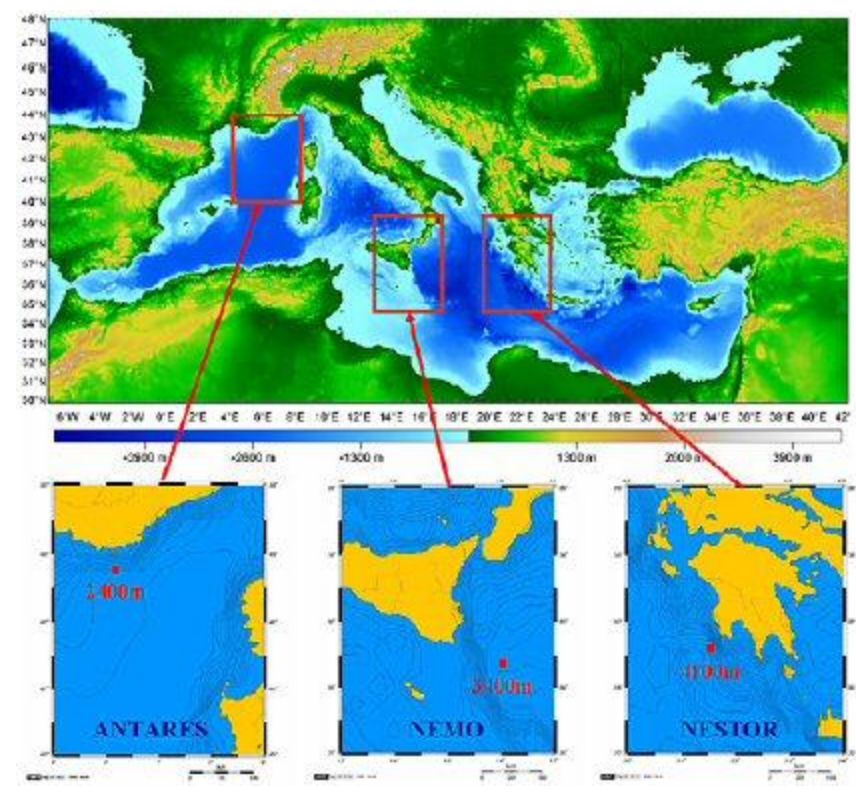

Figure 1.9: Three considered sites to build KM3NeT neutrino telescope.

The expected performance of the telescope following these parameters, together with the available infrastructures of the sites (communications with the rest of Europe, marine installations, etc.) and political factors (such as funding) will be issues to take into consideration for a final decision on site, or even for a multi-site option.

With respect to the technical implementation of the telescope, several decisions have already been taken and different studies are underway for a final decision. For instance, to obtain the large photocathode area required for the planned sensitivity in a cost-effective way, it is optimal to arrange photomultipliers in local clusters. Two options are possible: local groups of optical modules containing one or two large photomultipliers each, or groupings of smaller photomultipliers within a single multi-PMT optical module [SEI 11, KAV 11]. These two designs are currently being pursued, with a common solution for the front-end electronics that can be housed inside an optical module.

A modular solution has been adopted for the mechanical structures that facilitate production, transport and deployment procedures. A specific design with extended mechanical structures in the form of 6-meter long horizontal bars to support optical modules has been adopted as solution. One detection unit will consist of 20 horizontal bars (storeys), with a vertical separation of $40 \mathrm{~m}$ between storeys. For easier handle, transportation and deployment the detection unit can be pack compactly and it will be able to unfurl once placed on the seafloor. Such deployment techniques have not been used extensively in the past and need to be subjected to further field trials. If there would be problems in proving the proposed mechanical techniques, solutions similar to the method used in ANTARES will have to be considered. 
An electro-optical submarine cable network, initiated from the shore station and split with primary and secondary junction boxes, will be used for distributing the electrical power, for control, and for managing the acquired data. Sea bottom connections between the detection units and the cable network will be carried out with deep-sea remotely operated vehicles (ROVs).

The overall power consumption of the telescope will be approximately $125 \mathrm{~kW}$ and the expected data rate will be roughly $25 \mathrm{GBytes} / \mathrm{s}$. For managing this large data stream to shore, a point-to-point fibre optic network transferring all the optical module data to the shore will be probably used. On the other hand, the shore station will house the power supplies, the lasers that will drive the fibre optic network, and will also host the data acquisition system that will implement data filtering, recording and distribution.

It is planned that the studies of the various components will conclude during 2011 , to allow for a timely process of decision taking. In fact, two in situ tests are foreseen to prove these technologies: a NEMO tower at Capo Passero Site and the $\mathrm{KM} 3 \mathrm{NeT}$ pre-production model, which might be considered as the 'prototype 0 ' of the KM3NeT detection unit.

Software has been specifically developed [KOP 09] and simulations of the $\mathrm{KM} 3 \mathrm{NeT}$ neutrino telescope have been done in order to study the performance of this facility for the scientific aims described in section 1.2. Obviously, the sensitivity of the telescope will improve largely with respect to ANTARES. Moreover, it will have as well more sensitivity and angular resolution than Ice Cube, whereas both telescopes will be complementary to study the full sky. A more detailed description of the performance of KM3NeT on the different scientific topics can be found in [BAG 10]. 


\section{Acoustic positioning systems in underwater neutrino telescopes}

\subsection{ANTARES positioning system.}

As it was pointed in the previous chapters, ANTARES neutrino telescope is deployed at about $40 \mathrm{~km}$ off Toulon cost at a depth of $2475 \mathrm{~m}$. The detector has a string structure anchored on the sea bed and maintained vertical by a buoy. Since they are flexible structures, water current flows can drift the buoy by several meters, and therefore move the Optical Module (OM) positions from their ideal geometry, even for low values of sea current velocity $(\sim 5 \mathrm{~cm} / \mathrm{s})$. However, the quality of the reconstructed track direction depends on the timing resolution of the photo-sensors and on the knowledge of the photo-sensor position. ANTARES is expected to achieve very good angular resolution $\left(<0.3^{\circ}\right.$ for muons above $10 \mathrm{TeV}$ ). The pointing accuracy of the detector is mainly determined by the overall timing accuracy of each event, which is a quadratic sum of terms due to the precision with which the spatial positioning and orientation of the OMs is known; the accuracy with which the arrival time of photons at the OMs is measured and the precision with which local timing of individual OM signals can be synchronised with respect to each other. In order to determine accurately these parameters positioning and timing calibration systems are used. The performance of the telescope is highly sensitive to the distances between the OMs and it is necessary to monitor the relative positions of all OMs with an accuracy better than $20 \mathrm{~cm}$, equivalent to the $\sim 1 \mathrm{~ns}$ precision of timing measurements. The reconstruction of the muon trajectory and the determination of its energy also require the knowledge of the OM orientation with a precision of a few degrees. In addition, a precise absolute positioning of the whole detector has to be guaranteed as well in order to point to individual neutrino sources in the sky.

To attain a suitable precision on the overall positioning accuracy, a constant monitoring of two independent systems is used:

- A high-frequency Long BaseLine (LBL) Acoustic Positioning System (APS) that gives the 3D position of hydrophones placed along the line. These positions are obtained by triangulation from emitters anchored in the base of the line plus autonomous transponders on the sea floor.

- A Tiltmeter-Compass System (TCS) giving the local tilt angles of each OM storey with respect to the horizontal plane (pitch and roll), as well as its orientation with respect to the Earth magnetic north (heading).

The shape of each string is reconstructed by performing a global fit based on all this information. The relative positions of the OMs are then deduced from the reconstructed line shape and from the geometry of the OM frame.

This reconstruction requires the knowledge of two parameters: the water current flow and the sound velocity in sea water. For this, different oceanography instrumentation devices have been deployed as well: Acoustic Doppler Current Profilers, to monitor the water current flow along the full height of the detector strings; Conductivity-Temperature-Depth sensors, to monitor the temperature and salinity of the sea water at various depths (from these measurements, it is 
possible to determine the sound velocity); and Sound Velocimeters to monitor directly the sound velocity in sea water.

\section{The line shape model}

The reconstruction of the line shape (and therefore the positions of its different elements) is based on a model which predicts the mechanical behaviour of the line under the influence of the sea water flow taking into account the weight and drag coefficients of all elements of the line. For each element present along the line, named ' $i$ ', the zenith angle $\theta_{i}$ with respect to the position of the BSS can be calculated by

$$
\tan \left(\theta_{i}\right)=\frac{\sum_{j=i}^{N} F_{j}}{\sum_{j=i}^{N} W_{i}}
$$

where $F_{j}$ represents the drag horizontal force due to the sea current flow and $W_{j}$ is the effective weight (weight minus buoyancy) of the element submerged in water. The drag force can be obtained using:

$$
F_{j}=\frac{1}{2 \cdot \rho \cdot C_{w, j} \cdot A_{j} \cdot v^{2}}
$$

where $\rho$ represents the density of medium, $C_{w j}$ is the drag coefficient of each element, $A_{j}$ is the cross section area of elements present in the line and $v$ is the sea current velocity. The drag coefficient for an ANTARES storey was determined by a hydro-dynamical study in the IFREMER pool facility in Brest.

The zenith angle $\theta_{i}$ depends on the height along the line $z$ though the radial displacement with respect to the anchor, $\frac{d r}{d z}=\tan \left(\theta_{i}\right)$. This expression can be integrated in order to obtain the final expression of the line:

$$
r(z)=a \cdot v^{2} \cdot z-b \cdot v^{2} \cdot \ln [1-c \cdot z]
$$

where coefficients $a, b$ and $c$ are known mechanical constants, and $v$ is the sea current velocity, which coordinates $v\left(v_{x}, v_{y}\right)$ are treated as free fitting parameters in the model. The input data for the fits that gives the minimum value of $\chi^{2}$ comes from the APS monitoring, which gives few positions along the lines associated to the hydrophones, and the Compass-Tiltmeter system, which monitor the local tilt and heading angles of each storey with OMs.

\section{Acoustic positioning system}

The Acoustic Positioning System (APS) is composed by a set of transceiver hydrophones located at the bottom of each line, some autonomous transponders on the sea floor and five receiver hydrophones located at storeys $1,8,14,22$ and 25 , to monitor some strategic points of the line and minimise the uncertainties in the shape reconstruction since the positions of these receiver hydrophones are the data input used in the mechanical model fits. Electronic boards manage the settings of the system, for emission, reception, 
detection, filtering and communication. The emitters generate a tone burst signal of $2 \mathrm{~ms}$ in a specific frequency of the $[40 \mathrm{kHz}-60 \mathrm{kHz}]$ frequency range [KEL 07]. This frequency range is justified, in one hand, because it has an optimal spatial resolution and, on the other hand, by having an acceptable attenuation length at the distances of hundreds of meters.

Acoustic calibration runs are made every two minutes, which is enough since the line movements are quite slow. In the present configuration with the detector complete, each acoustic run is composed by fourteen cycles, being each cycle related to the emission of one emitter hydrophone. For each cycle, the detection time and the intensity level in each receiver is stored. Since the time of emission is known, the sound travel time between emitter and each receiver for all lines can be computed. Taking into account the profile of sound velocity obtained by different acoustic sound velocimeters and CTDs located along the detector and considering the sound travel time obtained previously, it is possible to calculate the distances between emitter and receivers. Thanks to an excellent time resolution of the system of few $\mu \mathrm{s}$, distances between fixed transducers are obtained with a stability better than $1 \mathrm{~cm}$. Finally, the final positions of the receiver hydrophones are obtained by an algorithm based on triangulation method applied to the distances between emitters and receivers calculated for the fourteen cycles.

In Figure 2.1 the radial displacement suffered by line 11 for a period of 16 weeks is shown. Figure 2.2 shows the horizontal movements of line 11 for the same period. From these figures it can be seen that hydrophone displacements are followed with few centimetres accuracy. As expected, larger displacements are observed for the top storeys. Naturally, there is a high correlation with the sea current, and the movement of the line is dominated mainly by East-West heading of the Ligurian current. Very similar behaviour is observed for the other lines.

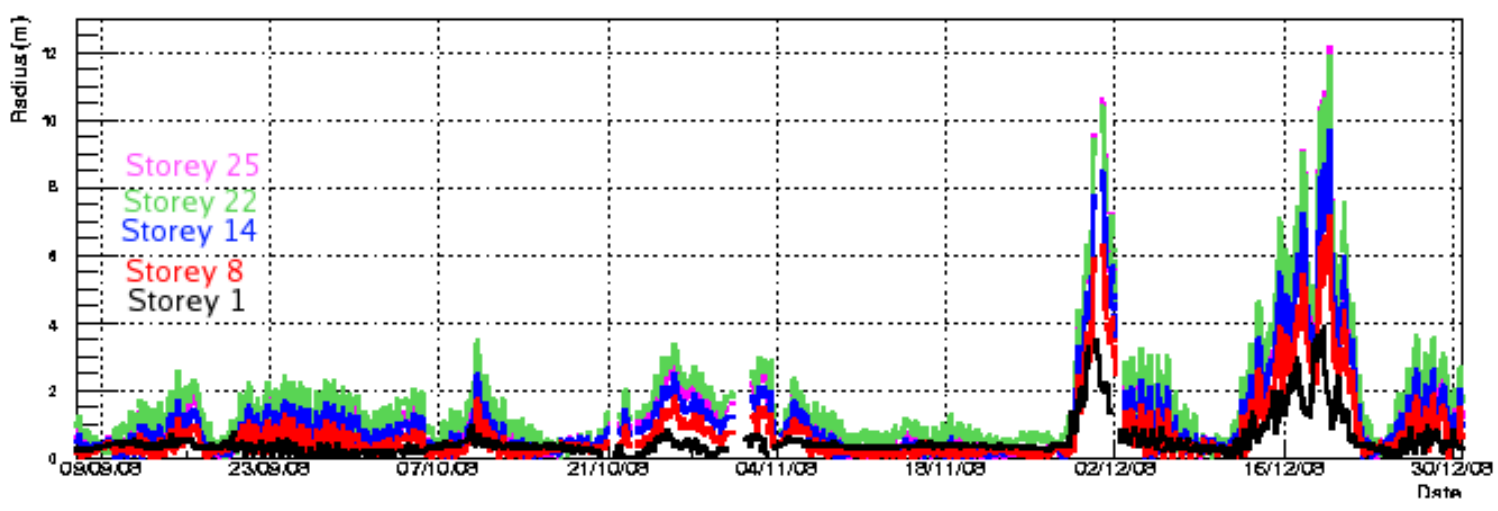

Figure 2.1: Radial displacement of line 11 over 16 week period time. 


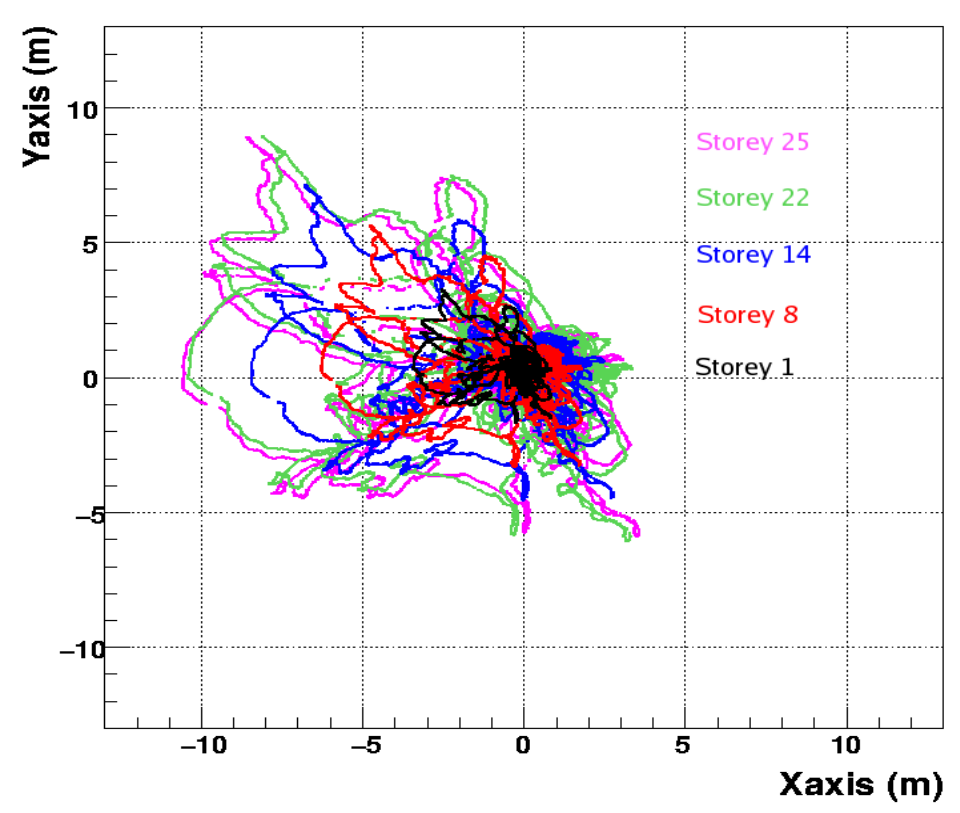

Figure 2.2: Horizontal movements described by line 11 over 6 months period.

\section{Tiltmeter-Compass System}

The Tiltmeter-Compass System (TCS) offers us the information about the local pitch, roll and heading angles of all the floors of each line. This information is obtained through the integration of the TCM2 sensor by Navigation Precision Inc. in a instrumentation board put in the electronic container of each storey. The measurement range of this sensor is $\pm 20^{\circ}$ for roll and pitch angles with an accuracy of $0.2^{\circ}$, and $360^{\circ}$ for heading with $1^{\circ}$ of resolution. It also allows a compensation of parasitic magnetic fields, and "in situ" calibration is needed to calculate the offsets. As in the case of the APS, data are recorded every two minutes.

\section{Performance of the Positioning System}

Taking into account a global fit calculated using equation 2.3 and considering data recorded by the APS and TCS systems, its possible to calculate the tridimensional positions of each OM located in the detector. Data are recorded every two minutes, although the radial displacement of the upper floors of the lines can reach to several meters, the movement is smooth and this data taking period is enough.

ANTARES neutrino telescope was completely built in May of 2008. During the process of construction the detector has passed through various configurations (five lines and ten lines configuration) and during these periods a lot of studies in order to test the correct operation of the positioning system, APS plus TCS, were done. For example, in Figure 2.3 the differences between the distances obtained using the APS system before and after applying the triangulation method is shown. It is possible to observe that the differences between both distances are usually well below $5 \mathrm{~cm}$. 


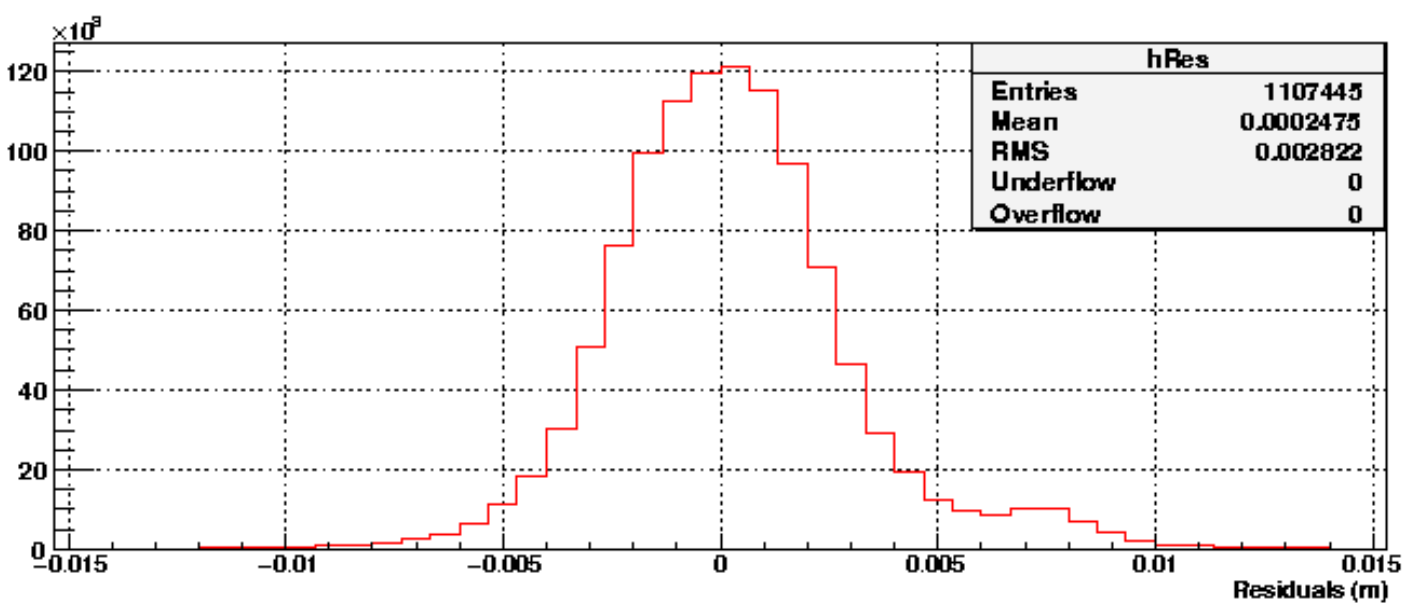

Figure 2.3: Difference between the distances obtained using the APS system directly and the distances obtained after applying triangulation.

Additionally, since the APS and the TCS to are quite independent and complementary, they offer the opportunity to cross-check the stability and accuracy of the systems separately and to evaluate the performance of the global positioning system. To this end, we have compared the hydrophone positions given by the line shape fit with respect to the triangulated positions obtained from the acoustic system. In this comparison the acoustic information from the hydrophone under study is not used in the line shape reconstruction in order not to bias the comparison study. Figure 2.4 shows the differences in the $X$ coordinate of the top hydrophone of line 4 obtained with the two compared methods for the period February-June 2007. A difference of less than $10 \mathrm{~cm}$ is observed. A similar behaviour is observed for the $Y$ coordinate. Usually better results are obtained in the studies of lower storeys, and similar results in the rest of the lines. Therefore, we can conclude from these studies that it is possible to reconstruct the position of the OMs with a resolution better than 20 $\mathrm{cm}$, as required, and that the positioning system is a tool able to provide a tridimensional image of the detector every two minutes [ARD 09 a].

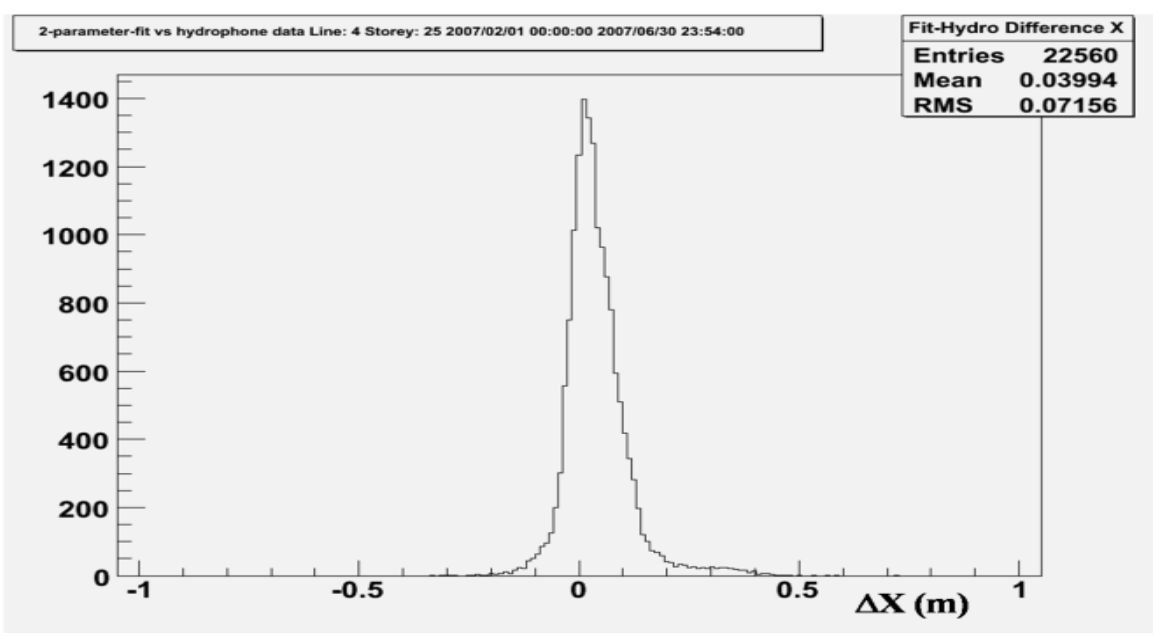

Figure 2.4: Difference in the $X$ coordinates of the line 4 top hydrophone from the line 
shape reconstruction and from the acoustic positioning directly.

\section{Contribution to the ANTARES acoustic positioning system.}

In the frame of the ANTARES collaboration, I have contributed mainly in topics related to the acoustic positioning system. I have developed software tools, using $\mathrm{C}++$ /Oracle, in order to allow the incorporation of data from the acoustic positioning system in the database both for writing and reading it. With this tool it was possible to make the results of acoustic data available in a shorter period, and thus to provide the data for the subsequent reconstruction of particles detected and for the different physic analyses. This was done for the different acoustic configurations (in terms of the definition and number of acoustic cycles and the number of data and positions computed) corresponding to different ANTARES configurations: 5 lines, 10 lines, and 12 lines. Moreover, during the work, it was realised that to increase the efficiency and the speed in writing and reading acoustic data from database, a different acoustic table should be used, which was implemented for the final 12-line configuration. The codes were, as well, incorporated in the tool developed by CPPM and UPV groups to automate the processing of acoustic data. I had the responsibility for this task in UPV. This tool allows having the results of the system sooner and with a much lower human intervention.

I have made, as well, some analysis of the acoustic positioning system data in order to study it, do some cross-checks and see if there might be some possible systematic uncertainties, and how this could affect in the performance of the telescope, mainly in the reconstruction quality and the angular resolution achieved. These cross-check studies have been: 1) The comparison of the distances obtained with the acoustic system with the distances between emitters and receivers (fixed distances for the case of the transceivers, or distances obtained from the position of the receiver given by the ANTARES positioning system; 2) The comparison of time offsets of the OMs, with or without the information of the positioning system of ANTARES, this study was done in collaboration with the IFIC group; 3) Study of the determination of the sea current speed from the acoustic data and comparison with the data from the ADCP [ARD 08].

All these activities and studies have been presented in different ANTARES Collaboration meetings either by me or by other participants.

The first three articles of this thesis are articles from the ANTARES Collaboration. Although they are not directly linked to the acoustic positioning system, the information of this system was used to have a right muon reconstruction, or a right positioning of the AMADEUS acoustic sensors. The forth article corresponds to the proceedings of the $11^{\text {th }}$ Pisa Meeting where we presented the ANTARES neutrino telescope and its status. 


\subsection{R\&D for the KM3NeT acoustic positioning system.}

The Acoustic Positioning System (APS) is a mandatory sub-system of the $\mathrm{km}^{3}$ scale underwater neutrino detector that be able to provide useful and accurate information during the deployment and the operation phases of the telescope. During the deployment phase, the APS must provide the position of the telescope mechanical structures, in a geo-referenced coordinate system, with an accuracy of about 1 metre. This is important both for a safe deployment of the mechanical structures and for the determination of the absolute position and pointing direction of the telescope (necessary for the localization of astrophysical sources). During the telescope operation phase, the APS data are used to measure the positions of OMs in deep sea, with an accuracy of about $10 \mathrm{~cm}$. As already mentioned monitoring the position of the OMs is necessary in order to be able to reconstruct the tracks of the muons correctly and to achieve a good angular resolution of the neutrino telescope. Moreover, for KM3NeT, it would be desirable that the system be able to record sounds in a wide frequency range in order to allow Earth and Sea Science studies (e.g. bioacoustics and geophysics), or even to perform studies on acoustic detection of neutrinos.

A deep-sea APS is composed by three main items:

1. a so called Long Base-Line (LBL) set of acoustic transceivers, anchored to the seabed in known positions;

2. an array of acoustic receivers (hydrophones) rigidly attached to the telescope mechanical structures;

3. an onshore PC farm to analize the APS data analysis, on-shore. The positions of the hydrophones are recovered by measuring the Acoustic Transit Time of the LBL transceivers signals on the hydrophones, thus determining, via triangulation, the position of the hydrophones with respect to the geo-referenced LBL.

The main part of this section is related to R\&D studies on item 1), the LBL acoustic transceivers.

The LBL acoustic transceiver system has been developed to a large extent at the IGIC-UPV, Gandia, in the framework of the KM3NeT consortium, and in collaboration with the INFN (Istituto Nazionale di Fisica Nucleare) and CPPM (Centre de Physique des Particules de Marseille) groups for the development of an innovative acoustic positioning system for KM3NeT [AME 11].

\section{Long Base-Line Acoustic transceivers}

The Long Base Line Acoustic Positioning system for KM3NeT consists of a series of acoustic transceivers distributed on the sea bottom. Each of these acoustic transceivers is composed of a transducer and the associated electronics. The transducer chosen for our studies is the SX30 Free Flooded Ring hydrophone from Sensortech Inc. With respect to the electronics, we have designed and developed a new electronic board, the Sound Emission Board, especially designed for the functionalities required by $\mathrm{KM} 3 \mathrm{NeT}$ and adapted to the transducer. Finally, the system has been characterized and tested for the 
different specifications and in various steps: each element separately, the acoustic transceiver, and even inside the APS proposed. Next, we describe the transducer, the electronic board and some of the tests performed.

- Transducer free flooded ring.

The FFR sensors, model SX30 manufactured by Sensor Technology Ltd, are efficient transducers that provide reasonable power level over a wide range of frequencies and deep ocean capability. These transducers are cylindrical tubes with dimensions: $4.4 \mathrm{~cm}$ outer diameter, $2 \mathrm{~cm}$ inner diameter and $2.5 \mathrm{~cm}$ height and a weight of $57.80 \mathrm{~g}$ (without cable in air). According to the manufacturer, they work in the $20-40 \mathrm{kHz}$ frequency range; they have unlimited depth for operation (already tested up to 440 bars) with a transmitting and receiving voltage response of $133 \mathrm{~dB} \operatorname{Re} 1 \mu \mathrm{Pa} / \mathrm{V}$ at $1 \mathrm{~m}$ and $-193 \mathrm{~dB} \mathrm{Re}$. $1 \mathrm{~V} / \mu \mathrm{Pa}$, respectively; and the maximum input power is $300 \mathrm{~W}$ with $2 \%$ duty cycle. These transducers are simple radiators and have an omnidirectional directivity pattern in the plan perpendicular to the axis of the ring, while the directivity in the other planes depends on the length of the cylinder, 60 for the SX30 model. In figures 2.5, 2.6 and 2.7 the directivity patterns and the curves of receiving and transmitting responses measured by the manufacturer are shown.

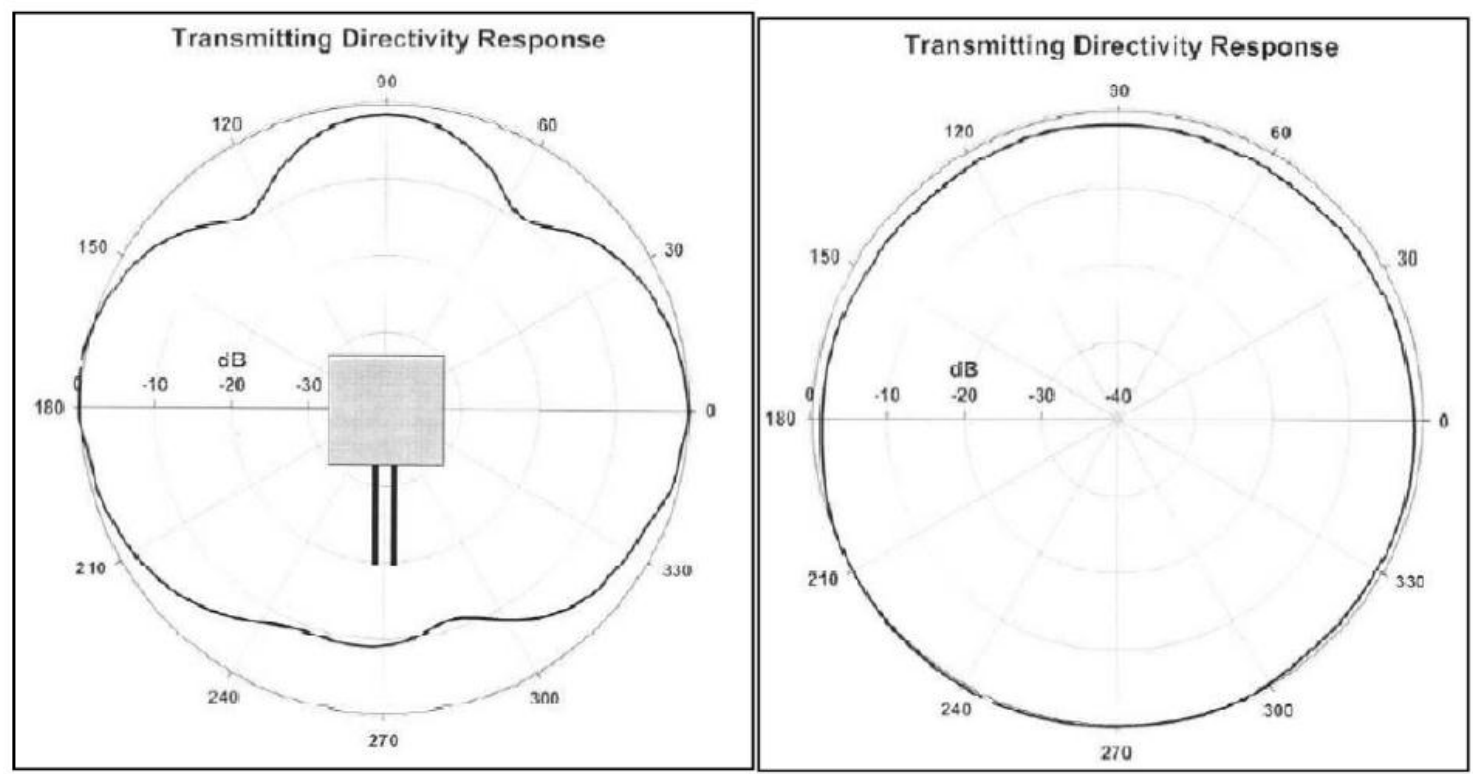

Figure 2.5: Directivity Pattern in the $X Z$ plane (left) and $X Y$ (right) measured at a depth of 0.6 meters and at the temperature of $20^{\circ} \mathrm{C}$. 


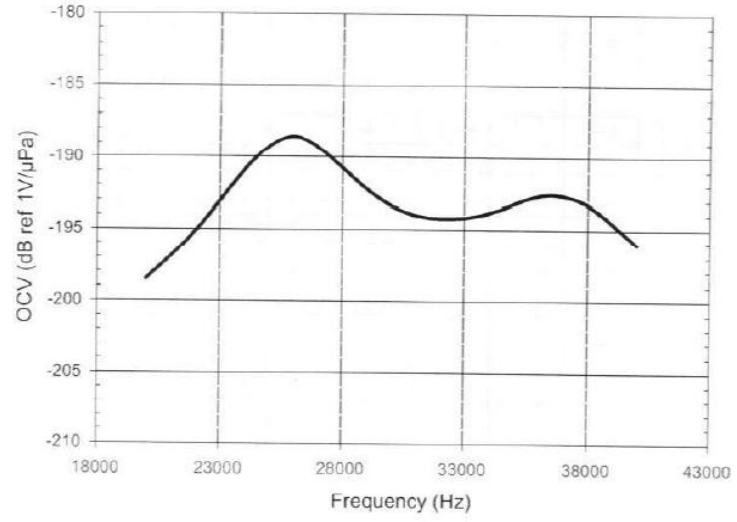

Figure 2.6 : Receiving Response of the FFR hydrophones measured at a depth of 0.6 meters and a temperature of $20^{\circ} \mathrm{C}$

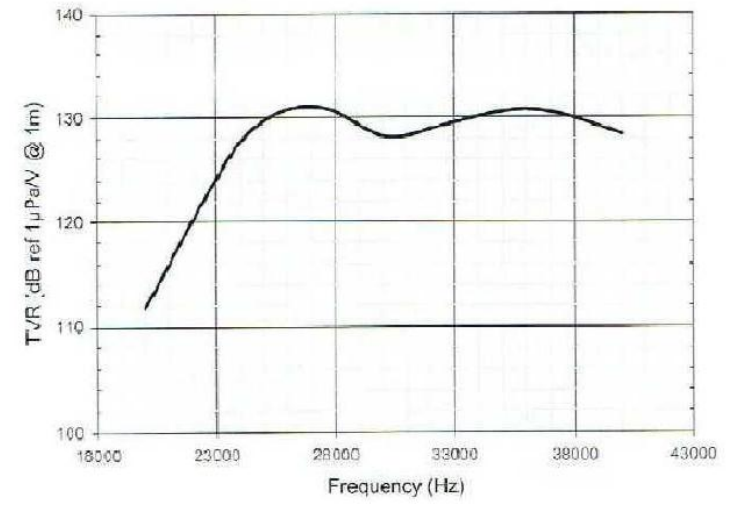

Figure 2.7: Transmitting Response of the hydrophones measured at a depth of 0.6 meters and a temperature of $20 \stackrel{\circ}{\circ}$

Moreover, these transducers are affordable and available in the large quantities needed for a cubic-kilometer facility (in case they are used as receiver hydrophones in the detection units as well).

\section{- Sound emission board}

The design of the Sound emission Board (SEB) should fulfil some requirements, some of them attending to the specifications for the APS system, and some others due to the integration in the $\mathrm{KM} 3 \mathrm{NeT}$ neutrino telescope infrastructure and its specific location and environment. For instance, it has to be operational for a long time period in the deep sea that is, in an inaccessible hostile location and under high pressure. In addition, it has to be very versatile since they should provide dual functionality: emission and reception, besides handling all the communication processes for configuration, triggering, etc. For emission, they should provide short, high-power signals generated from limited electrical supply power (about $1 \mathrm{~W}$ ); with respect to reception, low noise is required to profit from the all-data-to-shore data transmission approach, which increases the system reliability by allowing shore-based tuning options or for using recorded data for scientific purposes. These general requirements have been translated into particular ones for the designed SEB to be tested in-situ at the NEMO tower test in Capo Passero and for the KM3NeT Pre-production Model, both deployments foreseen in 2011.

The SEB prototype (with dimensions $7.3 \times 10.5 \mathrm{~cm}^{2}$, see Figure 2.8) has been designed and developed at IGIC-UPV Gandia. It has been adapted especially to the FFR transducers and is able to feed the transducer with high amplitude short signals (a few ms) with arbitrary waveform. It has also the capacity of acquiring and processing the received signal. As it is possible to observe in the diagram of the board prototype in Figure 2.8, it consists of three main parts: the communication and control part which contains the microcontroller (blue color), the emission part constituted by the digital feeding plus the transducer response (red color) and the reception part formed by the voltage limiter to protect from emission and the output for the analogical part (green part). 
The SEB has been designed for low-power consumption and it is adapted to the neutrino infrastructure using power supplies of $12 \mathrm{~V}$ and $5 \mathrm{~V}$ with a consumption of $1 \mathrm{~mA}$ and $100 \mathrm{~mA}$, respectively. With this, the capacitor of $22 \mathrm{mF}$ is charged allowing the energy storage for the emission. The charge of this capacitor is monitored using the input of the ADC of the micro-controller. Moreover, the output of the micro-controller is connected through a MOSFET driver and a MOSFET full bridge; this is successively connected to the transformer with a frequency and duty cycle programmed through the micro-controller. The transformer is able to convert the signal voltage of $24 \mathrm{Vpp}$ to an output signal within the range [30Vpp $-3000 \mathrm{Vpp}]$ and to send the signal at the transducer through a Zobel network that reduces the capacitive impedance of the transducer itself.

For the reception part of the board, it has a diode limiter able to limit the reception of the emitted signal to approximately of $\sim 1-2 \mathrm{Vpp}$; then, the diode output signal is amplified with a gain of about 4 times and reachable in the BNC output of the board. Thanks to a voltage limiter in the receiver part, the system can act as emitter and receiver almost simultaneously. This feature permits to study the board by looking at some echoes. The reception part of the board has an anti-aliasing filter and can be directed to an ADC on the microcontroller. The micro-controller contains the program for the emission of the signals and all the part of control of the board. It is able to emit arbitrary intense short signals based on the Pulse-Width Modulation technique [VER 08, VER 09]. The basic idea of this technique is to modulate the signal digitally at a higher frequency using different pulse width and to recover the lower frequency signal using a low-pass filter. In addition, the signal amplitude can be increased using a full $\mathrm{H}$ Bridge. The communication of the board with the PC is established with the standard protocol RS232 through an adapter SP233 put in the board.

In summary, the board can be configured from shore and emit arbitrary and intense short signals or act as receiver with very high timing precision. Although the board is working perfectly and within the specifications, at present, we are implementing some modifications in the board to improve the integration of the board in the INFN-CNRS-UPV acoustic positioning system for KM3NeT and to increase the efficiency. To be more explicit, the changes on the board that have been implemented are the following:

- Convert the actual Full Mosfet Driver into a 2x Full Mosfet Driver.

- Substitute the Limiter/Amplifier 4x Blocs with a mechanical relay controlled from the dsPIC. For the reception part, it will be equivalent to a receiver hydrophone of the Detection Unit, that is, the output will be directed to the SMID AM-401V1 preamplifier and to the INFN Acou Board for the digitisation and acquisition of the signal.

- Use the MOLEX connector selected to be used in the storey.

- Convert the TTL input trigger into a LVDS trigger.

- Fit a FRAM chip in the board to store the arbitrary signals.

- New transformer and better adaptation to the FFR transducer 
The diagram for the final design is shown in Figure 2.9.
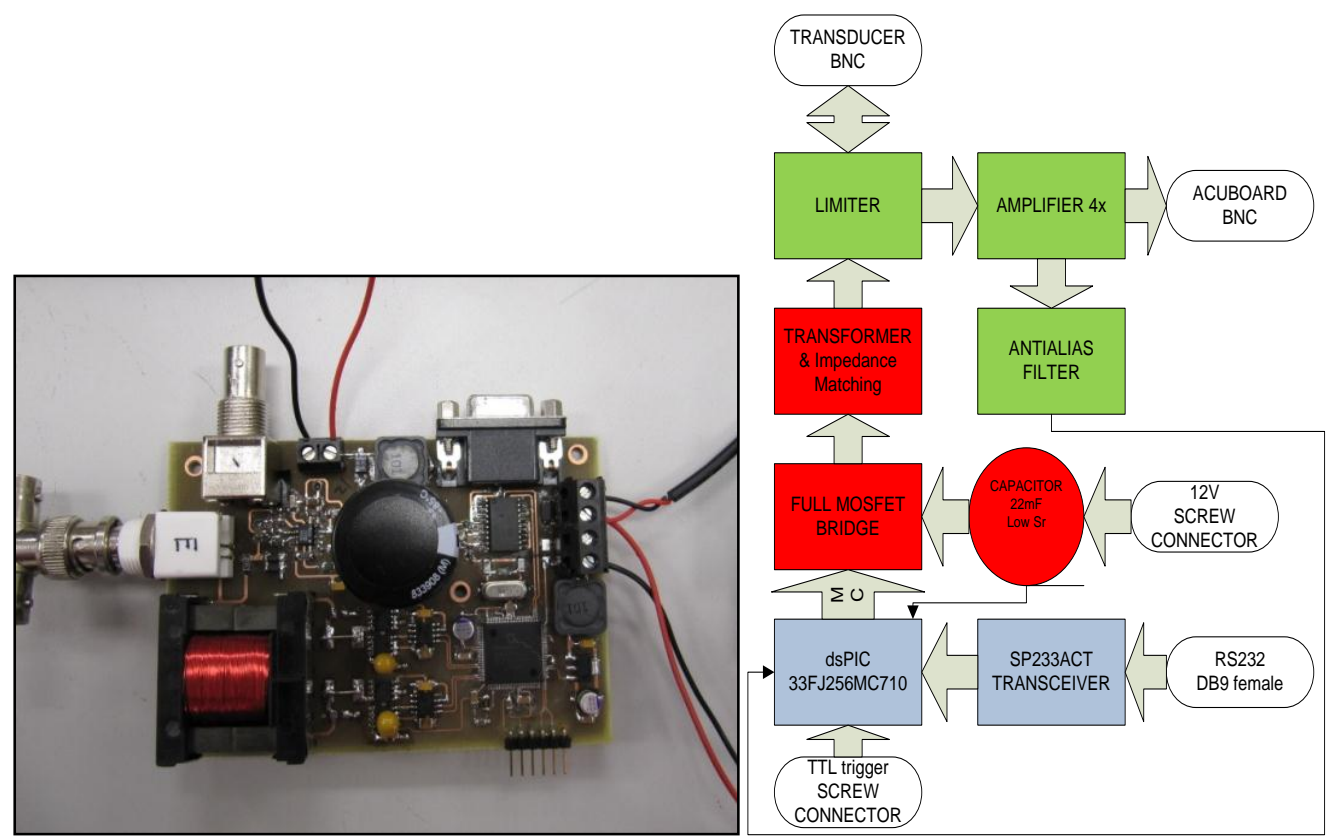

Figure 2.8: Image of the Sound Emission Board (left).View of the SEB board diagram (rigth).

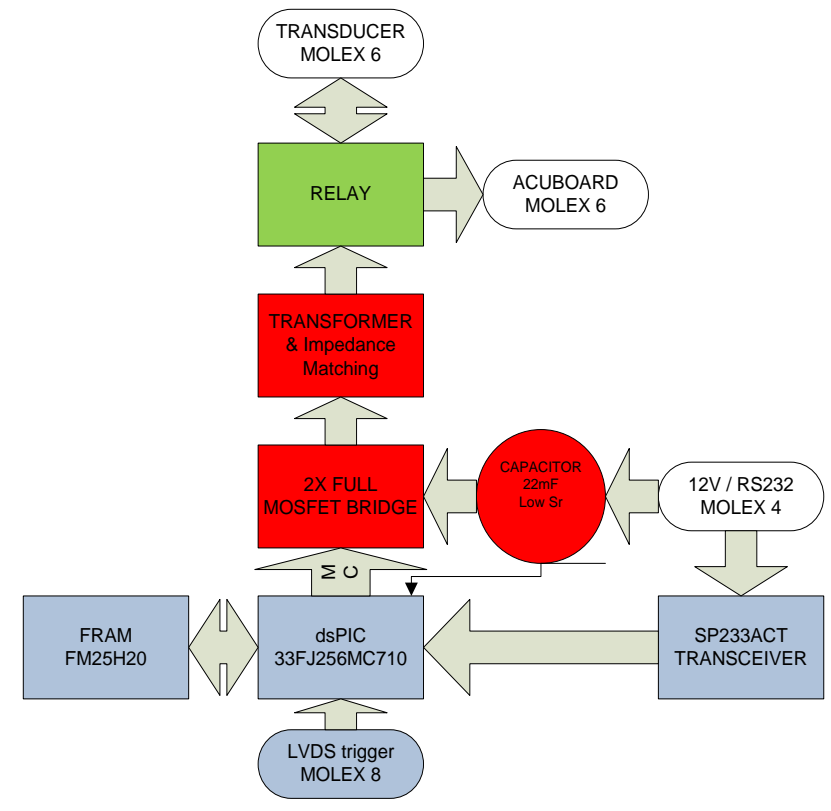

Figure 2.9: Diagram for the Final Sound Emission Board.

\section{Test of the system:}

Different studies and tests have been performed into order to check the behaviour and stability of the system. They can be divided in tests to study the performance of the SX30 FFR transducers and tests to characterise the FFR transducer plus the SEB prototype. 
- Characterization of transducers (FFR SX30).

Several tests have been made or are under way for the transducers

- Pressure tests on the transducers: the FFR transducers have been tested under pressure using the large hyperbaric tank laboratory at IFREMER Brest. An emitting-receiving system of short pulses with the FFR transducers was set up, and the transmission was monitored as a function of the pressure. Figure 2.10 shows the relative acoustic power transmitted as a function of frequency and pressure for a pair of FFR transducers. Little variations with the pressure were seen but no significant drifts over time were observed [ARD 10].

- Transmitting and Receiving Voltage Response of the transducers: the measurements of these parameters have been compared with a reference hydrophone in a $1.10 \times 0.85 \times 0.80 \mathrm{~m}^{3}$ water tank. A well calibrated Reson model TC4014 hydrophone was used as reference. In general, the results are in agreement with the measurements given by the supplier, and are shown in Figures 2.6 and 2.7.

- Directivity pattern of the transducers: directivity studies of the transducers have been done by positioning the receiver with a motorised system with accuracy better than $1 \mathrm{~mm}$. The measurements agree with the directivity patterns given by the manufacturer, shown in Figures 2.11 .

- Other studies have been made, such as the measurements of the intrinsic noise (which is below $100 \mathrm{nV} /(\mathrm{Hz})^{1 / 2}$, and other ones are ongoing, such as the effect of the way of holding the FFR transducer.

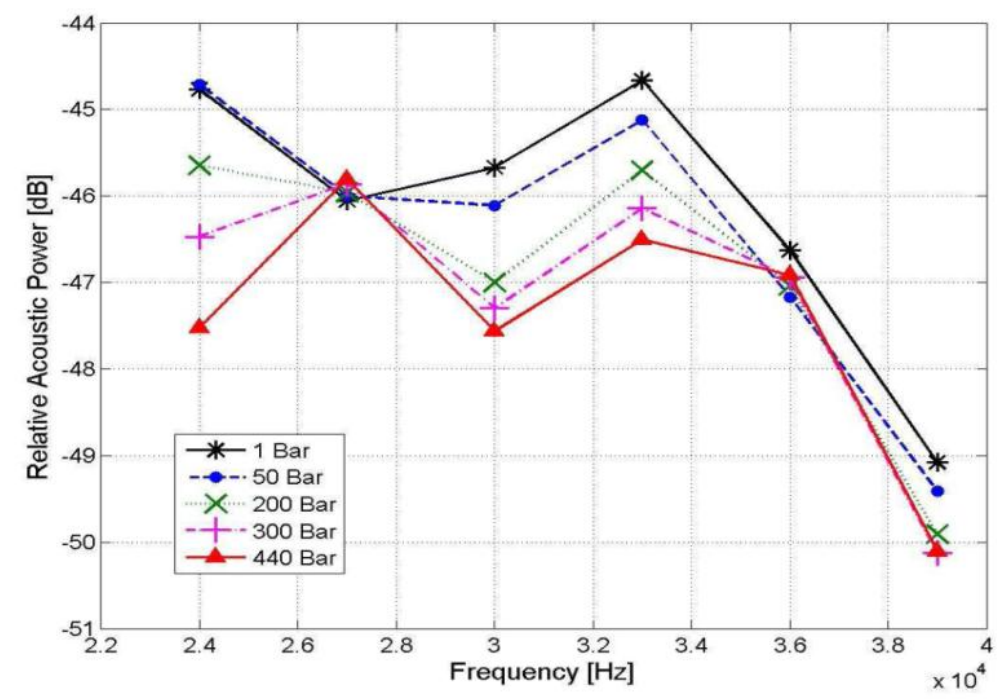

Figure 2.10: Relative acoustic power transmitted as a function of frequency and pressure for a couple of FFR transducers. The uncertainties in the measurements are about $0.5 \mathrm{~dB}$.

Following these results, it is possible to conclude that the SX30 FFR hydrophone is a good candidate to be used in the APS system of the KM3NeT neutrino telescope. 

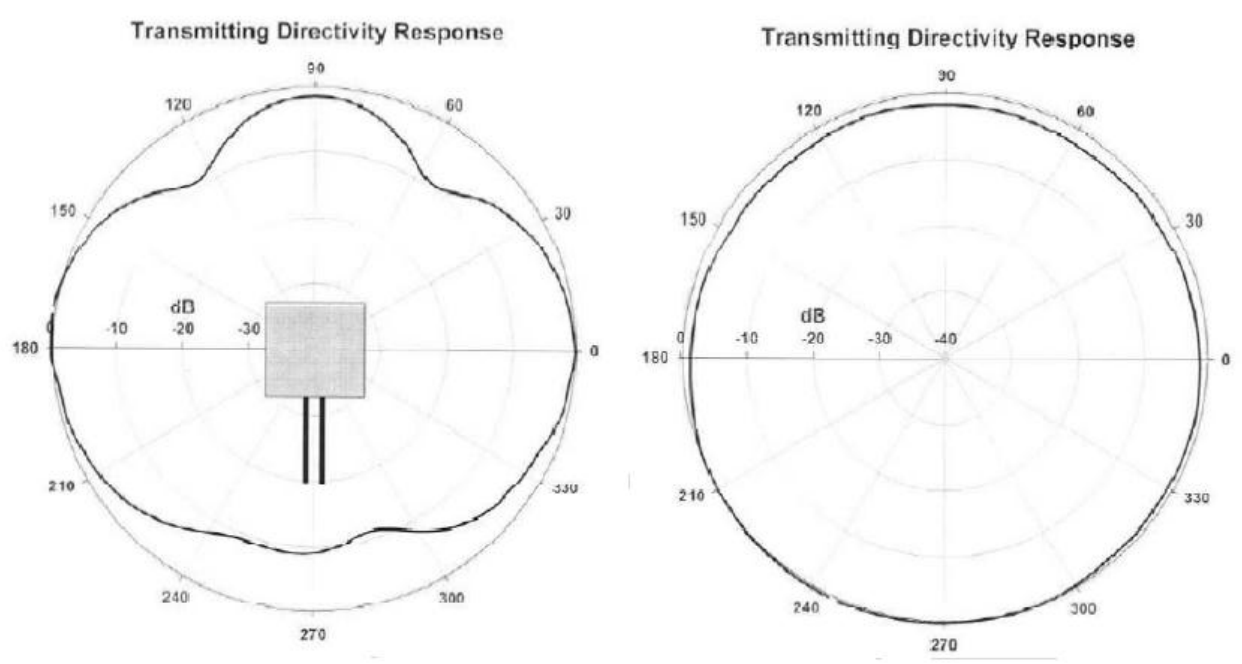

Figure 2.11: Directivity Pattern in the $X Z$ plane (left) and $X Y$ (right) measured at the depth of 0.6 meters and a temperature of $20^{\circ} \mathrm{C}$.

- Characterization of the prototype system (SEB plus FFR transducer).

We have tested the whole prototype transceiver system in the lab with different signals and using one calibrated transducer ITC 1042 as emitter or receiver to calculate the transmission power and receiving response of the system. In Figure 2.12-left the results for the transmitting acoustic power in the $20-40 \mathrm{kHz}$ frequency range are shown. It is about [177-186] dB ref. $1 \mu \mathrm{Pa@1m}$ in agreement with the electronics design and the specifications needed for the APS in KM3NeT. Figure 2.12-right shows the receiving response of the system [ARD 11 a].
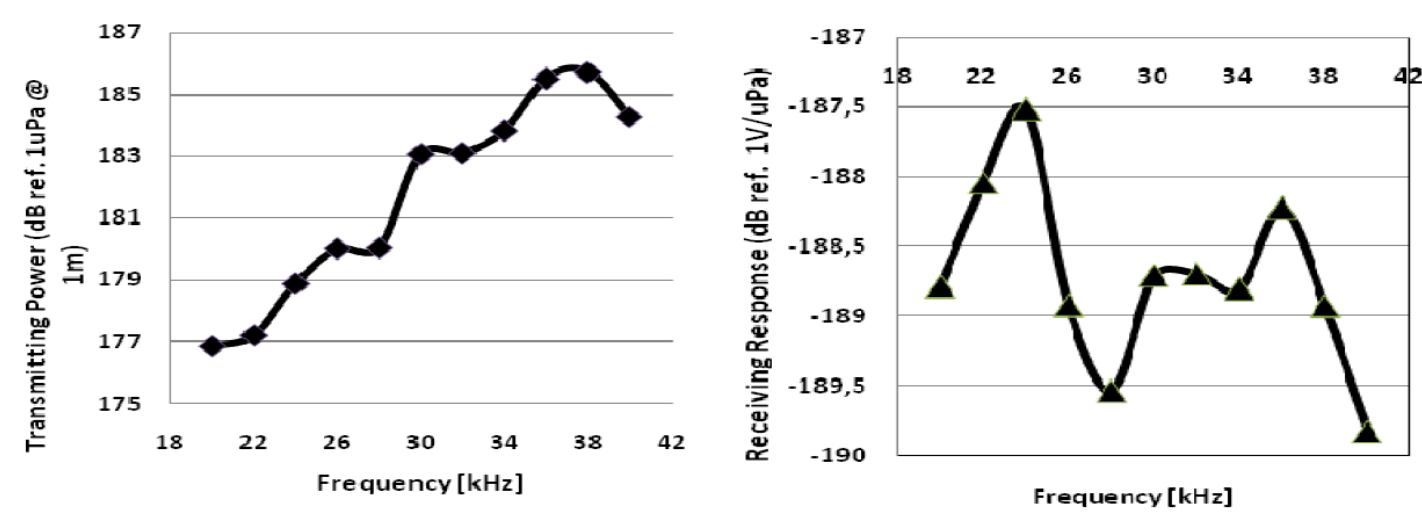

Figure 2.12 :Transmitting power of the system (left) and Receiving response of the system (right)

Additionally, the prototype system has been tested with other elements for the proposed APS system in order to prove the compatibility and functionality of different hardware and software developed within KM3NeT for an innovative acoustic positioning system. The tests were done in the laboratories of the IGIC-UPV in Gandia in May 2010 with the participation of INFN, CPPM and ECAP groups. In these tests, the electronic noise of the whole chain was measured, being lower than $-120 \mathrm{~dB}$ re $1 \mathrm{~V}^{2} / \mathrm{Hz}$. Moreover, the whole chain with 
the emission and reception was tested and the signal emission latency calculated. In Figure 2.13, an example of the measurements is shown. The measured latency is the sum of two components: $166 \mu$ s due to the AcouBoard (the electronic board of the receiver), while the contribution of the Signal Emission Board is $7.5 \mu \mathrm{s}$. The time latency is very stable, being the variation lower than $1 \mu \mathrm{s}$ [SIM 11].

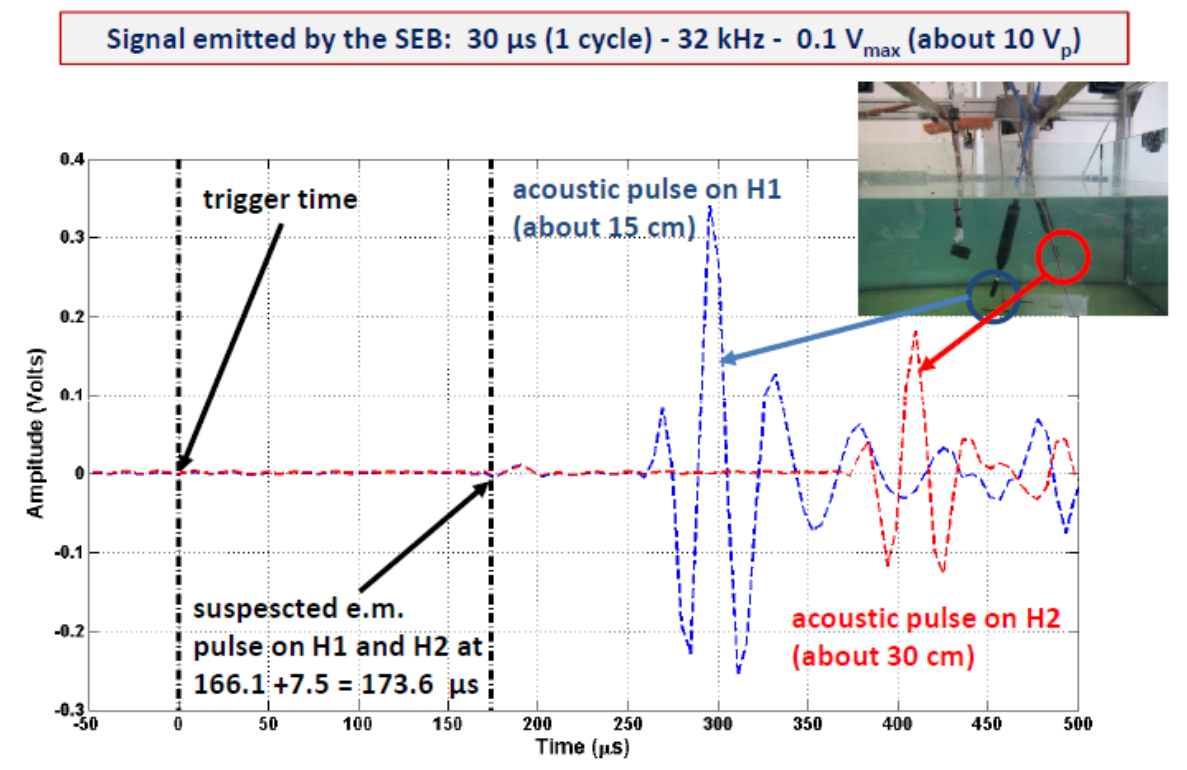

Figure 2.13: Example of a emission-reception test.

From the results of these lab tests, we can conclude that the acoustic transceiver system proposed seems a good option to be a part of the final APS of the KM3NeT neutrino telescope since almost all requirements and specifications has been achieved successfully. There is still work to be finalised, such as the development of the final SEB including the last changes proposed, or the mechanical setup to hold the FFR transducer. Moreover, the system has to be tested in real conditions, that is, in situ in a neutrino telescope infrastructure in the deep sea. It is foreseen that this will be done in 2011 in the NEMO tower test at Capo Passero and in the deployment of the Preproduction Model of KM3NeT.

\section{Contribution to the KM3NeT acoustic positioning system.}

In my Ph. D. work I have been involved in the design and development of the acoustic positioning system for the KM3NeT neutrino telescope. I have made some calculations and simulations of the system in order to study the specifications needed for the system, the number of elements needed and their characteristics. Additionally, Gandia's group have been very involved in the development of the transceiver of the APS system. For this, a study of different transducers was made, selecting the Free Flooded Ring SX30 from Sensortech Inc. Custom electronics, the Sound Emission Board, has been developed in order to be adapted to the transducer and to fulfil all the requirements needed for the transceiver of a cubic kilometre deep sea neutrino telescope. Although I 
have not been the responsible of these developments, I have been very actively involved in the definition of the system, in the studies leading to it, participating in the tests performed to the transducer and system, both in Gandia or outside (in LNS-Catania, and in ACSA company in Aix-En-Provence) and in the reports for the in situ tests.

My participation in the article 4.5 was related to the studies conducted to define the positioning system of the KM3NeT neutrino telescope. The article 4.6 presents the first studies for the development of the transceiver, whereas the article 4.7 describes the APS system for KM3NeT proposed and by INFN, CPPM and UPV groups and the studies for its development. 


\section{Development of calibration systems for acoustic detection of neutrinos}

The aim of this part is to expose the motivations for the study of Ultra High Energy (UHE) neutrinos and the possibility of detecting this kind of particles using acoustic detection systems. First, a brief introduction about the acoustic pulse generated by a neutrino interaction will be presented and how acoustic detection could be used as a new technique to detect high energy neutrinos $\left(E_{v} \geq 10^{18} \mathrm{eV}\right)$. Then, some basic concepts related to acoustic parametric generation will be introduced in order to understand how this technique can be applied in the process of developing a compact acoustic calibrator able to emit an acoustic pulse of identical properties as the predicted UHE neutrino signature. This device would be used in calibration tasks of acoustic detection systems installed in underwater neutrino telescope. Since acoustic detection of UHE neutrinos is still in its evaluation phase of the feasibility of the technique, calibration tools have a role that goes further the simply validation of the different sensors and medium. Moreover, it should serve also to explore the technique, and to perform tests that assure its reliability.

\section{Introduction to UHE neutrinos and the acoustic signature}

As described at the first part of the thesis, observation of UHE neutrinos has been motivated during years by the study of particles generated by cosmic ray interactions. Considering primary cosmic rays as high energy charged particles, originated in outer space, that travel at nearly the speed of light and strike the Earth from all directions. When these particles arrive to the Earth interact with a nucleus $(N)$ of the atmosphere. In these interactions part of the energy is converted in matter, creating new kind of particles (mainly pions). Depending of the shower generated in the interaction between cosmic ray and atmospheric nuclei secondary particles can be

$$
\begin{aligned}
p+N \rightarrow \pi^{+}\left(+K^{+} \ldots\right) & \rightarrow \mu^{+}+v_{\mu} \\
n+N \rightarrow \pi^{-}\left(+K^{-} \ldots\right) & \rightarrow \bar{v}_{\mu}+v_{e} \\
& \longrightarrow \mu^{-}+\bar{v}_{\mu} \\
\longrightarrow & e^{-}+v_{\mu}+\bar{v}_{e}
\end{aligned}
$$

During many years, astroparticle physicists have studied cosmic rays using different kind of experiments and have measured, or rather have tightened the flux of particles that arrives to the Earth. Limits of the measured flux as a function of energy are:

$$
\left\{\begin{array}{c}
10^{4} \mathrm{~m}^{-2} \mathrm{~s}^{-1} \rightarrow 10^{9} \mathrm{eV} \\
10^{-2} \mathrm{~km}^{-2} \mathrm{~s}^{-1} \rightarrow 10^{20} \mathrm{eV}
\end{array}\right\}
$$


In order to estimate the expected event rates in cosmic neutrino detectors such as ANITA [BAR 06], HiRes [BER 06], IceCube [KLE 08], and the Pierre Auger Observatory [ROU 08], it is thus essential to take new data on ultra high energy cosmic rays (UHECRs) into account. There has been significant recent progress in the field, in particular HiRes [ABB 08] and Auger [ABR 08] have established that the energy spectrum is attenuated beyond $5 \cdot 10^{19} \mathrm{eV}$.

In this large scale of energy the flux of particles is monotone except in the range $E^{-2.7} \rightarrow E^{-3.0}$ near $10^{15.5} \mathrm{eV}$, this part is known by the 'knee' of flux in the cosmic rays. Many experiments during last decades have been designed in order to measure cosmic rays in the range of $10^{19}-10^{22} \mathrm{eV}$. This range of energy is particularly interesting due to the 'cut-off' predicted by Greisen, Zatsepin and Kuzmin (GZK) [GRE 66], at the middle of 1960's. The prediction of this 'cut off' is based on the interaction between charged particles that compose cosmic rays and photons of the Cosmic Microwave Background, $\gamma_{C M B}$ through pion photo-production or creation of pairs. This effect could produce a stacking in the cosmic ray spectrum for energies lower than the GZK threshold and sudden decrease of flux for energies higher than threshold for distant sources.

Contrarily to the difficulties of doing astronomy of far sources using cosmic rays, there exists the possibility of study astrophysics objects by means of UHE neutrino detection, which could be very useful to study the GZK "cut-off" and the highest energy regime. Figure 3.1 shows the estimation of neutrino flux from GZK, as well as some limits from theory and from different experiments using different techniques (the optical Cherenkov for the lower energy regime and radio and acoustic technique for the highest energies).

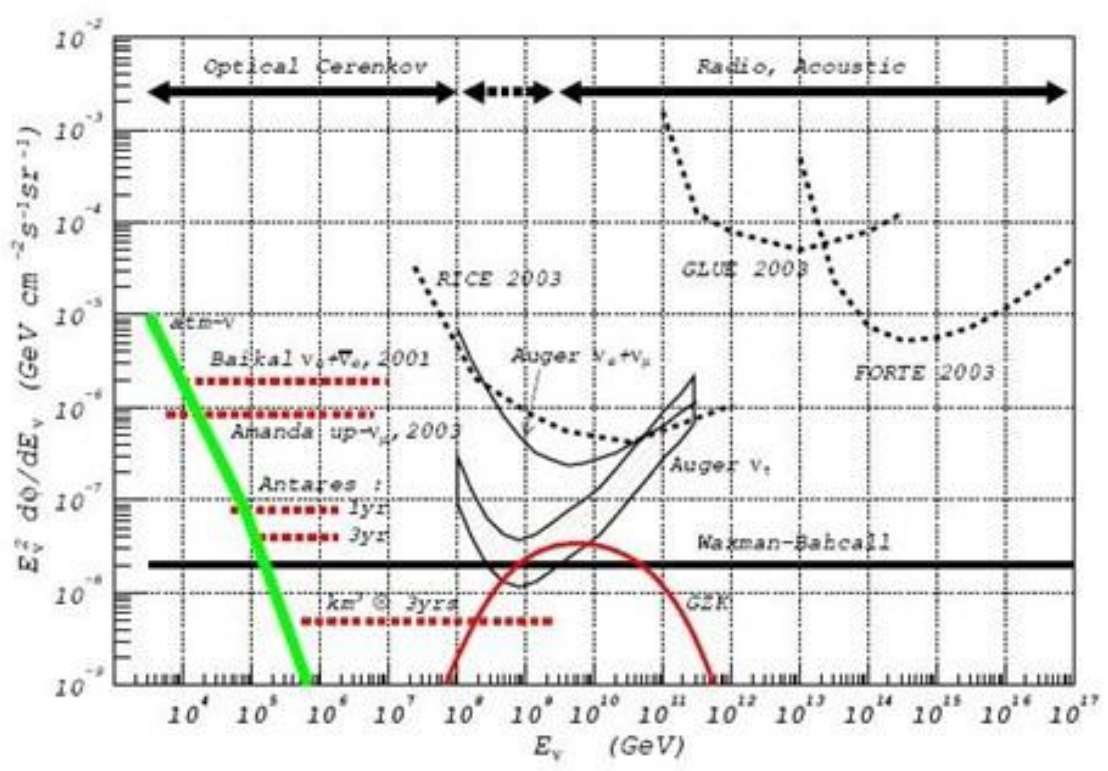

Figure 3.1: Estimation of the neutrino fluxes vs. energy and some limits from theory and different experiments.

Due to the small interaction probability of neutrinos with matter and the lower flux of neutrinos that arrives to Earth, it is necessary to have a large volume of medium that can be used as detector in order to have enough material to 
increase the detection probability of UHE neutrinos. Then, the only feasible solution is to use a natural medium as, for example sea water or ice from Polar Regions. The usual way to detect neutrinos using optical sensors is limited by the fact that the attenuation length of Cherenkov light in water is about $60 \mathrm{~m}$, and therefore, a huge number of photomultipliers will be needed to instrument detection volumes of at least a hundred cubic kilometre volume needed to detect UHE neutrinos. Other possible ways to detect UHE neutrinos was predicted by Askarian using acoustic (or radio) techniques [ASK 57]. The advantage of acoustics in comparison with optics is that the sound attenuation length in water is much larger than the one for light. For example, acoustic signals of $10 \mathrm{kHz}$ and $30 \mathrm{kHz}$ have attenuation lengths of about $10 \mathrm{~km}$ and 1 $\mathrm{km}$, respectively. This property allows the covering of a large detection volume using a lower number of sensors.

The thermo-acoustic pulse signals are produced by the particle cascades that evolve when neutrinos interact with nuclei in water. About $25 \%$ of the neutrino energy is deposed by hadronic cascade in a small cylindrical volume of a few centimetres in radius and several metres in length leading to a local heating of the medium which can be considered instantaneous with respect to the acoustic process. Following the thermo-acoustic model [ASK 79, LEA 79], the accelerated motion of the heated volume forms a pressure pulse of bipolar shape which propagates in the surrounding medium. The coherent superposition of the elementary sound waves produced over the long and thin cylindrical volume of the energy deposition leads to a 'pancake' directivity, that is, the propagation within a flat disk-like volume in the direction perpendicular to the axis of the particle cascade, similarly to that produced by a linear array. Experimental evidence of the thermo-acoustic pulse generation was first observed at Brookhaven NL [SUL 79] in 1979 using a $200 \mathrm{MeV}$ proton beam with a energy deposition in the medium of about $10^{18} \mathrm{eV}$.

Propagation of the acoustic pulse in sea water modifies its shape, and after several hundreds of metres the pulse has a characteristic frequency spectrum that is peak around $10 \mathrm{kHz}$ [BEV 07, BEV 09, NIE 06]. Given the strongly anisotropic propagation pattern of the sound waves, the details of the pressure pulse, namely its amplitude, asymmetry and frequency spectrum, depend on the distance and angular position of the observer with respect to the particle cascade induced by the neutrino interaction. As a reference example, shown in Figure 3.2 , at $1 \mathrm{~km}$ distance in direction perpendicular to a $10^{20} \mathrm{eV}$ hadronic shower the expected acoustic pulse is expected to have about $0.2 \mathrm{~Pa}$ (peak-topeak) in amplitude and about $50 \mu \mathrm{s}$ in width. With respect to the directivity pattern the full width half maximum of the pancake is expected to be about $1^{\circ}$. 


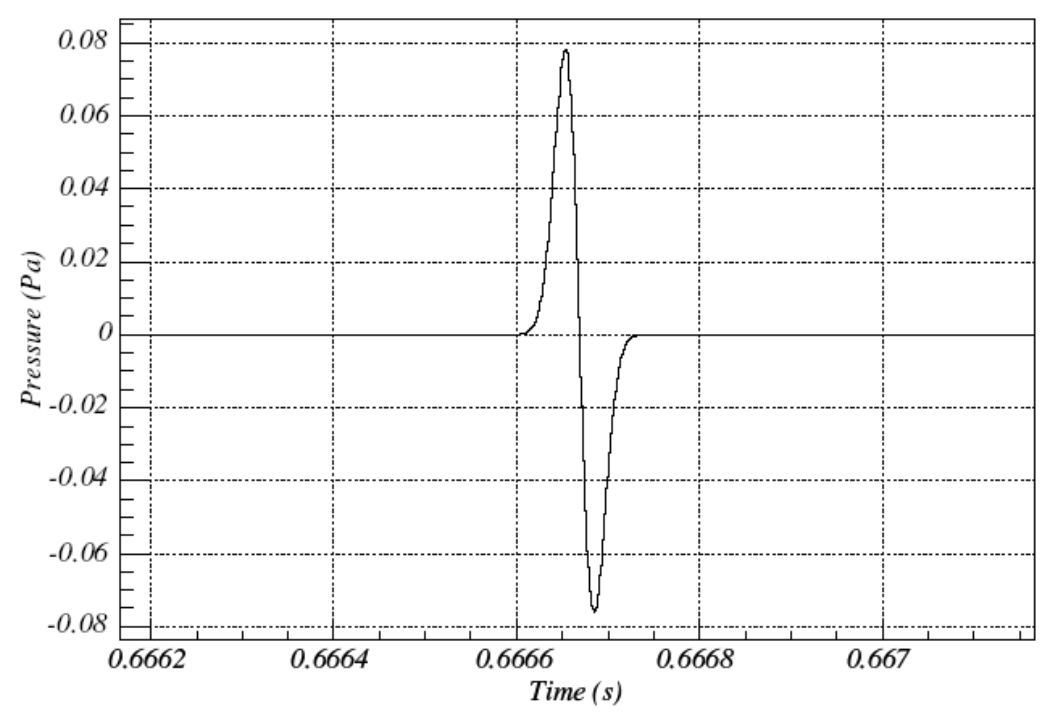

Figure 3.2: The pressure pulse for a $1.2 \cdot 10^{11} \mathrm{GeV}$ shower in sea water at a distance of $1 \mathrm{~km}$. The angle with the plane transverse to the shower direction is zero degrees.

Different projects are studying acoustic detection of UHE neutrinos in different media: ice [DES 09] and fresh water [ANT 07]. However, the most investigated medium is sea water. Besides AMADEUS (ANTARES Modules for the Acoustic Detection Under the Sea), different groups are also involved using military arrays of hydrophones [VAN 05, DAN 07] or exploiting other existing deep sea infrastructures [RIC 09].

\section{AMADEUS system}

The AMADEUS system comprises a total of six acoustic storeys of the ANTARES neutrino telescope: three on the Instrumentation Line (IL07) and three on the 12th detection line (L12). AMADEUS is fully functional and routinely taking data with 34 sensors. Two out of 36 hydrophones became inoperational during their deployment. The system has been designed for using different kind of acoustic sensors and having different distances between the different acoustic storeys in order to enhance different configuration studies. Figure 3.3 shows the system schematically. This system can be considered as a basic prototype to evaluate the feasibility of the acoustic detection technique. The main goals of the system are:

- Long-term background investigations (levels of ambient noise, spatial and temporal distributions of sources, rate of neutrino-like signals);

- Investigation of spatial correlations for transient signals and for persistent background on different length scales;

- Development and tests of data filter and reconstruction algorithms;

- Investigation of different types of acoustic sensors and sensing methods;

- Studies of hybrid (acoustic and optical) detection methods. 


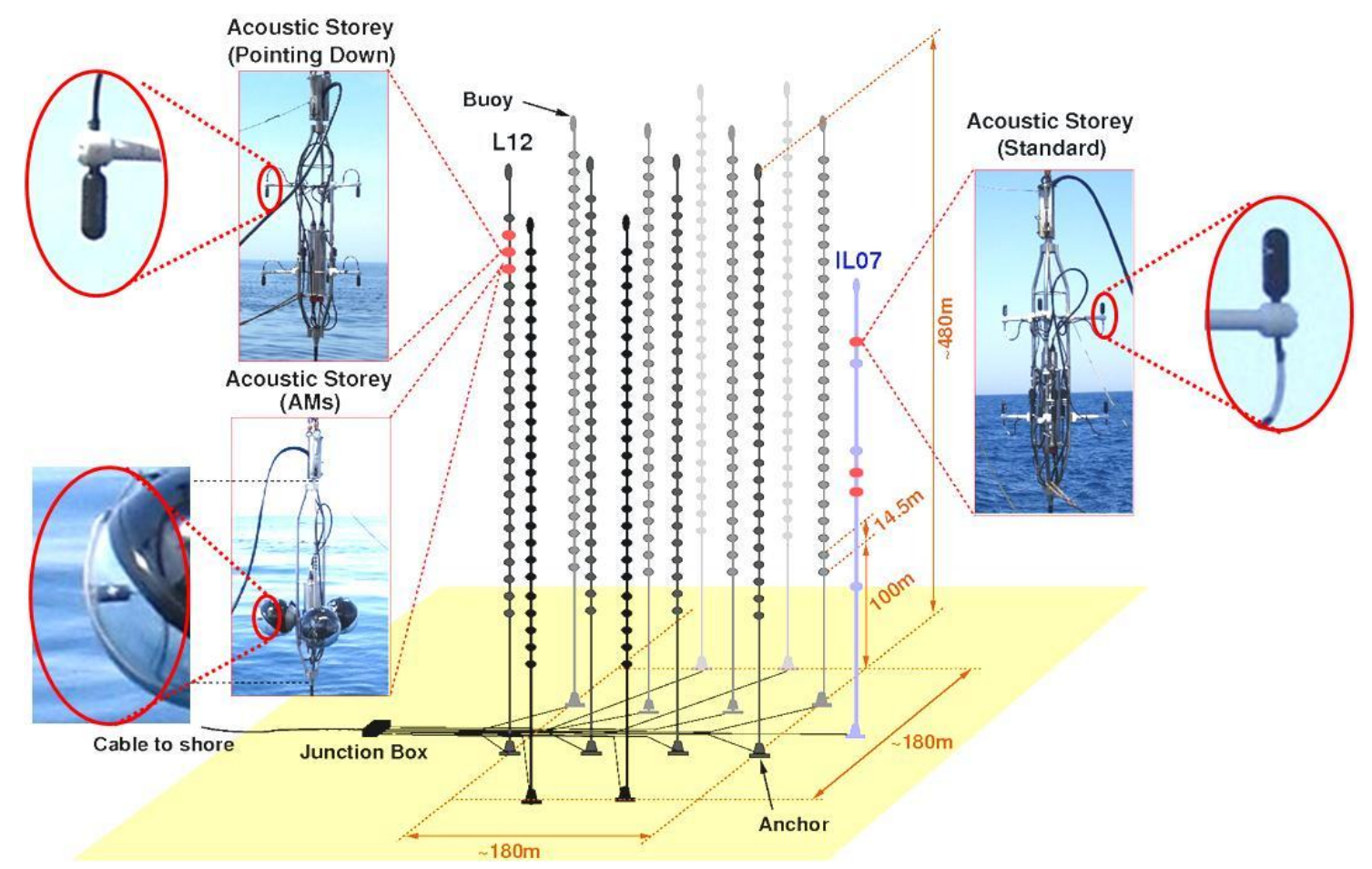

Figure 3.3. A schematic view of the ANTARES detector showing the AMADEUS system. The six acoustic storeys are highlighted in red and their three different setups are shown.

\section{Calibration in acoustic detection of neutrinos}

We can classify the calibration activities in two fields, in the lab and "in situ" in neutrino telescopes, covering a very broad range of topics. Acoustic sensors must be first calibrated in the lab in order to know the sensitivity and the time response of the sensors. Depending on the different environmental constraints, different techniques can or should be applied: reference calibrated hydrophones, reciprocity method, electrical impedance analysis, etc. Moreover, pressure tests and calibrations are needed to assure the right working of sensors in deep sea. In neutrino telescope sites, a calibration system with acoustic transmitters should be used to monitor the sensitivity and time response of sensors in site, as well as the response to neutrino-like signals. At the same time, it should provide not only a good tool for training the system for an optimized event reconstruction, but a test to the reconstruction as well. It is worth to mention that signal processing techniques can be very helpful to enhance the possibilities of different calibration techniques and having much faster and less disturbing calibration runs. They could even allow calibrating and taking physics data simultaneously [ARD 07].

In this context, the development of acoustic transmitters able to monitor the sensitivity of the different acoustic sensors, to train and tune the detector, and to test the reliability of these systems is of great importance [ARD $09 \mathrm{~b}$ ]. Transmitters able to reproduce the acoustic signature of a UHE neutrino could perform most of these tasks for undersea neutrino telescopes, but due to the nature of the acoustic pulse (i. e., a very directive 'pancake' short bipolar pulse), it is not straightforward to design such a system, able to reproduce the time and 
directivity patterns at the same time, especially if practical issues such as ease of deployment and operation are considered. The use of a linear array of omnidirectional emitters has been proposed for this task [OOP 11]. However, the approach of the IGIC-UPV group has been different trying to develop an acoustic neutrino calibrator using the non-linear parametric acoustic sources effect [ARD 09 c, WES 63]. The advantage of this technique is that the transmitter is more compact, and therefore, the difficulties for the deployment and operation in deep sea are smaller.

\section{Parametric acoustic sources}

Acoustic parametric generation is a well-known nonlinear acoustic effect. First theoretical studies were done by Westervelt in the 1960's [WES 63], and since then the technique has been studied quite extensively with the development of important applications in underwater acoustics, especially to obtain directive acoustic sources. This effect appears, for example, when there are two intense monochromatic acoustic beams with close frequencies travelling together along the medium (water, for example). Under these circumstances, in the region of non-linear interaction, secondary beams with sum, difference, double frequencies and harmonics appear. The main application consists of producing a directive low frequency beam by using the difference frequency generation from two close high frequency beams. At high frequency it is easy to have directive beams, property which is maintained for the secondary beams. Moreover, since the high frequency components are rapidly absorbed, for large range applications, it is just this secondary low frequency component the only one which is present in far distance applications.

The parametric acoustic sources have some advantages with respect to traditional linear radiating systems, such as the opportunity of obtaining narrow directional patterns at small overall dimensions of primary transducer, the absence or low level of side-lobes in a directional pattern on a difference frequency, and a broad band of operating frequencies of radiated signals. For all these reasons this kind of sources are widely used in underwater acoustics: sonar, communication, etc.

The same effect can be used for transient signals [MOF 77], [MOF 79] being possible to generate a short signal by a "special modulation" at a larger frequency in such a way that the pulse interacts with himself in the medium providing the desired signal due to the sum (integral) of difference frequencies from the spectral content of the short modulated signal. Theoretical and experimental studies show that the shape of the secondary signal is basically the second derivative of the envelop of the primary signal, where the pressure amplitude is proportional to the square of the primary pressure amplitude, and depends on the nonlinear acoustic parameter, besides other parameters of the medium. To determine the signal for the emission we have used the following expression:

$$
p(x, t)=\left(1+\frac{B}{2 A}\right) \frac{P^{2} S}{16 \pi \rho c^{4} \alpha x} \frac{\partial^{2}}{\partial t^{2}}\left[f\left(t-\frac{x}{c}\right)\right]^{2}
$$


where $P$ is the pressure amplitude of the primary beam pulse, $S$ the surface area of the transducer, $f(t-x / c)$ is the envelop function of the signal, which is modulated at the primary beam frequency, $x$ is the distance, $t$ is the time, $B / A$ the non-linear parameter of the medium, $\rho$ is the density, $c$ the sound speed and $\alpha$ is the absorption coefficient. With this, $p(x, t)$ is the expected parametric signal. In our studies we would like to have for $p(x, t)$ a bipolar signal similar to the acoustic signature of the UHE neutrino interaction, and then the envelope function $f(t-x / c)$ for the primary beam used can be calculated by integrating the expression.

The laboratory tests performed using planar transducers [ARD $09 c$ c] and cylindrical transducers [ARD $11 \mathrm{~b}$ ] help us to understand the control of the shape of the bipolar signal (secondary parametric beam), the studies to know the amplitude as functions of the tension in the transducer, and of the distance to it, as well as, the measurement of the directivity pattern. The results demonstrate that the acoustic parametric sources effect is a promising tool that could be used to generate neutrino like signals with good directivity using a cylindrical transducer (or a compact array with a few of them). Moreover, with this kind of transducers, a linear array of 3 transducers with $20 \mathrm{~cm}$ separation from each other could reproduce the $1^{\circ}$ 'pancake' directivity. The idea is to develop the prototype and test and use it in a sea campaign during 2011 with the AMADEUS system. With this, we deal with two aims: test the transmitter, and to perform some calibrations in the AMADEUS system.

\section{Contribution to the calibration for the acoustic detection of neutrinos.}

In the field of the acoustic detection of neutrinos I have worked mainly in activities related to calibration. In a first phase, we have proposed some techniques for the calibration of sensors to be used in neutrino telescopes based on acoustic detection. For instance, we made studies of the reciprocity calibration method under different configurations with the aim to apply this technique for the calibration in lab of the sensors to be used in neutrino telescopes. I did the measurements and the analysis of this study. A second study was made in order to generate bipolar pulses (neutrino-like signals) with common transducers, which are usually not flat in frequency. To deal with this, equalization techniques profiting from signal processing were investigated and contrasted with measurements in the lab. The inverse filter method gave very good results. In this case, , I was in charge of the measurements and the analysis too. Both studies were presented in ARENA (Newcastle, 2006), and the EAA-European Symposium on Hydroacoustics (Gandia, 2006) conferences, and published (article 4.8).

The last activities in this area were in the direction of developing a compact neutrino calibrator able to mimic the signature of a UHE neutrino interaction in terms of the shape of the signal (bipolar pulse) and in terms of the directivity ('pancake' directivity). As explained, the parametric effect has been studied performing measurements in the lab in order to understand and control the 
effect, and demonstrate that the technique could serve to this aim. In a first phase, we study it using planar transducers. I was participating in the measurements and in the analysis, and I presented the results in ARENA conference (Rome, 2008), whose proceeding was published (article 4.9). In a second phase, the study has been extended to the case of cylindrical symmetry, showing that under this situation it is also possible to use the parametric acoustic sources technique, and therefore concluding that this method can be applied to obtain a compact neutrino calibrator. Although I have not made the measurements of this second phase, I have helped on some aspects for them, I have participated in the analysis, and presented the results in the ARENA Conference (Nantes, 2010). 


\section{Publication summaries (in Spanish).}

\subsection{Performance of the First ANTARES Line.}

Autores: M. Ageron, et al. (ANTARES Collaboration)

Ref.: Astroparticle Physics, Volume 31, Issue 4, May 2009, Pages 277-283

Éste es el primero de los cuatro artículos de la Colaboración ANTARES que se adjunta. Durante la realización de la tesis doctoral, mi labor principal dentro de la Colaboración ha sido desarrollada en tareas relativas al sistema de posicionamiento acústico. Más concretamente se me encargó realización de diferentes programas, para facilitar la inserción de los datos acústicos (posiciones de los hidrófonos presentes a lo largo de cada una de las líneas) en la base de datos del experimento, quedando estos datos a disposición de la colaboración para el posterior análisis de los datos medidos. Los códigos desarrollados para establecer una interfaz con la base de datos fueron primero definidos para la configuración de 5 y 10 líneas y finalmente para la configuración de 12 líneas debiendo de realizar continuos updates hasta la llegada de la configuración final (incluida una nueva definición de la tabla de la base de datos para una mayor claridad y facilidad de uso para el resto de usuarios. Por último, y para facilitar el trabajo de ordenación y almacenamiento de los datos acústicos con una menor intervención humana, se insertó todo el código dentro del programa general quedando automatizado el proceso. Otra tarea realizada ha sido el análisis de los datos del sistema de posicionamiento acústico, con el fin de detectar posibles anomalías en el sistema, o acotar posibles errores sistemáticos, o extraer información relativa a la velocidad de las corrientes marinas a partir de los datos acústicos.

En este artículo, como su título indica, se describe el comportamiento de la primera línea de ANTARES. La construcción del telescopio de neutrinos ANTARES comenzó con la instalación de dicha línea el 14 de febrero de 2006 llevándose a cabo la conexión de la misma dos semanas después. En este artículo se presentan tanto los resultados obtenidos, a partir de los datos tomados durante los primeros seis meses de funcionamiento del detector, como las dificultades encontradas en el proceso de medida y posterior análisis. La línea sumergida estaba compuesta de 25 pisos, cada uno de ellos formado por tres fotomultiplicadores introducidos en esferas resistentes a la presión marina para la profundidad de operación ( $2475 \mathrm{~m}$ aproximadamente). La distancia entre cada uno de los pisos es de $14.5 \mathrm{~m}$ salvo el primer piso que está situado a una distancia de 100 metros del fondo marino. Una de las primeras tareas a la hora de testear el funcionamiento de la línea y de los datos medidos, fue la selección de datos y la manera óptima de realizar la adquisición de los mismos. Durante los seis primeros meses, que ocupan el tiempo de medida para los resultados expuestos en el artículo, se encontró con la dificultad de tener valores inusualmente altos de bioluminiscencia. Se esperaba tener un rate para los fotomultiplicadores comprendido entre $50-100 \mathrm{kHz}$, sin embargo tal y como se observa en la figura 2, durante el periodo de medida el rate estuvo habitualmente por encima de $250 \mathrm{kHz}$, coincidiendo además estos periodos con velocidades muy altas de la corriente submarina $>35 \mathrm{~cm} / \mathrm{s}$, cuando lo esperado era una velocidad de $\sim 5 \mathrm{~cm} / \mathrm{s}$, quedando sujeto a estudio la posible relación entre ambos fenómenos. Tras seleccionar los 'runs' de 
acuerdo a valores bajos de bioluminiscencia quedaron un total de 448 horas de medida de las cuales sólo 187 horas fueron efectivas debido a un problema con el tiempo muerto en el proceso de filtrado online de los datos medidos disponiendo al final de un total de $7.5 \cdot 10^{4}$ sucesos candidatos a ser muones provenientes de la interacción de neutrinos con la materia. A partir de los datos obtenidos se aplicaron técnicas de reconstrucción, que también son descritas en el artículo, para obtener la trayectoria de las partículas detectadas. Algunas simplificaciones fueron adoptadas de manera inicial para facilitar el análisis como considerar todos los módulos ópticos como estacionarios, así como no tomar en cuenta el valor de la orientación de cada uno de los pisos de la línea. En las figuras del artículo se observa como se ha calculado la distribución angular de las trazas reconstruidas encontrando un acuerdo razonable entre datos reales y la simulación correspondiente a las cascadas de muones en aire. Así mismo, y como se observa en la figura 9, se calculó también la variación de flujo de muones con la profundidad obteniéndose unos resultados similares a los obtenidos en otros experimentos. Con este artículo se demostró sobre todo el correcto funcionamiento de la primera línea de ANTARES, y por ende su diseño y los dispositivos que lo conforman. 


\subsection{Measurement of the atmospheric muon flux with a $4 \mathrm{GeV}$ threshold in the ANTARES neutrino telescope.}

Autores: J.A. Aguilar, et al. (ANTARES Collaboration)

Ref.: Astroparticle Physics, Volume 33, Issue 2, March 2010, Pages 86-90.

El telescopio de neutrinos ANTARES está situado en la costa sur de Francia a $40 \mathrm{~km}$ de Toulon y está constituido por líneas verticales de aproximadamente $450 \mathrm{~m}$ de longitud ancladas al fondo del mar, a una profundidad aproximada de $2475 \mathrm{~m}$. Cada una de las líneas está dividida en 25 pisos y a su vez cada uno de estos pisos está formado por tripletes de fotomultiplicadores de 10 pulgadas. El detector está diseñado para capturar la luz de Cherenkov emitida a partir de las partículas generadas por la interacción de los neutrinos con la materia. Las fuentes de ruido que dificultan la detección de dicha luz de Cherenkov son, el decaimiento de $\mathrm{K}^{40}$ presente en el medio y la bioluminiscencia. En el artículo citado se presenta, por un lado, la posibilidad de utilizar el decaimiento de $\mathrm{K}^{40}$ como medida de calibración de la sensibilidad de los distintos fotomultiplicadores presentes en el detector y, por otro lado, el estudio realizado a partir de las medidas tomadas por el telescopio para medir la variación del flujo de muones atmosféricos en función de la profundidad.

El proceso de desintegración del $\mathrm{K}^{40}$ se lleva a cabo mediante la reacción $K^{40} \rightarrow e^{-} \bar{v}_{e} C a^{40}$, el electrón resultante de la reacción puede llegar a tener energías superiores a $1.3 \mathrm{MeV}$, siendo por tanto superior al umbral y con lo que podría generar hasta 150 fotones. Estos fotones pueden generar coincidencias entre fotomultiplicadores vecinos siempre que la desintegración se lleve a cabo en las cercanías de un piso de una línea. Como se observa en las figuras del artículo citado, considerando los datos medidos y representando la diferencia temporal de los hits obtenidos en fotomultiplicadores vecinos se obtiene un pico centrado en cero, siendo esto coherente con lo esperado ya que son señales coincidentes y pueden ser utilizadas para realizar comprobaciones acerca de la estabilidad de los offsets temporales medidos por el sistema de calibración temporal. Además, estas medidas relacionadas con el decaimiento del $\mathrm{K}^{40}$ al ser un fenómeno espacialmente uniforme y temporalmente estable pueden ser de utilidad en la medida de eficiencias relativas de los fotomultiplicadores. En relación a la detección de muones que van hacia abajo, los datos han sido tomados teniendo en cuenta una ventana temporal de 20ns entre hits medidos en diferentes fotomultiplicadores de un mismo piso. Tanto el espectro de energía del flujo de muones como la distribución angular de los mismos se espera que varíen con la profundidad. Con el objetivo de estudiar este fenómeno se consideraron datos correspondientes al periodo comprendido entre enero de 2007 y mayo de 2008 observándose que el flujo de muones detectados decrece al aumentar la profundidad de manera exponencial tal y como se esperaba. Para contrastar el resultado obtenido fueron realizadas varias simulaciones por el método de Montecarlo observándose una coincidencia notable entre los datos reales y simulados (se puede observar en la figura 4). 


\subsection{AMADEUS - The acoustic neutrino detection test system of the ANTARES deep-sea neutrino telescope}

Autores: J.A. Aguilar, et al. (ANTARES Collaboration)

Ref.: Nuclear Instruments and Methods in Physics Research A: Accelerators, Spectrometers, Detectors and Associated Equipment, Volumes 626-627, 11 January 2011-21 January 2011, Pages 128-143.

El sistema AMADEUS (ANTARES Modules for the Acoustic Detection Under the Sea) se encuentra instalado en la línea de instrumentación y la línea 12 del telescopio. En cada una de estas líneas hay 3 pisos con un clúster de 6 sensores acústicos por piso. Los sensores acústicos están diseñados para realizar medidas en un rango de frecuencia entre 1 y $50 \mathrm{kHz}$ presentando una sensibilidad aproximada de $-145 \mathrm{~dB}$ re $1 \mathrm{~V} / \mu \mathrm{Pa}$. Este sistema tiene el objetivo de estudiar la viabilidad y mejorar tanto la tecnología como las técnicas de análisis, orientadas a realizar detección acústica de neutrino. Para ello, con este sistema se realizan investigaciones del fondo acústico y sus características, se estudian correlaciones espaciales a diferentes escalas de longitud de señales acústicas, se desarrollan filtros de datos y algoritmos de reconstrucción, se investigan diferentes tipos de sensores y se hacen estudios híbridos de detección (óptica y acústica). En el artículo se describe este sistema, así como los primeros resultados obtenidos con los datos registrados: caracterización de ruido marino, estudio de señales transitorias y su relación con la posibilidad de realizar detección acústica de neutrinos en el mar o correlación entre señales detectadas con el objetivo de realizar búsqueda de fuentes acústicas puntuales. 


\subsection{The ANTARES neutrino telescope: Performance one year after its completion}

Autores: M. Bou-Cabo, J.A. Martínez-Mora

Ref.: Nuclear Instruments and Methods in Physics Research Section A: Accelerators, Spectrometers, Detectors and Associated Equipment, Volume 617, Issues 1-3, 11 May 2010-21 May 2010, Pages 505-506

El telescopio de neutrinos ANTARES es en la actualidad el detector submarino de neutrinos más grande instalado y en funcionamiento en el mundo. Su proceso de construcción finalizó exitosamente en Mayo de 2008 con la instalación de la línea número doce. ANTARES está formado por doce líneas ancladas al fondo del mar a una profundidad aproximada de $2.5 \mathrm{~km}$. Estas líneas, mantenidas verticales mediante boyas, poseen una longitud de $350 \mathrm{~m}$ aproximadamente y constan de 25 pisos cada una. A su vez, cada uno de los pisos está formado por tres módulos ópticos que alojan en su interior un fotomultiplicador de 10 pulgadas. El objetivo principal del detector ANTARES es la detección de neutrinos de alta energía provenientes de objetos astrofísicos. La detección de estos neutrinos de lleva a cabo mediante la detección de la luz de Cherenkov emitida por las partículas secundarias, especialmente muones, generadas de la interacción del neutrino con la materia. Para realizar una correcta reconstrucción de las trazas generadas, resulta necesario por un lado disponer de un sistema de calibración temporal que nos permita disponer de una resolución adecuada y de un sistema de calibración espacial que nos ofrezca conocer las posiciones de cada uno de los módulos ópticos con una precisión mejor a $20 \mathrm{~cm}$. Durante el año en el cual estuvo funcionando la configuración de doce líneas que corresponde a cuando fue redactado el artículo que nos ocupa, numerosos estudios estaban siendo realizados en relación a la astronomía de neutrinos (estudio de fuentes puntuales y fuentes transitorias), detección de muones y neutrinos tanto atmosféricos como cósmicos difusos, oscilaciones de neutrinos, búsqueda de materia oscura, o incluso estudios acerca de la viabilidad de la detección acústica de neutrinos. A modo de ejemplo en la presente publicación se presenta un skymap preliminar de fuentes puntuales en el hemisferio sur y también un trabajo relacionado con el cálculo de la cota superior en el valor del flujo de neutrinos generado en la posible aniquilación de neutralinos en el Sol.

Este artículo se corresponde a la presentación realizada en nombre de la Colaboración ANTARES del telescopio de neutrinos y sus resultados en el 11th Pisa Meeting on Advanced Detectors celebrado en la Isla de Elba (Italia) en 2009. 


\subsection{Time calibration and positioning for KM3NeT.}

Autores: S. Toscano, M. Ardid, M. Bou-Cabo, M. Circella, J.J Hernández-Rey, J.Perkin, J-P. Schuller, L.F. Thompson

Ref.: Nuclear Instruments and Methods in Physics Research Section A: Accelerators,

Spectrometers, Detectors and Associated Equipment, Volume 602, Issue 1, 11 April 2009, Pages 183-186.

En el presente artículo se realiza un resumen de las técnicas y métodos propuestos para realizar tanto la calibración temporal como el posicionamiento de los módulos ópticos, del futuro detector KM3NeT. Actualmente dicha infraestructura se encuentra en su fase final del diseño y se hace necesario tomar decisiones acerca de su estructura, geometría y realizar estudios de viabilidad de las técnicas y sistemas. En el artículo que nos ocupa se realiza una presentación acerca de las técnicas que podrán ser utilizadas e implementadas en los sistemas de calibración temporal y de posicionamiento. En relación al sistema de calibración temporal y teniendo en cuenta la experiencia adquirida en el telescopio de neutrinos ANTARES diferentes métodos son propuestos para llegar a conseguir una resolución temporal de cómo mínimo 2ns que corresponde a disponer de una resolución angular del orden de $0.1^{\circ}$. Considerando que la resolución temporal conseguida para el telescopio de neutrinos ANTARES es de 1 ns aproximadamente, algunas de las técnicas utilizadas por este detector deben considerarse como candidatas a ser utilizadas en el detector KM3NeT (evidentemente siendo mejoradas y adaptadas al nuevo detector). Algunas de estas técnicas que se encuentran actualmente bajo estudio son la calibración temporal relativa, utilizando sistemas de LEDs (se presenta un detalle del LED-Beacon utilizado en ANTARES en la figura 1), laser beacons o incluso coincidencias debidas al decaimiento del $\mathrm{K}^{40}$.

El posicionamiento de los módulos ópticos es otro aspecto de suma importancia de cara a poder realizar el análisis de los datos adquiridos por el detector con el objetivo de reconstruir las trazas de los muones detectados. Las estructuras que sostienen los módulos ópticos, ancladas en el suelo y mantenidas verticales por boyas, son estructuras flexibles que se encuentran sometidos a la fuerza de la corriente marina pudiendo sufrir movimientos de decenas de metros. Por este motivo, se hace necesario disponer de un sistema capaz de monitorizar las posiciones de los módulos ópticos en tiempo real ya que la precisión requerida es de unos $40 \mathrm{~cm}$ (en ANTARES se ha conseguido una resolución mejor a $20 \mathrm{~cm}$ ). Es en este tema donde se han centrado los estudios realizados durante esta tesis doctoral. Pese a que se necesita conocer más detalles acerca de la geometría del detector KM3NeT para poder brindar detalles específicos del sistema de posicionamiento, parece claro que éste deberá contar con un sistema de tilt-meters/compasses que nos ofrezca información acerca de la orientación de cada uno de los pisos, así como un conjunto de transceptores acústicos fijados en el fondo marino e hidrófonos receptores estratégicamente colocados a lo largo de la estructura a posicionar con el fin de obtener datos de entrada con los que aplicar un modelo mecánico que permita obtener una imagen en tres dimensiones del detector. En el artículo también se presentan las tres técnicas para la calibración de la orientación absoluta del detector: el método acústico (teniendo en cuenta triangulación acústica desde un barco y medidas de presión con un ROV), el 
detector de superficie (mediante coincidencias de cascadas de rayos cósmicos con sistema de centelleadores en la superficie del mar, en barcos) y la observación de la sombra de la Luna (midiendo la deficiencia de muones provenientes en la dirección de la Luna por elu apantallamiento de los rayos cósmicos). 


\subsection{A prototype for the acoustic triangulation system of the KM3NeT deep sea neutrino telescope.}

Autores: M. Ardid, M. Bou-Cabo, F. Camarena, V. Espinosa, G. Larosa, C.D. Llorens, J.A. Martínez-Mora

Ref.: Nuclear Instruments and Methods in Physics Research Section A: Accelerators, Spectrometers, Detectors and Associated Equipment, Volume 617, Issues 1-3, 11 May 2010-21 May 2010, Pages 459-461.

Tal y como se explica en el anterior artículo para el correcto posicionamiento de los módulos ópticos del detector KM3NeT es necesario disponer de un conjunto de hidrófonos receptores correctamente colocados a lo largo de la estructura de detector así como de emisores acústicos colocados en la base de las estructuras que componen el detector. En esta publicación se presenta el prototipo desarrollado y construido por el grupo de la UPV - IGIC consistente en un conjunto de transductores que pueden operar a grandes profundidades en el ambiente marino (presiones superiores a 500 bar) trabajando en el rango de $20-40 \mathrm{kHz}$. Asimismo también ha sido diseñada la electrónica asociada al sistema emisor-receptor intentando en todo momento cumplir con las especificaciones exigidas por la Colaboración (doble funcionalidad emisiónrecepción, configurable, bajo consumo eléctrico, etc.). Como se muestra en el artículo con más detalle el sistema diseñado fue probado para comprobar/mejorar su funcionamiento. Utilizando un hidrófono de referencia en las instalaciones del laboratorio del IGIC en Gandia, la respuesta al impulso de los transductores fue calculada tanto en modo emisor como en modo receptor obteniéndose resultados en concordancia (de manera general) con los ofrecidos por el fabricante. A su vez también se comprobó la estabilidad de los hidrófonos elegidos bajo variaciones grandes de presión intentando simular el ambiente marino en el cual deberán trabajar. Estos test fueron realizados en el tanque hiperbárico de las instalaciones de IFREMER en la localidad de Brest (Francia) obteniendo los resultados representados en la figura 2 del presente artículo. Se puede observar como la respuesta del transductor no presenta variaciones importantes en función de la variación de la presión, lo que los convierte en candidatos aceptables para ser instalados en el futuro detector $\mathrm{KM} 3 \mathrm{NeT}$. Por todo lo expuesto se concluyó que la primera versión del sistema cumplió con las expectativas esperadas, y se ha seguido trabajando en sucesivas versiones mejoradas del sistema propuesto. 


\section{7. $R \& D$ for an innovative acoustic positioning system for the KM3NeT neutrino telescope}

Autores: F. Ameli, M. Ardid, V. Bertin, M. Bonori, M. Bou-Cabo, C. Calí, A. D’Amico, G.Giovanetti, M. Imbesi, P. Keller, G. Larosa, C.D. Llorens, R. Masullo, N. Randazzo, G.Riccobene,F. Speziale, S. Viola

Ref.: Nuclear Instruments and Methods in Physics Research Section A: Accelerators, Spectrometers, Detectors and Associated Equipment, Volumes 626-627, Supplement 1, 11 January 2011-21 January 2011, Pages S211-S213

En el marco del proyecto $\mathrm{KM} 3 \mathrm{NeT}$ se encuentra en fase de desarrollo el sistema de posicionamiento acústico de los módulos ópticos que constituirán el futuro detector. Este nuevo diseño de sistema de posicionamiento acústico está basado en la experiencia adquirida tanto en la construcción del telescopio de neutrinos ANTARES como la fase 1 del proyecto NEMO. En este artículo se presentan tanto la filosofía como los detalles del futuro sistema de posicionamiento acústico (Acoustic Positioning System, APS) que permitirá monitorizar las posiciones del detector y realizar estudios del ruido ambiental presente en fondo del mar. El APS se compone de las siguientes partes, transductores acústicos repartidos a lo largo de la estructura que se desea posicionar que actúan como receptores, transductores acústicos emisores/receptores fijos en el fondo del mar, y un centro de cálculo o granja de ordenadores donde realizar el análisis de los datos provenientes del APS y monitorizar la posición de los hidrófonos receptores. El trabajo realizado por el grupo del IGIC - UPV está relacionado con el sistema de transductores emisores/receptores y la electrónica asociada a dicho sistema. Cabe comentar que durante la semana del $5-12$ de mayo de 2010 se realizaron en las instalaciones del IGIC una serie de test que tenían como fin comprobar la compatibilidad y funcionalidad de las diferentes partes del APS trabajando todas integradas. Durante la semana de medidas estuvieron presentes los grupos del INFN-Catania, INFN-Roma, CPPM-Marsella y ECAP-Erlangen, además del grupo del IGIC con resultados positivos en cuanto a la integración de las diferentes partes y a las especificaciones técnicas obtenidas. Fruto de todo este trabajo se ha redactado una propuesta para probar todo el sistema de posicionamiento en la estructura de NEMO que será instalada en Capo Passero durante el 2011, que ha sido aprobada y se están terminando de desarrollar y caracterizar los prototipos para ello. 


\subsection{Calibration of sensors for acoustic detection of neutrinos}

Autores: M. Ardid, M. Bou-Cabo, V. Espinosa, J. Martinez-Mora, F. Camarena, J. Alba Ref.: Journal of Physics: Conference Series, Volume 81, 012015.

La tarea de detección acústica de neutrinos debe llevar asociada necesariamente un sistema de calibración mediante el cual tener caracterizado el comportamiento del sistema detector. Es por ello que se hace necesario disponer de un dispositivo que sea capaz de emitir una señal acústica, que posea las mismas características que el pulso acústico predicho teóricamente tras la interacción de un neutrino ultra energético con la materia. En esta comunicación se abordan dos aspectos importantes para la calibración. Por un lado, se estudia la posibilidad de utilizar la calibración por el método de reciprocidad para calibrar dispositivos acústicos, considerando diferentes tipos de señales y teniendo en cuenta diferentes condiciones de propagación del sonido, estudiando su posible influencia en el resultado final. El segundo aspecto es la generación de pulsos bipolares, tipo neutrino, por un emisor acústico. Dado que los transductores acústicos no siempre presentan respuestas planas en frecuencia, se producen distorsiones de la señal y conseguir dichas señales puede presentar dificultades. En el artículo se estudian diferentes técnicas de ecualización para superar estos problemas como el flatten spectrum o el inverse filter. Este método, basado en los estudios teóricos de Mourjopoulos, ha dado resultados muy positivos. 


\subsection{Use of parametric acoustic sources to generate neutrino-like signals}

Autores: M. Ardid, M. Bou-Cabo, F. Camarena, V. Espinosa, G. Larosa, J.A. Martínez-Mora, M. Ferri

Ref.: Nuclear Instruments and Methods in Physics Research Section A: Accelerators,

Spectrometers, Detectors and Associated Equipment, Volume 604, Issues 1-2, Supplement 1, 1 June 2009, Pages S208-S211

Reproducir la señal acústica emitida por un neutrino ultra energético que interacciona con la materia utilizando un dispositivo compuesto por transductores electro-acusticos no es una tarea sencilla teniendo en cuenta la especial forma de dicha señal (pulso bipolar de poca duración temporal) y la directividad esperada para dicha señal (directividad en forma de disco conocida como 'pancake', perpendicular a la dirección de la cascada y con un ancho de haz menor de $\left.1^{\circ}\right)$. La forma clásica de construir un calibrador acústico que reproduzca este tipo de señal involucra la necesidad de disponer de un array lineal largo con un número elevado de transductores que emitan en fase. En este artículo se pretende estudiar la viabilidad de aplicar la generación acústica paramétrica de ultrasonidos con el objetivo de conseguir reproducir mediante un número reducido de elementos, y en una composición mucho más compacta, tanto la forma como la directividad del pulso acústico del neutrino. El estudio se realizó con transductores planos en el laboratorio, obteniéndose resultados positivos. Actualmente se está adaptando la técnica para la aplicación real, desarrollando un prototipo que será utilizado durante el verano de 2011 desde un barco para la calibración del sistema AMADEUS. 


\section{References:}

[ABB 08] First observation of the Greisen - Zatsepin - Kuzmin Supression

R.U. Abbasi et al /\% Phys.Rev Lett 100, 101101 (2008)

[ABR 08] Observation of the Suppression of the Flux of Cosmic Rays above $4 \cdot 10^{19} \mathrm{eV}$

J.Abraham et al $\%$ Phys Rev Lett 101,061101

[ACE 11] First detection of VHE -rays from SN 1006 by H.E.S.S

F.Acero et al ./. Astronomy and Astrophysics, Volume 516, id.A62, 2010.

[ACH 06] On the selection of AGN neutrino source candidates for a source stacking analysis with neutrino telescopes

Achterberg et al. / Astroparticle Physics 26 (2006) 282-300

[AGE 09] Performance of the first ANTARES detector line

M. Ageron et al. / Astroparticle Physics 31 (2009) 277-283

[AGL 89] Experimental Study of Atmospheric Neutrino Flux in the NUSEX Experiment.

M. Aglietta et al. / Europhys. Lett., 8 (7), pp. 611-614 (1989)

[AGU 07] The data acquisition system for the ANTARES neutrino telescope

J.A. Aguilar et al. / Nuclear Instruments and Methods in Physics Research A 570 (2007) 107116

[AGU 10 a] Performance of the front-end electronics of the ANTARES neutrino telescope

J.A. Aguilar et al. / Nuclear Instruments and Methods in Physics Research A 622 (2010) 59-73

[AGU $10 \mathrm{~b}$ ] Measurement of the atmospheric muon flux with a $4 \mathrm{GeV}$ threshold in the ANTARES neutrino telescope

J.A. Aguilar et al. / Astroparticle Physics 33 (2010) 86-90

[AGU 11 a] Time calibration of the ANTARES neutrino telescop

J.A. Aguilar et al. / Astroparticle Physics 34 (2011) 539-549

[AGU $11 \mathrm{~b}$ ] AMADEUS-The acoustic neutrino detection test system of the ANTARES deep-sea neutrino telescope

J.A. Aguilar et al. / Nuclear Instruments and Methods in Physics Research A 626-627 (2011) 128-143

[AGU $11 \mathrm{c}$ ] Search for a diffuse flux of high-energy $v \mu$ with the ANTARES neutrino telescope J.A. Aguilar et al. / Physics Letters B 696 (2011) 16-22

[ALL 97] Measurement of the atmospheric neutrino flavour composition in Soudan 2 W.W.M. Allison et al / Physics Letters B 391 (1997) 491-500

[AME 11] R\&D for an innovative acoustic positioning system for the KM3NeT neutrino telescope F. Ameli et al. / Nuclear Instruments and Methods in Physics Research A 626-627 (2011) S211-S213

[AMR 02] The ANTARES optical module

P. Amram et al. / Nuclear Instruments and Methods in Physics Research A 484 (2002) 369- 
[ANT 07] A prototype device for acoustic neutrino detection in Lake Baikal K.Antipin / PROCEEDINGS OF THE 30st ICRC MERIDA, MEXICO

[ARD 07] Calibration of sensors for acoustic detection of neutrinos M. Ardid et al. / Journal of Physics: Conference Series 81 (2007) 012015

[ARD 08] System of reciprocal acoustic sensors for monitoring sea currents M. Ardid, M. Bou-Cabo, V. Espinosa, J.A. Martínez-Mora / SENSORCOMM 2008, Cap Esterel, Proceedings (2008) 705.

[ARD 09 a] Positioning system of the ANTARES neutrino telescope M. Ardid / Nuclear Instruments and Methods in Physics Research A 602 (2009) 174-176

[ARD $09 \mathrm{~b}] \quad$ Calibration in acoustic detection of neutrinos

M. Ardid / Nuclear Instruments and Methods in Physics Research A 604 (2009) S203-S207

[ARD $09 \mathrm{c}$ ] Use of parametric acoustic sources to generate neutrino-like signals M. Ardid et al. / Nuclear Instruments and Methods in Physics Research A 604 (2009) S208S211

[ARD 10] A prototype for the acoustic triangulation system of the KM3NeT deep sea neutrino telescope

M. Ardid et al. / Nuclear Instruments and Methods in Physics Research A 604 (2010) 459461

[ARD 11 a] R\&D towards the acoustic positioning system of KM3NeT

M. Ardid et al. / Nuclear Instruments and Methods in Physics Research A 626-627 (2011) S214-S216

[ARD $11 \mathrm{~b}] \quad R \& D$ studies for the development of a compact transmitter able to mimic the acoustic signature of a UHE neutrino interaction

M. Ardid et al. / Nuclear Instruments and Methods in Physics Research A (in press)

[ASK 57] G.A. Askarian, Sov. J. At. Energy 3, 921 (1957)

[ASK 79] Acoustic detection of high energy particle showers in water.

G.A.Askarian et al / Nuclear Instruments and Methods Volume 164, Issue 2, 15 August 1979, Pages 267-278

[ASL 99] A deep sea telescope for high energy neutrinos.

E. Aslanides et al / arXiv:astro-ph/9907432

[AYN 06] Status and new results from the BAIKAL detector

V Aynutdinov et al. / Journal of Physics: Conference Series 39 (2006) 441-443

[BAG 08] KM3NeT Conceptual Design Report for a Deep-Sea Research Infrastructure Incorporating a Very Large Volume Neutrino Telescope

Bagley, P. et al / KM3NeT CDR available from KM3NeT Consortium web site: http://www.KM3NeT.org, 2008 
[BAG 10]

[BAH 00]

[BAN 93]

[BAR 06]

[BAZ 09]

[BER 90]

[BER 90]

[BER 89]

[BER 06]

[BEV 07]

[BEV 09]

[BIG 09]

[BOU 09]

[BRO 09]

[BRU 11]

[CAS 91]

[CHI10]

KM3NeT Technical Design Report for a Deep-Sea Research Infrastructure in the Mediterranean Sea Incorporating a Very Large Volume Neutrino Telescope Bagley, P. et al / KM3NeT TDR available from KM3NeT Consortium web site: http://www.KM3NeT.org, 2010

5-10 GeV Neutrinos from Gamma-Ray Burst Fireballs

John N. Bahcall , Peter Mészáros / Physical Review Letters Volume 85 pags.1362 - 1365

BATSE observations of gamma-ray burst spectra. I - Spectral diversity

D. Band et al / Astrophysical Journal, Part 1 (ISSN 0004-637X), vol. 413, no. 1, p. 281-292

Constraints on Cosmic Neutrino Fluxes from the Antarctic Impulsive Transient Antenna Experiment

Barwick S W et al·/ Physical Review Letters Volume 96171101

Measurement of the atmospheric muon flux with the ANTARES detector M. Bazzotti / PROCEEDINGS OF THE 31st ICRC, Ł'OD'Z 2009

V.S. Berezinsky et al., Astrophysics of Cosmic Rays, North-Holland, 1990.

C. Berger et al., Phys. Lett. B245 (1990) 305.

V.S. Berezinsky and V.S. Ptuskin, Astron. Astrophys. 215 (1989), p. 399.

Latest Results from HiRes

Bergman et al·/ Proceedings of the 20th Recontres de Blois 2008

Simulation of ultra-high energy neutrino induced showers in ice and water S. Bevan et al. / Astroparticle Physics 28 (2007) 366-379

Study of the acoustic signature of UHE neutrino interactions in water and ice S. Bevan et al. / Nuclear Instruments and Methods in Physics Research A 607 (2009) 398411

First results of the ANTARES neutrino telescope

C Bigongiari on behalf of the ANTARES Collaboration ./.Journal of Physics: Conference Series 173 (2009) 012024.

The ANTARES neutrino telescope: Performance one year after its completion

M. Bou-Cabo, J.A. Martínez-Mora / Nuclear Instruments and Methods in Physics Research A617 (2010) $505-506$

Positioning system of the ANTARES Neutrino Telescope, A.M. Brown / PROCEEDINGS OF THE 31st ICRC, t’OD'Z 2009

The ANTARES neutrino telescope-Status and first results

J. Brunner / Nuclear Instruments and Methods in Physics Research A 626-627 (2011) S19S24

Measurement of atmospheric neutrino composition with the IMB-3 detector

D. Casper et al / Physical Review Letters Volume 66 pags. 2561- 2564

High-Energy Astrophysics with Neutrino Telescopes. 
T. Chiarusi, M. Spurio / The European Physical Journal C 65 (2010) 649.

[DAN 07] First Data from ACoRNE and Signal Processing Techniques

S.Danaher / Journal of Physics: Conference Series 81 (2007) 012011

[DAU 95] Determination of the atmospheric neutrino spectra with the Fréjus detector

K. Daum et al., Z. Phys. C66 (1995) 417.

[DES 09] Acoustic detection of high energy neutrinos in ice: Status and results from the South Pole Acoustic Test Setup

F.Descamps / PROCEEDINGS OF THE 31st ICRC, Ł’OD'Z 2009

[DIE 05] Earth-mass dark-matter haloes as the first structures in the early Universe

Diemand, J., B. Moore, and J. Stadel / Nature 433, 389-391 2005

[ESP 96] J.A. Esposito et al., Astrophys. J. 461 (1996) 820.

[FUK 98] Evidence for Oscillation of Atmospheric Neutrinos

Y. Fukuda et al., Physical Review Letters Volume. 81 pags $1562-1567$

[GAB 07] Searching for Galactic Cosmic-Ray Pevatrons with Multi-TeV Gamma Rays and Neutrinos Gabici, S. and Aharonian, F.A. Astrophys. J. Lett., 665 (2007) L131.

[GOL 83] Constraint on the photino mass from cosmology

Goldberg H 1983 / Physical Review Letters Volume. 50 pags 1419 - 1422

[GRE 66] End to the cosmic ray spectrum ?

K.Greisen, Physical Review Letters Volume.16 pags $748-750$

[HAL 98] Tau Neutrino Appearance with a 1000 Megaparsec Baseline

F. Halzen and D. Saltzberg / Physical Review Letters Volume. 81 pags $4305-4308$

[KAT 09] Status of the KM3NeT Project

U.F. Katz / Nuclear Instruments and Methods in Physics Research A 602 (2009) 40-46

[KAV 11] Photo-sensors for a Multi-PMT optical module in KM3NeT

Kavatsyuk et al. / Nuclear Instruments and Methods in Physics Research A 626-627 (2011) S154-S156

[KEL 07] Acoustic Positioning System for the Deep-Sea ANTARES Neutrino Telescope P. Keller / sensorcomm, pp.243-247, 2007

International Conference on Sensor Technologies and Applications (SENSORCOMM 2007), 2007

[KOP 09] $\quad$ A software framework for KM3NeT

C. Kopper / Nuclear Instruments and Methods in Physics Research A 602 (2009) 107-110

[KLE 08] Recent $v_{s}$ from IceCube

R.Klein et al / J.Phys.Conf.Ser.136:022050,2008

[LEA 79] Acoustic radiation by charged atomic particles in liquids: An analisis.

J.G. Learned / Physical Review D Volume 19, Issue 11, 1979, Pages 3293-3307 
[MAN 92] K. Mannheim and P.L. Biermann, Astron. Astrophys. 253 ( 1992) L21.

[MAR 60] M. A. Markov, Proc. Int. Conf. on High Energy Physics, p. 183, E. Sudarshan, et al, eds., Univ. of Rochester, 1960.

[MES 95] P. Meszaros, in Proceedings of the 17th Texas Conference on Relativistic Astrophysics, Annals of the New York Academy of Sciences, No. 759 (NY Acad. Sci. , NY, 1995)

[MIG 08] Recent achievements of the NEMO project

E. Migneco et al. / Nuclear Instruments and Methods in Physics Research A 588 (2008) 111118

[MOF 77] Model for parametric acoustic sources.

M.B. Moffett et al / J. Acoust. Soc. Am Volume. 61 pags $325-337$

[MOF 79] M.B. Moffett, P. Mello, J. Acoust. Soc. Am. 66 (1979) 1.

[MON 08] Review on Neutrino Telescopes

T. Montaruli / Proceeding of CRIS2008 Conference, Salina, Sept. 2008

[NIE 06] Underwater acoustic detection of ultra-high energy neutrinos

V. Niess, V. Bertin / Astroparticle Physics 26 (2006) 243-256

[OOP 11] Hydrophone calibration based on microcontrollers for acoustic detection of UHE neutrinos W. Ooppakaew, S. Danaher/ Nuclear Instruments and Methods in Physics Research A (in press)

[PIR 94] Fireballs

T. Piran / in Gamma-Ray Bursts, edited by Gerald J. Fishman, Jerome J. Brainerd, and Kevin Hurley, AIP Conf. Proc. (AIP, New York, 1994) Vol. 307, 1994, p.495

[RAP 09] The NESTOR underwater neutrino telescope project

P.A. Rapidis / Nuclear Instruments and Methods in Physics Research A 602 (2009) 54-57

[RAW 07] AMANDA and Ice Cube: News and Neutrino Analyses

K.Rawlins / Proceedings of Colliders to Cosmic Rays 2007 (C2CR07), Granlibakken, Lake Tahoe, USA, 25 February - 1 March 2007; AIP Conference Proceedings 928 (2007) 69-76

[RIC 09] Long-term measurements of acoustic background noise in very deep sea

G. Riccobene / Nuclear Instruments and Methods in Physics Research A 604 (2009) S149S157.

[ROU 08] Recent results from the Pierre Auger Observatory.

Esteban Roulet et al \% J.Phys.Conf.Ser.136:022051,2008

[SAL 07] The Optical Beacon Calibration System of the ANTARES Neutrino Telescope

F. Salesa / October 14-20, 2007 UNWAT 2007, International Workshop on Under Water

Sensors and Systems, Valencia, Spain

[SAL 10] Time calibration for the KM3NeT deep sea neutrino telescope

F. Salesa-Greus / Nuclear Instruments and Methods in Physics Research A 626-627 (2011)

S237-S239 
[SZA 92] A.P. Szabo and R.J. Pmtheroe, in Proc. High Energy Neutrino Astrophysics Workshop (Univ. of Hawaii, March 1992.

[SEC 91] D. Seckel, T. Stanev and T.K. Gaisser, Ap. J. 382 (1991) 652.

[SEI 11] Monte Carlo studies of a KM3NeT design option with multi-PMT optical modules T. Seitz, R. Shanidze / Nuclear Instruments and Methods in Physics Research A 626-627 (2011) S208-S210

[SIM 11] Design and first tests of an acoustic positioning and detection system for KM3NeT

F. Simeone et al. / Nuclear Instruments and Methods in Physics Research A (in press)

[SOF 01] Rotation curves of spiral galaxies

Sofue, Y., and V. Rubin / Annu. Rev. Astron. Astrophys. 39, 137-174, 2001

[SUL 79] Experimental studies of the acoustic signature of proton beams traversing fluid media L. Sulak et al / Nuclear Instruments and Methods Volume 161, pags 203-217

[SUS 84] The gauge hierarchy problem, technicolor, supersymmetry, and all that Susskind L / Physics Reports Volume 104 Pages 181-193

[STE 68] F.W. Stecker, Phys. Rev. Lett. 21 (1968) 1016.

[TOS 09] Time calibration and positioning for KM3NeT

S. Toscano et al. / Nuclear Instruments and Methods in Physics Research A 602 (2009) 183186

[VAN 05] Experimental study of acoustic ultra-high energy neutrino detection

J. Vandenbroucke et al / The Astrophysical Journal, Volume 621, pags 301-312

[VER 08] PIC Microcontrollers

Milan Verle / ISBN-13: 978-86-84417-15-4

[VER 09] PIC Microcontrollers - Programming in C

Milan Verle / ISBN-13: 978-86-84417-17-8

[WAX 95 a] Cosmological Gamma Ray Burst and the highest energy Cosmic Rays

E.Waxman/ Physical Review Letters Volume 75 pags. $386-389$

[WAX 95 b] E. Waxman, Astrophys. J. 452, L1 (1995).

[WES 63] Parametric acoustic array

P. J. Westervelt, / J. Acoust. Soc. Amer., vol.35, pp. 535-537, 1963.

[YOS 93] S. Yoshida and M. Teshima, Progr. Theor. Phys. 89 (1993) 833.

[ZWI 33] Zwicky F 1933 Helvetica Phys. Acta 6110 


\section{Performance of the first ANTARES detector line}

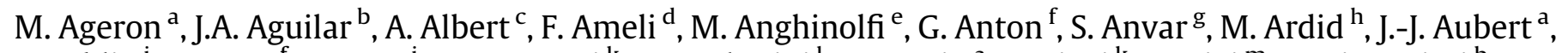

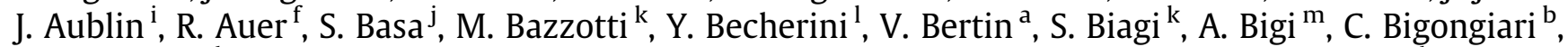
M. Bou-Cabo $^{\text {h }}$, M.C. Bouwhuis ${ }^{n}$, R. Bruijn ${ }^{\text {n,o }}$, J. Brunner ${ }^{a}$, G.F. Burgio ${ }^{\mathrm{p}}$, J. Busto ${ }^{\text {a }}$, F. Camarena ${ }^{\mathrm{h}}$, A. Capone ${ }^{\mathrm{d}}$, G. Carminati ${ }^{\text {, }}$, J. Carr ${ }^{\mathrm{a}}$, D. Castel ${ }^{\mathrm{c}}$, E. Castorina ${ }^{\mathrm{m}}$, V. Cavasinni ${ }^{\mathrm{m}}$, S. Cecchini ${ }^{\mathrm{k}, \mathrm{q}}$, Ph. Charvis ${ }^{\mathrm{r}}$, T. Chiarusi ${ }^{\mathrm{k}}$, M. Circella ${ }^{\mathrm{s}}$, C. Colnard $^{\mathrm{n}}$, R. Coniglione ${ }^{\mathrm{t}}$, H. Costantini ${ }^{\mathrm{e}}$, N. Cottini ${ }^{\mathrm{l}}$, P. Coyle $^{\mathrm{a}}$, G. De Bonis ${ }^{\mathrm{d}}$, P. Decowski $^{\mathrm{n}}$, I. Dekeyser ${ }^{\mathrm{u}}$, A. Deschamps ${ }^{\mathrm{r}}$, C. Donzaud ${ }^{\mathrm{i}, \mathrm{v}}$, D. Dornic ${ }^{\mathrm{a}}$, D. Drouhin ${ }^{\mathrm{c}}$, F. Druillole ${ }^{\mathrm{g}}$, T. Eberl $^{\mathrm{f}}$, J.-P. Ernenwein ${ }^{\mathrm{c}}$, S. Escoffier ${ }^{\text {a }}$, E. Falchini ${ }^{\mathrm{m}}$, F. Fehr ${ }^{\mathrm{f}}$, V. Flaminio ${ }^{\mathrm{m}}$, K. Fratini ${ }^{\mathrm{e}}$, J.-L. Fuda ${ }^{\mathrm{u}}$, G. Giacomelli ${ }^{\mathrm{k}}$, K. Graf ${ }^{\mathrm{f}}$, G. Guillard ${ }^{\mathrm{w}}$, G. Hallewell ${ }^{a}$, Y. Hello ${ }^{r}$, J.J. Hernández-Rey ${ }^{b}$, J. Hößl ${ }^{\mathrm{f}}$, M. de Jong ${ }^{\mathrm{n}}$, N. Kalantar-Nayestanaki ${ }^{\mathrm{x}}$, O. Kalekin ${ }^{\mathrm{f}}$, A. Kappes ${ }^{f}$, U. Katz ${ }^{f}$, P. Kooijman ${ }^{\text {y,o,n,*}, ~ C . ~ K o p p e r ~}{ }^{f}$, A. Kouchner ${ }^{i}$, W. Kretschmer ${ }^{f}$, S. Kuch ${ }^{f}$, R. Lahmann ${ }^{f}$, P. Lamare ${ }^{g}$, G. Lambard ${ }^{\mathrm{a}}$, H. Laschinsky ${ }^{\mathrm{f}}$, J. Lavalle ${ }^{\mathrm{a}}$, H. Le Provost $^{\mathrm{g}}$, D. Lefèvre ${ }^{\mathrm{u}}$, G. Lelaizant ${ }^{\mathrm{a}}$, G. Lim $^{\mathrm{n}, \mathrm{o}}$, D. Lo Presti ${ }^{p}$, H. Loehner ${ }^{\mathrm{x}}$, S. Loucatos ${ }^{\mathrm{f}}$, F. Louis ${ }^{a}$, F. Lucarelli ${ }^{\mathrm{d}}$, K. Lyons ${ }^{\mathrm{w}}$, S. Mangano ${ }^{\mathrm{n}}$, M. Marcelin ${ }^{\mathrm{j}}$, A. Margiotta ${ }^{\mathrm{k}}$, J.A. Martinez-Mora ${ }^{\mathrm{h}}$, G. Maurin ${ }^{1}$, A. Mazure $^{\mathrm{j}}$, M. Melissas ${ }^{\mathrm{a}}$, E. Migneco ${ }^{\mathrm{t}}$, T. Montaruli $^{\mathrm{s}, 1}$, M. Morganti ${ }^{\mathrm{m}}$, L. Moscoso ${ }^{\mathrm{i}, \mathrm{l}}$, H. Motz ${ }^{\mathrm{f}}$, C. Naumann ${ }^{\mathrm{f}, \mathrm{l}}$, R. Ostasch ${ }^{\mathrm{f}}$, G.E. Păvălaş ${ }^{\mathrm{z}}$, P. Payre ${ }^{\mathrm{a}}$, J. Petrovic ${ }^{\mathrm{n}}$, C. Petta ${ }^{\text {}}$, P. Piattelli ${ }^{t}$, C. Picq ${ }^{1}$, R. Pillet ${ }^{\mathrm{r}}$, V. Popa ${ }^{\mathrm{z}}$, T. Pradier ${ }^{\mathrm{w}}$, E. Presani ${ }^{\mathrm{n}}$, C. Racca ${ }^{\mathrm{w}}$, A. Radu ${ }^{\mathrm{z}}$, C. Reed $^{\mathrm{a}}$, C. Richardt ${ }^{\mathrm{f}}$, M. Rujoiu ${ }^{\mathrm{z}}$, M. Ruppi ${ }^{\mathrm{s}}$, G.V. Russo ${ }^{\mathrm{p}}$, F. Salesa ${ }^{\mathrm{b}}$, P. Sapienza ${ }^{\mathrm{t}}$, F. Schoeck ${ }^{\mathrm{f}}$, J.-P. Schuller $^{1}$, R. Shanidze ${ }^{f}$, F. Simeone ${ }^{d}$, M. Spurio ${ }^{k}$, G. van der Steenhoven ${ }^{n}$, C. Tamburini ${ }^{\mathrm{u}}$, L. Tasca $^{\mathrm{j}}$, S. Toscano $^{\mathrm{b}}$, M. Vecchi ${ }^{\mathrm{d}}$, P. Vernin ${ }^{1}$, G. Wijnker ${ }^{\mathrm{n}}$, E. de Wolf ${ }^{\mathrm{o}, \mathrm{n}}$, D. Zaborov ${ }^{\text {aa }}$, J.D. Zornoza ${ }^{\mathrm{b}}$, J. Zúñiga ${ }^{\mathrm{b}}$

a CPPM - Centre de Physique des Particules de Marseille, CNRS/IN2P3 et Université de la Méditerranée, 163 Avenue de Luminy, Case 902, 13288 Marseille Cedex 9, France

b IFIC - Instituto de Física Corpuscular, Edificios Investigación de Paterna, CSIC - Universitat de València, Apdo. de Correos 22085, 46071 Valencia, Spain

${ }^{\mathrm{C}}$ GRPHE - Groupe de Recherche en Physique des Hautes Energies, Université de Haute Alsace, 61 Rue Albert Camus, 68093 Mulhouse Cedex, France

${ }^{\mathrm{d}}$ Dipartimento di Fisica dell'Università "La Sapienza" e Sezione INFN, P.le Aldo Moro 2, 00185 Roma, Italy

e Dipartimento di Fisica dell'Università e Sezione INFN, Via Dodecaneso 33, 16146 Genova, Italy

${ }^{\mathrm{f}}$ Friedrich-Alexander-Universität Erlangen-Nürnberg, Physikalisches Institut, Erwin-Rommel-Str. 1, D-91058 Erlangen, Germany

${ }^{\mathrm{g}}$ Direction des Sciences de la Matière - Institut de Recherche sur les lois Fondamentales de l'Univers - Service d'Electronique des Détecteurs et d'Informatique, CEA Saclay, 91191 Gif-sur-Yvette Cedex, France

${ }^{\mathrm{h}}$ Institut de Gestió Integrada de Zones Costaneres (IGIC) - Universitat Politècnica de Valéncia. Cra. Nazaret-Oliva S/N E-46730 Gandia, València, Spain

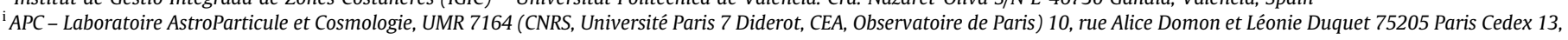
France

${ }^{\mathrm{j}}$ LAM - Laboratoire d'Astrophysique de Marseille, CNRS/INSU et Université de Provence, Traverse du Siphon - Les Trois Lucs, BP 8, 13012 Marseille Cedex 12, France

${ }^{\mathrm{k}}$ Dipartimento di Fisica dell'Università e Sezione INFN, Viale Berti Pichat 6/2, 40127 Bologna, Italy

${ }^{1}$ Direction des Sciences de la Matière - Institut de Recherche sur les lois Fondamentales de l'Univers - Service de Physique des Particules, CEA Saclay,

91191 Gif-sur-Yvette Cedex, France

${ }^{\mathrm{m}}$ Dipartimento di Fisica dell'Università e Sezione INFN, Largo B. Pontecorvo 3, 56127 Pisa, Italy

${ }^{n}$ FOM Instituut voor Subatomaire Fysica Nikhef, Kruislaan 409, 1098 SJ Amsterdam, The Netherlands

${ }^{\circ}$ Universteit van Amsterdam, Instituut voor Hoge-Energiefysica, Kruislaan 409, 1098 SJ Amsterdam, The Netherlands

${ }^{\mathrm{p}}$ Dipartimento di Fisica ed Astronomia dell'Università e Sezione INFN, Viale Andrea Doria 6, 95125 Catania, Italy

${ }^{\mathrm{q}}$ INAF-IASF, via P. Gobetti 101, 40129 Bologna, Italy

${ }^{\mathrm{r}}$ GéoSciences Azur, CNRS/INSU, IRD, Université de Nice Sophia-Antipolis, Université Pierre et Marie Curie - Observatoire Océanologique de Villefranche, BP48, 2 quai de la Darse, 06235 Villefranche-sur-Mer Cedex, France

${ }^{s}$ Dipartimento Interateneo di Fisica e Sezione INFN, Via E. Orabona 4, 70126 Bari, Italy

${ }^{\mathrm{t}}$ INFN - Laboratori Nazionali del Sud (LNS), Via S. Sofia 44, 95123 Catania, Italy

"COM - Centre d'Océanologie de Marseille, CNRS/INSU et Université de la Méditerranée, 163 Avenue de Luminy, Case 901, 13288 Marseille Cedex 9, France

${ }^{v}$ Université Paris-Sud 11 - Département de Physique - F - 91403 Orsay Cedex, France

${ }^{\mathrm{w}}$ IPHC - Institut Pluridisciplinaire Hubert Curien, Université Louis Pasteur (Strasbourg 1) et IN2P3/CNRS, 23 rue du Loess, BP 28, 67037 Strasbourg Cedex 2, France

${ }^{\mathrm{x}}$ Kernfysisch Versneller Instituut (KVI), University of Groningen, Zernikelaan 25, 9747 AA Groningen, The Netherlands

${ }^{\mathrm{y}}$ Universiteit Utrecht, Faculteit Betawetenschappen, Princetonplein 5, 3584 CC Utrecht, The Netherlands

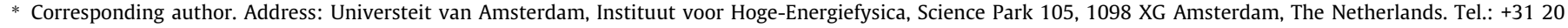
5925043.

E-mail address: h84@nikhef.nl (P. Kooijman).

1 On leave at University of Wisconsin - Madison, 53715 WI, USA.
} 
${ }^{\mathrm{z}}$ Institute for Space Sciences, $R$-77125 Bucharest, Măgurele, Romania

aa ITEP - Institute for Theoretical and Experimental Physics, B. Cheremushkinskaya 25, 117259 Moscow, Russia

\section{A R T I C L E I N F O}

\section{Article history:}

Received 18 November 2008

Received in revised form 25 January 2009

Accepted 16 February 2009

Available online 28 February 2009

\section{Keywords:}

ANTARES

Neutrino

Deep-sea

First line

\begin{abstract}
A B S T R A C T
In this paper we report on the data recorded with the first Antares detector line. The line was deployed on the 14th of February 2006 and was connected to the readout 2 weeks later. Environmental data for one and a half years of running are shown. Measurements of atmospheric muons from data taken from selected runs during the first 6 months of operation are presented. Performance figures in terms of time residuals and angular resolution are given. Finally the angular distribution of atmospheric muons is presented and from this the depth profile of the muon intensity is derived.
\end{abstract}

(c) 2009 Elsevier B.V. All rights reserved.

\section{Introduction}

Ever since Markov discussed the possibility of detecting cosmic neutrinos using the Cherenkov effect in sea water [1], many experimental groups have attempted to perform such an experiment. The DUMAND collaboration pioneered the technique in an experiment off the coast of Hawaii [2]. This was followed by the Baikal collaboration who built the first full detector in the fresh water of Lake Baikal [3]. Since then the AMANDA/IceCube collaboration has installed and operated large neutrino Cherenkov detectors in the ice of Antarctica [4]. More recently several collaborations have begun to investigate the Mediterranean Sea as a place to install a neutrino detector. The NESTOR [5] and NEMO [6] collaborations have deployed and operated prototypes of their detectors for short periods of time.

ANTARES is ideally situated, in the northern hemisphere, to search for neutrino sources near the galactic centre. It also allows for investigation of the sun as a source of neutrinos from dark matter annihilation. It complements the sky coverage of the AMANDA/ IceCube detectors, which are situated in the southern hemisphere. The very large scattering length of the Mediterranean seawater affords the telescope a pointing accuracy expected to be better than $0.3^{\circ}$ at neutrino energies of $10 \mathrm{TeV}$ and above. The present paper deals with data collected from the first detector line. This line has been in continuous operation since its deployment. The data from this line have been used for tuning the data acquisition, trigger and offline reconstruction chain. The present paper shows that the major goals in terms of timing and reconstruction accuracy have been met for the single line. The ANTARES detector has in the mean time been completed in stages. In 2007 several months were dedicated to data taking with 5 of the 12 detector lines installed. The first data from the full 12 line detector became available in June 2008.

The deployment of the first detector line, Line 1, occurred on February 14, 2006. The connection to the seabed communications cable occurred two weeks later using a submersible vehicle.

The detector line is situated at a depth of $2475 \mathrm{~m}$ approximately $40 \mathrm{~km}$ south east of the French town of Toulon. It consists of optical detectors attached to a cable which provides mechanical strength, electrical contact and fibre optic readout. This cable is held on the seabed by a deadweight anchor and kept vertical by a buoy at the top of its $450 \mathrm{~m}$ length.

Along this detector line 25 storeys of optical detectors are placed at an inter-storey distance of $14.5 \mathrm{~m}$ starting $100 \mathrm{~m}$ above the seabed. On each storey three spherical glass pressure vessels [7] contain 10" Hamamatsu photomultipliers (PMTs), which are oriented with their axes pointing downward at an angle of $45^{\circ}$ from the vertical (see Fig. 1). A titanium cylinder houses the electronics for data acquisition and slow control. The orientation of each storey is determined continuously with the aid of a compass and a tilt meter. The position of every fifth storey is monitored using a hydrophone for acoustic triangulation. Front-end chips (analogue ring samplers - ARS) [8] sample the data from the photomultiplier tubes. If the pulse height exceeds a preset threshold the chips digitize the arrival time and charge of the PMT pulse. In order to limit dead time due to digitisation, each photomultiplier is sampled alternately by two ARS. For the analysis described in this paper the thresholds were effectively at the level of about 0.5 times the most probable pulse height produced by a single photoelectron (spe). Time and charge data of all hits are stored in memory. A master clock synchronizes the time stamping of this data. The time offsets between different PMTs are measured before deployment in a dedicated setup and then validated and monitored in situ by a system of calibration flashers distributed throughout the line [9]. In order to provide an efficient transfer of the data, the memory is divided into buffers of $104 \mathrm{~ms}$ length (a time slice). The starting times of the buffers on each storey are synchronized. These buffers are transmitted to shore via an Ethernet network to a farm of processors, where candidate events are filtered (online filter) from the continuous data stream for further processing offline. Individual processors in the farm receive and process all buffers from the full detector associated with a single time slice [10].

\section{Data selection}

Since the start of data taking the singles rate (i.e. the single photon count rate) from each optical module has been monitored. Fig. 2 shows the singles rate observed on Line 1 from March 2006 until the end of April 2008. At the beginning of the data taking period the singles rates increased from the expected 50 $100 \mathrm{kHz}$ per PMT to over $250 \mathrm{kHz}$, with rates exceeding $1 \mathrm{MHz}$ in some periods. This increase in rate was due to increased bioluminescent activity. The onset of this high background period coincided with a period of unusually high water currents. While normal current values are typically below $5 \mathrm{~cm} / \mathrm{s}$ the onset of this high background period was characterized by current speeds of up to $35 \mathrm{~cm} / \mathrm{s}$. The cause of these effects is still under study. After 3 months, however, the noise rates subsided and returned to the anticipated levels of $50-100 \mathrm{kHz}$. The expectation from the presence of the radioactive isotope ${ }^{40} \mathrm{~K}$ in the seawater is a singles rate of around $50 \mathrm{kHz}$. Since the end of June 2006 the fraction of time that the rate has surpassed $250 \mathrm{kHz}$ is less than $5 \%$. The 


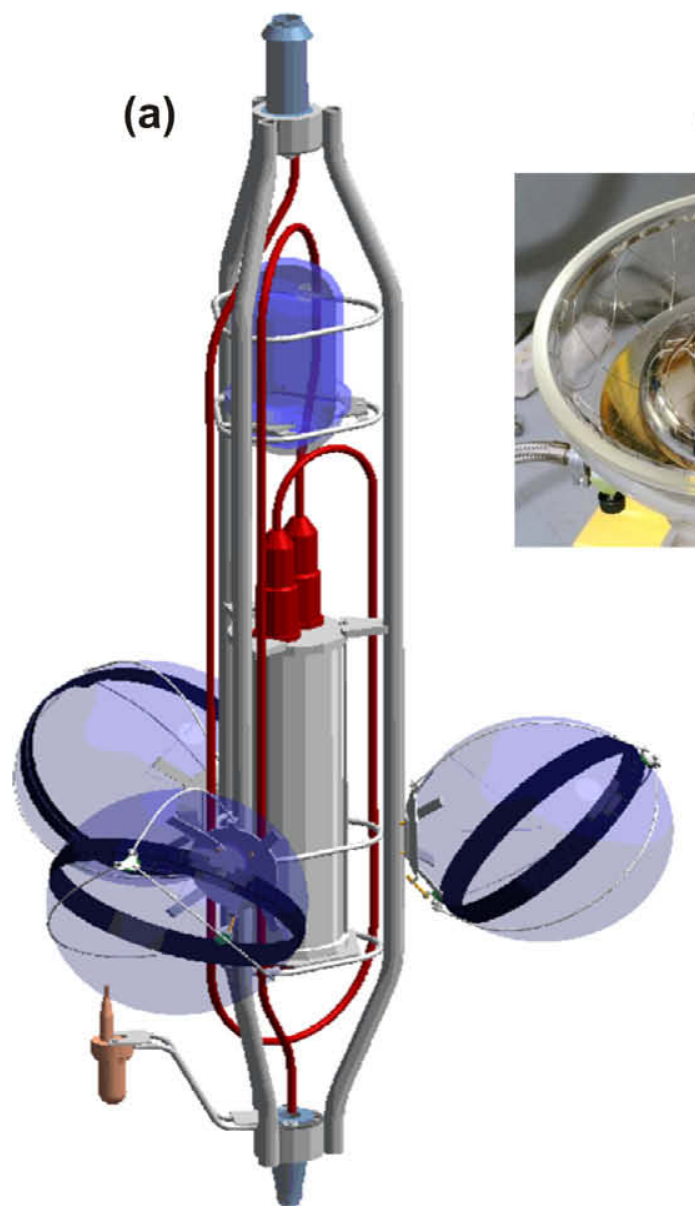

(b)

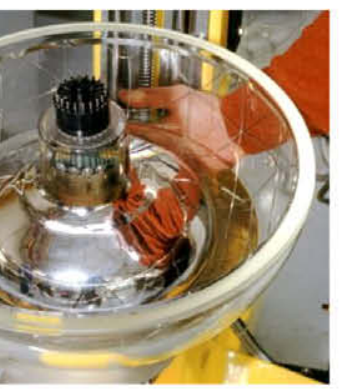

(d)

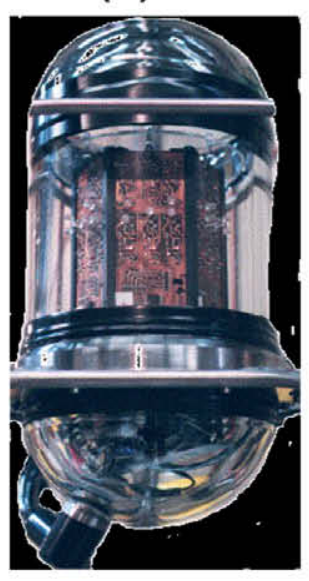

(c)

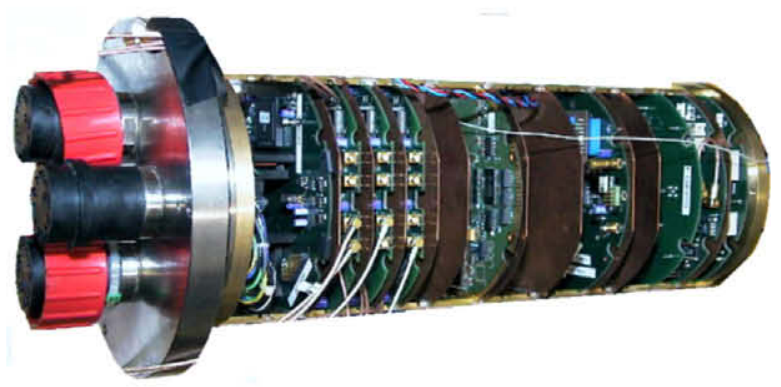

(e)

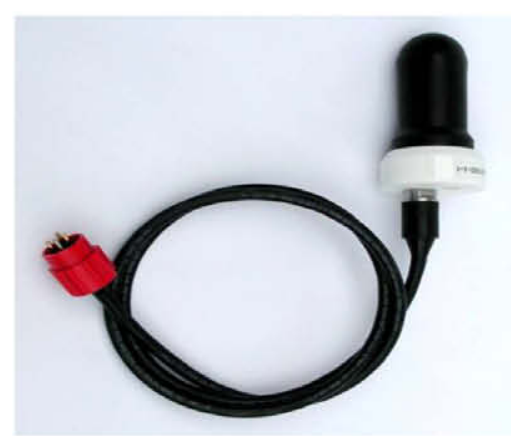

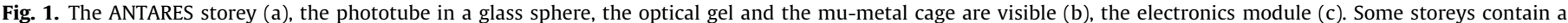
calibration flasher (d) and an acoustic receiver (e).

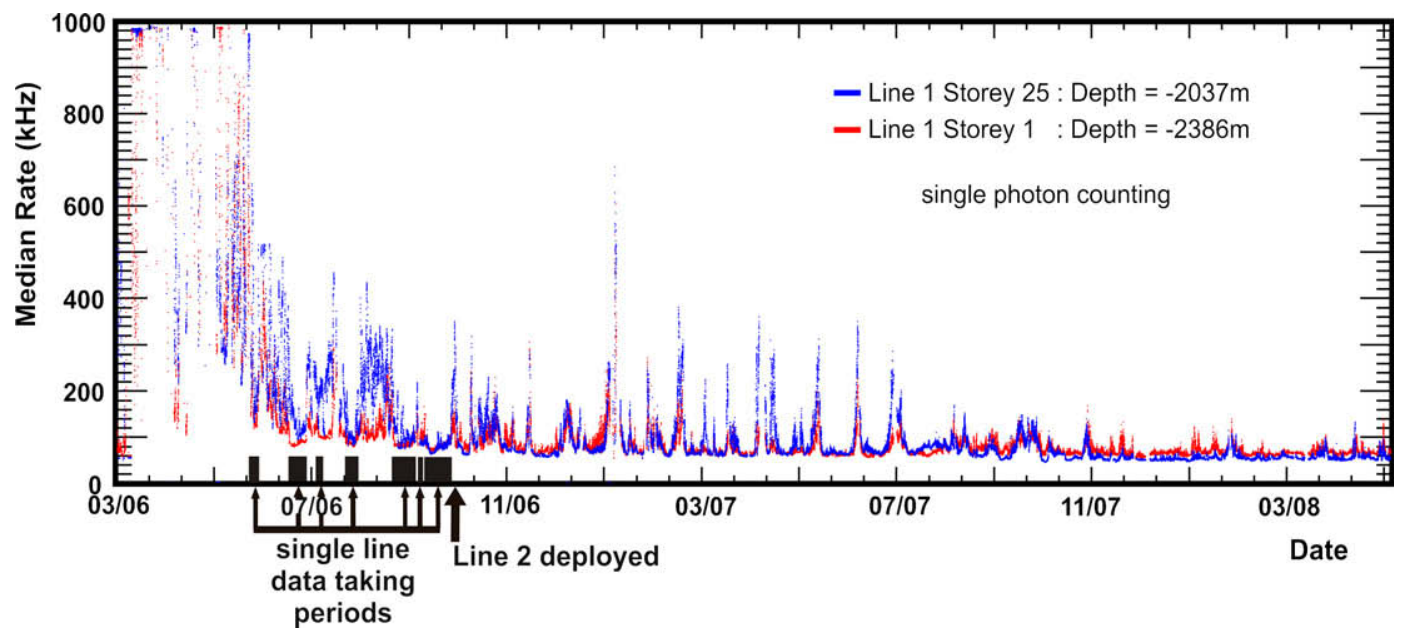

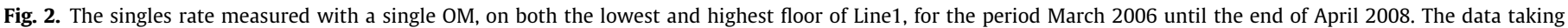
periods for this analysis are indicated.

high rate period was challenging for both data acquisition and filtering.

On the 26th of September 2006 the second line of the detector was connected and the period of single line running was terminated. For this paper data runs were selected with the singles rate averaged over all active components less than $120 \mathrm{kHz}$. In addition to the steady singles rate some optical activity arrives in short bursts, most likely associated with bioluminescence emitted by macroscopic organisms. To avoid periods where this burst activity was too large we also required that the fraction of time the singles rate was above $250 \mathrm{kHz}$ should be less than 0.15 .

The periods passing these criteria in the 6 months of exclusively one line data taking are indicated in Fig. 2. The integrated acquisition time for the one line setup was $448 \mathrm{~h}$. In this period, however, 
the data acquisition was not yet fully functional and only every second time slice was transferred from the detector to shore. In addition an effective dead-time of $20 \%$ was present in the online data filtering process. These issues have since been corrected for later data taking periods. The total effective live time of the experiment was therefore $187 \mathrm{~h}$.

Events were filtered from the data stream by searching within the time slice of $104 \mathrm{~ms}$ for PMT signals that were correlated in position and time. Seeds for the search, level 1 trigger hits (L1 hits), were either coincidences between PMTs within a single storey, in a 20 ns time window, or single PMTs with a pulse height in excess of 10 spe. If a cluster of at least five L1 hits was found, where for any pair $|\Delta t|<\frac{n}{c}|\Delta \vec{x}|+20 \mathrm{~ns}$, a candidate event was considered to be found. Here $|\Delta t|$ is the absolute time difference between the hits, $|\Delta \vec{x}|$ is the distance in space between the PMT pairs involved, $n=1.34$ is the refractive index of the sea water and $c$ is the velocity of light. All information from the full detector in a time window, the snapshot, extending from $2 \mu$ s before the first L1 to $2 \mu$ s after the last L1 in the cluster was stored for further offline processing. In total $7.5 \times 10^{4}$ candidates were stored.

\section{Reconstruction}

In this analysis the detector is assumed to be a single perfectly straight vertical line. All optical modules are taken to be stationary at the same position $x=y=0$ ( $x$ and $y$ are the horizontal coordinates, $z$ the vertical). As their orientation is not used in the analysis there is no information from which the azimuthal angle of the track can be determined. In reality the line is subject to forces due to the undersea water currents. Two factors will then contribute to the uncertainty in the position of the optical modules: the rotation of a storey around its axis and the deformation of the flexible line. The distance from the centre of the photocathode of the PMT to the axis is $57.9 \mathrm{~cm}$. Ignoring the rotation of a storey introduces an uncertainty of $40 \mathrm{~cm}$. This error on the position corresponds to a timing inaccuracy of about $2.0 \mathrm{~ns}$. Deformation of the line shape introduces relative offsets in the $x-y$ plane between storeys. As a result, an error in the relative positioning of the storeys and thus of the optical modules is introduced. In the selected data taking period the water velocities were such that $94 \%$ of the time the top of the line did not deviate horizontally more than $1 \mathrm{~m}$. When the detector line is tilted, while assuming a vertical orientation, the true zenith is displaced with respect to the assumed zenith. A displacement of the top of the line of $1 \mathrm{~m}$ corresponds to a shift of the zenith of about $0.15^{\circ}$. All results presented in this paper include these orientation effects and where relevant they are included in the systematic errors.

The track model [11] used in the reconstruction is that of a relativistic muon traversing the detector and emitting Cherenkov light. The fit is performed following the assumption of a single muon track, although a large fraction of the events is composed of muon bundles. The arrival time $t_{j}$ of Cherenkov photons at the PMT $j$ located on the line at vertical height $z_{j}$ is then defined by

$c\left(t_{j}-t_{d}\right)=\left(z_{j}-z_{d}\right) \cos \theta+\sqrt{n^{2}+1} \sqrt{d^{2}+\left(z_{j}-z_{d}\right)^{2} \sin ^{2} \theta}$

with $d$ being the track's distance of closest approach to the line, $z_{d}$ and $t_{d}$ being the height and time at which the closest distance is reached, $\theta$ being the zenith. These variables are shown in Fig. 3.

The L1 hits that caused the trigger are used as a starting point for the reconstruction. For L1s, which are comprised of coincident hits, only the earliest time is considered. Due to the non-linear nature of the fitting procedure, a series of fits is performed varying the track direction, $\theta$. Given this direction the muon trajectory is determined by three remaining parameters, which fix the spatial and

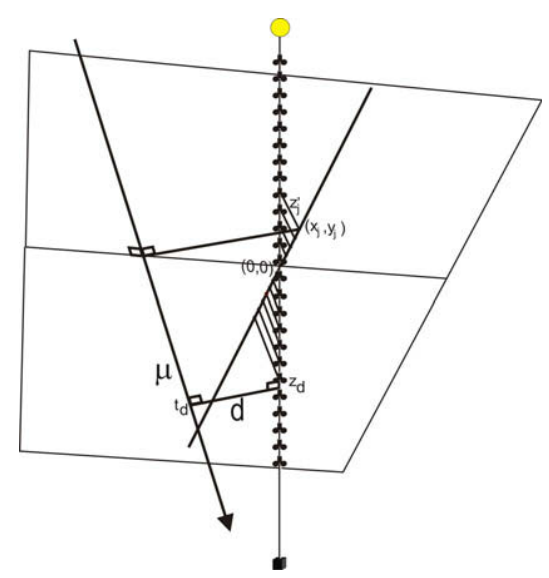

Fig. 3. The muon track intersecting the plane perpendicular to the track and passing through the centre $(0,0)$ of the active part of the line. Parameters used in the tracking are also indicated.

temporal position of the track. These parameters are $t_{0}$, the time at which the track intersects a plane perpendicular to the assumed track direction and passing through the centre of the active part of the line and $x_{0}$ and $y_{0}$, at which the track crosses this plane (see Fig. 3). All positions of the hit PMTs are projected onto this plane. The time at which PMT $j$ is hit is given by $t_{j}=t_{0}+\frac{1}{c}\left(z_{j}^{\prime}+k r_{j}\right)$ where $z_{j}^{\prime}$ is the signed distance of PMT $j$ to the plane (positive in the direction of travel of the muon), $r_{j}$ is the distance of PMT $j$ to the track and $\kappa=\frac{c}{v_{g}} \frac{1}{\sin \theta_{c}}-\frac{1}{\tan \theta_{c}}$ with $v_{g}$ being the group velocity of light in water and $\theta_{c}$ being the Cherenkov angle. Using these definitions a criterion can be defined which is more restrictive than the causality criterion used in the online filter:

$\left[-\kappa R+z_{j}^{\prime}-z_{i}^{\prime}\right] / c-20 \mathrm{~ns} \leqslant t_{j}-t_{i} \leqslant\left[\kappa R+z_{j}^{\prime}-z_{i}^{\prime}\right]+20 \mathrm{~ns}$

where $R$ is the projected distance on the plane between PMT $i$ and $j$ and the 20 ns have been included as safety margin. In addition it is required that two correlated hits not be further apart than $90 \mathrm{~m}$, two times the absorption length of light in water [12]. The L1 hits of the filter are subjected to these more stringent criteria and if a cluster of at least 5 L1 hits remain then additional single hits, L0s, are sought. If an LO obeys the criteria with respect to all hits in the cluster it is added to the cluster.

The hits in the cluster are then used to fit the three track parameters $x_{0}, y_{0}$ and $t_{0}$. This is done in several steps. The starting values of the parameters are determined from the average position and time, calculated from all hits in the cluster weighted by their pulse height. First the hit residuals are minimized using Powell's method and this is then followed by Marquardt's method of $\chi^{2}$ minimization [13]. This full procedure is repeated for different values of the zenith angle, between $0^{\circ}$ and $180^{\circ}$, in steps of $5^{\circ}$. If a sufficiently large cluster is found each separate angle will give an optimally fitted track and a set of hits used in the fit. For each fit a new $\chi^{2}$ minimization is performed with $\theta$ now left free as an additional parameter. After convergence all fits with a $\chi^{2}$ probability $P_{\chi^{2}}>0.01$ are kept. For fits with $P_{\chi^{2}} \leqslant 0.01$ hits with an individual contribution to the $\chi^{2}$ of more than 25 are removed one by one and the fit is redone and $P_{\chi^{2}}$ recalculated. If three hits are removed and $P_{\chi^{2}}$, remains below 0.01 , the fit is rejected.

All fits are finally ordered according to the number of hits used in the fit. If multiple solutions have the same number of hits, the one with the smallest $\chi^{2}$ is considered the best. Solutions with less than $20 \%$ of the hits of the best solution are rejected.

Two events are displayed in Figs. 4 and 5. In these figures the $y$-axis corresponds to the vertical height along the line and the 


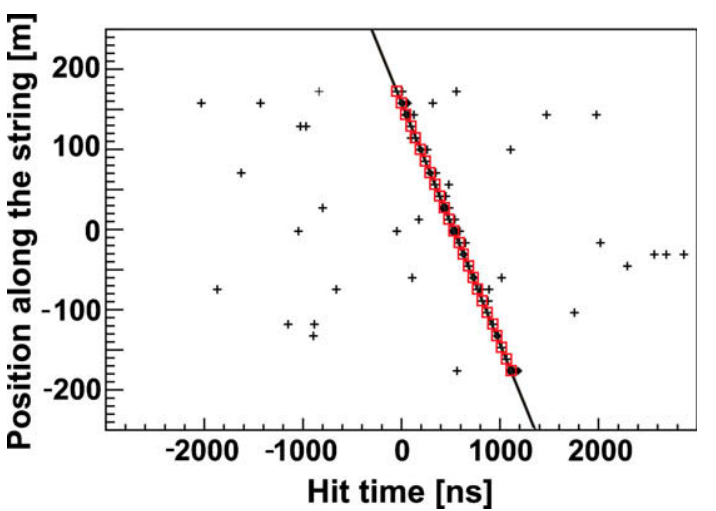

Fig. 4. A muon traversing the detector in the downward vertical direction. Crosses indicate hits, closed circles are the hits selected by the online filter algorithm. Hits used in the fit are indicated by open squares. For this particular track all storeys participate in the fit.

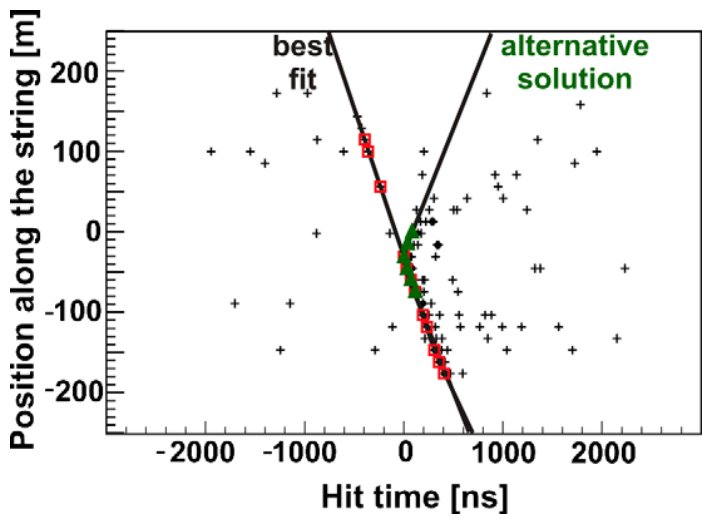

Fig. 5. A downward going muon with two possible track solutions. The best solution is a vertical track. The alternative solution is a horizontal track. Open squares indicate the hits used in the best fit, closed triangles those used in the alternative solution.

$x$-axis displays the arrival time of the photons. The event shown in Fig. 4 has been reconstructed as a muon passing the detector line in the vertically downward direction. All storeys of the line have been used in determining the fit. The hit times can be seen to propagate down the line at the speed of light, following the relativistic muon's Cherenkov cone propagation.

The event shown in Fig. 5 shows a more complex structure, nevertheless a single downward-going track has been fitted. Approximately at the centre of the line a parabolic pattern of hits is superimposed on the track hits. These are most likely due to a bremsstrahlung photon having been radiated from the downward-going muon, causing an electromagnetic cascade. The Cherenkov light produced by this cascade is detected on the line as the equivalent of a point source emitting light. If these hits are used in the track fit an alternative, approximately horizontal, track solution is found. Both solutions are indicated in the figure. In this event the best solution (most hits) is the downward-going track; in other cases the horizontal track can turn out to be the best solution.

\section{Results}

The distribution of time residuals of all hits in the snapshot with respect to the predictions from the track parameters, obtained

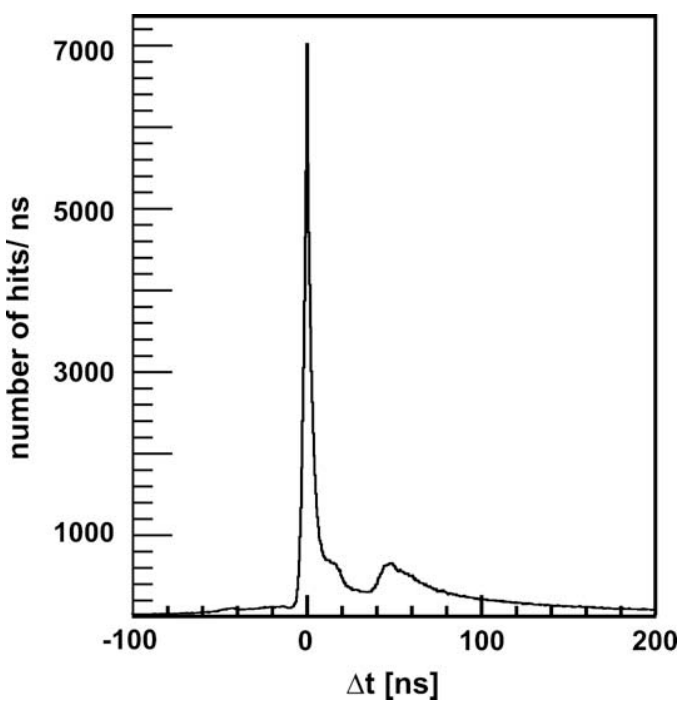

Fig. 6. The residual distribution for all hits in the snapshot. See the text for an explanation of the different structures observed in the distribution.

from the best fit, is shown in Fig. 6. The fit is performed according to the procedure described above but excluding the hit under consideration. This is done to obtain an unbiased measure of the residual. There is a sharp peak at zero time difference, corresponding to photons arriving at the time expected from the track model. A broad enhancement is seen starting at $45 \mathrm{~ns}$. This is due to the loss of the time information of a second pulse from the PMT, which arrives either before the end of the $25 \mathrm{~ns}$ integration gate or during the $15 \mathrm{~ns}$ dead time of swapping from one ARS to the other. The long tail towards late arrival times is due either to light emitted from bremsstrahlung showers or to scattered light. The small shoulder occurring at $20 \mathrm{~ns}$ is due to the trigger requirement. Since each fit contains five L1s, and since the fit uses only the earliest time of each L1 component-hit, the remaining component-hits give rise to the shoulder, which has a width of $20 \mathrm{~ns}$ and is equal to the L1 coincidence window.

Finally, the small constant level of early hits is due to random background, mostly from ${ }^{40} \mathrm{~K}$, whereas the small shoulder at early times is due to poorly reconstructed tracks. The RMS width of the central peak depends on the number of hits used in the fit. As shown in Fig. 7, it decreases from 12 ns for tracks with the minimum number of 5 hits, to 2 ns for the maximum number of 24 hits.

To investigate the tracking method in more detail, a simulation of downward going muons from extended air showers has been performed. This simulation uses the parameterization of the muon flux, given by MUPAGE [14], at the depth of the ANTARES detector. All tracks that pass within two and a half light attenuation lengths, or $135 \mathrm{~m}$, from the detector line are passed to the program KM3 [15] that performs the detailed simulation of the detector response. This program uses parameterizations of light intensities as a function of the distance from the light source that incorporate the scattering of light in water, the effects of light dispersion and a detailed simulation of the PMT and subsequent ARS response. Optical noise, in the form of random single photon hits with rates commensurate with those measured during the runs used for this analysis, is added to these simulated events. As can be seen from Fig. 7, this simulation reproduces the time residuals very well. It also indicates that the degraded resolution at small numbers of hits is due to poor reconstruction, where hits originating from electromagnetic showers or from more than one muon are combined in a single track fit. 


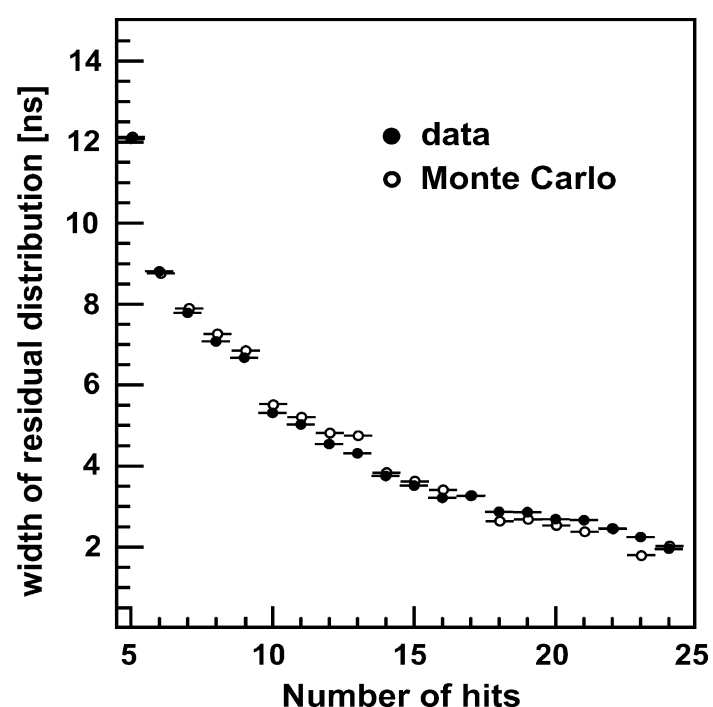

Fig. 7. The RMS width of the central peak of Fig. 6 as a function of the number of hits used in the fit. Closed circles represent the data and open circles are the results of the fits to simulated data.

By taking the best track solution for each event an estimate of the zenith angular resolution has been obtained. First, all tracks were refitted using hits from even numbered floors only or from odd numbered floors only. These two solutions were then compared and the angular difference determined. The size of such angular difference depends on the number of hits used in the fit; it decreases from around $2^{\circ}$ for tracks with only five hits to below $1^{\circ}$ for tracks with more than eight hits. Since both tracks contribute equally, the angular resolution for each track is therefore around $0.7^{\circ}$. Taking into account the improvement to be expected when the track is fitted over its full length, the full zenith-angular resolution for tracks with more than 16 hits on only one detector line approaches $0.5^{\circ}$.

As the optical modules are facing downwards at $45^{\circ}$, the acceptance for Cherenkov light for downward going muons is limited. It depends quite strongly on the sensitivity of the optical module for light arriving from the rear. The sensitivity of the optical modules has been measured [7] and simulated using ray tracing through the different parts of the optical module. The results differ for photons arriving with an incident angle of more than $90^{\circ}$ with respect to the axis of the PMT. For upward-going tracks the differences have a negligible effect on the acceptance. However, for downwardgoing muons, these differences are significant and lead to an increase in the systematic uncertainties. New measurements are being performed in order to better understand the angular acceptance of the optical modules.

The angular distribution of the best fit solutions found for all data obtained with Line 1 before October 2006 is shown in Fig. 8. The distribution follows the expected pattern for small angles with respect to vertically downward-going muons $(\cos \theta=-1)$. As the angle moves away from vertically down-going, the intensity decreases rapidly. At somewhat larger angles the distribution flattens out and rises. The simulation shows a similar behaviour, although not quite as strong. In the simulation this feature is caused by vertical tracks producing bremsstrahlung showers, which are mistakenly interpreted as approximately horizontal tracks. The size of this effect is sensitive to the angular distribution of photons emitted in bremsstrahlung showers. In the absence of information from additional detector lines, this misreconstruction is unavoidable. The simulations show that for values of $\cos \theta<-0.5$, there is minimal distortion of the angular distribution and the acceptance

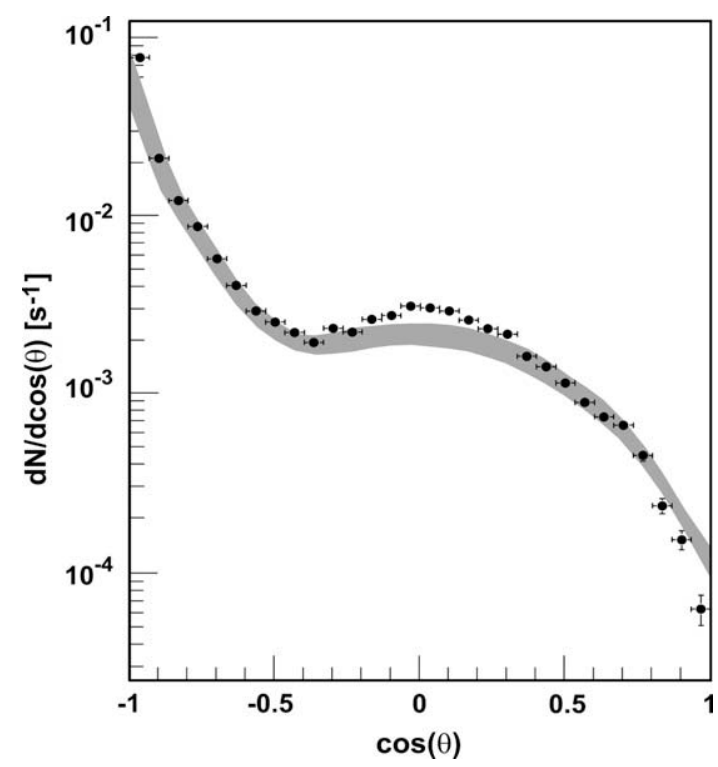

Fig. 8. Distribution of the cosine of the angle with respect to the vertical for all tracks extracted from the ANTARES Line 1 data. A value of -1 corresponds to downward-going muons. The points are data; the shaded band is the result of the simulation. Errors on the data points are statistical only. The width of the band is due mainly to the uncertainty in the angular acceptance of the PMT.

correction is flat in this region. The region with $\cos \theta>-0.5$ becomes more and more dominated by poorly reconstructed vertical tracks.

To measure the vertical muon intensity versus depth, the measured rate of reconstructed tracks is converted to the single muon intensity using the Monte Carlo simulation. Only tracks having $\cos \theta<-0.5$, where the conversion is almost independent of angle, is used. Each value of the zenith angle corresponds to a slant depth through the water mass above the detector. Therefore, the mea-

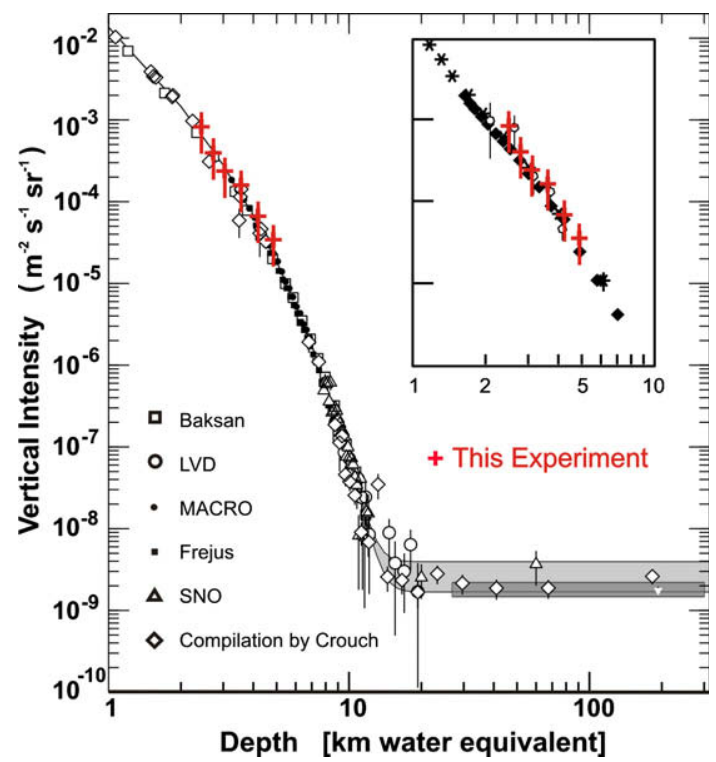

Fig. 9. Vertical muon intensity versus depth. Crosses are the results of the present experiment, other data are from: the compilations of Crouch [16], Baksan [17], LVD [18], MACRO [19], Frejus [20], and SNO [21]. The shaded area at large depths represents neutrino-induced muons of energy above $2 \mathrm{GeV}$. The upper line is for horizontal neutrino-induced muons, the lower one for vertically upward muons. In the inset the data from the present experiment is compared to other water or ice experiments [22-24]. For the present experiment the measurements correspond to $187 \mathrm{~h}$ of data taking. 
sured single muon flux can also be given as a function of slant depth. In order to calculate the vertical muon intensity, the energy distribution of muons at sea level has to be taken into account. This distribution for small angles, i.e. $\pi-\theta$ small, is given by [25]:

$\frac{d N_{\mu}}{d E_{\mu}} \approx 0.14 E_{\mu}^{-2.7}\left(\frac{1}{1-\frac{1.1 E_{\mu} \cos \theta}{115}}+\frac{0.054}{1-\frac{1.1 E_{\mu} \cos \theta}{850}}\right)\left[\mathrm{cm}^{-2} \mathrm{~s}^{-1} \mathrm{sr}^{-1} \mathrm{Gev}^{-1}\right]$

All energies are given in GeV. For a given value of $\cos \theta$ this distribution is integrated over the energy range from $2 \mathrm{TeV}$ to $10 \mathrm{PeV}$ to yield $R(\cos \theta)$. The correction factor $F(\cos \theta)=R(\cos \theta) / R(-1)$ is used to correct the intensity as a function of slant depth to the vertical muon intensity. The measured values of the vertical muon intensity versus depth vary between $(7.4 \pm 3.5) \times 10^{-4} \mathrm{~m}^{-2} \mathrm{~s}^{-1} \mathrm{sr}^{-1}$ at $2400 \mathrm{~m}(3.8 \pm 1.9) \times 10^{-5} \mathrm{~m}^{-2} \mathrm{~s}^{-1} \mathrm{sr}^{-1}$ to at $4800 \mathrm{~m}$. The data are presented in Fig. 9 and compared to other measurements compiled by the Particle Data Group [26]. The errors are systematic and of the order of $50 \%$. They are dominated by the uncertainty in the PMT acceptance, with variations observed in the PMT thresholds yielding an error of $6 \%$ and variations in the filter dead-time giving a further $5 \%$ error. All other errors including the statistical errors are negligible. Agreement between the present data and other published values is good. Our data are also consistent with [5].

\section{Conclusions}

We have presented data on the performance of the first detector line deployed by the ANTARES collaboration. Although bioluminescent activity was extreme in the first months after deployment such activity has subsided. No technical problems have been encountered during the two years of running. The full readout and reconstruction chain has been described. The measured angular distribution of the reconstructed tracks agrees reasonably well with the results from simulations of muons from extensive air showers. The major systematic error on the acceptance of these mainly downward-going tracks is due to the uncertainty in the angular acceptance of the PMT, especially in the rearward direction. The measured intensity as a function of depth of these muons agrees well with previous measurements. The zenith angular resolution of tracks with 16 or more hits on a single line is found to be of the order of half a degree.

\section{Acknowledgements}

The authors acknowledge the financial support of the funding agencies: Centre National de la Recherche Scientifique (CNRS), Commissariat à l'Energie Atomique (CEA), Commission Européenne
(FEDER fund and Marie Curie Program), Région Alsace (contrat CPER), Région Provence-Alpes-Côte d'Azur, Département du Var and Ville de La Seyne-sur-Mer, in France; Bundesministerium für Bildung und Forschung (BMBF), in Germany; Istituto Nazionale di Fisica Nucleare (INFN), in Italy; Stichting voor Fundamenteel Onderzoek der Materie (FOM), Nederlandse organisatie voor Wetenschappelijk Onderzoek (NWO), in The Netherlands; Russian Foundation for Basic Research (RFBR), in Russia; National Authority for Scientific Research (ANCS) in Romania; Ministerio de Ciencia e Innovación (MICINN), in Spain.

We also acknowledge the technical support of Ifremer, AIM and Foslev Marine for the sea operation and the CC-IN2P3 for the computing facilities.

\section{References}

[1] M.A. Markov, in: Proc. Int. Conf. on High-Energy Physics, Rochester, 1960, p. 578.

[2] P. Bosetti et al. (DUMAND collaboration), Harvard HDC-2-88, 1988, <http:// www.phys.hawaii.edu/ dumand>.

[3] R. Wischnewski et al., BAIKAL collaboration, Int. J. Mod. Phys. A20 (2005) 6932.

[4] K. Rawlins (for the IceCube collaboration), AIP Conf. Proc. 928 (2007) 69.

[5] G. Aggouras et al., NESTOR collaboration, Astropart. Phys. 23 (2005) 377.

[6] E. Migneco et al., NEMO collaboration, Nucl. Instrum. Meth. A588 (2008) 111.

[7] P. Amram et al., ANTARES collaboration, Nucl. Instrum. Meth. A484 (2002) 369.

[8] F. Feinstein, for the ANTARES collaboration, Nucl. Instrum. Meth. A504 (2003) 258.

[9] J.A. Aguilar et al., ANTARES collaboration, Nucl. Instrum. Meth. A570 (2007) 107.

[10] M. Ageron et al., ANTARES collaboration, Nucl. Instrum. Meth. A578 (2007) 498.

[11] R. Bruijn, Ph.D. Thesis. University of Amsterdam, The Netherlands, 2008, http://antares.in2p3.fr/Publications/index.html\#thesis.

[12] J.A. Aguilar et al., ANTARES collaboration, Astropart. Phys. 23 (2005) 131.

[13] W.H. Press, S.A. Teukolsky, W.T. Vetterling, B.P. Flannery, Numerical recipies in C++, Cambridge University Press, 2003.

[14] Y. Becherini, A. Margiotta, M. Sioli, M. Spurio, Astropart. Phys. 25 (2006) 1.

[15] D.J.L. Bailey, Ph.D. Thesis. Oxford University, United Kingdom, 2002, <http:// antares.in2p3.fr/Publications/index.html\#thesis>.

[16] M. Crouch, in: Proc. 20th Int. Cosmic Ray Conf., Moscow, 6, 1987, 165.

[17] Y.M. Andreev, V.I. Gurentzov, I.M. Kogai, in: Proc. 20th Int. Cosmic Ray Conf., Moscow, 6, 1987, 200.

[18] M. Aglietta et al., LVD Collaboration, Astropart. Phys. 3 (1995) 311.

[19] M. Ambrosio et al., MACRO collaboration, Phys. Lett. B434 (1998) 451.

[20] Ch. Berger et al., Frejus collaboration, Phys. Rev. D40 (1989) 2163.

[21] C. Waltham et al. (SNO Collaboration), in: Proc. 27th Int. Cosmic Ray Conf., Hamburg, 2001, 991.

[22] I.A. Belolaptikov et al., Astropart. Phys. 7 (1997) 263.

[23] J. Babson et al., Phys. Rev. D42 (1990) 41.

[24] P. Desiati et al., in: Proc. 28th Int. Cosmic Ray Conf., Tsukuba, 2003, 1373.

[25] T.K. Gaisser, Cosmic Rays and Particle Physics, Cambridge University Press, 1990.

[26] W.M. Yao et al., J. Phys. G33 (2006) 1. 


\section{Measurement of the atmospheric muon flux with a $4 \mathrm{GeV}$ threshold in the ANTARES neutrino telescope}

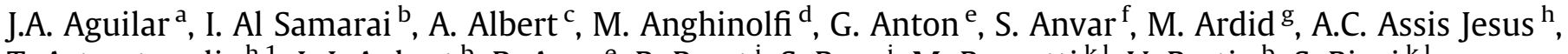 T. Astraatmadja ${ }^{\text {h,1 }}$, J.-J. Aubert ${ }^{\mathrm{b}}$, R. Auer ${ }^{\mathrm{e}}$, B. Baret ${ }^{\mathrm{i}}$, S. Basa ${ }^{\mathrm{j}}$, M. Bazzotti ${ }^{\mathrm{k}, \mathrm{l}}$, V. Bertin ${ }^{\mathrm{b}}$, S. Biagi $^{\mathrm{k}, \mathrm{l}}$, C. Bigongiari ${ }^{\mathrm{a}}$, M. Bou-Cabo ${ }^{\mathrm{g}}$, M.C. Bouwhuis ${ }^{\mathrm{h}}$, A. Brown $^{\mathrm{b}}$, J. Brunner $^{\mathrm{b}}$, J. Busto ${ }^{\mathrm{b}}$, F. Camarena $^{\mathrm{g}}$, A. Capone ${ }^{\mathrm{m}, \mathrm{n}}$, C. Cârloganu $^{\mathrm{o}}$, G. Carminati ${ }^{\mathrm{k}, \mathrm{l}}$, J. Carr $^{\mathrm{b}}$, E. Castorina ${ }^{\mathrm{p}, \mathrm{q}}$, V. Cavasinni $^{\mathrm{p}, \mathrm{q}}$, , S. Cecchini $^{\mathrm{l}, \mathrm{r}}$, Ph. Charvis ${ }^{\mathrm{s}}$, T. Chiarusi ${ }^{1}$, N. Chon Sen ${ }^{\mathrm{c}}$, M. Circella ${ }^{\mathrm{t}}$, R. Coniglione ${ }^{\mathrm{u}}$, H. Costantini $^{\mathrm{d}}$, N. Cottini ${ }^{\mathrm{v}}$, P. Coyle $^{\mathrm{b}}$, C. Curtil $^{\text {b }}$, G. De Bonis ${ }^{\mathrm{m}, \mathrm{n}}$, M.P. Decowski ${ }^{\mathrm{h}}$, I. Dekeyser ${ }^{\mathrm{w}}$, A. Deschamps ${ }^{\mathrm{s}}$, C. Distefano ${ }^{\mathrm{u}}$, C. Donzaud $^{\mathrm{i}, \mathrm{x}}$, D. Dornic $^{\mathrm{b}}$, D. Drouhin ${ }^{\mathrm{c}}$, T. Eberl $^{\mathrm{e}}, \mathrm{U}_{\text {. Emanuele }}^{\mathrm{a}}$, J.-P. Ernenwein ${ }^{\mathrm{b}}$, S. Escoffier $^{\mathrm{b}}$, F. Fehr $^{\mathrm{e}}$, V. Flaminio $^{\mathrm{p}, \mathrm{q}}$, K. Fratini ${ }^{\text {y,d }}{ }^{\text {, U. Fritsch }}{ }^{\text {e }}$, J.-L. Fuda ${ }^{\text {w }}$, P. Gay ${ }^{\mathrm{o}}$, G. Giacomelli ${ }^{\text {k,l }}$, J.P. Gómez-González ${ }^{\mathrm{a}}$, K. Graf ${ }^{\mathrm{e}}$, G. Guillard ${ }^{\mathrm{ag}}$, G. Halladjian ${ }^{\mathrm{b}}$, G. Hallewell ${ }^{\mathrm{b}}$, H. van Haren ${ }^{\mathrm{z}}$, A.J. Heijboer ${ }^{\text {h }}$, Y. Hello ${ }^{\text {, }}$, J.J. Hernández-Rey ${ }^{\mathrm{a}}$, B. Herold ${ }^{\mathrm{e}}$, J. Hößl ${ }^{\mathrm{e}}$, M. de Jong ${ }^{\text {h,1 }}$, N. Kalantar-Nayestanaki ${ }^{\text {aa }}$, O. Kalekin ${ }^{\mathrm{e}}$, A. Kappes ${ }^{\mathrm{e}}$, U. Katz ${ }^{\mathrm{e}}$, P. Kooijman ${ }^{\text {h,ab,ac }}$, C. Kopper ${ }^{\mathrm{e}}$, A. Kouchner ${ }^{\mathrm{i}}$, W. Kretschmer ${ }^{\mathrm{e}}$, R. Lahmann ${ }^{\mathrm{e}}$, P. Lamare ${ }^{\mathrm{f}}$, G. Lambard ${ }^{\mathrm{b}}$, G. Larosa ${ }^{\mathrm{g}}$, H. Laschinsky ${ }^{\text {e }}$, D. Lefèvre ${ }^{\mathrm{w}}$, G. Lelaizant $^{\mathrm{b}}$, G. Lim $^{\text {h,ac }}$, D. Lo Presti ${ }^{\text {ad }}$, H. Loehner $^{\text {aa }}$, S. Loucatos ${ }^{\mathrm{v}}$, F. Lucarelli $^{\mathrm{m}, \mathrm{n}}$, S. Mangano ${ }^{\mathrm{a}}$, M. Marcelin ${ }^{\mathrm{j}}$, A. Margiotta ${ }^{\mathrm{k}, \mathrm{l}}$, J.A. Martinez-Mora ${ }^{\mathrm{g}}$, A. Mazure $^{\mathrm{j}}$, T. Montaruli ${ }^{\text {t,ae }}$, M. Morganti ${ }^{\mathrm{p}, \mathrm{q}}$, L. Moscoso v,i, H. Motz ${ }^{\mathrm{e}}$, C. Naumann ${ }^{\mathrm{v}}$, M. Neff ${ }^{\mathrm{e}}$, R. Ostasch ${ }^{\mathrm{e}}$, G. Palioselitis ${ }^{\text {h }}$, G.E. Păvălaş ${ }^{\text {af }}$, P. Payre $^{\text {b }}$, J. Petrovic ${ }^{\text {h }}$, P. Piattelli ${ }^{\text {u }}$, N. Picot-Clemente ${ }^{\mathrm{b}}$, C. Picq ${ }^{\mathrm{v}}$, R. Pillet ${ }^{\mathrm{s}}$, V. Popa ${ }^{\text {af }}$, T. Pradier ${ }^{\text {ag }}$,

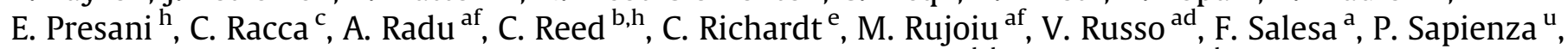 F. Schoeck ${ }^{\mathrm{e}}$, J.-P. Schuller ${ }^{\mathrm{v}}$, R. Shanidze ${ }^{\mathrm{e}}$, F. Simeone ${ }^{\mathrm{n}}$, M. Spurio ${ }^{\text {k,1 }}$, J.J.M. Steijger ${ }^{\mathrm{h}}$, Th. Stolarczyk ${ }^{\mathrm{v}}$,

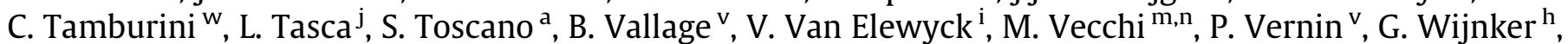 E. de Wolf $^{\text {h,ac }}$, H. Yepes ${ }^{\text {a }}$, D. Zaborov ${ }^{\text {ah,*, J.D. Zornoza }}{ }^{\mathrm{a}}$, J. Zúñiga ${ }^{\mathrm{a}}$

${ }^{a}$ IFIC - Instituto de Física Corpuscular, Edificios Investigación de Paterna, CSIC - Universitat de València, Apdo. de Correos 22085, 46071 Valencia, Spain

b CPPM - Centre de Physique des Particules de Marseille, CNRS/IN2P3 et Université de la Méditerranée, 163 Avenue de Luminy, Case 902, 13288 Marseille Cedex 9, France

${ }^{\mathrm{c}}$ GRPHE - Institut Universitaire de Technologie de Colmar, 34 Rue du Grillenbreit, BP 50568, 68008 Colmar, France

${ }^{\mathrm{d}}$ INFN - Sezione di Genova, Via Dodecaneso 33, 16146 Genova, Italy

${ }^{\mathrm{e}}$ Friedrich-Alexander-Universität Erlangen-Nürnberg, Erlangen Centre for Astroparticle Physics, Erwin-Rommel-Str. 1, D-91058 Erlangen, Germany

${ }^{\mathrm{f}}$ Direction des Sciences de la Matière - Institut de Recherche sur les lois Fondamentales de l'Univers - Service d'Electronique des Détecteurs et d'Informatique,

CEA Saclay, 91191 Gif-sur-Yvette Cedex, France

${ }^{\mathrm{g}}$ Institut de Gestió Integrada de Zones Costaneres (IGIC) - Universitat Politècnica de València, Cra. Nazaret-Oliva S/N, E-46730 Gandia, València, Spain

${ }^{\mathrm{h}}$ FOM Instituut voor Subatomaire Fysica Nikhef, Science Park 105, 1098 XG Amsterdam, The Netherlands

${ }^{\mathrm{i}}$ APC - Laboratoire AstroParticule et Cosmologie, UMR 7164 (CNRS, Université Paris 7 Diderot, CEA, Observatoire de Paris) 10, Rue Alice Domon et Léonie Duquet,

75205 Paris Cedex 13, France

${ }^{\mathrm{j}}$ LAM - Laboratoire d'Astrophysique de Marseille, Pôle de l'Étoile Site de Château-Gombert, Rue Frédéric Joliot-Curie 38, 13388 Marseille Cedex 13, France

${ }^{\mathrm{k}}$ Dipartimento di Fisica dell'Università, Viale Berti Pichat 6/2, 40127 Bologna, Italy

${ }^{1}$ INFN - Sezione di Bologna, Viale Berti Pichat 6/2, 40127 Bologna, Italy

${ }^{\mathrm{m}}$ Dipartimento di Fisica dell'Università La Sapienza, P.le Aldo Moro 2, 00185 Roma, Italy

n INFN - Sezione di Roma, P.le Aldo Moro 2, 00185 Roma, Italy

${ }^{\circ}$ Laboratoire de Physique Corpusculaire, IN2P3-CNRS, Université Blaise Pascal, Clermont-Ferrand, France

${ }^{\mathrm{P}}$ Dipartimento di Fisica dell'Università, Largo B. Pontecorvo 3, 56127 Pisa, Italy

${ }^{\mathrm{q}}$ INFN - Sezione di Pisa, Largo B. Pontecorvo 3, 56127 Pisa, Italy

${ }^{\mathrm{r}}$ INAF-IASF, via P. Gobetti 101, 40129 Bologna, Italy

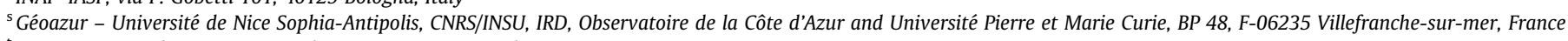
${ }^{\mathrm{t}}$ INFN - Sezione di Bari, Via E. Orabona 4, 70126 Bari, Italy

u INFN - Laboratori Nazionali del Sud (LNS), Via S. Sofia 44, 95123 Catania, Italy

${ }^{v}$ Direction des Sciences de la Matière - Institut de Recherche sur les lois Fondamentales de l'Univers - Service de Physique des Particules,

CEA Saclay, 91191 Gif-sur-Yvette Cedex, France

\footnotetext{
* Corresponding author. Tel.: +7 4997896692.

E-mail address: Dmitry.Zaborov@itep.ru (D. Zaborov)

1 Also at University of Leiden, The Netherlands.
} 
${ }^{\mathrm{w}}$ COM - Centre d'Océanologie de Marseille, CNRS/INSU et Université de la Méditerranée, 163 Avenue de Luminy, Case 901, 13288 Marseille Cedex 9, France

${ }^{\mathrm{x}}$ Université Paris-Sud 11, Département de Physique, F-91403 Orsay Cedex, France

${ }^{\mathrm{y}}$ Dipartimento di Fisica dell'Università, Via Dodecaneso 33, 16146 Genova, Italy

${ }^{\mathrm{z}}$ Royal Netherlands Institute for Sea Research (NIOZ), Landsdiep 4, 1797 SZ 't Horntje, Texel, The Netherlands

${ }^{\text {aa }}$ Kernfysisch Versneller Instituut (KVI), University of Groningen, Zernikelaan 25, 9747 AA Groningen, The Netherlands

${ }^{\mathrm{ab}}$ Universiteit Utrecht, Faculteit Betawetenschappen, Princetonplein 5, 3584 CC Utrecht, The Netherlands

${ }^{a}$ Universteit van Amsterdam, Instituut voor Hoge-Energie Fysika, Science Park 105, 1098 XG Amsterdam, The Netherlands

${ }^{\text {ad }}$ Dipartimento di Fisica ed Astronomia dell'Università, Viale Andrea Doria 6, 95125 Catania, Italy

${ }^{\text {ae }}$ University of Wisconsin - Madison, 53715 WI, USA

af Institute for Space Sciences, R-77125 Bucharest, Măgurele, Romania

ag IPHC - Institut Pluridisciplinaire Hubert Curien, Université Louis Pasteur (Strasbourg 1) et IN2P3/CNRS, 23 Rue du Loess, BP 28, 67037 Strasbourg Cedex 2, France

ah ITEP - Institute for Theoretical and Experimental Physics, B. Cheremushkinskaya 25, 117218 Moscow, Russia

\section{A R T I C L E I N F O}

Article history:

Received 28 October 2009

Received in revised form 1 December 2009

Accepted 7 December 2009

Available online 13 December 2009

Keywords:

Atmospheric muons

Depth intensity relation

Potassium-40

\begin{abstract}
A B S T R A C T
A new method for the measurement of the muon flux in the deep-sea ANTARES neutrino telescope and its dependence on the depth is presented. The method is based on the observation of coincidence signals in adjacent storeys of the detector. This yields an energy threshold of about $4 \mathrm{GeV}$. The main sources of optical background are the decay of ${ }^{40} \mathrm{~K}$ and the bioluminescence in the sea water. The ${ }^{40} \mathrm{~K}$ background is used to calibrate the efficiency of the photo-multiplier tubes.
\end{abstract}

(c) 2009 Elsevier B.V. All rights reserved.

\section{Introduction}

The ANTARES neutrino telescope is installed in the Mediterranean Sea, $40 \mathrm{~km}$ offshore from Toulon (France) at a depth of $2475 \mathrm{~m} \mathrm{[1,2]}$. The elements of the detector are arranged in 12 vertical lines, each of which is attached to the seabed with an anchor and kept taut by a buoy. A detector line comprises 25 storeys distributed along the length of the $450 \mathrm{~m}$ long electro-mechanical cable, starting $100 \mathrm{~m}$ above the seabed. The storeys are separated by $14.5 \mathrm{~m}$ and contain a triplet of large-area hemispherical $10 \mathrm{in}$. photo-multiplier tubes (PMTs), arranged as in Fig. 1 [3-5]. The detector has been operated in partial configurations since March 2006 and was completed in May 2008 [2]. First results are published in [6,7].

A large flux of muons produced in the atmosphere by high energy cosmic rays passes through the detector. The Cherenkov light produced in water by a muon with an energy in excess of $4 \mathrm{GeV}$ can generate correlated signals in adjacent storeys. Background light, mainly due to ${ }^{40} \mathrm{~K}$ decays and bioluminescent organisms, is also present [8]. Although a single ${ }^{40} \mathrm{~K}$ decay will produce a relatively small number of Cherenkov photons, it can be observed as a coincidence between neighbouring PMTs within a storey if the decay occurs in the vicinity. Bioluminescence is a single photon process and contributes only to the accidental coincidence rate $[9,10]$.

The present analysis employs a coincidence method to identify ${ }^{40} \mathrm{~K}$ decays and low-energy atmospheric muons on a statistical basis. The flux of atmospheric muons is measured at 24 different depths. The ${ }^{40} \mathrm{~K}$ signal is used to calibrate the efficiency of the PMTs.

The paper is organized as follows. The calibration procedure is introduced in Section 2. The method to determine the muon flux is presented in Section 3. The depth dependence is discussed in Section 4.

\section{Calibration with potassium-40}

Potassium-40 is a radioactive isotope naturally present in the sea water. The decay ${ }^{40} \mathrm{~K} \rightarrow \mathrm{e}^{-} \bar{v}_{e}{ }^{40} \mathrm{Ca}$ yields an electron with an energy up to $1.3 \mathrm{MeV}$. This energy exceeds the Cherenkov threshold for electrons in sea water $(0.25 \mathrm{MeV})$, and is sufficient to produce up to 150 Cherenkov photons. Another source of electrons above the Cherenkov threshold is the Compton scattering of $1.46 \mathrm{MeV}$ photons, which are produced in the process of electron capture ${ }^{40} \mathrm{~K}+\mathrm{e}^{-} \rightarrow{ }^{40} \mathrm{Ar}^{*}+v_{e}$, followed by ${ }^{40} \mathrm{Ar}^{*} \rightarrow{ }^{40} \mathrm{Ar}+\gamma$. If the decay occurs within a few meters of a detector storey, a coincident signal may be recorded by two of the three PMTs on the storey. This is referred to as a local coincidence. An example of the distribution of the measured time differences between hits in neighbouring PMTs

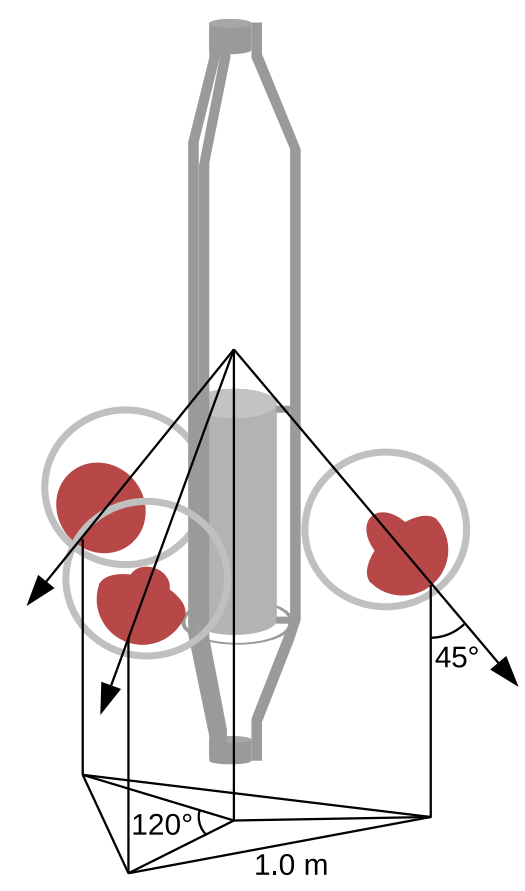

Fig. 1. Schematic view of one of the detector storeys. The storey contains three transparent glass vessels (17 in. diameter), each housing a 10 in. PMT. The PMTs are oriented downwards at an angle of $45^{\circ}$ from the vertical and with an angle of $120^{\circ}$ from each other. The distance between the centers of the photo-cathodes of the PMTs is $1.0 \mathrm{~m}$. The storey also contains an electronics module for the readout of the PMTs. 

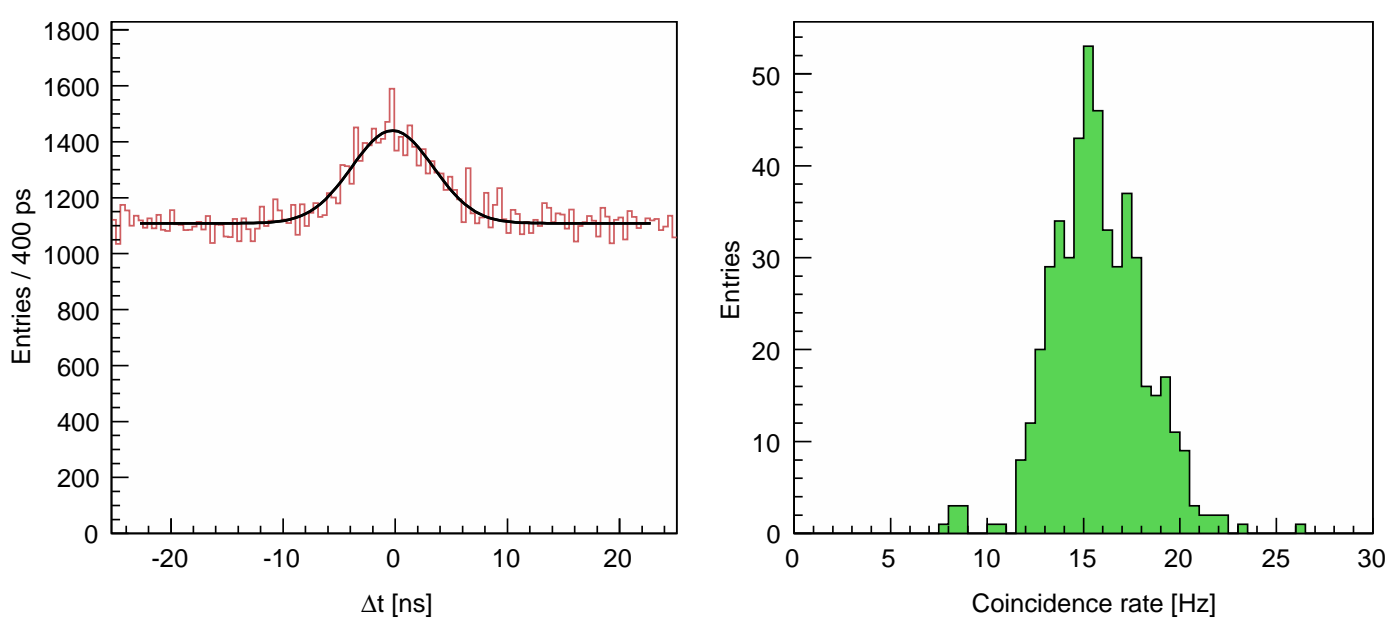

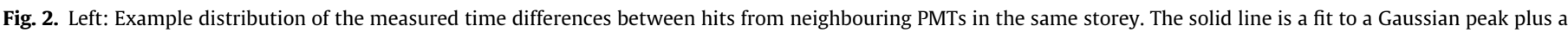
flat background (see text). Right: Histogram of the coincidence rates (background subtracted) observed in the 12 detector lines.

in the same storey is shown in Fig. 2 (left). A clear peak around 0 ns is visible. This peak is mainly due to single ${ }^{40} \mathrm{~K}$ decays producing coincident signals. The data has been fitted to a sum of a Gaussian distribution and a flat background. The full width half maximum of the Gaussian function is about 9 ns. This width is mainly due to the spatial distribution of the ${ }^{40} \mathrm{~K}$ decays around the storey. The rate of genuine coincidences is given by the integral under the peak and can be extracted from the distribution by subtracting the flat background of random coincidences. The positions of the peaks of the time distributions for different pairs of PMTs in the same storey are consistent with zero and are used to cross-check the time offsets computed by the time calibration system [11].

The spatial uniformity and temporal stability of the rate of ${ }^{40} \mathrm{~K}$ decays is used to calibrate the relative efficiencies of the PMTs. For every detector storey three coincidence rates, $r_{12}, r_{23}$ and $r_{31}$, are measured, which are related to the efficiencies of the three PMTs, $s_{1}, s_{2}$ and $s_{3}$, where the subscript refers to the position of the PMT inside the storey. The efficiencies are derived from the measured rates assuming that the rate is proportional to the efficiency of each module, $r_{i j} \propto s_{i} s_{j}$. From a combined analysis of the coincidence rates and single rates, the uncertainty of the extracted efficiencies was estimated to be $5 \%$. An average coincidence rate of $16 \pm 2 \mathrm{~Hz}$ is observed. This agrees with the expected value of $19 \pm 3 \mathrm{~Hz}$, obtained from a dedicated Monte Carlo simulation. The distribution of observed coincidence rates is shown in Fig. 2 (right). The spread of the coincidence rates corresponds to a $10 \%$ spread in the PMT and front-end electronics efficiencies. The measured efficiencies have an overall normalization uncertainty of about $15 \%$, originating from the limited knowledge of the quantum efficiency and angular response of the PMT.

\section{Measurement of the atmospheric muon flux}

A muon passing through the detector can produce correlated signals in several storeys of the line. In the following, hits from two adjacent storeys with a local coincidence in each storey are considered, where the local coincidence is defined as a pair of hits detected by two different PMTs of the same storey within a \pm 20 ns time window. The rate of accidental coincidence events between adjacent storeys is about $0.1 \mathrm{~Hz}$. The data have been recorded during dedicated data taking runs, when bioluminescent activity was low compared to ${ }^{40} \mathrm{~K}$ background.

The distribution of the measured time differences between hits in adjacent storeys is presented in Fig. 3. A clear peak is visible centred around $+20 \mathrm{~ns}$, demonstrating that the majority of muons are

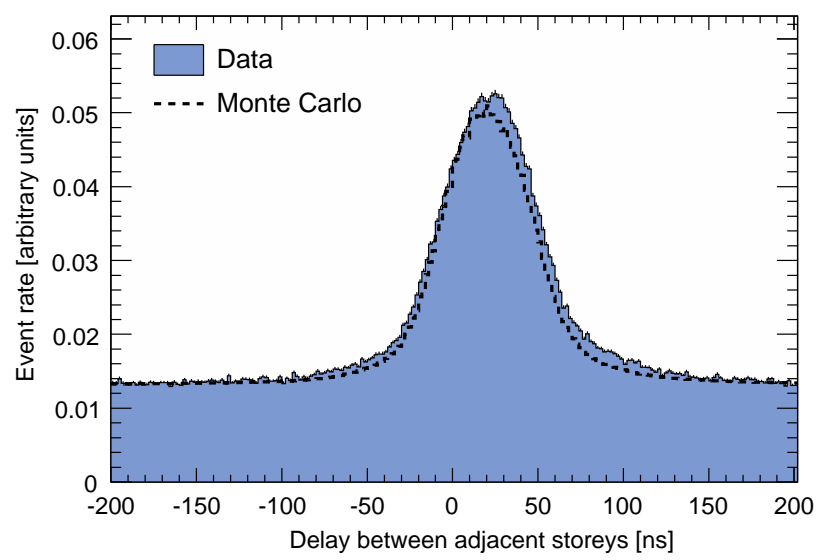

Fig. 3. Distribution of the measured time differences between hits from adjacent storeys (lower-upper). A local coincidence is required in both storeys. The dashed line corresponds to a Monte Carlo simulation based on MUPAGE (see text).

downgoing. The width of the distribution is mainly due to the angular distribution of the atmospheric muons. The flat background is due to random coincidences from ${ }^{40} \mathrm{~K}$ and bioluminescence. The tails, which extend beyond $\pm 65 \mathrm{~ns}$, can be attributed to multiple muons and light scattering. The muon event rate, $R$, is defined as the integral of the peak after subtraction of the flat background. On average, $R$ is found $\approx 0.06 \mathrm{~Hz}$. Since the probability that ${ }^{40} \mathrm{~K}$ decay is seen by two PMTs separated by $14.5 \mathrm{~m}$ is very small, the ${ }^{40} \mathrm{~K}$ contamination in $R$ is negligible.

The results of a Monte Carlo simulation based on MUPAGE [12] are also presented in Fig. 3. The detector response was simulated using a Geant- 4 based model of the PMT angular acceptance and includes the effect of the detector inefficiencies. As can be seen from Fig. 3, the predicted peak is in agreement with the observations.

\section{Depth dependence of the atmospheric muon flux}

The rate of genuine coincidences between adjacent storeys is mainly due to the flux of vertical and nearly vertical muons. The muon flux includes, by definition, the corresponding contributions from multiple muons. The energy threshold for detecting downgoing muons is determined by the minimum track length to reach two adjacent storeys, and is about $4 \mathrm{GeV}$.

The efficiency to detect atmospheric muons can be characterized by a single parameter, $A$, which gives the ratio between the 
event rate and the muon flux, and can be interpreted as an effective area. From the Monte Carlo simulation based on MUPAGE, the value for a pair of nominal storeys is $A=87_{-30}^{+43} \mathrm{~m}^{2}$. The uncertainty originates from the limited knowledge of the quantum efficiency and angular acceptance of the PMTs, as well as uncertainties in the measurements of light absorption length in the sea water $[3,13]$. These three systematic effects induce a normalization uncertainty of about $\pm 15 \%,{ }_{-30}^{+40} \%$ and $\pm 15 \%$, respectively. A low energy cutoff of $1 \mathrm{GeV}$ has been used for the flux integration.

The energy spectrum and angular distribution of the muons change with depth. Therefore, $A$ should be determined as a function of depth. From the Monte Carlo simulation, the difference between the bottom and top storey is found to be less than $1 \%$. This difference has been neglected in the following.

This analysis uses many short calibration runs taken between January 2007 and May 2008. During that period, in November 2007, the detector was extended from 5 to 10 lines. The effective live times of the data samples taken with 5 and 10 lines are 4 and $3 \mathrm{~h}$, respectively. The two subsets of data have been merged together. The number of active storeys on each line and the efficiency of each storey is measured following the calibration procedure described above. From these the average efficiency of all the storeys at the same depth is computed via Monte Carlo simulation. The average efficiency for this method is about $58 \%$ with a systematic uncertainty of less than $10 \%$. Because a coincidence between two storeys is required, a measurement of the event rate can be made at 24 different depths. The event rates are then corrected for the computed efficiencies and converted into flux units using the effective area $A$. The depth dependent muon flux thus obtained is shown in Fig. 4.

The observed muon flux decreases with increasing depth, $h$, as expected from the energy loss of the muon in the water. An exponential function has been used to fit the data, $\Phi(h)=\Phi_{0} \times$ $\exp \left(\left(h_{0}-h\right) / \lambda\right)$. We find $\Phi_{0}=+0.63 /-0.39$ (syst) $\times 10^{-3} \mathrm{~m}^{-2} \mathrm{~s}^{-1}$ at $h_{0}=2200 \mathrm{~m}$, with a slope given by $\lambda=540 \pm 25 \mathrm{~m}$. It is worth noting that the large uncertainty of $A$ only affects the normalization of the measured dependence $\left(\Phi_{0}\right)$, but not the slope $(\lambda)$. The uncertainty in $\lambda$ is dominated by the statistical uncertainties of the individual data points and is given by the fit.

The values obtained from the Monte Carlo can be parametrized in the same way. This yields $\Phi_{0}^{\text {MUPAGE }}=1.08 \times 10^{-3} \mathrm{~m}^{-2} \mathrm{~s}^{-1}$ at $2200 \mathrm{~m}$ and a slope $\lambda^{\text {MUPAGE }}=560 \mathrm{~m}$ (Fig. 4). The data are in agree-

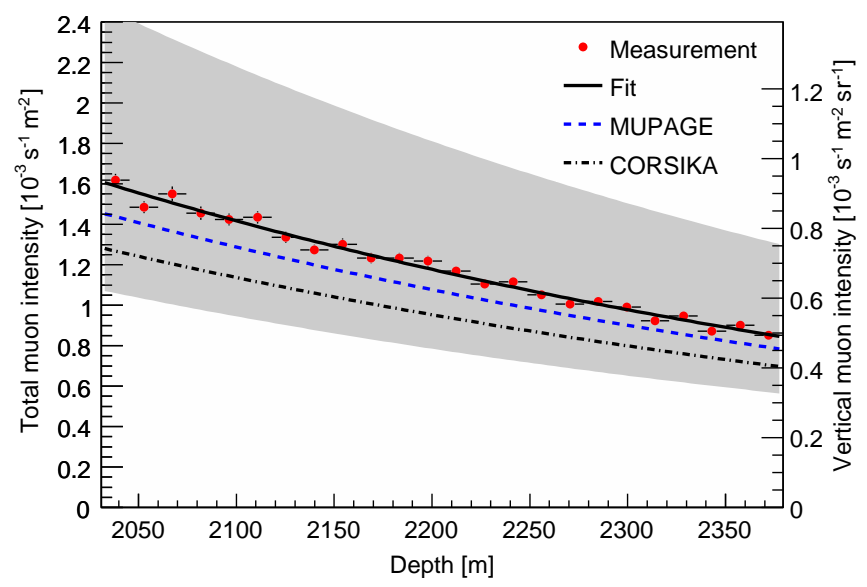

Fig. 4. The measured flux of muons as a function of depth. The results can be interpreted in terms of total muon intensity (left axis) as well as vertical muon intensity (right axis). The grey band shows the normalization uncertainty of the data. The predictions of the Monte Carlo simulations based on MUPAGE and CORSIKA are shown by dashed and dash-dotted lines, respectively. ment with the simulation within a relatively large scale error. A similar result is obtained from a Monte Carlo simulation based on CORSIKA [14]. The simulation incorporates the QGSJET model of hadronic interactions and the NSU model of the primary cosmic ray spectrum [15]. The propagation of muons in the water was simulated with MUSIC [16]. The simulation yields $\Phi_{0}{ }^{\text {CORSIKA }}=0.95 \times 10^{-3} \mathrm{~m}^{-2} \mathrm{~s}^{-1}$ and $\lambda^{\text {CORSIKA }}=570 \mathrm{~m}$. This result, also shown in Fig. 4, is compatible with the calculation from MUPAGE.

The muon flux is often presented in terms of vertical muon intensity $[17,18,6,7]$. The method presented here does not require a deconvolution procedure to obtain the flux at different depths from the measured zenith angle distribution, and provides the depth dependence of the muon flux directly. Hence, the results can be expressed in the form of vertical muon intensity. For this a constant conversion factor $K$, which translates the total flux to the corresponding vertical intensity at the same depth, is used. Using the Monte Carlo simulation, a conversion factor $K=0.58$ $\mathrm{sr}^{-1}$ is found. The uncertainty of $K$ is small compared to other normalization uncertainties. The variations with depth are negligible in the depth range of the ANTARES detector. The result of this conversion is also shown in Fig. 4, right vertical scale. Within uncertainties these results are compatible with the results of [6,7], which refer to a broader depth range, partly including the depth range covered in this analysis.

\section{Summary}

A simple method for the determination of the atmospheric muon flux and its dependence on depth in the ANTARES neutrino telescope has been presented. The method is based on the measurement of photon coincidences between adjacent storeys and has a low energy detection threshold. The atmospheric muon flux has been measured in the depth range from 2030 to $2380 \mathrm{~m}$ with a step of $14.5 \mathrm{~m}$ using a combined data sample of 5 and 10 line detector configurations. The data have been corrected for the presence of dead channels and unequal efficiencies of the PMTs, which were measured with a novel calibration technique using the natural radioactivity of sea water. A reasonable agreement is found between our data and Monte Carlo simulations.

\section{Acknowledgements}

The authors acknowledge the financial support of the funding agencies: Centre National de la Recherche Scientifique (CNRS), Commissariat à l'Energie Atomique (CEA), Commission Européenne (FEDER fund and Marie Curie Program), Région Alsace (contrat CPER), Région Provence-Alpes-Côte d'Azur, Département du Var and Ville de La Seyne-sur-Mer, in France; Bundesministerium für Bildung und Forschung (BMBF), in Germany; Istituto Nazionale di Fisica Nucleare (INFN), in Italy; Stichting voor Fundamenteel Onderzoek der Materie (FOM), Nederlandse organisatie voor Wetenschappelijk Onderzoek (NWO), in The Netherlands; Russian Foundation for Basic Research (RFBR), in Russia; National Authority for Scientific Research (ANCS) in Romania; Ministerio de Ciencia e Innovación (MICINN) and Prometeo of Generalitat Valenciana, in Spain. We also acknowledge the technical support of Ifremer, AIM and Foselev Marine for the sea operation and the CC-IN2P3 for the computing facilities.

\section{References}

[1] E. Aslanides et al., A deep sea telescope for high energy neutrinos. arXiv:astroph/9907432.

[2] J. Carr, for the ANTARES collaboration, First data from the operation of the ANTARES neutrino telescope, J. Phys. Conf. Ser. 136 (2008) 022047. 
[3] P. Amram et al., The ANTARES optical module, Nucl. Instrum. Meth. A 484 (2002) 369.

[4] J.A. Aguilar et al., Study of large hemispherical photomultiplier tubes for the ANTARES neutrino telescope, Nucl. Instrum. Meth. A 555 (2005) 132.

[5] J.A. Aguilar et al., The data acquisition system for the ANTARES neutrino telescope, Nucl. Instrum. Meth. A 570 (2007) 107.

[6] M. Ageron et al., Performance of the first ANTARES detector line, Astropart. Phys. 31 (2009) 277.

[7] J.A. Aguilar et al., Zenith distribution and flux of atmospheric muons measured with the 5-line ANTARES detector, in preparation.

[8] P. Amram et al., Background light in potential sites for the ANTARES undersea neutrino telescope, Astropart. Phys. 13 (2000) 127.

[9] P.M.S. Monk, Physical Chemistry: Understanding our Chemical World, John Wiley and Sons Ltd., Chichester, West Sussex, England, 2004. p. 478.

[10] J.A. Aguilar et al., First results of the instrumentation line for the deep-sea ANTARES neutrino telescope, Astropart. Phys. 26 (2006) 314.

[11] M. Ageron et al., The ANTARES optical beacon system, Nucl. Instrum. Meth. A 578 (2007) 498.
[12] G. Carminati, A. Margiotta, M. Spurio, Atmospheric MUons from PArametric formulas: a fast GEnerator for neutrino telescopes (MUPAGE), Comput. Phys. Commun. 179 (2008) 915.

[13] J.A. Aguilar et al., Transmission of light in deep sea water at the site of the Antares neutrino telescope, Astropart. Phys. 23 (2005) 131.

[14] D. Heck, G. Schatz, T. Thouw, J. Knapp, J.N. Capdevielle, CORSIKA: a Monte Carlo code to simulate extensive air showers, Forschungszentrum Karlsruhe Report FZKA-6019, 1998.

[15] S.I. Nikolsky, I.N. Stamenov, S.Z. Ushev, The composition of cosmic rays at energies of 10 to the 15th eV and higher, Sov. Phys. JETP 60 (1984) 10; S.I. Nikolsky, I.N. Stamenov, S.Z. Ushev, Zh. Eksp. Teor. Fiz. 87 (1984) 18

[16] P. Antonioli, C. Ghetti, E.V. Korolkova, V.A. Kudryavtsev, G. Sartorelli, A threedimensional code for muon propagation through the rock: MUSIC, Astropart. Phys. 7 (1997) 357.

[17] I.A. Belolaptikov et al., The Baikal underwater neutrino telescope: design, performance, and first results, Astropart. Phys. 7 (1997) 263.

[18] E. Andres et al., The AMANDA neutrino telescope: principle of operation and first results, Astropart. Phys. 13 (2000) 1 


\section{AMADEUS-The acoustic neutrino detection test system of the ANTARES deep-sea neutrino telescope}

J.A. Aguilar ${ }^{\text {a }}$, I. Al Samarai ${ }^{\text {b }}$, A. Albert ${ }^{\text {c }}$, M. Anghinolfi ${ }^{\text {d }}$, G. Anton ${ }^{\text {e }}$, S. Anvar ${ }^{\text {f }}$, M. Ardid ${ }^{\text {g }}$, A.C. Assis Jesus $^{\text {h }}$, T. Astraatmadja ${ }^{\mathrm{h}, 1}$, J.-J. Aubert ${ }^{\mathrm{b}}$, R. Auer ${ }^{\mathrm{e}}$, E. Barbarito ${ }^{\mathrm{i}}$, B. Baret $^{\mathrm{j}}$, S. Basa ${ }^{\mathrm{k}}, \mathrm{M}$. Bazzotti ${ }^{\mathrm{l}, \mathrm{m}}$, V. Bertin $^{\mathrm{b}}$, S. Biagi ${ }^{\mathrm{l}, \mathrm{m}}$, C. Bigongiari ${ }^{\mathrm{a}}$, M. Bou-Cabo ${ }^{\mathrm{b}}$, M.C. Bouwhuis ${ }^{\mathrm{h}}$, A. Brown $^{\mathrm{b}}$, J. Brunner ${ }^{\mathrm{b}, 2}, \mathrm{~J}$. Busto ${ }^{\mathrm{b}}$, F. Camarena ${ }^{\mathrm{g}}$, A. Capone ${ }^{\mathrm{n}, \mathrm{o}}$, C. Cârloganu ${ }^{\mathrm{p}}$, G. Carminati ${ }^{\mathrm{l}, \mathrm{m}}$, J. Carr ${ }^{\mathrm{b}}$, B. Cassano ${ }^{\mathrm{i}}$, E. Castorina ${ }^{\mathrm{q}, \mathrm{r}}$, V. Cavasinni ${ }^{\mathrm{q}, \mathrm{r}}$, S. Cecchini ${ }^{\mathrm{m}, \mathrm{s}}$, A. Ceres ${ }^{\mathrm{i}}$, Ph. Charvis ${ }^{\mathrm{t}}$, T. Chiarusi ${ }^{\mathrm{m}}$, N. Chon Sen ${ }^{\mathrm{c}}$, M. Circella ${ }^{\mathrm{i}}$, R. Coniglione ${ }^{\mathrm{u}}$, H. Costantini ${ }^{\mathrm{d}}$, N. Cottini ${ }^{\mathrm{v}}$, P. Coyle $^{\mathrm{b}}$, C. Curtil $^{\mathrm{b}}$, G. De Bonis ${ }^{\mathrm{n}, \mathrm{o}}$, M.P. Decowski ${ }^{\mathrm{h}}$, I. Dekeyser ${ }^{\mathrm{w}}$, A. Deschamps ${ }^{\mathrm{t}}$, C. Distefano ${ }^{\mathrm{u}}$, C. Donzaud $^{\mathrm{j}, \mathrm{x}}$, D. Dornic $^{\mathrm{b}, \mathrm{a}}$, D. Drouhin $^{\mathrm{c}}$, T. Eberl $^{\mathrm{e}}$, U. Emanuele $^{\mathrm{a}}$, J.-P. Ernenwein ${ }^{\mathrm{b}}$, S. Escoffier ${ }^{\mathrm{b}}$, F. Fehr ${ }^{\mathrm{e}}$, C. Fiorello ${ }^{\mathrm{i}}$, V. Flaminio ${ }^{\mathrm{q}, \mathrm{r}}$, U. Fritsch ${ }^{\mathrm{e}}$, J.-L. Fuda ${ }^{\text {w }}$, P. Gay ${ }^{\text {p }, ~ G . ~ G i a c o m e l l i ~}{ }^{\text {l,m }}$, J.P. Gómez-González ${ }^{\mathrm{a}}$, K. Graf ${ }^{\mathrm{e}}$, G. Guillard ${ }^{\mathrm{y}}$, G. Halladjian ${ }^{\mathrm{b}}$, G. Hallewell ${ }^{\text {b }}$, H. van Haren ${ }^{\text {z }}$, A.J. Heijboer ${ }^{\text {h }}$, E. Heine ${ }^{\text {h }}$, Y. Hello ${ }^{\text {t }}$, J.J. Hernández-Rey ${ }^{\text {a }}$, B. Herold ${ }^{\mathrm{e}}$, J. Hößl ${ }^{\text {e }}$, M. de Jong ${ }^{\text {h,1 }}$, N. Kalantar-Nayestanaki ${ }^{\text {aa }}$, O. Kalekin ${ }^{\mathrm{e}}$, A. Kappes ${ }^{\mathrm{e}}$, U. Katz ${ }^{\mathrm{e}}$, P. Keller ${ }^{\mathrm{b}}$, P. Kooijman ${ }^{\text {h,ab,ac }}$, C. Kopper ${ }^{\mathrm{e}}$, A. Kouchner ${ }^{\mathrm{j}}$, W. Kretschmer ${ }^{\mathrm{e}}$, R. Lahmann ${ }^{\mathrm{e}, *}$, P. Lamare ${ }^{\mathrm{f}}$, G. Lambard $^{\mathrm{b}}$, G. Larosa ${ }^{g}$, H. Laschinsky ${ }^{\mathrm{e}}$, H. Le Provost ${ }^{\mathrm{f}}$, D. Lefèvre ${ }^{\mathrm{w}}$, G. Lelaizant $^{\mathrm{b}}$, , G. Lim $^{\text {h,ac }}$, D. Lo Presti ${ }^{\text {ad }}$, H. Loehner ${ }^{\text {aa }}$, S. Loucatos ${ }^{\text {v }}$, F. Louis ${ }^{\mathrm{f}}$, F. Lucarelli ${ }^{\mathrm{n}, \mathrm{o}}$, S. Mangano ${ }^{\mathrm{a}}$, M. Marcelin ${ }^{\mathrm{k}}$, A. Margiotta ${ }^{\mathrm{l}, \mathrm{m}}$, J.A. Martinez-Mora ${ }^{\mathrm{g}}$, A. Mazure ${ }^{\mathrm{k}}$, M. Mongelli ${ }^{\mathrm{i}}$, T. Montaruli ${ }^{\mathrm{i}, \mathrm{ae}}$, M. Morganti ${ }^{\mathrm{q}, \mathrm{r}}$, L. Moscoso $^{\mathrm{v}, \mathrm{j}}, \mathrm{H}$ Motz $^{\mathrm{e}}$, C. Naumann ${ }^{\mathrm{v}, 4}$, M. Neff ${ }^{\mathrm{e}}$, R. Ostasch ${ }^{\mathrm{e}}$, D. Palioselitis ${ }^{\mathrm{h}}$, G.E. Păvălaș ${ }^{\text {af }}$, P. Payre $^{\mathrm{b}}$, J. Petrovic ${ }^{\mathrm{h}}$, N. Picot-Clemente ${ }^{\mathrm{b}}$, C. Picq ${ }^{\mathrm{v}}$, V. Popa ${ }^{\text {af }}$, T. Pradier $^{\mathrm{y}}$, E. Presani $^{\mathrm{h}}$, C. Racca $^{\mathrm{c}}$, A. Radu $^{\text {af }}$, C. Reed $^{\mathrm{b}, \mathrm{h}}$, G. Riccobene ${ }^{\mathrm{u}}$, C. Richardt ${ }^{\mathrm{e}}$, M. Rujoiu ${ }^{\text {af }}$, M. Ruppi ${ }^{\mathrm{i}, 3}$, G.V. Russo ${ }^{\text {ad }}$, F. Salesa ${ }^{\mathrm{a}}$, P. Sapienza ${ }^{\mathrm{u}}$, F. Schöck $^{\mathrm{e}}$, J.-P. Schuller v ${ }^{\text {, R. Shanidze }}{ }^{\text {, }}$ F. Simeone ${ }^{o}$, M. Spurio ${ }^{1, m}$, J.J.M. Steijger ${ }^{\text {h }}$, Th. Stolarczyk ${ }^{\text {v }}$, M. Taiuti ${ }^{\text {ag,d }}$, C. Tamburini ${ }^{w}$, L. Tasca ${ }^{\mathrm{k}}$, S. Toscano ${ }^{\mathrm{a}}$, B. Vallage ${ }^{\mathrm{v}}$, V. Van Elewyck ${ }^{\mathrm{j}}$, G. Vannoni ${ }^{\mathrm{v}}$, M. Vecchi $^{\mathrm{n}, \mathrm{b}}$, P. Vernin ${ }^{\mathrm{v}}$, G. Wijnker ${ }^{\mathrm{h}}$, E. de Wolf ${ }^{\mathrm{h}, \mathrm{ac}}$, H. Yepes ${ }^{\mathrm{a}}$, D. Zaborov ${ }^{\mathrm{ah}}$, J.D. Zornoza ${ }^{\mathrm{a}}$, J. Zúñiga ${ }^{\mathrm{a}}$

a IFIC - Instituto de Física Corpuscular, Edificios Investigación de Paterna, CSIC - Universitat de València, Apdo. de Correos 22085,46071 Valencia, Spain

${ }^{\mathrm{b}}$ CPPM - Centre de Physique des Particules de Marseille, CNRS/IN2P3 et Université de la Méditerranée, 163 Avenue de Luminy, Case 902, 13288 Marseille Cedex 9, France

${ }^{\mathrm{c}}$ GRPHE - Institut Universitaire de Technologie de Colmar, 34 rue du Grillenbreit BP 50568, 68008 Colmar, France

${ }^{\mathrm{d}}$ INFN - Sezione di Genova, Via Dodecaneso 33, 16146 Genova, Italy

e Friedrich-Alexander-Universität Erlangen-Nürnberg, Erlangen Centre for Astroparticle Physics, Erwin-Rommel-Str. 1, 91058 Erlangen, Germany

${ }^{\mathrm{f}}$ Direction des Sciences de la Matière - Institut de Recherche sur les lois fondamentales de l'Univers - Service d'Electronique des Détecteurs et d'Informatique, CEA Saclay,

91191 Gif-sur-Yvette Cedex, France

${ }^{\mathrm{g}}$ Institut d'Investigació per a la Gestió Integrada de Zones Costaneres (IGIC) - Universitat Politècnica de València. C/ Paranimf 1., 46730 Gandia, Spain

${ }^{\mathrm{h}}$ FOM Instituut voor Subatomaire Fysica Nikhef, Science Park 105, 1098 XG Amsterdam, The Netherlands

i INFN - Sezione di Bari, Via E. Orabona 4, 70126 Bari, Italy

${ }^{\mathrm{j}}$ APC - Laboratoire AstroParticule et Cosmologie, UMR 7164 (CNRS, Université Paris 7 Diderot, CEA, Observatoire de Paris) 10, rue Alice Domon et Léonie Duquet, 75205 Paris Cedex 13, France

${ }^{\mathrm{k}}$ LAM - Laboratoire d'Astrophysique de Marseille, Pôle de l'Étoile Site de Château-Gombert, rue Frédéric Joliot-Curie 38, 13388 Marseille Cedex 13, France

${ }^{1}$ Dipartimento di Fisica dell'Università, Viale Berti Pichat 6/2, 40127 Bologna, Italy

${ }^{\mathrm{m}}$ INFN - Sezione di Bologna, Viale Berti Pichat 6/2, 40127 Bologna, Italy

n Dipartimento di Fisica dell'Università La Sapienza, P.le Aldo Moro 2, 00185 Roma, Italy

${ }^{\circ}$ INFN - Sezione di Roma, P.le Aldo Moro 2, 00185 Roma, Italy

p Clermont Université, Université Blaise Pascal, CNRS/IN2P3, Laboratoire de Physique Corpusculaire, BP 10448, 63000 Clermont-Ferrand, France

${ }^{\mathrm{q}}$ Dipartimento di Fisica dell'Università, Largo B. Pontecorvo 3, 56127 Pisa, Italy

${ }^{\mathrm{r}}$ INFN - Sezione di Pisa, Largo B. Pontecorvo 3, 56127 Pisa, Italy

${ }^{s}$ INAF-IASF, via P. Gobetti 101, 40129 Bologna, Italy

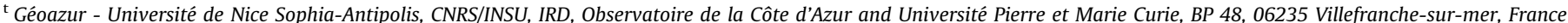

" INFN - Laboratori Nazionali del Sud (LNS), Via S. Sofia 62, 95123 Catania, Italy

${ }^{v}$ Direction des Sciences de la Matière - Institut de recherche sur les lois fondamentales de l'Univers - Service de Physique des Particules, CEA Saclay, 91191 Gif-sur-Yvette Cedex, France

${ }^{\mathrm{w}}$ COM - Centre d'Océanologie de Marseille, CNRS/INSU et Université de la Méditerranée, 163 Avenue de Luminy, Case 901, 13288 Marseille Cedex 9, France

${ }^{\mathrm{x}}$ Université Paris-Sud 11 - Département de Physique, 91403 Orsay Cedex, France 


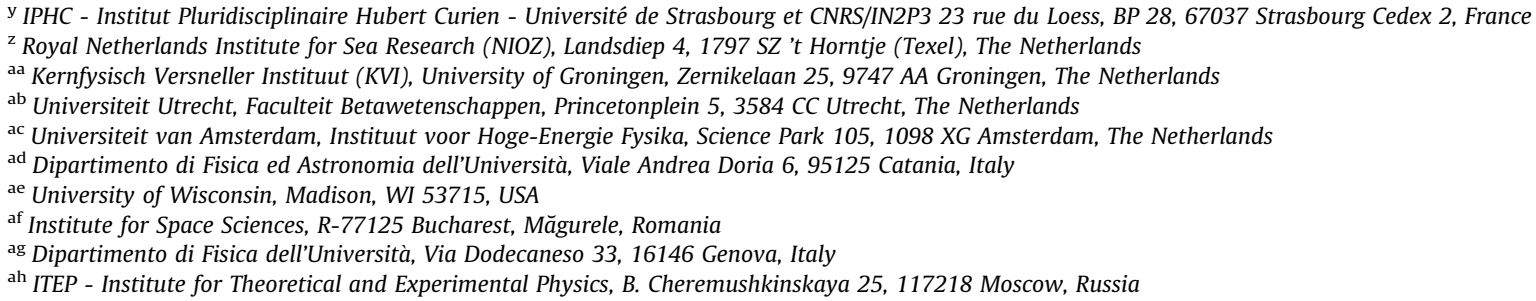

\section{A R T I C L E I N F O}

\section{Article history:}

Received 3 May 2010

Received in revised form 13 September 2010

Accepted 14 September 2010

Available online 21 September 2010

Keywords:

AMADEUS

ANTARES

Neutrino telescope

Acoustic neutrino detection

Thermo-acoustic model

\begin{abstract}
A B S T R A C T
The AMADEUS (ANTARES Modules for the Acoustic Detection Under the Sea) system which is described in this article aims at the investigation of techniques for acoustic detection of neutrinos in the deep sea. It is integrated into the ANTARES neutrino telescope in the Mediterranean Sea. Its acoustic sensors, installed at water depths between 2050 and $2300 \mathrm{~m}$, employ piezo-electric elements for the broad-band recording of signals with frequencies ranging up to $125 \mathrm{kHz}$. The typical sensitivity of the sensors is around $-145 \mathrm{~dB}$ re $1 \mathrm{~V} / \mu \mathrm{Pa}$ (including preamplifier). Completed in May 2008, AMADEUS consists of six "acoustic clusters", each comprising six acoustic sensors that are arranged at distances of roughly $1 \mathrm{~m}$ from each other. Two vertical mechanical structures (so-called lines) of the ANTARES detector host three acoustic clusters each. Spacings between the clusters range from 14.5 to $340 \mathrm{~m}$. Each cluster contains custom-designed electronics boards to amplify and digitise the acoustic signals from the sensors. An on-shore computer cluster is used to process and filter the data stream and store the selected events. The daily volume of recorded data is about $10 \mathrm{~GB}$. The system is operating continuously and automatically, requiring only little human intervention. AMADEUS allows for extensive studies of both transient signals and ambient noise in the deep sea, as well as signal correlations on several length scales and localisation of acoustic point sources. Thus the system is excellently suited to assess the background conditions for the measurement of the bipolar pulses expected to originate from neutrino interactions.
\end{abstract}

(c) 2010 Elsevier B.V. All rights reserved.

\section{Introduction}

Measuring acoustic pressure pulses in huge underwater acoustic arrays is a promising approach for the detection of cosmic neutrinos with energies exceeding $100 \mathrm{PeV}$. The pressure signals are produced by the particle cascades that evolve when neutrinos interact with nuclei in water. The resulting energy deposition in a cylindrical volume of a few centimetres in radius and several metres in length leads to a local heating of the medium which is instantaneous with respect to the hydrodynamic time scales. This temperature change induces an expansion or contraction of the medium depending on its volume expansion coefficient. According to the thermo-acoustic model $[1,2]$, the accelerated motion of the heated volume-a micro-explosionforms a pressure pulse of bipolar shape which propagates in the surrounding medium. Coherent superposition of the elementary sound waves, produced over the volume of the energy deposition, leads to a propagation within a flat disc-like volume (often referred to as pancake) in the direction perpendicular to the axis of the particle cascade. After propagating several hundreds of metres in sea water, the pulse has a characteristic frequency spectrum that is expected to peak around $10 \mathrm{kHz}$ [3-5]. Given the strongly anisotropic propagation pattern of the sound waves, the details of the pressure pulse, namely its amplitude, asymmetry and frequency spectrum, depend on the distance and angular position of the observer with respect to the particle cascade

\footnotetext{
* Corresponding author. Tel.: +4991318527147.

E-mail address: robert.lahmann@physik.uni-erlangen.de (R. Lahmann).

${ }^{1}$ Also at University of Leiden, the Netherlands.

2 On leave at DESY, Platanenallee 6, 15738 Zeuthen, Germany.

${ }^{3}$ Now at Altran Italia, Corso Sempione 66, 20100 Milano, Italy.

${ }^{4}$ Now at LPNHE - Laboratoire de Physique Nucléaire et des Hautes Énergies, UMR 7585, 4 place Jussieu - 75252 Paris Cedex 05, France.
}

induced by the neutrino interaction [3]. Besides sea water, which is the medium under investigation in the case of the AMADEUS (ANTARES Modules for the Acoustic Detection Under the Sea) project, ice [6] and fresh water [7] are investigated as media for acoustic detection of neutrinos. Studies in sea water are also pursued by other groups using military arrays of hydrophones (i.e. underwater microphones) [8,9] or exploiting other existing deep sea infrastructures [10].

Two major advantages over an optical neutrino telescope motivate studying acoustic detection. First, the attenuation length in sea water is about $5 \mathrm{~km}(1 \mathrm{~km})$ for $10 \mathrm{kHz}(20 \mathrm{kHz})$ signals. This is one to two orders of magnitude larger than for visible light with a maximum attenuation length of about $60 \mathrm{~m}$. The second advantage is the more compact sensor design and simpler readout electronics for acoustic measurements. Since on the other hand the speed of sound ${ }^{5}$ is small compared to the speed of light, coincidence windows between two spatially separated sensors are correspondingly large. Furthermore, the signal amplitude is relatively small compared to the acoustic background in the sea, resulting in a high trigger rate at the level of individual sensors and making the implementation of efficient online data reduction techniques essential. To reduce the required processing time without sacrificing the advantages given by the large attenuation length, the concept of spatially separated clusters of acoustic sensors is used in AMADEUS. Online data filtering is then predominantly applied to the closely arranged sensors within a cluster.

The AMADEUS project was conceived to perform a feasibility study for a potential future large-scale acoustic neutrino detector. For this purpose, a dedicated array of acoustic sensors was

\footnotetext{
${ }^{5}$ The speed of sound in sea water depends on temperature, salinity and pressure, i.e. depth. A good guideline value for the speed of sound at the location of AMADEUS is $1500 \mathrm{~m} / \mathrm{s}$.
} 
integrated into the ANTARES neutrino telescope $[11,12]$. In the context of AMADEUS, the following aims are being pursued:

- Long-term background investigations (levels of ambient noise, spatial and temporal distributions of sources, rate of neutrinolike signals).

- Investigation of spatial correlations for transient signals and for persistent background on different length scales.

- Development and tests of data filter and reconstruction algorithms.

- Investigation of different types of acoustic sensors and sensing methods.

- Studies of hybrid (acoustic and optical) detection methods.

In particular the knowledge of the rate and correlation length of neutrino-like acoustic background events is a prerequisite for estimating the sensitivity of a future acoustic neutrino detector.

The focus of this paper is the AMADEUS system within the ANTARES detector. In Section 2, an overview of the system is given, with particular emphasis on its integration into the ANTARES detector. In Section 3, the system components are described and in Section 4 the system performance is discussed. The characteristic features of the AMADEUS system are mainly determined by the acoustic sensors and the custom-designed electronics board, which performs the off-shore processing of the analogue signals from the acoustic sensors. These two components are discussed in detail in Sections 3.1 and 3.4.

\section{Overview of the AMADEUS system}

\subsection{The ANTARES detector and its sub-system AMADEUS}

AMADEUS is integrated into the ANTARES neutrino telescope $[11,12]$, which was designed to detect neutrinos by measuring the Cherenkov light emitted along the tracks of relativistic secondary muons generated in neutrino interactions. A sketch of the detector, with the AMADEUS modules highlighted, is shown in Fig. 1. The detector is located in the Mediterranean Sea at a water depth of about $2500 \mathrm{~m}$, about $40 \mathrm{~km}$ south of the town of Toulon

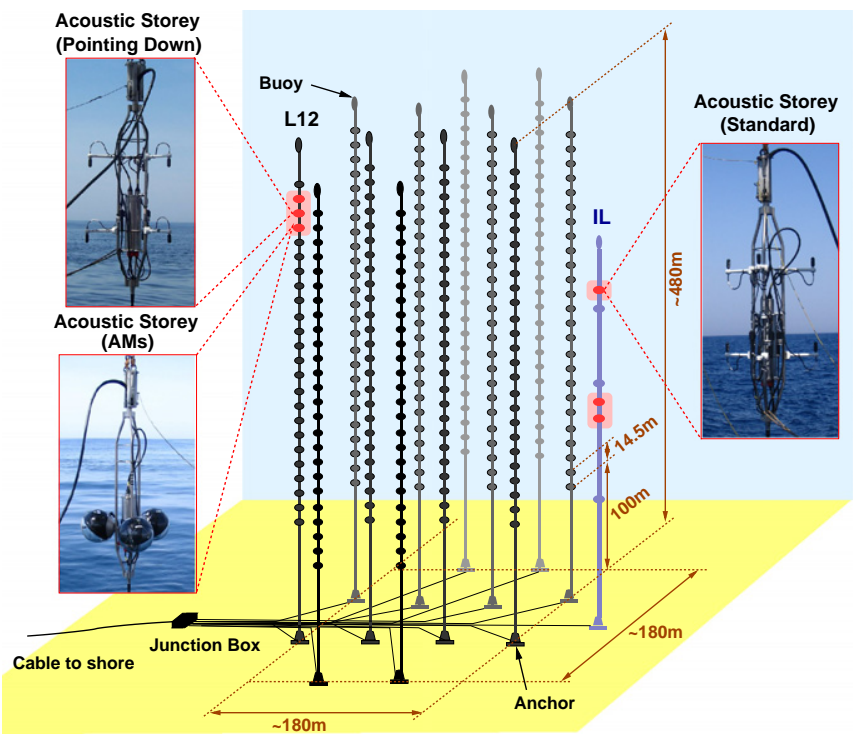

Fig. 1. A sketch of the ANTARES detector. The six acoustic storeys are highlighted and their three different setups are shown (see text for details). L12 and IL denote the 12 th detection line and the Instrumentation Line, respectively. on the French coast and was completed in May 2008. It comprises 12 vertical structures, the detection lines. Each detection line holds up to 25 storeys that are arranged at equal distances of $14.5 \mathrm{~m}$ along the line, starting at about $100 \mathrm{~m}$ above the sea bed and interlinked by electro-optical cables. A standard storey consists of a titanium support structure, holding three Optical Modules [13] (each one consisting of a photomultiplier tube (PMT) inside a water-tight pressure-resistant glass sphere) and one Local Control Module ( $L C M)$. The LCM consists of a cylindrical titanium container and the off-shore electronics within that container (see Section 3.3).

A 13th line, called Instrumentation Line (IL), is equipped with instruments for monitoring the environment. It holds six storeys. For two pairs of consecutive storeys in the IL, the vertical distance is increased to $80 \mathrm{~m}$. Each line is fixed on the sea floor by an anchor equipped with electronics and held taut by an immersed buoy. An interlink cable connects each line to the Junction Box from where the main electro-optical cable provides the connection to the shore station.

The ANTARES lines are free to swing and twist in the undersea current. In order to determine the positions of the storey with a precision of about $20 \mathrm{~cm}$-which is necessary to achieve the required pointing precision for neutrino astronomy-the detector is equipped with an acoustic positioning system [14]. The system employs an acoustic transceiver at the anchor of each line and four autonomous transponders positioned around the 13 lines. Along each detection line, five positioning hydrophones receive the signals emitted by the transceivers. By performing multiple time delay measurements and using these to triangulate the positions of the individual hydrophones, the line shapes can be reconstructed relative to the positions of the emitters. Currently, the sequence of positioning emissions is repeated every 2 min.

In AMADEUS, acoustic sensing is integrated in the form of acoustic storeys that are modified versions of standard ANTARES storeys, in which the Optical Modules are replaced by customdesigned acoustic sensors. Dedicated electronics is used for the digitisation and pre-processing of the analogue signals. The acoustic storeys are equivalent to the acoustic clusters introduced in Section 1.

The AMADEUS system comprises a total of six acoustic storeys: three on the IL, which started data taking in December 2007, and three on the 12th detection line (Line 12), which was connected to shore in May 2008. AMADEUS is now fully functional and routinely taking data with 34 sensors. Two out of 36 hydrophones became inoperational during their deployment. In both cases, the defect was due to pressurisation.

The acoustic storeys on the IL are located at 180, 195, and $305 \mathrm{~m}$ above the sea floor. On Line 12, which is anchored at a horizontal distance of about $240 \mathrm{~m}$ from the IL, the acoustic storeys are positioned at heights of 380,395 , and $410 \mathrm{~m}$ above the sea floor. With this setup, the maximum distance between two acoustic storeys is $340 \mathrm{~m}$. AMADEUS hence covers three length scales: spacings of the order of $1 \mathrm{~m}$ between sensors within a storey (i.e. an acoustic cluster); intermediate distances of $14.5 \mathrm{~m}$ between adjacent acoustic storeys within a line; and large scales from about $100 \mathrm{~m}$ vertical distance on the IL up to $340 \mathrm{~m}$ between storeys on different lines. The sensors within a cluster allow for efficient triggering of transient signals and for direction reconstruction. The combination of the direction information from different acoustic storeys yields (after verifying the consistency of the signal arrival times at the respective storeys) the position of an acoustic source [15]. The AMADEUS system includes time synchronisation and a continuously operating data acquisition setup and is in principle scalable to a largevolume detector. 


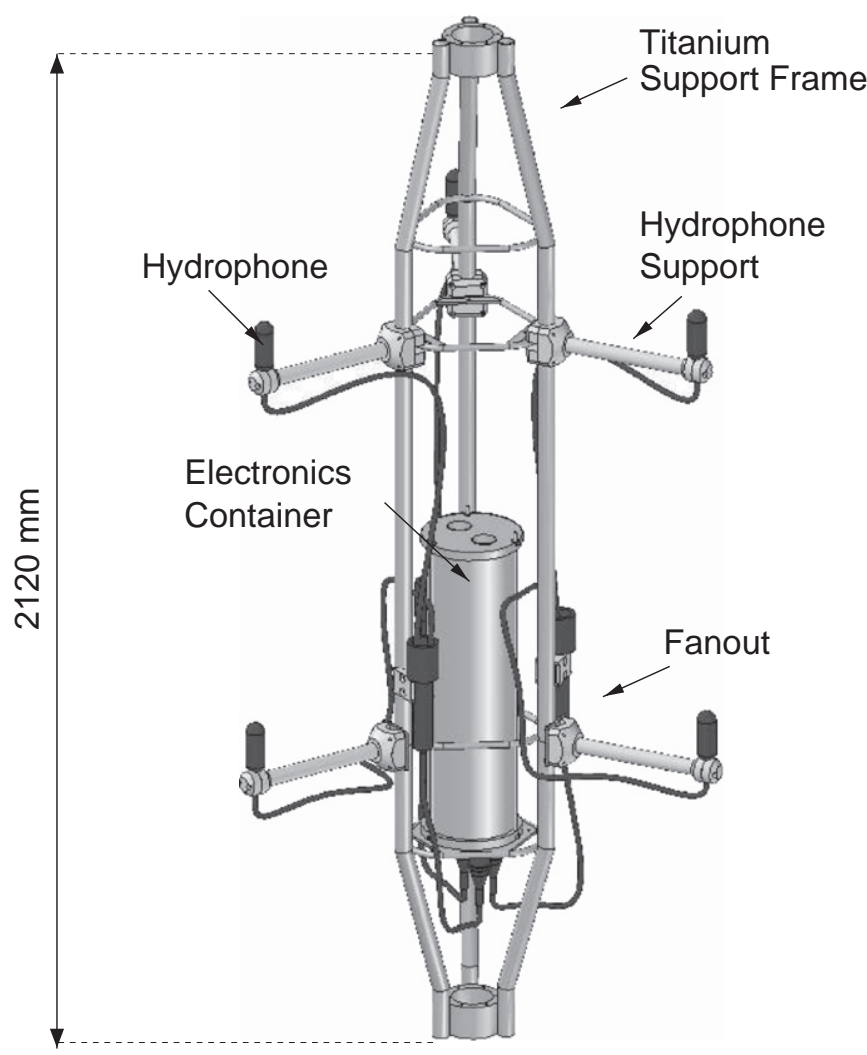

Fig. 2. Drawing of a standard acoustic storey, or acoustic cluster, with hydrophones.

\subsection{Acoustic storeys}

Two types of sensing devices are used in AMADEUS: hydrophones and Acoustic Modules (AMs). The sensing principle is in both cases based on the piezo-electric effect and is discussed in Section 3.1. For the hydrophones, the piezo-elements are coated in polyurethane, whereas for the AMs they are glued to the inside of standard glass spheres which are normally used for Optical Modules. Fig. 2 shows the design of a standard acoustic storey with hydrophones.

Fig. 3 shows the three different designs of acoustic storeys installed in AMADEUS. The acoustic storeys on the IL house hydrophones only, whereas the lowermost acoustic storey of Line 12 holds AMs. The hydrophones are mounted to point upwards, except for the central acoustic storey of Line 12, where they point downwards. The sensitivity of the hydrophones is largely reduced at their cable junctions and therefore shows a strong dependence on the polar angle. The different configurations allow for investigating the anisotropy of ambient noise, which is expected to originate mainly from the sea surface.

Three of the five storeys holding hydrophones are equipped with commercial models, dubbed "HTI hydrophones", 6 and the other two with hydrophones, described in detail in Section 3.1, developed and produced at the Erlangen Centre for Astroparticle Physics (ECAP).

\subsection{Design principles}

A fundamental design guideline for the AMADEUS system has been to use existing ANTARES hardware and software as much as

\footnotetext{
${ }^{6}$ Custom produced by High Tech Inc (HTI) in Gulfport, MS (USA).
}

possible. This eases the operation of the system within the environment of the ANTARES neutrino telescope; at the same time, the design efforts were kept to a minimum and new quality assurance and control measures had to be introduced only for the additional components. These were subjected to intensive testing procedures, in particular in view of the hostile environment due to the high water pressure of up to 240 bar and the salinity of the water.

In order to integrate the AMADEUS system into the ANTARES neutrino telescope, design and development efforts in the following basic areas were necessary:

- The development of acoustic sensing devices that replace the Optical Modules of standard ANTARES storeys and of the cables to route the signals into the electronics container.

- The development of an off-shore acoustic digitisation and preprocessing board.

- The setup of an on-shore server cluster for the online processing of the acoustic data and the development of the online software.

- The development of offline reconstruction and simulation software.

Six acoustic sensors per storey were implemented. This number was the maximum compatible with the design of the LCM and the bandwidth of data transmission to shore. Furthermore, the acoustic storeys were designed such that their size did not exceed the size of the standard ANTARES storeys in radial dimension, hence assuring compatibility with the deployment procedure of the ANTARES lines.

\subsection{The AMADEUS-0 test apparatus}

In March 2005, a full-scale mechanical prototype line for the ANTARES detector was deployed and subsequently recovered [16]. This line, dubbed Line 0 , contained no photomultipliers and no readout electronics. Instead, an autonomous data logging system and shore-based optical time-domain reflectometry were used to record the status of the setup.

Line 0 provided a well-suited environment to study the properties of the acoustic sensors in situ at a time when the readout electronics for AMADEUS was still in the planning phase and the piezo-preamplifier setup in the design phase. For this purpose, an autonomous system within a standard LCM container, the AMADEUS-0 device, was integrated into Line 0 . It recorded acoustic signals at the ANTARES site using five piezo-sensors with custom-designed preamplifiers with an overall sensitivity of about $-120 \mathrm{~dB}$ re $1 \mathrm{~V} / \mu \mathrm{Pa}$ in the range from 5 to $50 \mathrm{kHz}$, glued to the inside of the LCM container. A battery-powered readout and data logging system was devised and implemented using commercially available components. The system was further equipped with a timing mechanism to record data over two predefined periods: The first one lasted for about $10 \mathrm{~h}$ and included the deployment of the line. During this period, a total of $2: 45 \mathrm{~h}$ of data were recorded over several intervals. In the second period, with the line installed on the sea floor, 1:45 h of data were taken over a period of $3: 30 \mathrm{~h}$ until the battery power was exhausted.

The analysis of the data [17] provided valuable information for the design of the AMADEUS system. In particular, the level of the recorded noise allowed for tuning the sensitivity and frequency response of the preamplifiers and amplifiers. A filtered amplitude distribution is shown in Fig. 4, where signals saturating the readout electronics have been removed. The Gaussian fit shown in the figure is a measure of the combined ambient noise of the deep sea and inherent noise of the system, while the excess of data is 
a

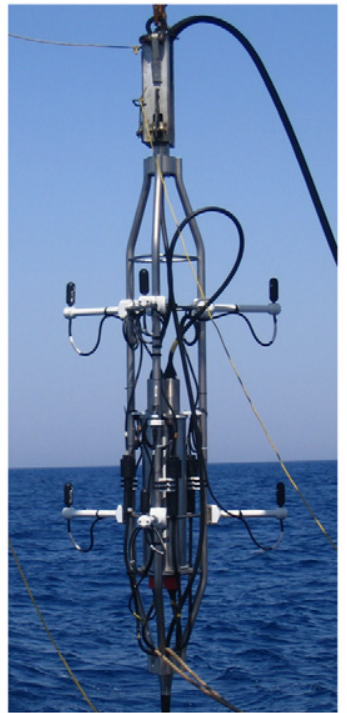

b

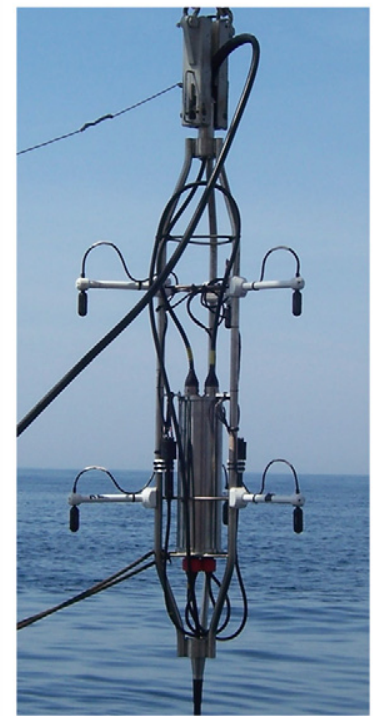

C

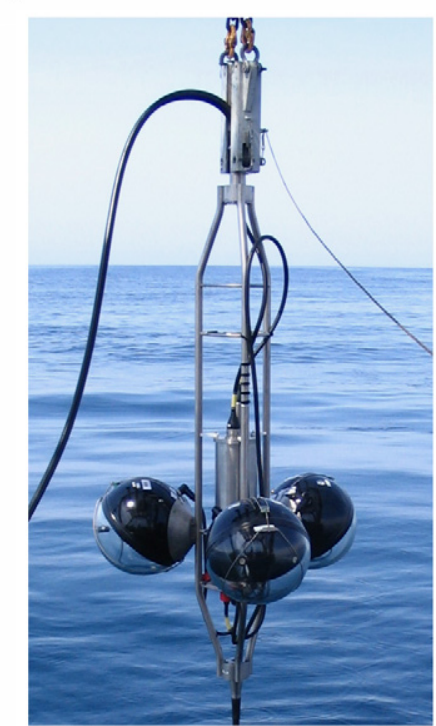

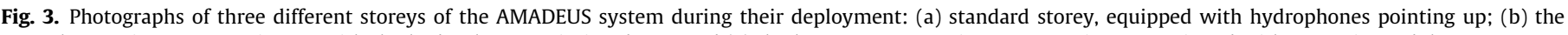
central acoustic storey on Line 12 with the hydrophones pointing down; and (c) the lowermost acoustic storey on Line 12 equipped with Acoustic Modules.

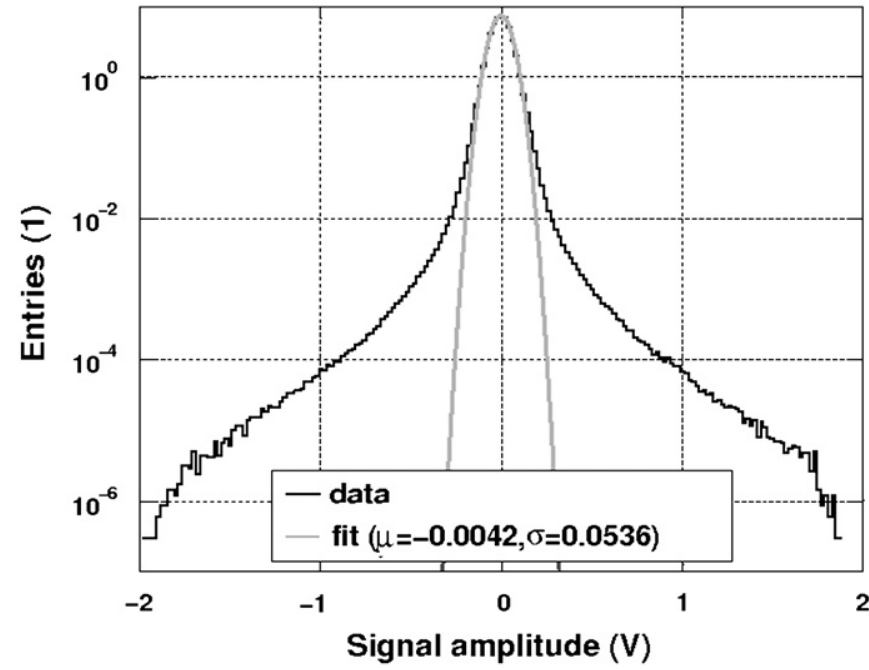

Fig. 4. Normalised distribution of signal amplitudes for all data recorded with the AMADEUS-0 device. High amplitude $(>2 \mathrm{~V})$ signals, saturating the readout electronics, have been removed. A Gaussian fit to the data yields mean $\mu$ and standard deviation $\sigma$.

due to transient signals. This shows that the sensitivity of the system is well matched to record background noise while at the same time allowing for a wide dynamic range of transient signals. A comparable overall sensitivity was hence chosen for the AMADEUS setup. The design of the commercial readout electronics proved to be not suitable in terms of long-term stability and the response to signals that saturated the readout electronics. This experience was returned to the design of the AMADEUS readout electronics, which will be described in Section 3.4.

\section{System components}

\subsection{The acoustic sensors}

The fundamental components of both the hydrophones and the AMs, collectively referred to as acoustic sensors, are piezo-electrical ceramic elements, converting pressure waves into voltage signals [18], and preamplifiers. In this subsection, the hydrophones, the AM sensors, and the calibration of their sensitivity will be discussed.

\subsubsection{Hydrophones}

A schematic drawing of an ECAP hydrophone is shown in Fig. 5. For these hydrophones, ${ }^{7}$ two-stage preamplifiers were used: adapted to the capacitive nature of the piezo-elements and the low induced voltages, the first preamplifier stage is charge integrating while the second one is amplifying the output voltage of the first stage. The shape of the ceramics is that of a hollow cylinder.

Due to hardware constraints of the electronics container, the only voltage available for the operation of the preamplifiers was $6.0 \mathrm{~V}$. In order to minimise electronic noise, the preamplifiers were designed for that voltage rather than employing $\mathrm{DC} / \mathrm{DC}$ converters to obtain the $12.0 \mathrm{~V}$ supply typically used.

The piezo-elements and preamplifiers of the hydrophones are coated in polyurethane. Plastic endcaps prevent the material from pouring into the hollow part of the piezo-cylinder during the moulding procedure. The ECAP as well as the HTI hydrophones have a diameter of $38 \mathrm{~mm}$ and a length (from the cable junction to the opposite end) of $102 \mathrm{~mm}$.

The equivalent inherent noise level in the frequency range from 1 to $50 \mathrm{kHz}$ is about $13 \mathrm{mPa}$ for the ECAP hydrophones and about $5.4 \mathrm{mPa}$ for the HTI hydrophones. This compares to $6.2 \mathrm{mPa}$ of the lowest expected ambient noise level in the same frequency band for a completely calm sea [19], referred to as sea state 0 [20].

At the ANTARES site, the hydrophones are subject to an external pressure of 210 to 240 bar, depending on the depth at which they are installed. Prior to deployment, each hydrophone was pressure-tested in accordance with the standard ANTARES procedure, i.e. the pressure was ramped up to 310 bar at $12 \mathrm{bar} / \mathrm{min}$, held there for two hours and then ramped down again at $12 \mathrm{bar} / \mathrm{min}$.

\footnotetext{
${ }^{7}$ For the commercial hydrophones, details were not disclosed by the manufacturer, but the main design is similar to the one described here.
} 


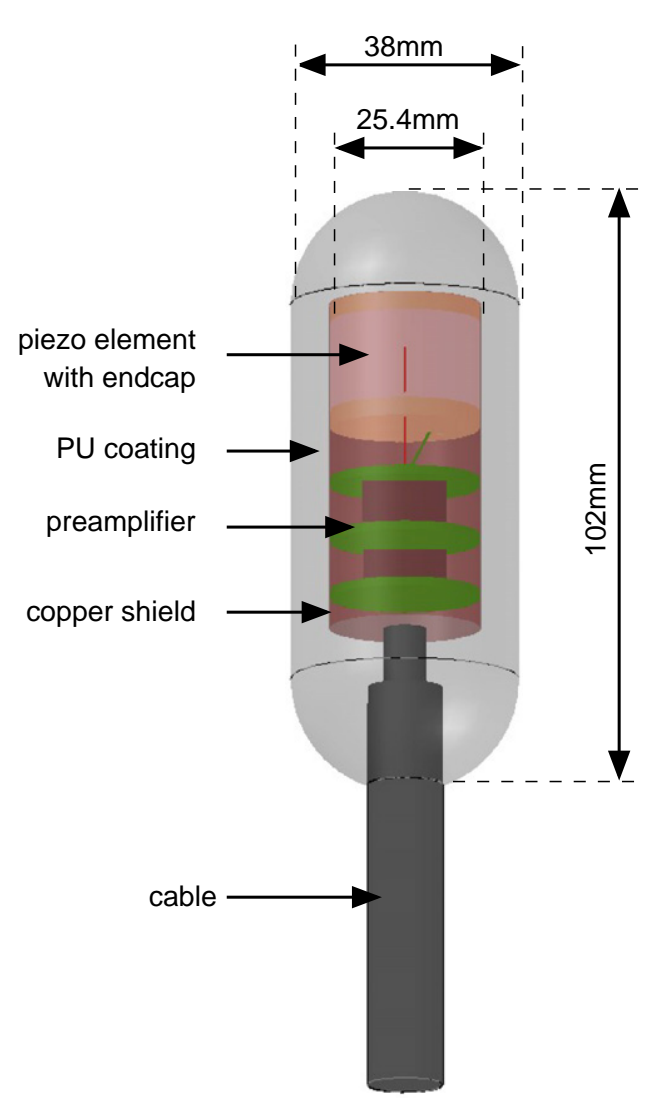

Fig. 5. Schematic drawing of an ECAP hydrophone. Piezo-element and preamplifier (consisting of three circular circuit boards, interconnected by pin connectors) are moulded into polyurethane (PU).

\subsubsection{Acoustic modules}

For the AMs, the same preamplifiers are used as for the ECAP hydrophones. The piezo-elements have the same outer diameter but are solid cylinders in case of the AMs. Two sensors are glued to the inside of each sphere. This design was motivated by the idea to operate the piezo-elements at low pressure and also to investigate an option for acoustic sensing that can be integrated together with a PMT in the same glass sphere. In order to assure a good acoustic coupling, the space between the curved sphere and the flat end of the piezo-sensor of the AMs was filled with epoxy. A photograph of an Acoustic Module and a schematic drawing of the sensors glued to the inside of the glass sphere are shown in Figs. 6(a) and (b), respectively.

In order to obtain a $2 \pi$ azimuthal coverage, the six sensors are distributed over the three AMs of the storey within the horizontal plane defined by the three centres of the spheres as shown in Fig. 6(c). The spheres have outer diameters of $432 \mathrm{~mm}$.

\subsubsection{Calibration}

All sensors are tuned to have a low noise level and to be sensitive over the frequency range from 1 to $50 \mathrm{kHz}$ with a typical sensitivity around $-145 \mathrm{~dB}$ re $1 \mathrm{~V} / \mu \mathrm{Pa}$ (including preamplifier). The sensitivities of all sensors as a function of frequency, polar angle and azimuthal angle were measured before deployment in a water tank, using a calibrated emitter [21]. The analysis was restricted to frequencies above $10 \mathrm{kHz}$. Towards lower frequencies, measurements become increasingly less significant. This is due to the quadratic frequency dependence of the emitter's transmit voltage response and to the increasingly adverse effect of reflections for increasing wavelengths. In accordance with the expected behaviour of the piezo-elements, the sensitivity is assumed to be constant below $10 \mathrm{kHz}$.

The sensitivity of one of the commercial hydrophones is shown in Fig. 7 as a function of frequency for different polar angles. For frequencies below $50 \mathrm{kHz}$, the sensitivity decreases once the polar angle approaches $180^{\circ}$, which defines the direction at which the cable is attached to the hydrophone. The beginning of this trend can be seen for the polar angle of $150^{\circ}$.

The sensitivity as a function of the azimuthal angle for a given frequency is essentially flat at the $3 \mathrm{~dB}$ level for all hydrophones. The sensitivity as a function of polar angle and frequency shows deviations of less than $2 \mathrm{~dB}$ between different HTI hydrophones in the frequency range from 10 to $50 \mathrm{kHz}$. The deviations for the hydrophones produced at ECAP are at a level of 3 to $4 \mathrm{~dB}$. The sensitivity of an ECAP hydrophone is shown in Fig. 8. Compared to the HTI hydrophones, the sensitivity in the frequency range from 10 to $50 \mathrm{kHz}$ is higher but less uniform, both as a function of frequency and as a function of polar angle.

As a consequence of their design, the solid angle over which the sensors of the AMs are sensitive is smaller compared to the hydrophones. Furthermore, reflections and resonances within the glass sphere affect the signal shape and frequency dependence, making laboratory measurements more difficult to interpret. The calibration was performed by varying the position of the emitter along a half circle, such that each emitter position has the same distance to the piezo-element. Angles were then given by the position of the emitter along the half circle with respect to the longitudinal axis of the piezo-sensor, which defined the angle of $0^{\circ}$. Results are shown in Fig. 9. The higher sensitivity compared to the ECAP hydrophones is due to the different piezo-element that is used and the acoustic coupling between water, the glass sphere and the piezo-sensor.

All sensitivity measurements were done at normal pressure. A verification with an in situ calibration has not yet been carried out at the time of the writing of this paper.

For the calibration that was describe above, Gaussian signals were emitted which in the frequency domain cover the range of the calibration. In addition, the response of the sensors to bipolar pulses was recorded. This is shown in Fig. 10. The agreement between the different sensor types is quite good. The asymmetry of the input pulse, i.e. the ratio of the pulse heights at the positive and negative peaks, can be seen to be diminished in the response of the sensors. This is due to the excitation of oscillations of the piezo-elements.

\subsection{Cables and connectors}

Each electronics container is equipped with three 12-pin SubConn connector sockets. ${ }^{8}$ In order to connect two hydrophones to each of the three sockets, special fanout cables were produced (see Fig. 2). To the electronics container end of the cable, the same mating connector plugs are used as for the Optical Modules. At the other end of the cable, a bulkhead connector AWQ-4/24 of the ALL-WET split series by Seacon ${ }^{9}$ was moulded, which fans out into six wedge-shaped sectors. Each sector has a 4-pin connector socket, serving the four leads for individual power supply and differential signal readout of the hydrophones. Each of the mating 4-pin connectors is moulded to a neoprene cable with the hydrophone at its other end. The remaining four sectors of the bulkhead connector are sealed with blind plugs.

The standard cables used in the ANTARES detector between the electronics container and the Optical Modules are also used to

\footnotetext{
${ }^{8}$ MacArtney Underwater Technology group, http://www.subconn.com/.

${ }^{9}$ Seacon (Europe) LTD, Great Yarmouth, Norfolk, UK, http://www.seaconeu rope.com/.
} 
a

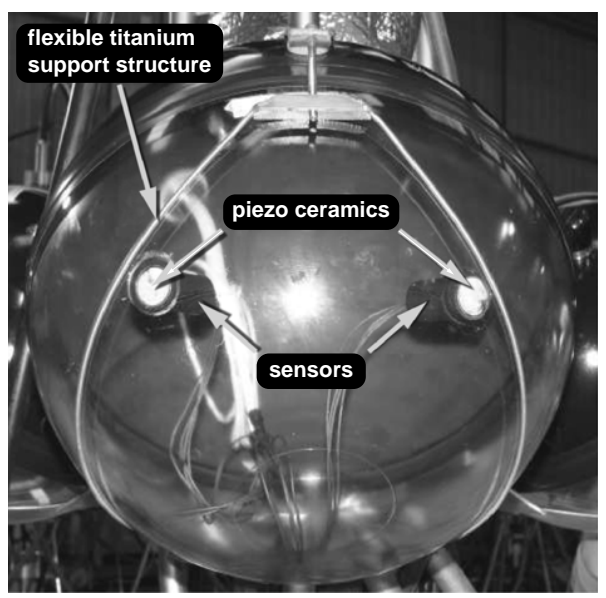

b

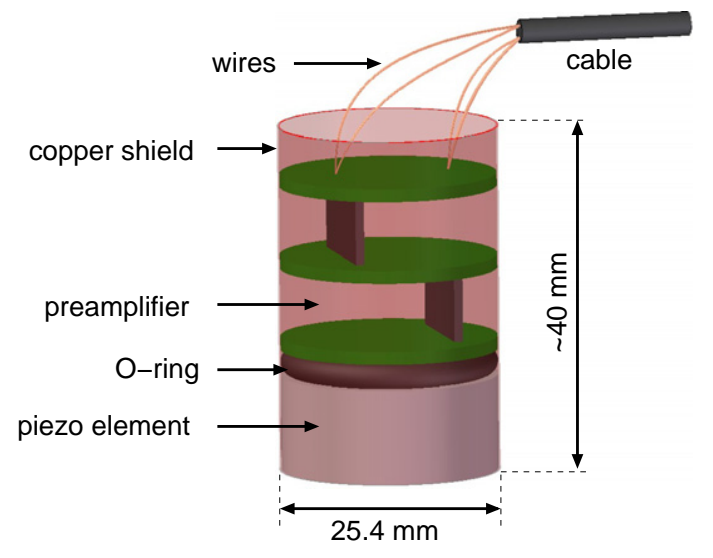

C

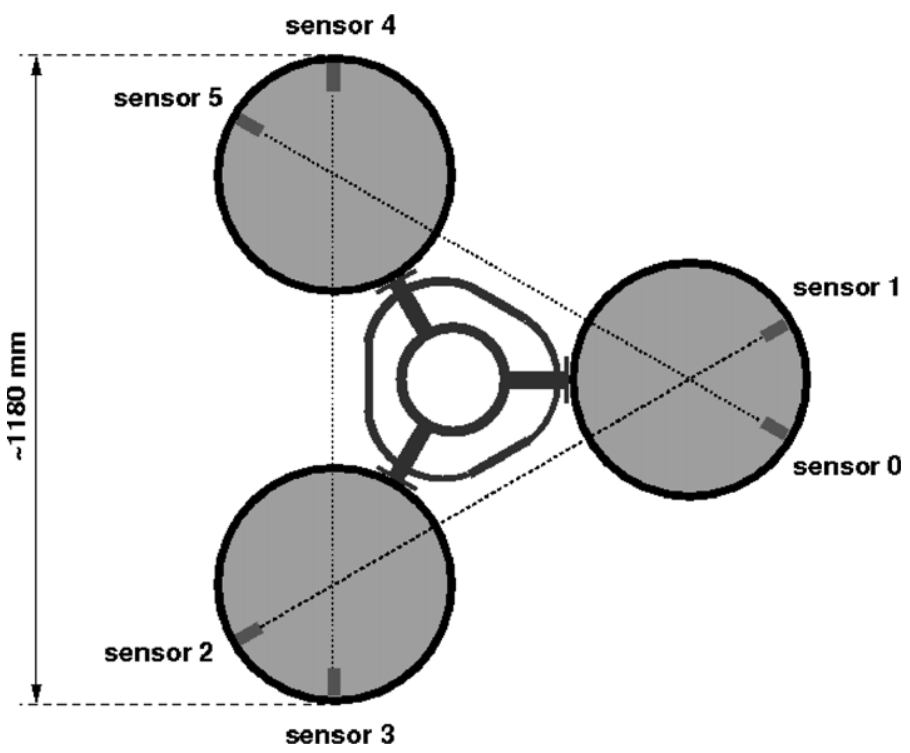

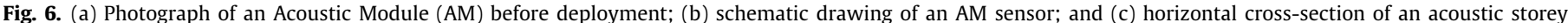

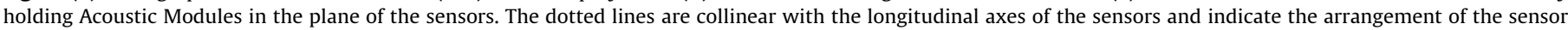
within the storey. The lines intersect at angles of $60^{\circ}$ at the centres of the glass spheres.

connect the AMs. The LCMs integrated into storeys with AMs and with hydrophones are interchangeable. All connections and cables within AMADEUS are functioning as expected.

\subsection{Off-shore electronics}

In the ANTARES data acquisition (DAQ) scheme [22], the digitisation is done within the off-shore electronics container (see Section 2). Each LCM contains a backplane that is equipped with sockets for the electronics cards and provides them with power and data lines. A standard LCM for processing the data from PMTs contains the following electronics boards:

- Three ARS motherboards, each comprising two Analogue Ring Sampler (ARS) ASICs, for conditioning and digitisation of the analogue signals from the PMTs [23].

- A DAQ board, which reads out the ARS motherboards and handles the communication to shore via TCP/IP.

- A Clock board that provides the timing signals to correlate measurements performed in different storeys (see Section 3.6).

- A Compass board to measure the tilt and the heading of the storey.
The transmission of data to shore is done through a Master LCM (MLCM) which-in addition to the components of an LCM described above-contains an ethernet switch and additional boards for handling incoming and outgoing fibre-based optical data transmission. Up to five storeys form a sector, in which the individual LCMs transmit the data to the MLCM.

For the digitisation of the acoustic signals and for feeding them into the ANTARES data stream, the AcouADC board was designed. These boards are pin-compatible with the ARS motherboards and replace them in the acoustic storeys. Fig. 11 shows the fully equipped LCM of an acoustic storey.

\subsection{The AcouADC board}

Each AcouADC board serves two acoustic sensors and has the following major tasks:

- Pre-processing of the analogue signals (impedance matching, application of an anti-alias filter, selectable gain adjustment).

- Digitisation of the analogue signals and preparation of the digitised data stream for transmission to the DAQ board. 

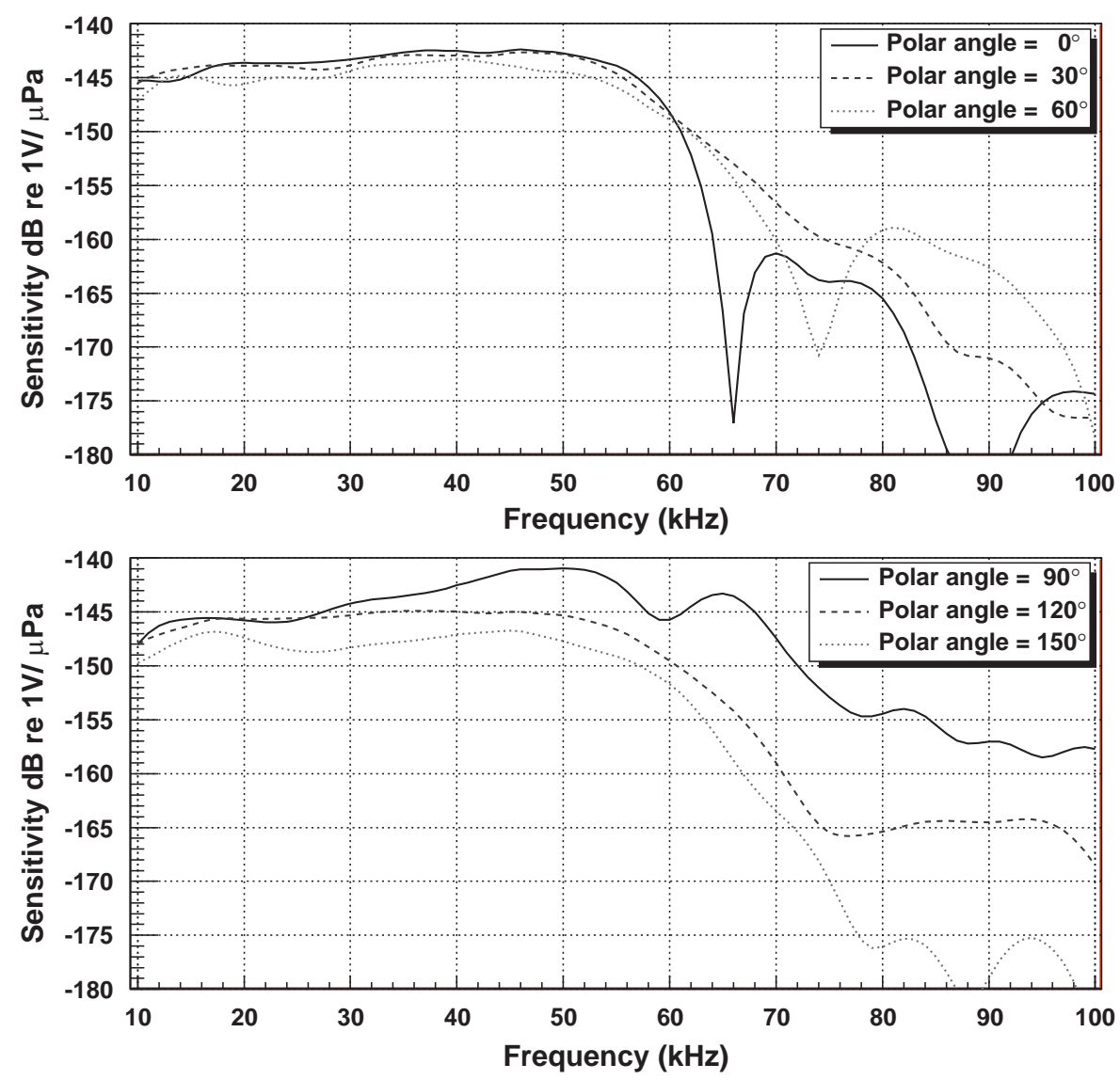

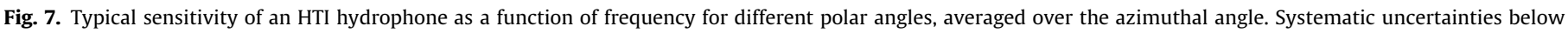
$50 \mathrm{kHz}$ are $2-3 \mathrm{~dB}$.

- Provision of stable low-noise voltage (6.0 V) for power supply of the acoustic sensors.

- Provision of an interface to the on-shore slow control software (see Section 3.5).

A photograph and a block diagram of an AcouADC board are shown in Figs. 12 and 13, respectively. The board consists of an analogue and a digital signal processing part. Each board processes the differential voltage signals from two acoustic sensors, referred to as "Sig 0" and "Sig 1" in the diagram. The two signals are processed independently and in parallel for the complete (analogue and digital) data processing chain.

A main design criterion for the board was a low inherent noise level, so that even for sea state 0 no significant contribution to the recorded signal originates from the electronics of the board. To protect the analogue parts from potential electromagnetic interference, they are shielded by metal covers. Tests of the electromagnetic compatibility (EMC) of the board have shown that this design is not significantly affected by electromagnetic noise even for conditions that are far more unfavourable than those present in situ [19].

The two $6.0 \mathrm{~V}$ power supply lines on each AcouADC board (connectors labelled "Pow 0" and "Pow 1" in Fig. 13) are protected by resettable fuses against short circuits that could be produced by the sensors due to water ingress. In addition, each voltage line can be individually switched on or off.

\subsubsection{Analogue signal processing}

The analogue signal is amplified in two stages. The first stage applies a coarse gain with nominal amplification factors of 1,10 or 100. It is implemented as a differential amplifier with single-ended output, referenced to $2.5 \mathrm{~V}$. The gain factor 1 is used for recording dedicated runs with large signal amplitudes, e.g. from the emitters of the ANTARES acoustic positioning system (see Section 2.1), whereas the factor of 100 was only foreseen for the case that the sensitivity of the hydrophones would degrade after deployment.

The second amplification stage, the fine gain, is intended to adjust the gains of different types of hydrophones. It is a noninverting amplification with single ended output and a reference voltage of $2.5 \mathrm{~V}$. Gain factors of $1.00,1.78,3.16$, and 5.62 (corresponding to $0,5,10$, and $15 \mathrm{~dB}$, respectively) are selectable by switching between four appropriate resistors in the feedback loop of the operational amplifier. Combining the two stages, the gain factor can be set to one of 12 values between 1 and 562 . The standard setting is an overall gain factor of 10 , yielding the approximate sensitivity of $-125 \mathrm{~dB}$ re $1 \mathrm{~V} / \mu \mathrm{Pa}$.

After amplification, the signal is coupled into a linear-phase 10th-order anti-alias filter ${ }^{10}$ with a root-raised cosine amplitude response and a $3 \mathrm{~dB}$ point at a frequency of $128 \mathrm{kHz}$. In low-power mode, the filter output range is about $3.9 \mathrm{~V}$. The output is referenced to $2.0 \mathrm{~V}$ and fed into a 16-bit analogue-to-digital converter (ADC) that will be described below. Accordingly, the $\mathrm{ADC}$ reference voltage is set to $2.0 \mathrm{~V}$, implying that the digital output of zero corresponds to this analogue value. The input range of the ADC is $0.0-4.0 \mathrm{~V}$.

The three analogue stages (coarse and fine amplification and anti-alias filtering) and the ADC are decoupled by appropriate capacitors. Furthermore, several RCL elements within the

\footnotetext{
${ }^{10}$ Filter LTC1569-7 from Linear Technology, http://www.linear.com/.
} 

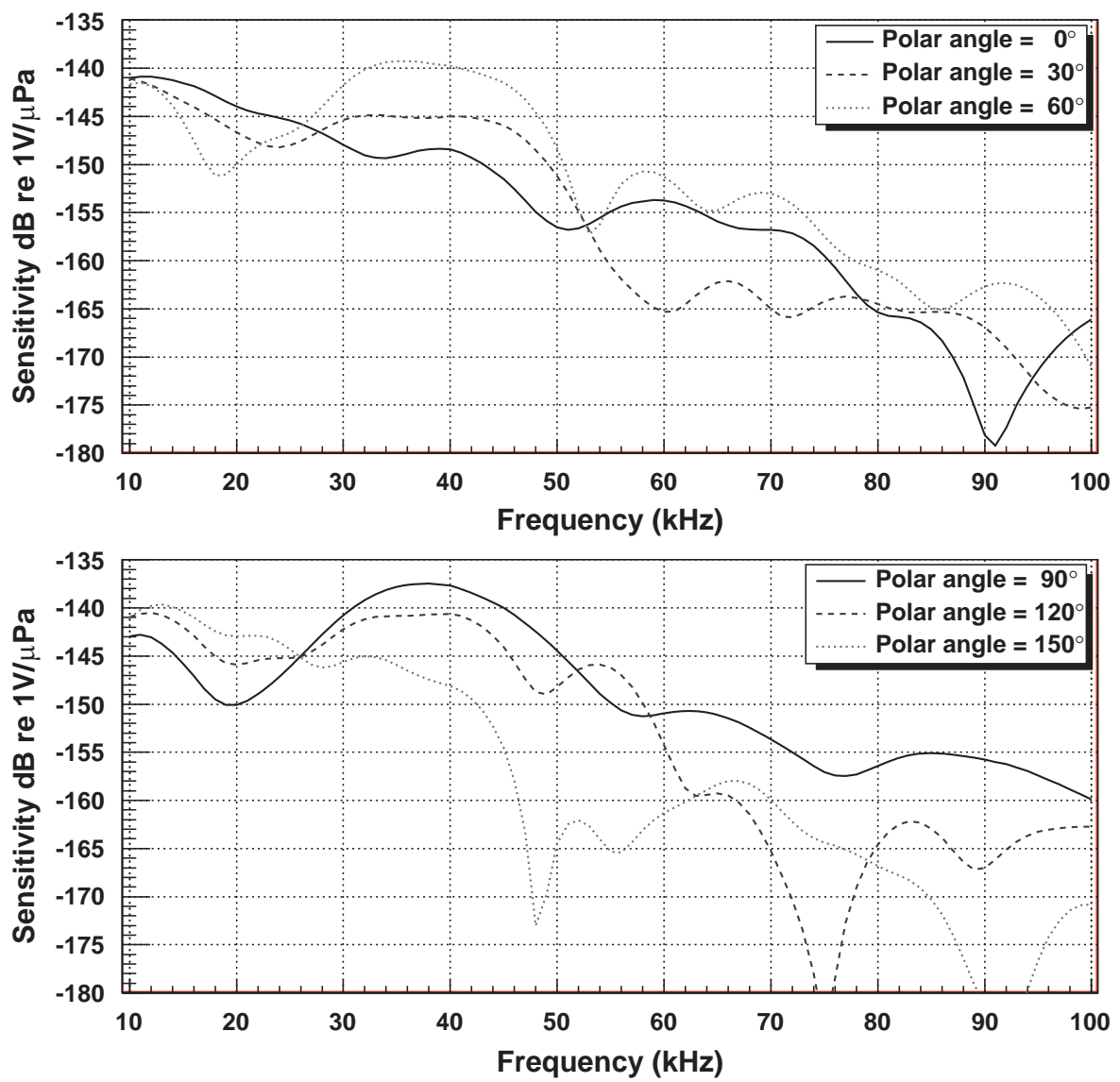

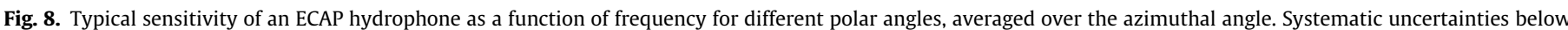
$50 \mathrm{kHz}$ are $2-3 \mathrm{~dB}$.

analogue signal chain form an additional band-pass filter. Its lowfrequency $3 \mathrm{~dB}$ point is at about $3 \mathrm{kHz}$ and cuts into the trailing edge of the low-frequency noise of the deep-sea acoustic background [24], protecting the system from saturation. The highfrequency $3 \mathrm{~dB}$ point is above $1 \mathrm{MHz}$ and was introduced to comply with the input requirements of active components of the circuitry.

\subsubsection{Digital signal processing}

The digital part of the AcouADC board digitises the acoustic signals and processes the digitised data. It is flexible due to the use of a micro controller $(\mu \mathrm{C})^{11}$ and a field programmable gate array (FPGA) ${ }^{12}$ as data processor. All communication with the shore is done via the DAQ board; the $\mu \mathrm{C}$ handles the slow control (see Section 3.5) and the FPGA the data transfer. The $\mu \mathrm{C}$ is accessed from the on-shore control software and is used to adjust settings of the analogue part and the data processing. It can also be used to update the firmware of the FPGA. This firmware is stored in a flash memory and loaded after a reset of the FPGA. In situ, this reset is asserted from the $\mu \mathrm{C}$. If a firmware update is performed, the $\mu \mathrm{C}$ first loads the code from the shore into the random access memory (RAM). Once the integrity of the code has been confirmed by means of a checksum, the code is transmitted into the flash memory. In order to avoid the potential risk that a software error renders the $\mu \mathrm{C}$ inaccessible, its boot memory can only be changed in the laboratory. For testing and programming

11 STR710 from STMicroelectronics, http://www.st.com/.

12 Spartan-3 XC3S200 from XilinX, http://www.xilinx.com/. in the laboratory, $\mathrm{JTAG}^{13}$ is used to access the FPGA, the $\mu \mathrm{C}$, and the flash memory.

For each of the two input channels, the digitisation is done at $500 \mathrm{kS}$ ps (kilosamples per second) by one 16-bit successive approximation $\mathrm{ADC}^{14}$ with output range from $-32,768$ to $+32,767$ counts. The two ADCs are read out in parallel by the FPGA and further formatted for transmission to the DAQ board.

ADCs commonly show relatively high deviations from a linear behaviour near the zero value of their digital output. The size of this effect depends on the circuitry into which the ADC is embedded. For the prototypes of the AcouADC boards, this effect proved to be fairly pronounced. For this reason, the reference voltage of the anti-alias filter output can be switched from its standard value of $2.0-1.0 \mathrm{~V}$, thereby moving the centre of the acoustic noise distribution away from the digital value of zero. This leads to an asymmetry of the recordable range for positive and negative amplitudes of acoustic signals, effectively reducing the dynamic range by a factor of 2 if one requires both positive and negative amplitudes to be fully recorded. For standard data taking, this is not desirable whereas the non-linearities of the ADCs proved to be unproblematic. Therefore, the reference voltage of the anti-alias filter output is set to $1.0 \mathrm{~V}$ only for special measurements.

In standard mode, the sampling rate is reduced to $250 \mathrm{kS}$ ps in the FPGA, corresponding to a downsampling by a factor of 2 (DS2). Currently implemented options are DS1 (i.e. no downsampling),

\footnotetext{
13 The IEEE standard 1149.1 "Test Access Port and Boundary-Scan Architecture" is commonly referred to as JTAG, the acronym for Joint Test Action Group. It defines an interface to individual components on a circuit board.

${ }^{14}$ ADS8323 from Analogue Devices, http://www.analog.com/.
} 

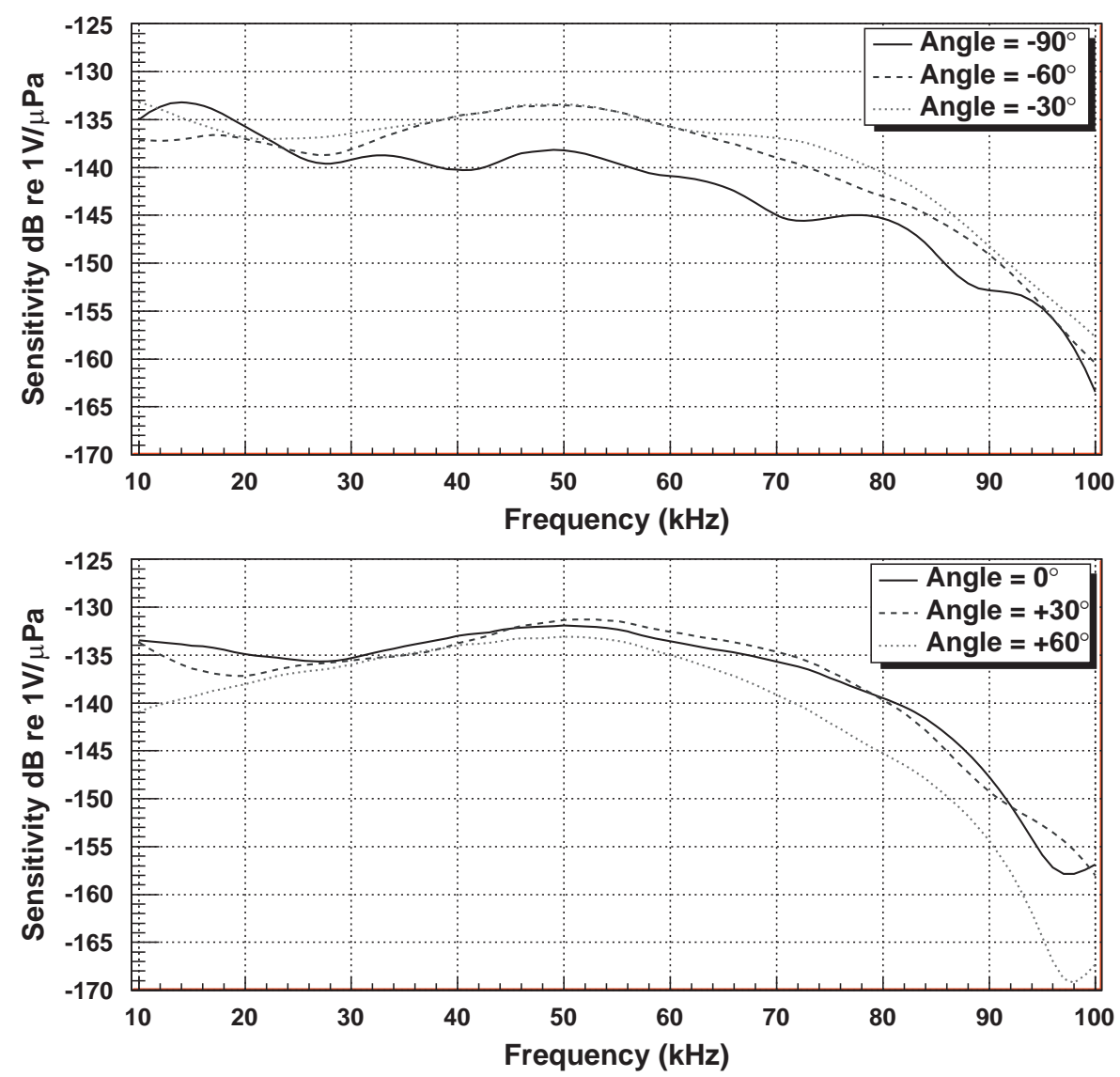

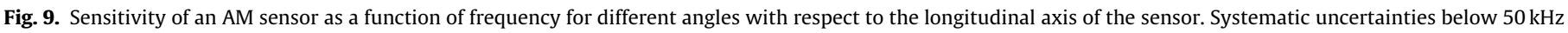
are $2-3 \mathrm{~dB}$.

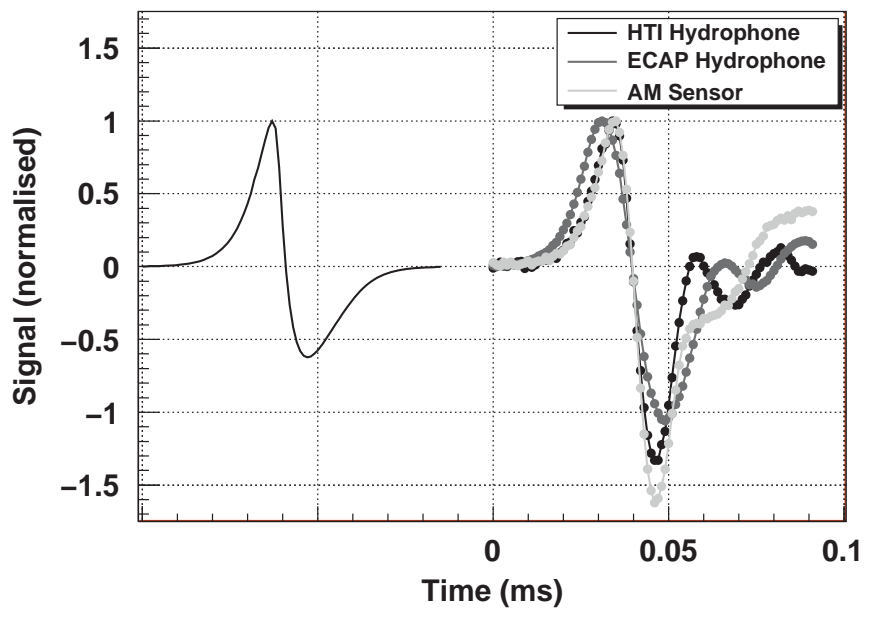

Fig. 10. Comparison of the response of different acoustic sensor types to a bipolar pulse. The emitted signal is shown on the left. The response of the hydrophones was measured for a polar angle of $90^{\circ}$, the response of the AM sensor for an angle of 0 . The first peak of each pulse (including the emitted one) was normalised to 1 and the time axis of each received signal was adjusted such that the times of the zero crossings coincide. The time offset between emitted and received pulses in the depiction is arbitrary.

DS2, and DS4, which can be selected from the shore. For each downsampling factor an adapted digital anti-alias filter, compliant with the Nyquist-Shannon sampling theorem, is implemented in the FPGA as a finite impulse response (FIR) filter with a length of 128 data points. For DS2, the frequency spectrum between the $3 \mathrm{~dB}$ points at 2.8 and $108.8 \mathrm{kHz}$ passes the filter.

\subsubsection{System characteristics}

The complex response function of the AcouADC board (i.e. amplitude and phase) was measured in the laboratory prior to deployment for each board and a parametrisation of the function was derived [19]. Fig. 14 shows the frequency response of the AcouADC board. The measurement was done by feeding Gaussian white noise into the system and analysing the digital output recorded by the board. Without downsampling (DS1), the rolloff at high frequencies is governed by the analogue anti-alias filter. For DS2 and DS4, the digital FIR filters are responsible for the behaviour at high frequencies. At low frequencies, the effect of the band-pass filter described above can be seen. Fig. 14 furthermore demonstrates that within each passband, the filter response is essentially flat. The comparison of the recorded data with the parametrisation shows excellent agreement.

The parametrisation of the response function allows to calculate the response of the system to any input pulse and vice versa the reconstruction of the original shape of any recorded pulse. Fig. 15 shows a comparison of the measured and calculated response of the analogue signal processing part of the AcouADC board to a generic bipolar input pulse as it would be expected from a neutrino-induced cascade (see Section 1). The digital FIR filter introduces an additional time offset of $128 \mu$ s of the digitised data for DS2 and DS4.

The ADCs of the AcouADC board were investigated in detail [19]. For each individual ADC, the transfer curve from input voltage to ADC counts was measured and distortions from the ideal linear behaviour quantified in terms of the differential nonlinearity (DNL) and integral non-linearity (INL). The distribution of the DNL values for all bins of all calibrated signal channels shows negligible deviations from the ideal situation (i.e. a peak at 


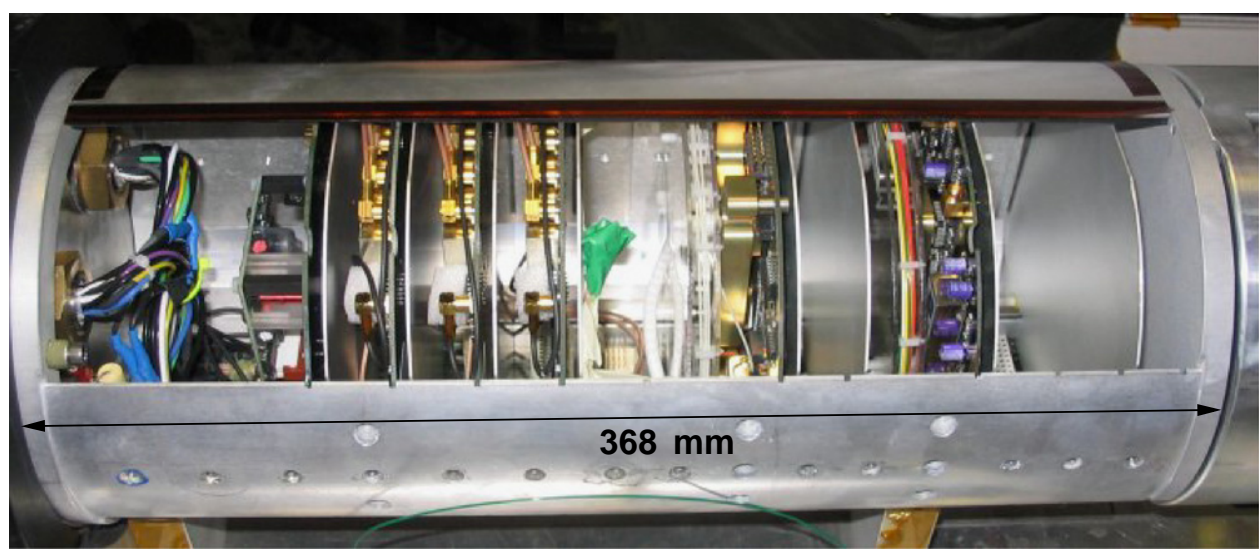

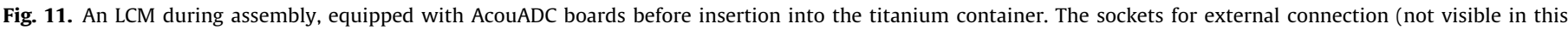

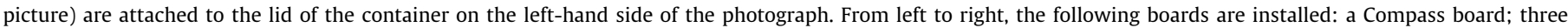
AcouADC boards; a DAQ board; and a Clock board.

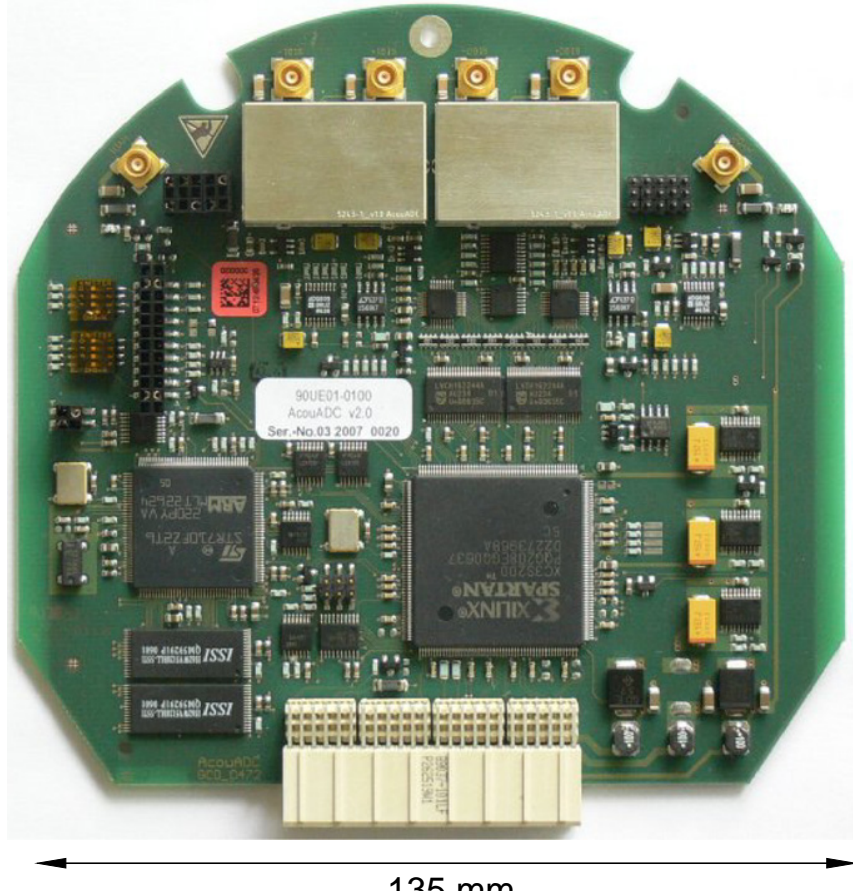

$135 \mathrm{~mm}$

Fig. 12. Photograph of an AcouADC board. The four connectors for the two differential input signals are located at the top, the analogue signal processing electronics is covered by metal shields.

zero) with a mean of -0.02 ADC counts and a standard deviation of $0.06 \mathrm{ADC}$ counts, corresponding to $3.4 \mu \mathrm{V}$. The values of the INL of the ADCs stay within \pm 50 ADC counts for all signal channels over the full input range, corresponding to $\pm 3.1 \mathrm{mV}$.

The spurious-free dynamic range (SFDR) of an ADC is a measure of its dynamic range. Using a sinusoidal input signal, the average SFDR of the ADCs of all boards in AMADEUS was measured to be $59.9 \pm 1.1 \mathrm{~dB}$, meaning that harmonics of the sine wave distorting the output signal are suppressed by three orders of magnitude in the amplitude. Hence, a clear determination of the frequency is possible even for saturated signals, for which the harmonic components are enhanced.

The 12 gain factors for each channel were calibrated and the correction factor for gain 1 was measured to be $1.05 \pm 0.01$. The gain factors of the other 11 settings were measured with respect to this value and were found to deviate from the nominal factors by about $10 \%$ at maximum.

The inherent noise of the electronics (output for open signal input) and the cross-talk between the two signal channels of an AcouADC board were measured to be negligible in comparison with the inherent noise of the acoustic sensors.

\subsection{Slow control system}

The ANTARES slow control (SC) system has two main tasks. It provides the off-shore components with initialisation and configuration parameters and it regularly monitors whether the operational parameters are within their specified ranges. In addition, the readout of some instruments for environmental monitoring [25], performed at intervals of a few minutes, is polled and sent through the SC interface.

For the AMADEUS system, the following parameters can be set from shore via the SC system for each acoustic channel individually: one of the 12 values for the gain; downsampling factors of 1,2 , or 4 (or no data transmission from the AcouADC board); power supply for the acoustic sensor on or off; reference voltage of the analogue signal fed into the ADC 2.0 or $1.0 \mathrm{~V}$.

To monitor the environment within each LCM container, a humidity sensor and temperature sensors on several boards are installed. One temperature sensor is placed on each AcouADC board. Values read out by the SC system are stored in an Oracle ${ }^{\circledR}$ database that is centrally used by ANTARES.

\subsection{Data acquisition and clock system}

AMADEUS uses the same DAQ system and follows the same "all data to shore" strategy [22] as the ANTARES neutrino telescope, i.e. all digitised data are transmitted to shore via optical fibres using the TCP/IP protocol. The data stream from the sender DAQ board is tagged with the IP address of the receiving on-shore server. In the control room, the acoustic data are routed to a dedicated computer cluster by using the transmitted IP address. The ANTARES clock system operates separately from the DAQ system, using a different set of optical fibres to synchronise data from different storeys. The system provides a highly stable $20 \mathrm{MHz}$ synchronisation signal, corresponding to a resolution of $50 \mathrm{~ns},{ }^{15}$ which is generated by a

${ }^{15}$ The much higher precision that is required for the synchronisation of the optical signals from the PMTs is provided by a 256 -fold subdivision of the $20 \mathrm{MHz}$ signal in the ARS motherboards. 


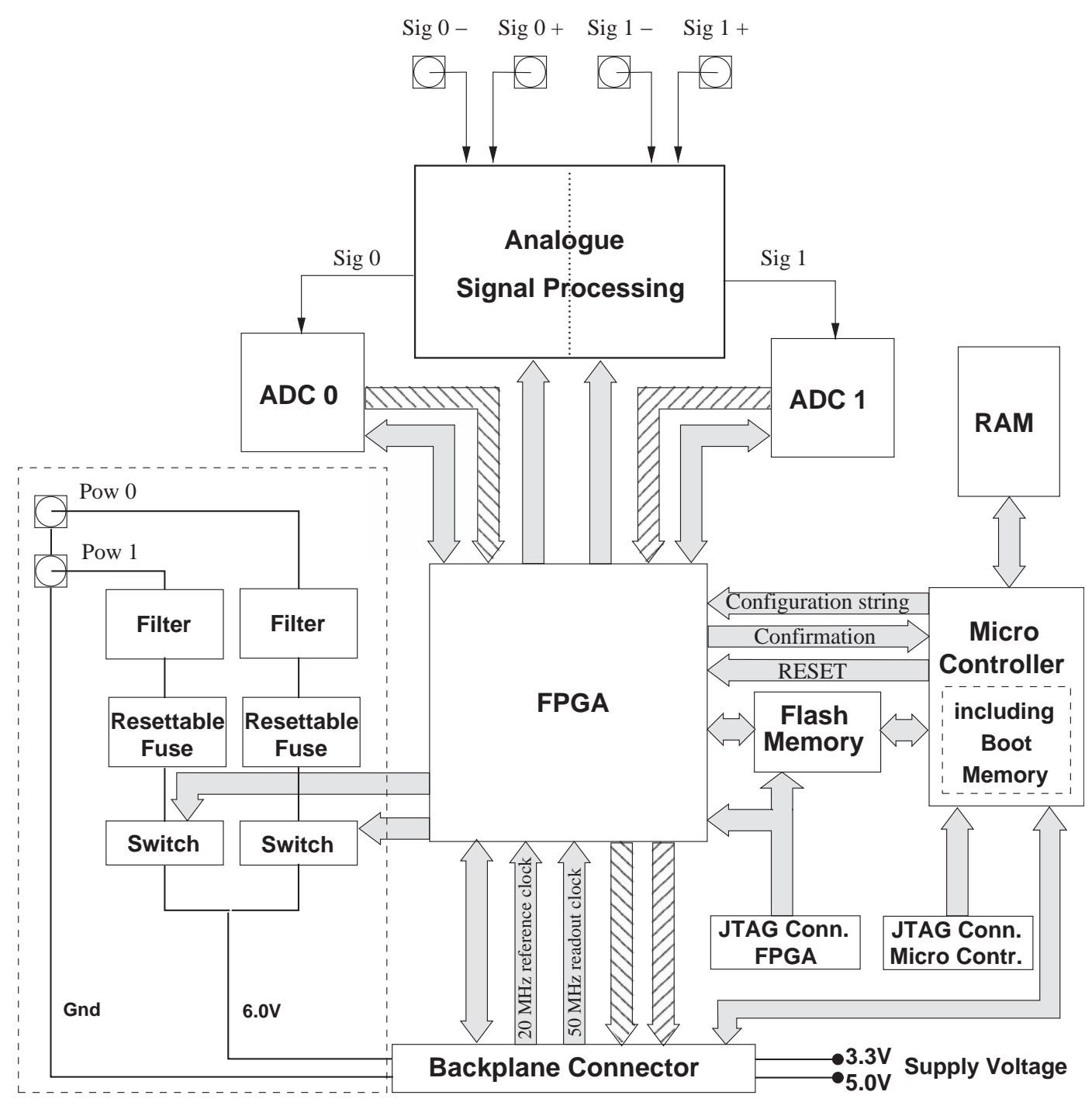

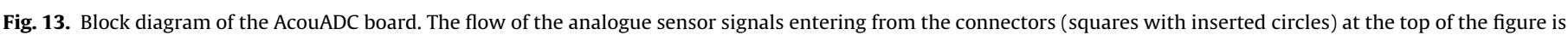

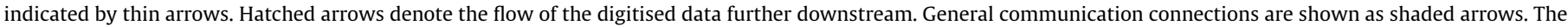

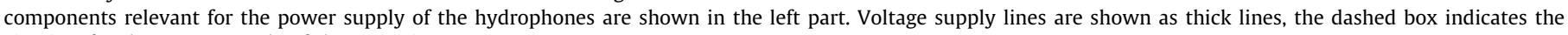
circuitry for the power supply of the acoustic sensors.

custom-designed system at the ANTARES control room. The synchronisation of this internal clock with the UTC ${ }^{16}$ of the GPS system is established with a precision of $100 \mathrm{~ns}$.

The synchronisation signal is broadcast to the off-shore clock boards and from there transmitted further to the FPGA of the AcouADC board. Based on this signal, the data packages sent from the AcouADC board to shore via the DAQ board receive a timestamp which allows for correlating the data from different storeys. The 50 ns resolution of the timestamp by far exceeds the requirements given by the standard sampling time of $4 \mu \mathrm{s}$ corresponding to DS2. Differences in the signal transit times between the shore station and the individual storeys are also smaller than $4 \mu \mathrm{s}$ and do not need to be corrected for.

\subsection{On-shore data processing and system operation}

The AMADEUS system is operated with its own instance of the standard ANTARES control software called RunControl [22]. This is a programme with a graphical user interface to control and

\footnotetext{
${ }^{16}$ Coordinated Universal Time.
}

operate the experiment. It is $\mathrm{Java}^{\mathrm{TM}}$-based and reads the configuration of the individual hard- and software components from the ANTARES database, allowing for an easy adaption of individual run parameters for the AMADEUS system. Via the clock system the absolute time of the run start is logged in the database with the aforementioned precision of $100 \mathrm{~ns}$. The end of a run is reached if either the data volume or the duration exceed predefined limits (in which case a new run is started automatically) or the run is stopped by the operator. The data of one AMADEUS run are stored in a single file in ROOT format [26]. The typical duration of a run ranges from 2 to $5 \mathrm{~h}$.

For the computing requirements of AMADEUS, a dedicated onshore computer cluster was installed. It currently consists of four server-class computers, of which two are used for data triggering $^{17}$ (equipped with $2 \times$ dual core $3 \mathrm{GHz}$ Intel Xeon 5160 and $2 \times$ quad core $3 \mathrm{GHz}$ Intel Xeon 5450 processors, respectively). Hence, a total of 12 cores are available to process the data. One of the remaining two computers is used to write the data to an

17 While this functionality might be more commonly referred to as filtering, it is ANTARES convention to refer to the "on-shore trigger". 


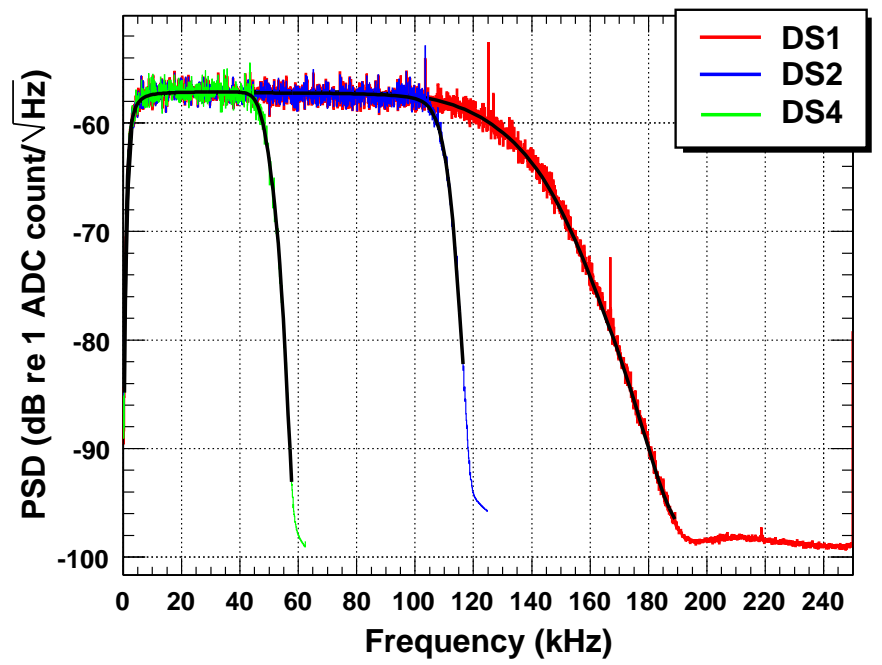

Fig. 14. The AcouADC board filter response, characterised by a power spectral density (PSD) as a function of frequency, measured for the three different downsampling factors. For each of the three measurements, the parametrisation is shown as a black line.

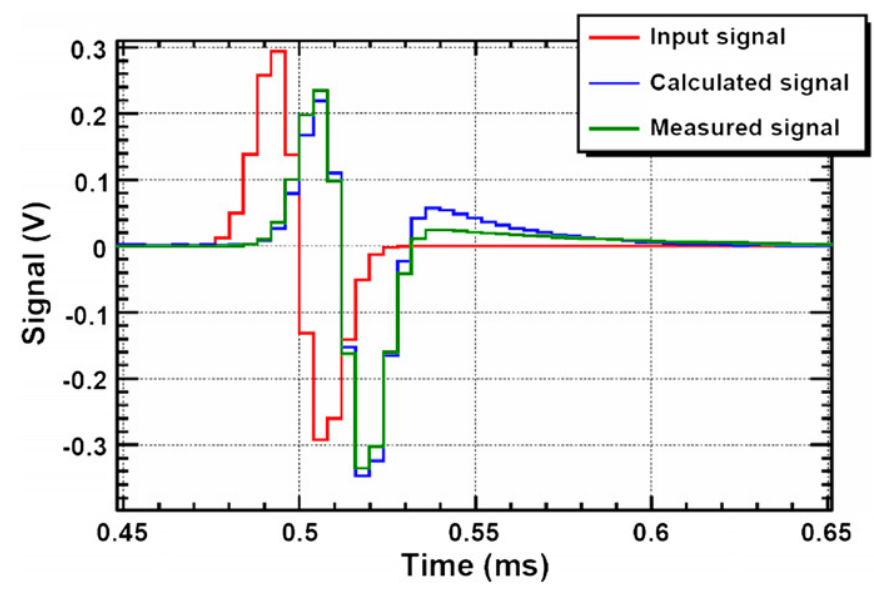

Fig. 15. The response of the analogue part of an AcouADC board to a bipolar input pulse. Shown are the measured output signal and the output signal calculated from the parametrised response function. The measured output signal was obtained with an oscilloscope at the input of the ADC. The measurement was done for a nominal gain factor of 1 .

internal $550 \mathrm{~GB}$ disc array (RAID), while the other is used to operate the RunControl software and other miscellaneous processes and to provide remote access to the system via the Internet.

The AMADEUS trigger searches the data by an adjustable software filter; the events thus selected are stored to disc. This way the raw data rate of about $1.5 \mathrm{~TB} /$ day is reduced to about $10 \mathrm{~GB} /$ day for storage. Currently, three trigger schemes are in operation [27]: A minimum bias trigger which records data continuously for about $10 \mathrm{~s}$ every $60 \mathrm{~min}$, a threshold trigger which is activated when the signal exceeds a predefined amplitude, and a pulse shape recognition trigger. For the latter, a cross-correlation of the signal with a predefined bipolar signal, as expected for a neutrino-induced cascade, is performed. The trigger condition is met if the output of the cross-correlation operation exceeds a predefined threshold. With respect to a matched filter, this implementation reduces the run time complexity while yielding a comparable trigger performance.

As discussed in Section 1, for pressure pulses induced by neutrino interactions the amplitude, asymmetry and frequency spectrum depend on the position of the observer with respect to the particle cascade. The predefined bipolar signal used for the pulse shape recognition trigger corresponds to the pulse shape expected at a distance of roughly $300 \mathrm{~m}$ from the shower centre in the direction perpendicular to the shower axis, i.e. where the maximum signal within the flat volume of sound propagation is expected. The cross-correlation with pulses whose shape differs from the implemented one changes the peak in the crosscorrelation output: it is broadened and diminished as compared to the filter response on the predefined signal. This effectively increases the trigger threshold in terms of pressure amplitude for such pulses. As will be described below, the final trigger decision requires coincidences within an acoustic storey, which allows the trigger threshold for the cross-correlation output of each individual acoustic sensor to be set to a low value. Given that the main purpose of the AMADEUS system is the investigation of background noise, this implementation is very efficient in recording a wide range of bipolar and multipolar events. Dedicated searches for neutrino signals - which are difficult due to the geometry of the acoustic storeys within the AMADEUS system-are done offline, taking into account the variations of the pulse shapes with distance and direction.

Both the threshold and the pulse shape recognition trigger are applied to the individual sensors and are self-adjusting to the ambient noise, implying that all trigger thresholds are defined in terms of a signal-to-noise ratio. The trigger thresholds are software parameters and therefore can be set at will. The noise level is calculated from and applied to the data of the frame that is currently being analysed. A frame denotes the structure in which data are buffered off-shore by the DAQ board before being sent to shore and contains data sampled during an interval of about $105 \mathrm{~ms}$ [22]. If one of these two trigger conditions is met, an additional trigger condition is imposed, which requires coincidences of a predefined number of acoustic sensors on each storey. The coincidence window is fixed to the length of a frame. Currently, the coincidence trigger requires that the threshold or pulse shape recognition trigger conditions have been met for at least four out of six sensors of a storey.

In the ANTARES DAQ system, the frames start at fixed intervals with respect to the run start. Trigger conditions are imposed on temporally corresponding frames from all storeys simultaneously, whereupon the frames are discarded and data not selected by the trigger are lost. Processing subsequent frames at the same time is not possible. Given the distances of typically $1 \mathrm{~m}$ between sensors within one storey, time delays between signals from a given source are always less than $1 \mathrm{~ms}$. Therefore, the number of sources for which the signals extend over two frames, and hence the coincidence trigger may not be activated, is small. The disadvantage of a large trigger window, the increased probability for random coincidences, leads only to a small increase of the recorded data volume. The coincidence trigger can be optionally extended to require coincidences between different storeys on the same line. With distances between storeys ranging from about 10 to $100 \mathrm{~m}$ (corresponding to delays of the order of $10-100 \mathrm{~ms}$ ) signals originating from above or below are suppressed. This trigger is currently not enabled.

The data of all sensors that have fired a coincidence trigger are stored within a common time window that covers all triggered signals. Its minimum length is $1.536 \mathrm{~ms}$ for $4 \mu \mathrm{s}$ sampling time (corresponding to 384 data samples) and its maximum length corresponds to the length of a frame.

The triggers of the AMADEUS system and the main ANTARES optical neutrino telescope are working completely independently. Hence, the search for correlated signals relies on offline analyses.

Both the off-shore and on-shore part of the AMADEUS system are scalable, rendering it very flexible. The enlargement of the 
system from three to six acoustic storeys with the commissioning of Line 12 (see Section 2.1) was easily implemented by increasing the on-shore computing power and updating the control software. In principle, the system could be upgraded to much bigger numbers of acoustic storeys. To reduce the data volume transmitted to shore, it would also be possible to move parts of the trigger algorithms into the FPGA of the AcouADC board.

AMADEUS is controlled remotely via the Internet. Data are centrally stored and are remotely available.

\section{System performance}

\subsection{General}

AMADEUS is continuously operating and taking data with only a few operator interventions per week. The up-time of each sensor is typically better than $80 \%$. Its ability to continuously send unfiltered data, sampled at high frequency, to shore for further analysis renders the AMADEUS system a multipurpose apparatus for neutrino feasibility studies, acoustic positioning and marine research.

The concept of acoustic clusters (i.e. the acoustic storeys) is very beneficial for fast online processing. By requiring coincident signals from at least four sensors within a storey, the trigger rate is significantly reduced, improving the purity of the sample selected with the pulse shape recognition trigger.

The parallel operation of two separate RunControl programmes for AMADEUS and the main ANTARES neutrino telescope, which was originally not foreseen, has proven to be very successful. No interference between the two programmes has been observed while the two systems can optimise their detection efficiency and respond to potential problems almost independently. At the same time, both systems profit in the same fashion from developments and improvements of the RunControl software and monitoring tools.

The stability of the system response is excellent. This was verified prior to deployment as well as in situ. It was quantified by observing the mean of the ambient noise distribution as a function of time. In situ, the $10 \mathrm{~s}$ of continuous data recorded every hour with the minimum bias trigger were used to calculate the mean. The standard deviation of this value for the first year of operation is less than $2 \times 10^{-5}$ of the full range.

All sensor types described in Section 2.2 are well suited for the investigation of acoustic particle detection methods. A comparison of the characteristics of the different sensor types will be drawn below.

\subsection{Ambient noise}

Studies of the power spectral density of the ambient noise at the ANTARES site have been performed using the minimum bias trigger data. Fig. 16 shows the noise levels recorded with representative HTI and ECAP hydrophones and with one AM sensor on Line 12 over several time periods with a combined duration of six months. For each sensor, the power spectral density was calculated for the $10 \mathrm{~s}$ intervals of continuous data and then for each $1 \mathrm{kHz}$ bin, the median and the $0.27 \%$ quantile (corresponding to a $3 \sigma$ deviation from the median) were derived for the complete set of measurements. For each sensor, one can observe a characteristic frequency above which the $0.27 \%$ quantile of the noise level shows a constant difference to the median. The corresponding frequencies are about 35,30 , and $40 \mathrm{kHz}$ for the HTI hydrophones, ECAP hydrophones and AM sensors, respectively. For higher frequencies, the noise is dominated by the

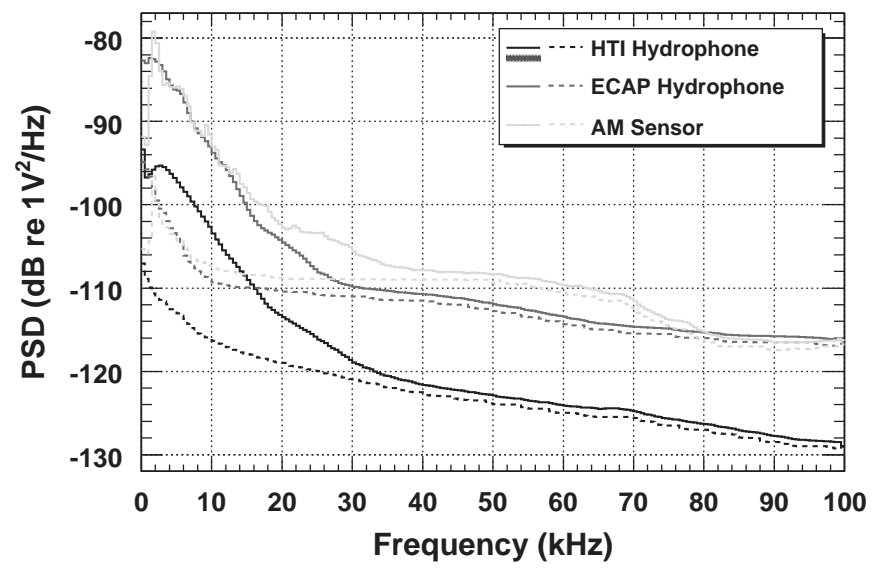

Fig. 16. Power spectral density (PSD) of the noise level recorded in situ. Solid lines represent the median, dotted lines the $0.27 \%$ quantile (corresponding to a $3 \sigma$ deviation from the median). The voltage used is the calibrated input voltage of the AcouADC board.

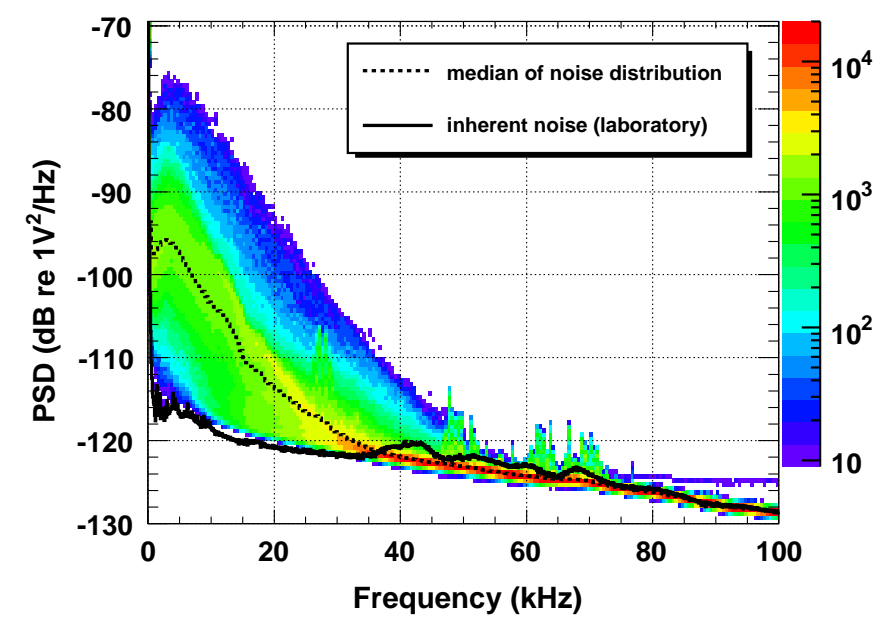

Fig. 17. Power spectral density (PSD) of the ambient noise recorded with one HTI sensor on the topmost storey of the IL. The voltage used is the calibrated input voltage of the AcouADC board. Shown in shades of grey is the occurrence rate in arbitrary units, where dark colours indicate higher rates. Shown as a white dotted line is the median value of the in situ PSD and as a black solid line the noise level recorded in the laboratory prior to deployment.

intrinsic electronics noise, limiting the capability to study the acoustic noise.

The noise floor is the lowest for the HTI hydrophones, the difference in the power spectral density to the ECAP hydrophones and AM sensors being $10-15 \mathrm{~dB}$. When recording transient signals, the effect on the signal-to-noise ratio is partially compensated by the higher sensitivity of the ECAP hydrophones and the AM sensors. The noise spectrum of the AM sensor displays some structure for frequencies up to about $25 \mathrm{kHz}$. This is due to coupling of the sensor to the glass spheres. In summary, for studies of the in situ ambient noise, the HTI hydrophones are the most suited type of sensors.

In Fig. 17 a more detailed presentation of the noise data recorded with an HTI hydrophone during the year of 2008 is given. An algorithm to remove strong transient signals (mostly coming from the emitters of the acoustic positioning system) was applied. The relics of such signals and electronics noise show up as spikes between 45 and $75 \mathrm{kHz}$. The lowest level of recorded noise in situ was confirmed to be consistent with the inherent noise of the system recorded in the laboratory prior to deployment. The observed in situ noise can be seen to go below the noise 
level measured in the laboratory for frequencies exceeding $35 \mathrm{kHz}$. This is due to electronic noise coupling into the system in the laboratory that is absent in the deep sea.

The overall noise levels (i.e. the RMS of the signal amplitudes in each $10 \mathrm{~s}$ sample) recorded at the same time with any two active sensors of the same type are correlated at a level above $90 \%$. This shows that the recorded data are indeed representative of the ambient conditions and not determined by the inherent noise of the system.

\subsection{Transient signals and dynamic range}

The signals recorded with the three different types of acoustic sensors on Line 12 for a common source is shown in Fig. 18. The signals were recorded in May 2010 and were received under an angle of about $65^{\circ}$ with respect to the direction pointing vertically upwards. The agreement between the signal shapes can be seen to be very good. For the second positive peak at about $0.20-0.25 \mathrm{~s}$, the AM sensor shows a differing behaviour from the hydrophones, which can be attributed to the coupling of the sensor to the glass sphere.

Bipolar signals selected with the pulse shape recognition trigger typically have a signal-to-noise ratio exceeding 2 for a single sensor. Assuming a noise level of $10 \mathrm{mPa}$ in the frequency range from 1 to $50 \mathrm{kHz}$, which is a typical level recorded at calm sea, i.e. sea state 0 , a signal of $20 \mathrm{mPa}$ can be detected. Such a signal is expected to be emitted from a $2 \mathrm{EeV}$ cascade emerging from a neutrino interaction at a distance of about $200 \mathrm{~m}$ [3]. Improving the trigger techniques may further enhance the energy sensitivity. Furthermore, the optimal frequency range must be determined to maximise the signal-to-noise ratio for pulses stemming from neutrino interactions. To conclude on the feasibility of a large-scale acoustic neutrino detector in the deep sea-the main objective pursued with the AMADEUS systemfurther detailed studies are required.

The maximal pressure amplitude that can be recorded for a gain factor of 10 without saturating the input range of the ADC is about $5 \mathrm{~Pa}$. Usually, only anthropogenic signals originating close to the detector reach this pressure level at the positions of the hydrophones.

The direction and position reconstruction of acoustic point sources are currently being pursued as one of the major

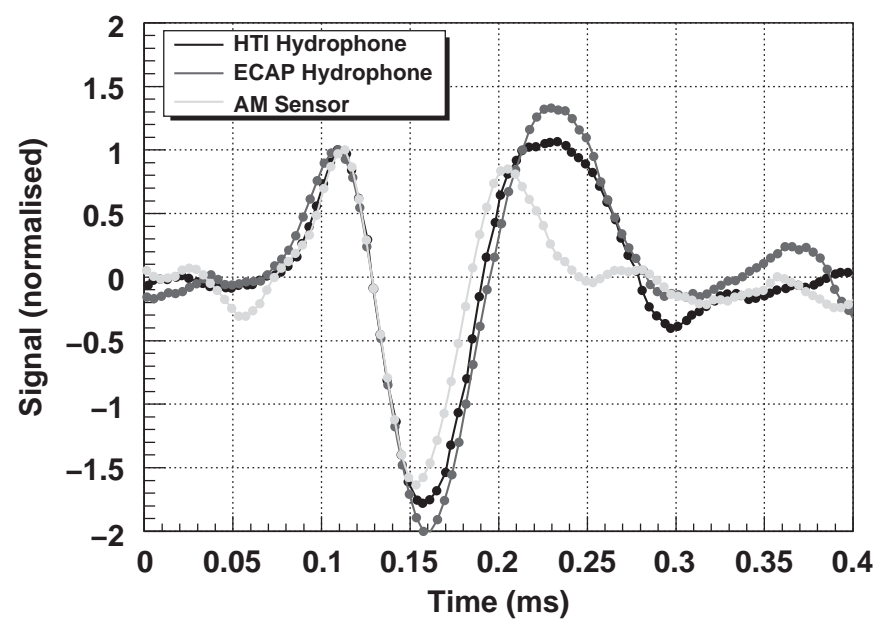

Fig. 18. Comparison of the signals originating from a common source as recorded by three different types of acoustic sensors, each one located on a different storey of Line 12. For better comparability, the first peak of each signal has been normalised to 1 and the time axis of each signal adjusted such that the times of the zero crossings between the first positive and negative peak coincide.

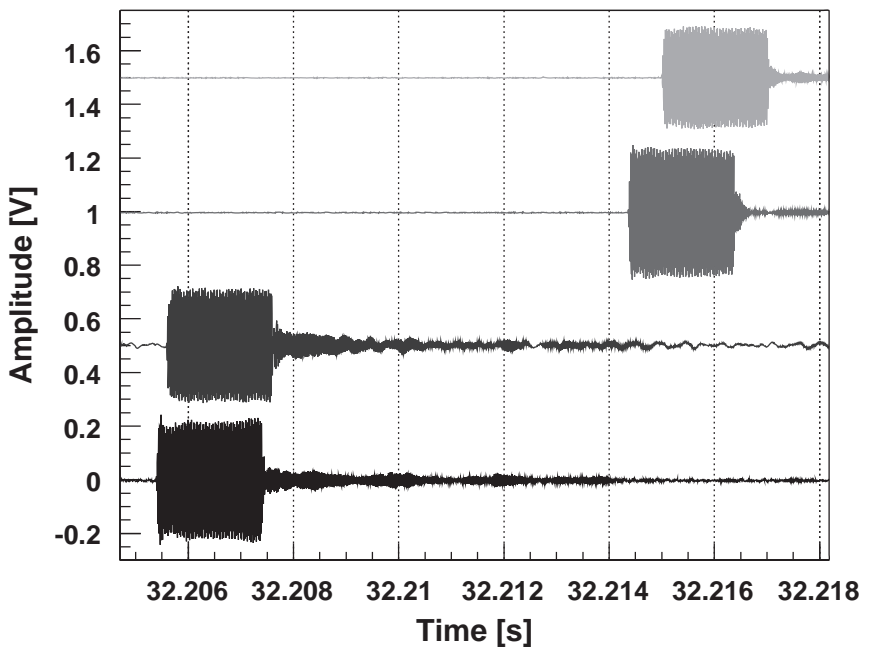

Fig. 19. Typical signals of the ANTARES acoustic positioning system as recorded with four sensors of the AMADEUS system for gain factor 1 of the AcouADC board. For better clarity an offset, starting with $0 \mathrm{~V}$ and incremented by $0.5 \mathrm{~V}$ with respect to the previous one, is added to the amplitude of each sensor. The first two signals along the time axis were recorded by the acoustic storey holding AMs (see Fig. 1). The following two signals were recorded with two hydrophones on the acoustic storey just above-one hydrophone mounted at the bottom and the other one at the top of the storey. The time is counted since the start of the run.

prerequisites to identify neutrino-like signals. First results are presented in Refs. [15,28].

\subsection{Position calibration of acoustic storeys}

Just as for the PMTs in the standard storeys, the relative positions of the acoustic sensors within the detector have to be continuously monitored. This is done by using the emitter signals of the ANTARES acoustic positioning system (see Section 2.1). Fig. 19 shows such a signal as recorded by four typical sensors. The delays between the signal arrival times are clearly visible: short delays of less than $1 \mathrm{~ms}$ within each storey and a long delay of about $10 \mathrm{~ms}$ between the signals arriving in two different storeys.

The time shown in the figure is given in seconds since the start of the run and can be converted into UTC using the data recorded by the clock system (see Section 3.6). As the emission times of the positioning signals are also recorded in UTC, the time difference between emission and reception of the signal can be calculated. Using the signals from multiple emitters and their known positions at the anchors of the lines, the positions of the AMADEUS sensors can be reconstructed.

The position calibration has statistical uncertainties of a few millimetres for each hydrophone. Systematic uncertainties due to the size of the receiving piezo-elements, the knowledge of their relative positions within the acoustic storey, the knowledge of the speed of sound in sea water and the position uncertainties of the emitters are still under study. For the AMs, the position reconstruction is less precise and has a statistical uncertainty of the order of a centimetre.

\section{Summary and conclusions}

The AMADEUS system for the investigation of techniques for acoustic particle detection in the deep sea has been integrated into the ANTARES neutrino telescope in the Mediterranean Sea at water depths between 2050 and $2300 \mathrm{~m}$. The system started to take data in December 2007 and was completed in May 2008. It 
comprises 36 acoustic sensors, of which currently 34 are operational, arranged in six acoustic clusters. Different configurations of sensor clusters are used. The sensors consist of piezoelectric elements and two-stage preamplifiers with combined sensitivities around $-145 \mathrm{~dB}$ re $1 \mathrm{~V} / \mu \mathrm{Pa}$.

For the off-shore data acquisition, a dedicated electronics board has been designed. One of 12 steps of analogue amplification between 1 and 562 can be set with the on-shore control software. Data sampling is done at $500 \mathrm{kS}$ ps with 16 bits and an analogue anti-alias filter with a $3 \mathrm{~dB}$ point at a frequency of $128 \mathrm{kHz}$. Digital downsampling with factors of 2 and 4 is implemented inside an off-shore FPGA. This value is also selectable using on-shore control software. The system parameters were tuned using the data collected with the autonomous precursor device AMADEUS-0 that was deployed and subsequently recovered at the ANTARES site in March 2005.

Where appropriate, the components of the AMADEUS system have been calibrated in the laboratory prior to deployment; the in situ performance is in full accordance with the expectations. Data taking is going on continuously and the data are recorded if one of three adjustable trigger conditions is met.

The system is well suited to conclude on the feasibility of a future large-scale acoustic neutrino telescope in the deep sea. Furthermore, it has the potential of a multi-purpose device, combining its design goal to investigate acoustic neutrino detection techniques with the potential to perform marine science studies. AMADEUS is a promising starting point for instrumenting the future neutrino telescope project KM3NeT $[29,30]$ with acoustic sensors for position calibration and science purposes.

\section{Acknowledgments}

The authors acknowledge the financial support of the funding agencies: Centre National de la Recherche Scientifique (CNRS), Commissariat à l'énergie atomique et aux énergies alternatives (CEA), Agence National de la Recherche (ANR), Commission Européenne (FEDER fund and Marie Curie Program), Région Alsace (contrat CPER), Région Provence-Alpes-Côte d'Azur, Département du Var and Ville de La Seyne-sur-Mer, France; Bundesministerium für Bildung und Forschung (BMBF), Germany; Istituto Nazionale di Fisica Nucleare (INFN), Italy; Stichting voor Fundamenteel Onderzoek der Materie (FOM), Nederlandse organisatie voor Wetenschappelijk Onderzoek (NWO), the Netherlands; Council of the President of the Russian Federation for young scientists and leading scientific schools supporting grants, Russia; National Authority for Scientific Research (ANCS), Romania; Ministerio de Ciencia e Innovacion (MICINN), Prometeo of Generalitat Valenciana (GVA) and MULTIDARK, Spain. We also acknowledge the technical support of Ifremer, AIM and Foselev Marine for the sea operation and the CC-IN2P3 for the computing facilities.

\section{References}

[1] G.A. Askariyan, B.A. Dolgoshein, et al., Nucl. Instr. and Meth. 164 (1979) 267.

[2] J. Learned, Phys. Rev. D 19 (1979) 3293.

[3] S. Bevan, et al., ACoRNE Collaboration, Astropart. Phys. 28 (3) (2007) 366 arXiv:astro-ph/0704.1025v1.

[4] S. Bevan, et al., ACoRNE Collaboration, Nucl. Instr. and Meth. A 607 (2009) 389 arXiv:0903.0949v2 [astro-ph.IM]

[5] V. Niess, V. Bertin, Astropart. Phys. 26 (2006) 243 arXiv:astro-ph/0511617v3.

[6] F. Descamps for the IceCube Collaboration, in: Proceedings of the 31st International Cosmic Ray Conference, 2009, arXiv:0908.3251v2 [astro-ph.IM].

[7] K. Antipin, et al., BAIKAL Collaboration, in: Proceedings of the 30th International Cosmic Ray Conference, 2007, arXiv:0710.3113 [astro-ph].

[8] J. Vandenbroucke, G. Gratta, N. Lehtinen, Astrophys. J. 621 (2005) 301 arXiv:astro-ph/0406105.

[9] S. Danaher for the ACoRNE Collaboration, in: Proceedings of ARENA 2006, the Second International Workshop on Acoustic and Radio EeV Neutrino Detection Activities, J. Phys. Conf. Ser. 81, IOP Publishing, Philadelphia, 2007, p. 012011.

[10] G. Riccobene for the NEMO Collaboration, Nucl. Instr. Meth. A 604 (2009) 149

[11] The ANTARES Collaboration, ANTARES, the first operational Neutrino Telescope in the Mediterranean Sea, Nucl. Instr. and Meth. A, submitted for publication.

[12] M. Ageron, et al., ANTARES Collaboration, Astropart. Phys. 31 (2009) 277 arXiv: 0812.2095 v1 [astro-ph].

[13] P. Amram, et al., ANTARES Collaboration, Nucl. Instr. and Meth. A 484 (2002) 369.

[14] M. Ardid for the ANTARES Collaboration, Nucl. Instr. Meth. A 602 (2009) 174.

[15] C. Richardt, et al., Astropart. Phys. 31 (2009) 19 arXiv:0906.1718v1 [astroph.IM].

[16] M. Ageron, et al., ANTARES Collaboration, Nucl. Instr. and Meth. A 581 (2007) 695.

[17] F. Deffner, Studie zur akustischen Neutrinodetektion: Analyse und Filterung akustischer Daten aus der Tiefsee, Diploma Thesis, Univ. Erlangen-Nürnberg, FAU-PI1-DIPL-07-001, 2007, Obtainable from:〈http://www.antares.physik. uni-erlangen.de/publications $>$.

[18] G. Anton, et al., Astropart. Phys. 26 (2006) 301.

[19] K. Graf, Experimental studies within ANTARES towards acoustic detection of ultra-high energy neutrinos in the deep sea, Ph.D. Thesis, Univ. ErlangenNürnberg, FAU-PI1-DISS-08-001, 2008, Obtainable from: <http://www. antares.physik.uni-erlangen.de/publications $>$.

[20] R.J. Urick, Ambient Noise in the Sea, Peninsula Publishing, Los Altos, USA 1986, ISBN 0-932146-13-9.

[21] C.L. Naumann, Development of sensors for the acoustic detection of ultra high energy neutrinos in the deep sea, Ph.D. Thesis, Univ. Erlangen-Nürnberg FAU-PI4-DISS-07-002, 2007, Obtainable from:〈http://www.antares.physik. uni-erlangen.de/publications $>$.

[22] J.A. Aguilar, et al., ANTARES Collaboration, Nucl. Instr. and Meth. A 570 (2007) 107.

[23] J.A. Aguilar, et al., ANTARES Collaboration, Nucl. Instr. and Meth. A 622 (2010) 59 arXiv:1007.2549v1 [astro-ph.IM].

[24] R.J. Urick, Principles of Underwater Sound, Peninsula Publishing, Los Altos, USA, 1983, ISBN 0-932146-62-7.

[25] J.A. Aguilar, et al., ANTARES Collaboration, Astropart. Phys. 26 (2006) 314.

[26] F. Rademakers, R. Brun, Root: an object-oriented data analysis framework, Linux Journal $51<$ http://root.cern.ch/ $>$.

[27] M. Neff, Studie zur akustischen Teilchendetektion im Rahmen des ANTARESExperiments: Entwicklung und Integration von Datennahmesoftware, Diploma Thesis, Univ. Erlangen-Nürnberg, FAU-PI1-DIPL-07-003, 2007, Obtainable from: 〈http://www.antares.physik.uni-erlangen.de/publications >

[28] C. Richardt, et al., Nucl. Instr. Meth. A 604 (2009) 189.

[29] U.F. Katz, et al., KM3NeT Consortium, Nucl. Instr. Meth. A 602 (2009) 40.

[30] KM3NeT Consortium, Conceptual Design for a Deep-Sea Research Infrastructure Incorporating a Very Large Volume Neutrino Telescope in the Mediterranean Sea, ISBN 978-90-6488-031-5<http://www.km3net.org/CDR/ CDR-KM3NeT.pdf >, 2008. 


\title{
The ANTARES neutrino telescope: Performance one year after its completion
}

\author{
M. Bou-Cabo, J.A. Martínez-Mora* \\ Institut per a la gestió integrada de zones costaneres, Universitat Politècnica Valéncia, Spain
}

\section{A R T I C L E I N F O}

Available online 28 October 2009

Keywords:

ANTARES

Underwater neutrino telescopes

Astroparticle

\begin{abstract}
A B S T R A C T
Astronomy with a Neutrino Telescope and Abyss environmental REsearch (ANTARES) is a neutrino telescope that has been deployed under the Mediterranean Sea at $40 \mathrm{~km}$ of Toulon (French coast) at a depth of $2475 \mathrm{~m}$. The detector is composed of 12 strings equipped with 900 optical modules. The detection mechanism is based on the detection of Cherenkov light emitted by muon from neutrino interaction in the surroundings of the detector. From the light collected of different optical modules in coincidence it is possible to reconstruct the track of the muon and estimate the direction and energy of the neutrino.
\end{abstract}

(c) 2009 Elsevier B.V. All rights reserved.

\section{Introduction}

The production mechanism of high-energy cosmic rays remains one of the open problems in astroparticle physics. The detection of high-energy cosmic neutrino produced in the decay of charged pions in the hadro-production case would be an important help in understanding the mechanism involved. Compared to $\mathrm{X}$ and $\gamma$ rays, neutrinos have the advantage of carrying information from the core of the astrophysical objects. Moreover, neutrinos are not affected by galactic magnetic fields. The disadvantage of neutrinos is the detection difficulties due to the small cross section, and for this reason a huge volume of detection media is required.

The detection principle is shown in Fig. 1, muons produced by up-going neutrinos interacting in the earth's crust underneath the instrumented volume are detected through the Cerenkov photons emitted in the water. A large photomultiplier array records the position and arrival time of the Cherenkov photons thus allowing a precise reconstruction of the muon direction. The angle between neutrino and muon is very small at high energies, so the muon direction gives a good approximation than that of the neutrino.

To avoid background of muons coming from cosmic rays, the experiment has been optimized for a detection of up-going muons generated by neutrinos that have crossed the earth. As shown in Fig. 2, a detector installed in the Mediterranean Sea has a complementary view of the sky to the ones located at the South Pole like Amanda or Icecube, having a better view of the galactic center region.

\footnotetext{
* Corresponding author.

E-mail address: jmmora@fis.upv.es (J.A. Martínez-Mora).
}

\section{ANTARES detector}

The ANTARES detector [1,2] is composed by 12 strings of $480 \mathrm{~m}$-length anchored on the sea bed at a depth of $2475 \mathrm{~m}$ and straightened by buoys. Strings are separated by about $70 \mathrm{~m}$ from each other. Each string has 25 floors (also called storeys) containing triplets of optical modules, and a local control module for the associated electronics. Additionally, there are different kinds of sensors and instrumentation (LED beacons, hydrophones, compasses/tiltmeters) for the timing and position calibration of the module. The first storey is about $100 \mathrm{~m}$ from the sea floor, and the rest ones are vertically spaced by $14.5 \mathrm{~m}$. The optical modules [3] are looking downwards at $45^{\circ}$ from the vertical and are composed of a large area hemispherical (10 in.) photomultiplier tube (PMT) glued in a pressure resistant glass sphere with optical gel. A $\mu$-metal cage is used to shield the PMT against the Earth's magnetic field. Electronics inside the sphere are reduced to the PMT high voltage power supply and a LED system used for internal calibration. The data acquisition system has several levels and functionalities [4]: it takes care of the digitisation of the PMT signals, data transport, data filtering, and data storage. The detector is operated using a control program interfaced with all elements.

For a proper reconstruction of the muon track, calibration systems are needed. The relative positioning of the detector is obtained using a high frequency acoustic network (around $50 \mathrm{kHz}$ ) giving the 3-dimension position of hydrophones placed along the line, and a set of tiltmeter-compass sensors giving the local tilt angles of each optical module. The shape of each string is reconstructed by performing a global fit based on these information obtaining an accuracy in the position of the optical modules better than $20 \mathrm{~cm} \mathrm{[5].} \mathrm{The} \mathrm{relative} \mathrm{time} \mathrm{synchronisation} \mathrm{of} \mathrm{the}$ optical modules is obtained by a precise monitoring of the lengths 


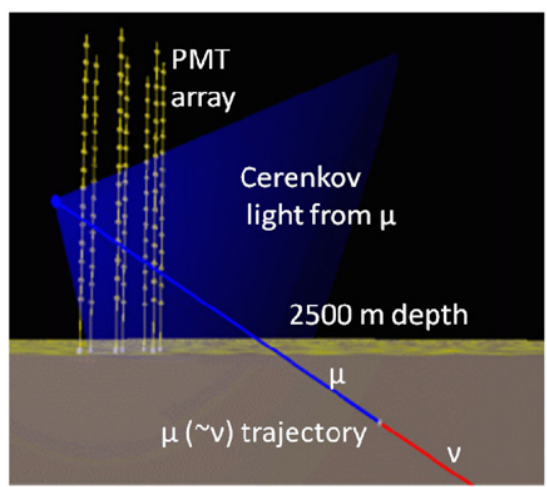

Fig. 1. This schema represents the interaction of a neutrino with the medium generating a muon. The muon produces Cherenkov light.

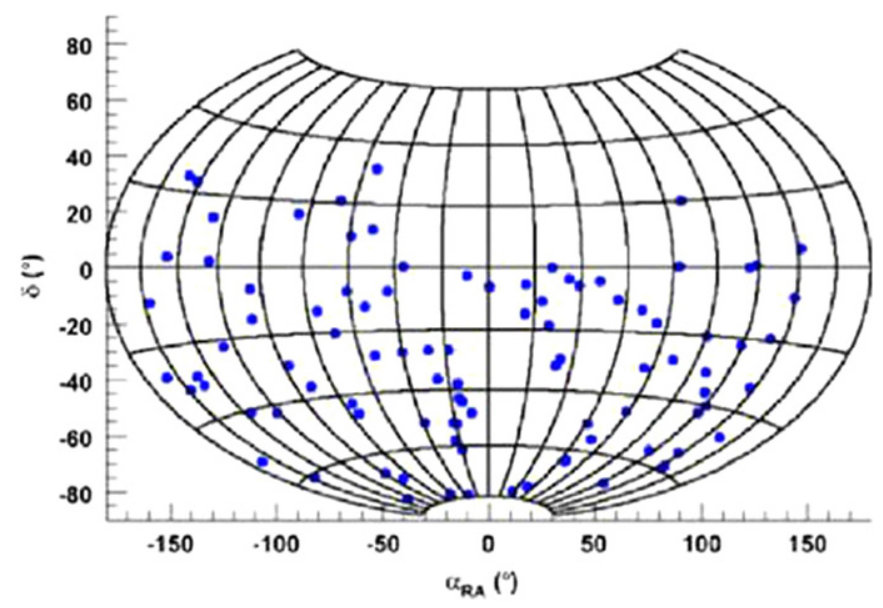

Fig. 2. Field of view of neutrino telescopes, for different locations.

of the clock optical fibers, a measurement of the arrival time of short intense light pulses produced by optical LED and laser beacons, and detection of coincidences from $40 \mathrm{~K}$ decay (natural component of the sea water) and downgoing atmospheric muons. Synchronization better than $1 \mathrm{~ns}$ is achieved [6].

In addition, there is an instrumentation line, which has 6 storeys with equipment for monitoring the sea, 3 of them with acoustic sensors. In line 12, there are also 3 storeys equipped with hydrophones. This acoustic system, called AMADEUS [7], constitutes a basic prototype array to evaluate the feasibility of the underwater acoustic detection of neutrinos.

Although there have been some little problems and troubles we can conclude that the detector, in general, is working according to the specifications and the performance is good $[2,8]$.

\section{The first physics analysis}

ANTARES aims to open a new field of scientific exploration of the universe. Neutrino detection provides a novel tool to explore high-energy phenomena in astrophysical objects. These are the main ANTARES physics capabilities: neutrino astronomy (point like sources, transient sources), neutrino diffuse, astrophysical and atmospheric muons, dark matter searches, neutrino oscillations, magnetic monopoles, nuclearites, and acoustic neutrino detection studies.

Two examples of results of these studies are presented in Figs. 3 and 4 using the 2007 data with the 5 line setup. The
Field of view of neutrino telescopes

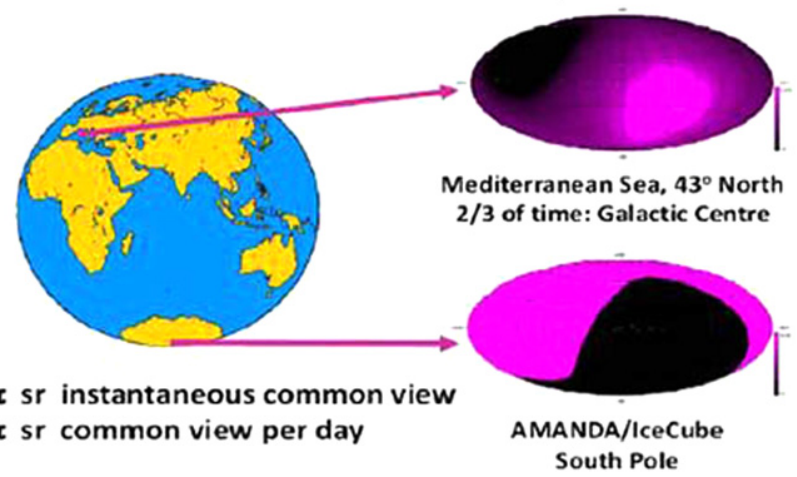

Fig. 3. Sky map in equatorial coordinates of 94 neutrino events (preliminary).

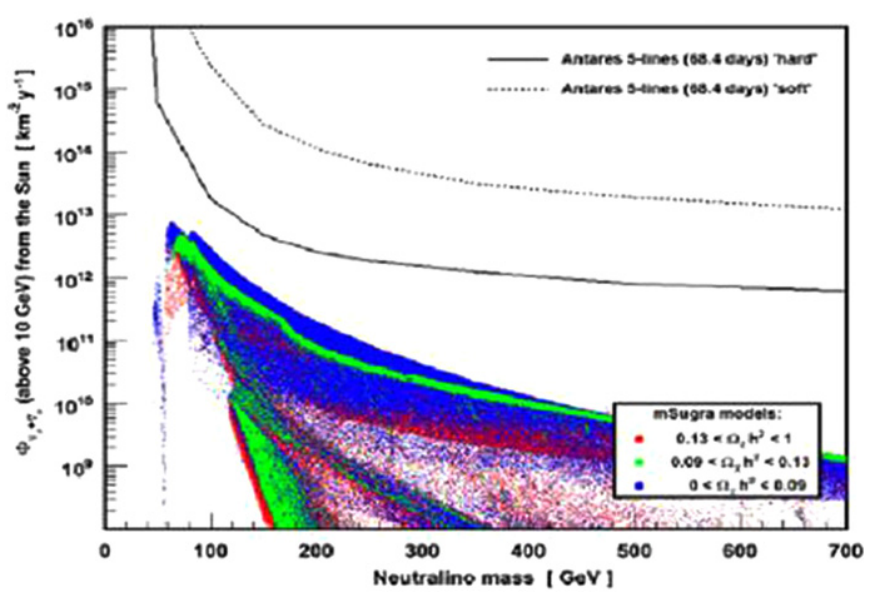

Fig. 4. Upper limit on the total neutrino fluxes from neutralino annihilation in the Sun with the 5-line data (preliminary).

preliminary map of the searching point-like sources in the Southern hemisphere is shown in Fig. 3. According to this analysis [9], no evidence of point-like source is observed, but even with such a limited configuration and measured time, competitive flux limits for the Southern Hemisphere are obtained. Dark matter searches are also possible by looking for an excess of neutrinos from celestial bodies like the Sun or the Galactic Center, due to the fact that neutrinos with energy below TeV could be produced by annihilation of neutralinos. The limits for the fluxes from the Sun obtained with the 5-line data are shown in Fig. 4.

\section{Acknowledgement}

We acknowledge the Spanish Ministerio de Ciencia e Innovación for the funding support, Contract FPA2007-63729.

\section{References}

[1] ANTARES Collaboration, A deep sea telescope for high energy neutrinos, 1999 (arXiv:astro-ph/9907432).

[2] M. Ardid, Ad Hoc Sensors \& Wireless Network 8 (2009) 21.

[3] P. Amram, et al., Nucl. Instr. and Meth. A 484 (2002) 369.

[4] J.A. Aguilar, et al., Nucl. Instr. and Meth. A 570 (2007) 107.

[5] M. Ardid, Nucl. Instr. and Meth. A 602 (2009) 174.

[6] F. Salesa-Greus, Nucl. Instr. and Meth. A 602 (2009) 72.

[7] R. Lahmann, Nucl. Instr. and Meth. A 602 (2009) 255.

[8] M. Ageron, et al., Astropart. Phys. 31 (2009) 277.

[9] J.D. Zornoza, Nucl. Instr. and Meth. A 588 (2008) 135. 


\title{
Time calibration and positioning for KM3NeT
}

\author{
S. Toscano ${ }^{\mathrm{a}, *, 1}$, M. Ardid ${ }^{\mathrm{b}}$, M. Bou-Cabo ${ }^{\mathrm{b}}$, M. Circella $^{\mathrm{c}}$, J.J. Hernández-Rey ${ }^{\mathrm{a}}$, J. Perkin ${ }^{\mathrm{e}}$, \\ J-P. Schuller ${ }^{\text {, }}$, L.F. Thompson ${ }^{\mathrm{e}}$ \\ ${ }^{a}$ IFIC - Instituto de Física Corpuscular, Edificios de Investigación de Paterna, CSIC - Universitat de València, Apdo. de Correos 22085, 46071 Valencia, Spain \\ ${ }^{\mathrm{b}}$ Institut de Investigaciò per la Gestiò de Zones Costaneres - Universitat Politècnica de València, Carretera Nazaret-Oliva S/N E-46730 Gandia, Spain \\ c INFN Sezione di Bari, Via E. Orabona 4, 70126 Bari, Italy \\ ${ }^{\mathrm{d}}$ DSM/Dapnia - Direction des Sciences de la Matiére, Institut de Recherche sur les lois fondamentales de l'Univers, CEA Saclay, 91191 Gif-sur-Yvette Cedex, France \\ e Department of Physics and Astronomy, University of Sheffield, Sheffield S3 7 RH, UK
}

\section{A R T I C L E I N F O}

\section{Available online 24 December 2008}

\section{Keywords:}

Neutrino telescope

Time calibration

Acoustic positioning

\begin{abstract}
A B S T R A C T
In this contribution we review the concepts put forward for the time calibration and positioning systems of the future KM3NeT neutrino telescope in the Mediterranean Sea. Even though the final layout of the detector, its mechanical structures and the light detection technologies to be used are not yet defined, much progress has been made in clarifying the possible technologies available for calibration and positioning. Concerning time calibration, we review the different concepts proposed, namely optical beacons (LED and laser), fibres or copper cables, ${ }^{40} \mathrm{~K}$, and a pre-deployment calibration. For positioning, the use of acoustic signals with lower frequency components in combination with cheaper hydrophones than in ANTARES is being investigated. The need and use of compasses and tiltmeters is strongly correlated to the mechanical structure chosen. For absolute positioning several methods are being considered. In the following, the solutions proposed in the KM3NeT Conceptual Design Report (CDR) [2001, available at: 〈http://www.km3net.org/CDR/〉] are discussed.
\end{abstract}

(c) 2008 Elsevier B.V. All rights reserved.

\section{Introduction}

Building on the experience gained on neutrino detection with the pilot projects ANTARES, NEMO and NESTOR, the three collaborations have joined efforts to develop, construct and operate a $\mathrm{km}^{3}$-scale neutrino telescope, KM3NeT, in the Mediterranean Sea [1].

The neutrino detection is based on the measurement of the Cherenkov light induced by the muons produced by neutrino interactions with matter in or around the detector. The Cherenkov radiation emitted by the muons can be measured by using sensitive optical detectors like photomultiplier tubes (PMTs). The muon track, and therefore the neutrino direction $\left(E_{v}>1 \mathrm{TeV}\right)$, can be reconstructed from the arrival time of the Cherenkov photons at the PMTs, knowing the optical sensor positions. The quality of the reconstruction thus depends on the timing and position resolutions.

Monte Carlo studies show that a total instrumental time resolution of $3 \mathrm{~ns}$ is enough to reach an angular resolution better than $0.1^{\circ}$. This corresponds to a PMT and an electronics resolution better than $2 \mathrm{~ns}$ and a positioning precision better than $40 \mathrm{~cm}$.

\footnotetext{
*Corresponding author. Tel.: +34 963543537; fax: +34963543488.

E-mail address: toscano@ific.uv.es (. Toscano).

${ }^{1}$ For the KM3NeT Consortium.
}

\section{The timing calibration systems}

The experience gained in previous experiments shows that a relative timing calibration at the $1 \mathrm{~ns}$ level can be achieved. To determine the absolute and the relative time between the optical modules (OMs) that contain the optical sensors, several complementary time calibration systems are under study.

\subsection{Relative timing}

- LED beacons. Commercial LEDs can be pulsed using a dedicated circuit to generate nanosecond-scale flashes which directly illuminate the PMTs. This technique is used in both intra-line (on the same line) and inter-line (on different lines) calibration in ANTARES [2] via optical beacons made up of several LEDs (Fig. 1). In order to ensure that the light pulses are coincident for all LEDs, a synchronization of the LEDs emission times ( $\sim 20 \mathrm{ps})$ is required which constitutes the main drawback of this system. Alternatively, recent investigations focus on the identification of more powerful LEDs which will reduce the number of LEDs required in a single device, as well as on the development of different pulsing circuits.

To simplify and reduce the cost of the calibration system, the possibility of decoupling the intra-line and the inter-line calibration is currently under study. A very simple system, 


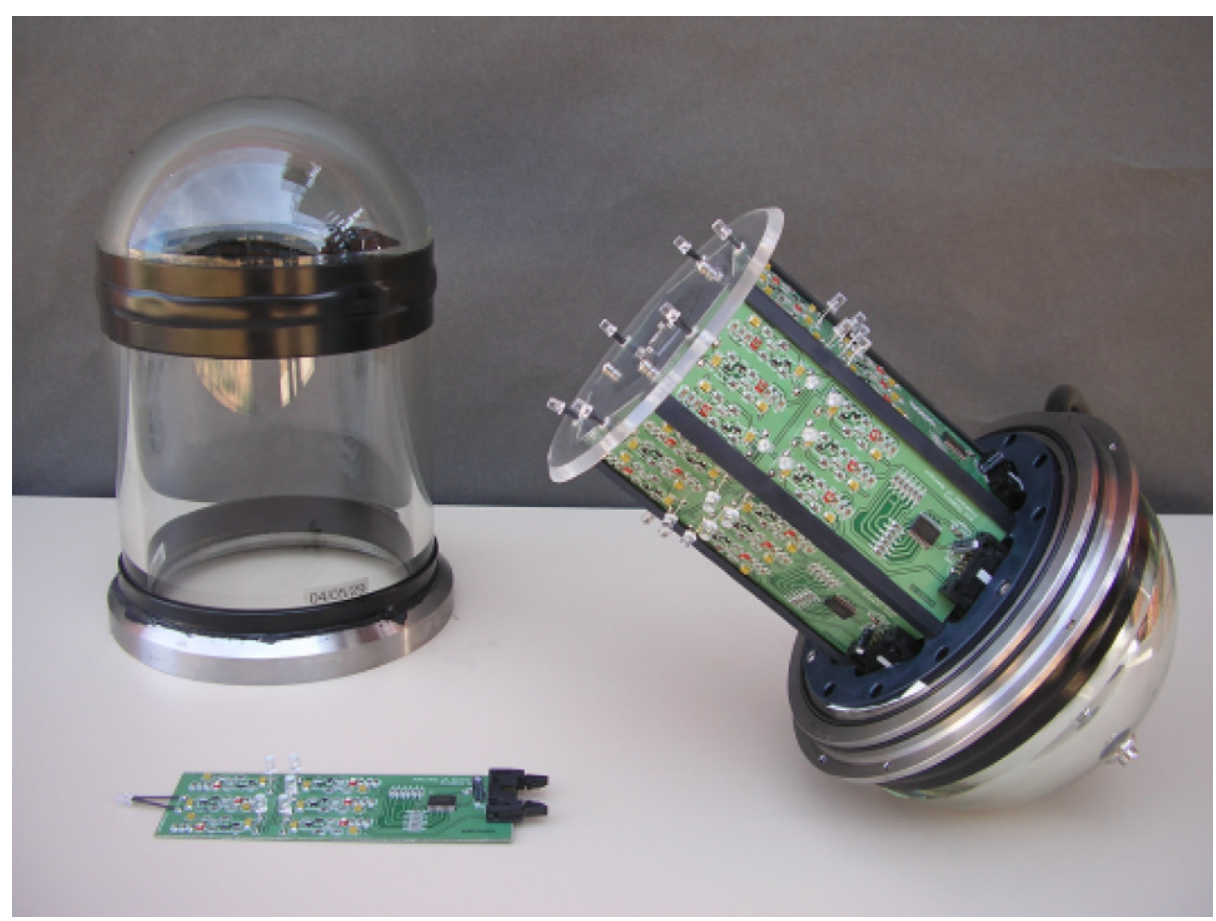

Fig. 1. The ANTARES LED optical beacons with its container. Six faces each containing six LEDs are arranged on a hexagonal cylinder.

made of only one LED housed inside the OM and pointing upwards, could be used to make the relative timing between the OMs in the same line, while a more sophisticated system could be used to perform the calibration of a few "strategic" OMs needed for the relative timing between lines.

- Laser beacons. Lasers, as those used in the ANTARES optical beacon system [2], produce high intensity pulses $(\sim 1 \mu \mathrm{J})$ of short duration (below $800 \mathrm{ps}$ of FWHM). They emit a collimated beam with a not-tuneable intensity. In the final design of the ANTARES laser beacon a dispersion device and a voltage-controlled optical attenuator were included in order to control the intensity.

- ${ }^{40} \mathrm{~K}$ coincidences. Underwater neutrino telescopes are subject to an environmental background due to the $\beta$-decay of the ${ }^{40} \mathrm{~K}$ isotope present in the oceanic salt. The Cherenkov light produced by the emitted electron usually reaches only $1 \mathrm{OM}$. However, as experienced in ANTARES, some detector configurations will enable the light to be observed by two different PMTs simultaneously. The coincidence rate of these disintegrations can be used to validate the time calibration results of a more sophisticated system.

- Optical fibres. Optical fibres are used to lead the light coming from an optical pulser towards the OMs. The approach based on LED pulsers has been developed inside the NEMO collaboration, whereas the solution adopted in the IceCube detector uses lasers as the source emitters. An important issue is that this system requires to accurately determine the path length of the fibres.

Solutions that facilitate in situ timing calibration are of paramount importance for the continuous monitoring of timing calibration constants. Prior to the deployment of the detector, however, a pre-deployment calibration in a dedicated darkroom is foreseen after the integration of the structure, in order to measure the initial timing calibration constants. This will require calibration test benches to be built at the sites where final construction and assembly will take place.

\subsection{Absolute timing}

While the primary requirement for timing calibration hardware for KM3NeT is to determine the relative timing between PMTs, it is also necessary to accurately determine the absolute timing of the events. In particular, this is crucial when requiring the observation of a high-energy neutrino to be synchronized with, for instance, a transient astrophysical source. Timestamping at the millisecond accuracy is enough to study any conceivable transient astrophysical object and this is easily achievable with commercially available GPS units.

\section{The position calibration systems}

Since the optical sensors of the neutrino telescope are attached to non-rigid structures, they are subject to undersea currents that can displace them by up to several metres. For an accurate muon reconstruction, a real-time measurement of the PMT positions is needed with an accuracy better than $40 \mathrm{~cm}$ (equivalent to $2 \mathrm{~ns}$ ).

\subsection{Acoustic and tiltmeter/compass system}

The requirements of the positioning system strongly depend on the given mechanical structure that will hold the PMTs. Two possible systems can be envisaged to provide the necessary information:

- A long baseline (LBL) acoustic system gives the 3D position of hydrophones placed along the structure. It is done by triangulation from the measurements of the travel times of acoustic pulses between the emitters, fixed on the sea bed, and the receiving hydrophones. Based on the experience of the ANTARES acoustic positioning system [3], a precision on acoustic distance measurements of $\sim 2 \mathrm{~cm}$ and an accuracy on the 3D hydrophones spatial positions better than $5 \mathrm{~cm}$ can be achieved. 


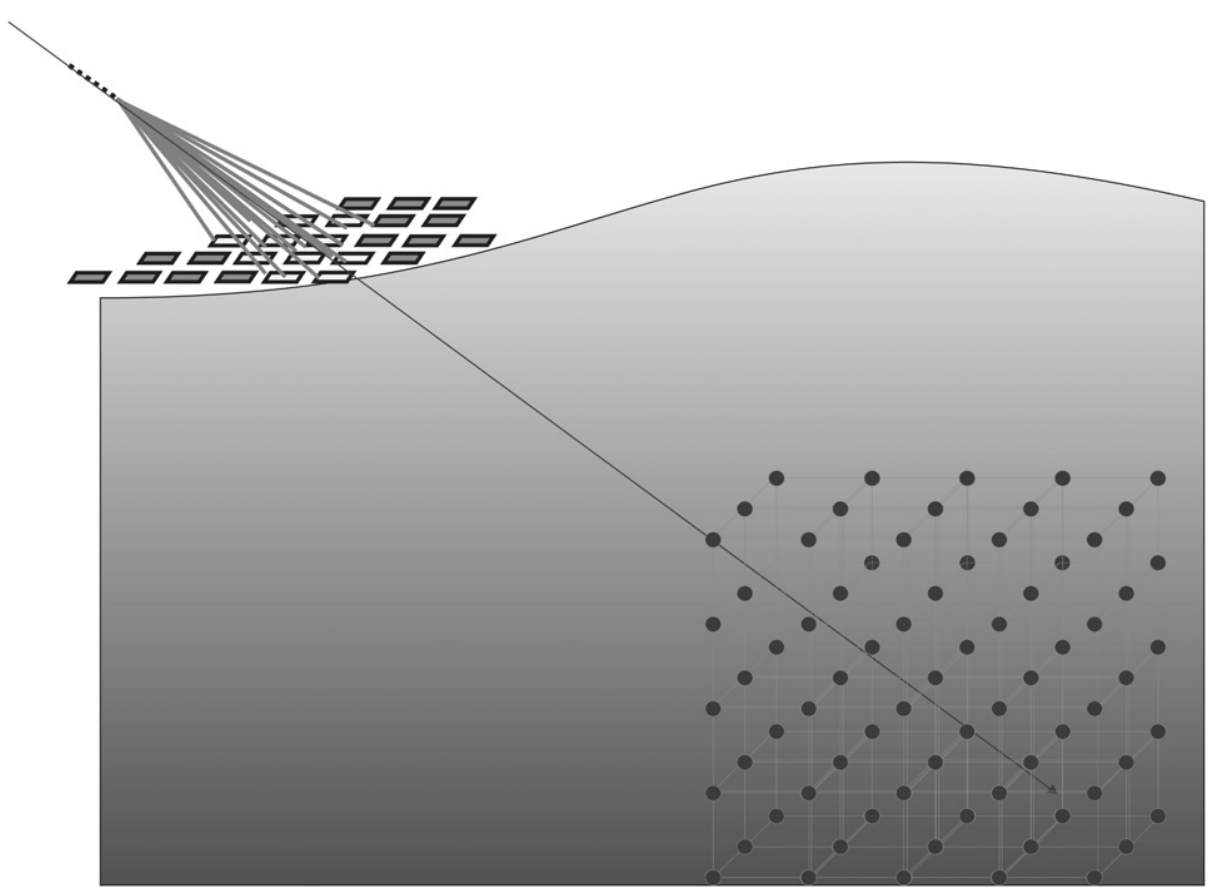

Fig. 2. Artistic view of the HELYCON stations. The floating array has been proposed as a calibration infrastructure for the KM3NeT neutrino telescope.

- A tiltmeter/compass system gives the local tilt angles of each detection unit with respect to the horizontal plane (pitch and roll) as well as its orientation with respect to the Earth Magnetic North (heading). Complementary to the acoustic positioning system, tiltmeters and compasses are necessary for the shape reconstruction of the structure as well as for measuring the OM orientations.

Using this information as input for a 3D mechanical model, the detection unit shape is reconstructed taking into account the weight and drag coefficients of all the elements in the unit. This kind of system has been successfully used both in ANTARES and in NEMO.

A possibility to reduce the cost of the acoustic positioning system with respect to the ANTARES would be to substantially reduce the number of acoustic emitters-receivers, i.e. triangulating over longer distances. This would imply the use of lower sound frequencies, and, therefore, a worsening in the time and positioning resolutions would be expected. Pulse compression signals are being studied in order to compensate this effect and improve the resolution [4].

An alternative approach to reduce the unit cost of the system has been proposed consisting in attaching ceramic piezoelectric transducers inside the OM containing the optical sensor [5].

Additional measurements of the water currents and the sound velocity in sea water are needed in order to apply the aforementioned methods. The design of calibration lines equipped with dedicated instrumentation (Acoustic Doppler Current Profiler, Conductivity-Temperature-Depth sensors, and Sound Velocimeter) is foreseen to this end.

\section{Absolute orientation system}

In order to observe celestial objects and compare the results with other experiments an absolute positioning and a pointing calibration are required. Three different systems have been proposed to provide such calibrations.

\subsection{Acoustic method}

The position determination is based on the precise measurements of the geographical coordinates ( $x$ and $y$, in the UTM grid system) and the depth $z$ of the acoustic transducers fixed on the anchors of the detection units. To measure the geographical coordinates, a surface boat, equipped with an acoustic transducer, determines its own position with a GPS/Galileo receiver and the distance to a given deep-sea transducer by sound transit time. This measurement gives the absolute azimuth of the detector with an accuracy of $\sim 0.02^{\circ}$.

On the other hand, the depth is measured by a pressure sensor located in the anchor of the detection unit which can be verified by the measurement from a Remote Operated Vehicle (ROV) equipped with an accurate pressure sensor. Furthermore, the temperature and salinity profiles are performed on the same day to get the pressure-depth relationship. The measurement gives the tilt of the detector with an accuracy of $\sim 0.01^{\circ}$.

A combination of these measurements gives an absolute pointing accuracy for the neutrino telescope better than $\sim 0.03^{\circ}$.

\subsection{Sea surface detector}

The method based on the HELYCON design [6] employs cosmic ray induced showers that contain muons of sufficient energy $\left(E_{\mu}>2 \mathrm{TeV}\right)$ to reach the undersea detector. A Monte Carlo study has been performed to quantify the calibration capabilities of three autonomous detector arrays on floating platforms $(4000 \mathrm{~m}$ above the telescope) at distances of $150 \mathrm{~m}$ from each other. The direction of the shower axis (reconstructed for the surface detector) is compared with the direction of the muon reconstructed in the underwater telescope (Fig. 2). An absolute pointing accuracy of $\sim 0.05^{\circ}$ is reachable with this method in 10 days of data taking.

The absolute position of the detector can be estimated by measuring the distance between the impact points of the reconstructed muon track and the shower axis. The accuracy is better than $1 \mathrm{~m}$ within a 10-day data taking period. 


\subsection{Moon shadow}

A verification of the detector angular resolution and its absolute position can be performed by looking at the "Moon Shadow" in the reconstructed downgoing muon tracks [7]. Since the moon absorbs cosmic rays, a lack of atmospheric muons from the direction of the moon disk (angular radius $R_{\text {Moon }}=0.26^{\circ}$ ) is expected.

NEMO simulation studies indicate that a $3 \sigma$ effect can be observed in less than one year of data taking with a $\mathrm{km}^{3}$ apparatus [8].

\section{Conclusions}

Following the success of the first generation neutrino experiments the three collaborations ANTARES, NEMO and NESTOR have formed the KM3NeT consortium to study the construction of a $\mathrm{km}^{3}$-scale neutrino telescope in the Mediterranean Sea.

In order to achieve an angular resolution of $0.1^{\circ}$ at $E>10 \mathrm{TeV}$ several calibration systems have been proposed inside the collaboration, and the experiences based on the pilot projects have been evaluated to implement new ideas and to study the feasibility for KM3NeT. All these systems are within the guidelines of the KM3NeT CDR, recently presented by the collaboration. The culmination of the current studies on these systems will provide the basis for the design of the final calibration system in the technical design report, containing the technical specifications for the future KM3NeT infrastructure.

\section{Acknowledgements}

This work was supported by the KM3NeT design study, EC Contract number DS 011937. S. Toscano and J.J. Hernandez-Rey acknowledge the support from MICINN (Spain), Contract CAC2007-12 (KM3NeT). M. Ardid and M. Bou-Cabo as well acknowledge Contract CAC-2007-51.

\section{References}

[1] KM3NeT Cons. Conceptual Design Report, 2001, available at: 〈http://www. $\mathrm{km} 3$ net.org/CDR/ $/$.

[2] F. Salesa, ANTARES Collaboration 2007, The optical beacon calibration system of the ANTARES neutrino telescope, in: Proceeding of UNWAT 2007, 2007.

[3] P. Keller, et al., ANTARES Collaboration 2007, Acoustic positioning system for the deep-sea ANTARES neutrino telescope, in: Proceeding of UNWAT 2007, 2007.

[4] M. Ardid, et al., Acoustic positioning system for underwater neutrino telescopes, in: Proceedings of the 19th International Congress on Acoustic, Madrid, 2-7 September 2007.

[5] G. Anton, et al., Astropart. Phys. 26 (2006) 301.

[6] A.G. Tsirigotis, HELYCON Collaboration, HELYCON: a statur report, in: Proceedings of the 20th European Cosmic Ray Symposium, Lisbon, Portugal, 5-8 September 2006.

[7] M. Ambrosio, et al., Astropart. Phys. 20 (2003) 145.

[8] C. Distefano, et al., Nucl. Instr. and Meth. A 567 (2006) 495. 


\title{
A prototype for the acoustic triangulation system of the KM3NeT deep sea neutrino telescope
}

\author{
M. Ardid *, M. Bou-Cabo, F. Camarena, V. Espinosa, G. Larosa, C.D. Llorens, J.A. Martínez-Mora \\ Institut de Investigació per a la Gestió Integrada de les Zones Costaneres, Universitat Politècnica de València, Cra. Nazaret-Oliva S/N, 46730 Gandia, Spain
}

For the KM3NeT Consortium

\section{A R T I C L E I N F O}

Available online 27 October 2009

Keywords:

Underwater neutrino telescope

KM3NeT

Acoustic positioning system

Calibration

\begin{abstract}
A B S T R A C T
The KM3NeT consortium is designing a research facility with a cubic kilometer-scale neutrino telescope in the Mediterranean Sea. The neutrino telescope will consist of an array of optical modules which detect Cherenkov light from muon tracks. The optical modules are subject to motion in the presence of deep sea currents, and an acoustic triangulation system is needed to determine their positions to provide the required tracking precision and angular resolution for astronomical neutrino source searches. In this paper we will describe one of the solutions proposed for the acoustic system for KM3NeT and the work done in order to develop a prototype. The system consists of an array of affordable transducers that can operate as transceivers in the $20-40 \mathrm{kHz}$ region and withstand the high pressures (up to 500 bar). Versatile associated low-power electronics has been developed, implementing the all-data-to-shore approach. Besides accomplishing the control of signal transmission and reception, it allows for transducer configuration from shore to benefit from varied on-shore signal processing techniques.
\end{abstract}

(c) 2009 Elsevier B.V. All rights reserved.

\section{Introduction}

The KM3NeT project aims at the construction and operation of a cubic-kilometer scale neutrino telescope in the Mediterranean Sea. The KM3NeT telescope will consist of an array of optical modules (photon sensors contained in glass sphere vessels) which detect Cherenkov light from muon tracks [1]. However, the optical modules are subject to motion in the presence of deep sea currents and it is necessary to monitor their positions with a precision of $40 \mathrm{~cm}$ or better [3], so as to provide the tracking precision and angular resolution required for astronomical neutrino source searches. An acoustic triangulation system with transceivers on the sea floor and receivers in the KM3NeT structures is foreseen to obtain the input information to predict the shape of the structures by using a mechanical model [2]. In this paper we present the work done for designing and developing a prototype that could be used as a solution for the acoustic positioning system of KM3NeT, especially for the transceivers part. Other options for this system are also being investigated.

\section{Prototype for the acoustic positioning system}

Following the ideas of reducing cost and increasing reliability, a prototype of the positioning system is being developed. It

\footnotetext{
* Corresponding author. Tel.: +34 962849314; fax: +34962849309.

E-mail address: mardid@fis.upv.es (M. Ardid).
}

basically consists of two parts: the acoustic transducers and the electronics [4]. The acoustic transducers are commercially available Free Flooded Rings (FFR) transducers SX30 from Sensor Tech. Ltd. have been chosen for the prototype. These are affordable transducers for a cubic kilometer facility. The unlimited depth for operation, the working frequency range $(20-40 \mathrm{kHz})$, the transmitting and receiving voltage responses (133 dB Ref. $1 \mu \mathrm{Pa} / \mathrm{V}$ at $1 \mathrm{~m}$ and $-183 \mathrm{~dB}$ Ref. $1 \mathrm{~V} / \mu \mathrm{Pa}$, respectively) and the input power ( $300 \mathrm{~W}, 2 \%$ duty cycle) make these transducers a very good option for the proposed application. The design of the electronics for these transducers working as transceivers is quite challenging due to the versatility and reliability required and the limitations imposed of working in deep sea. First, they should provide double functionality: emitting and receiving. As emitter, it should provide short high power signals generated from limited electrical power supply, as receiver, it should have low noise and limit the maximum level and to fulfil all-data-to-shore approach, which increases reliability and tuning out options at the same time that acoustic data could be used for other studies such as bioacoustics or acoustic detection of neutrinos. Additionally, the system has to be able to be reconfigured by RS232 in order to increase versatility, reconfiguration and optimization in situ, and must be very accurate and stable on time synchronization. The solution proposed is schematically shown in Fig. 1, together with a picture of the board and an example of the emission-reception using it with FFR transducers. The board consist of three parts: the microcontroller part, the emitting part and the reception part. Due to 

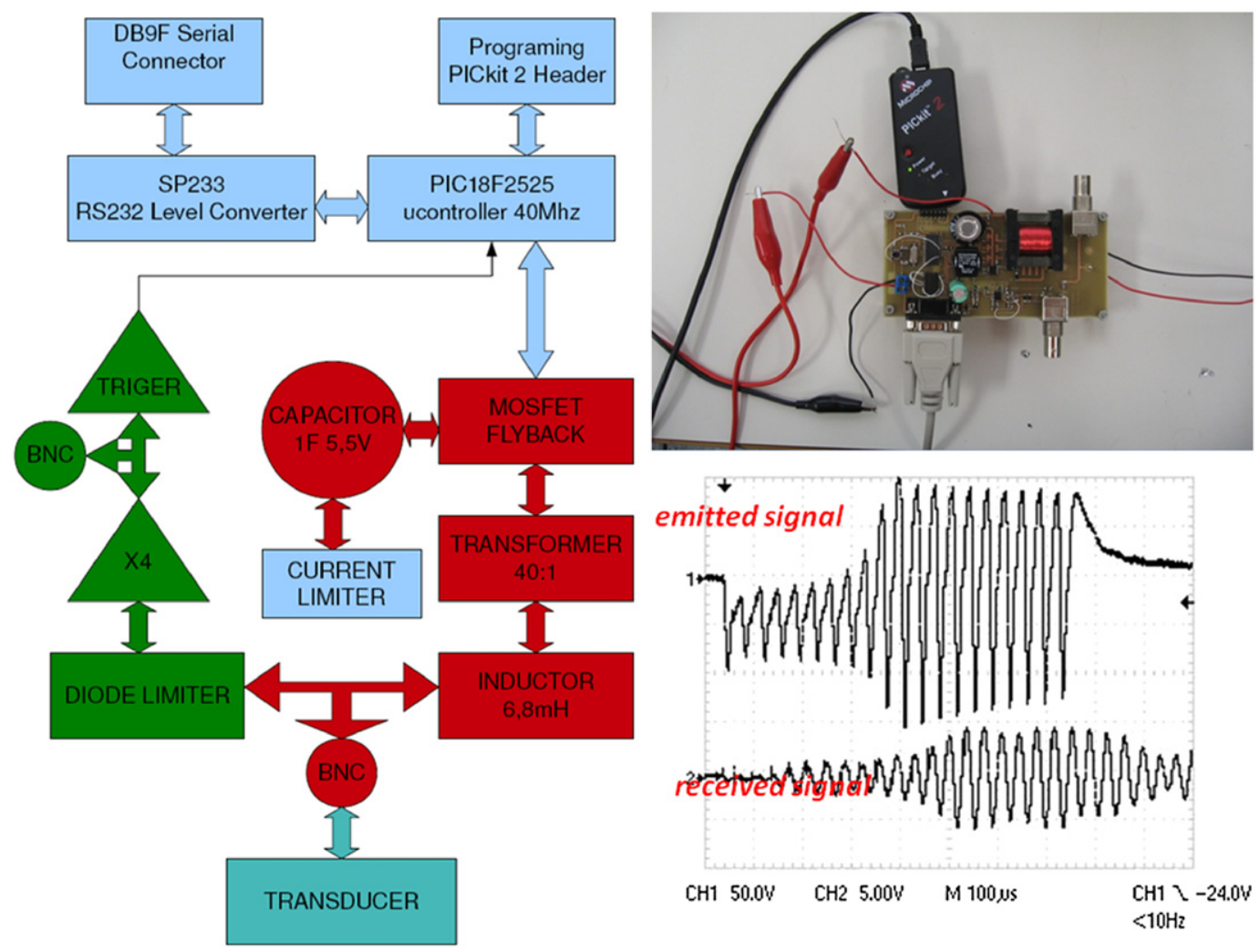

Fig. 1. Electronic board scheme, picture of it and example of the emission-reception using the board.

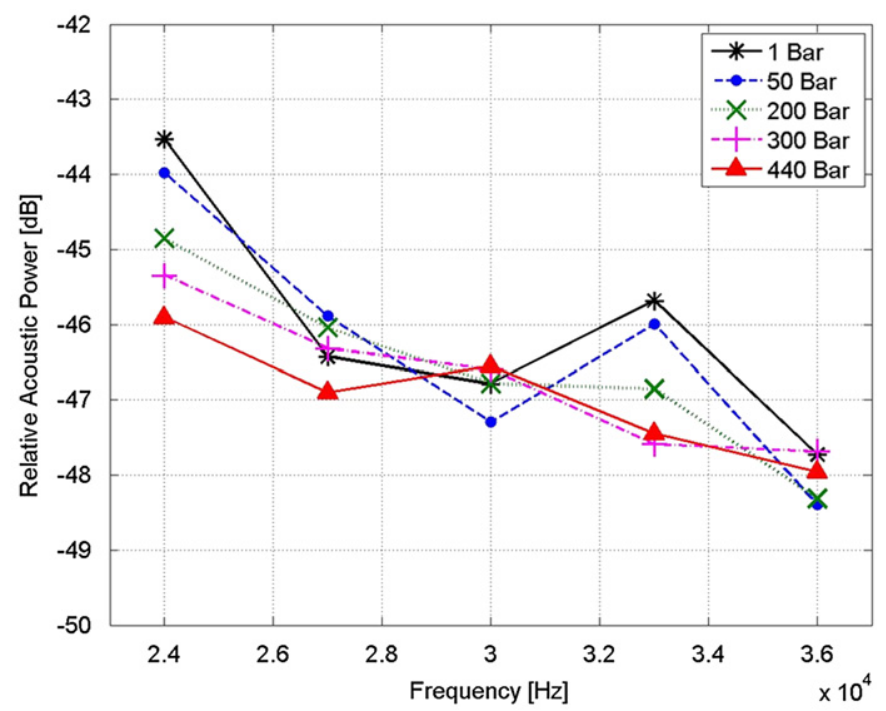

Fig. 2. Relative acoustic power transmitted as a function of frequency and pressure for a couple of FFR transducers. Uncertainties of the measurements are about $0.5 \mathrm{~dB}$.

power limitations ( $200 \mathrm{~mA}$ at $5 \mathrm{~V}$ ) the board has a current limiter for charging one capacitor of $1 \mathrm{~F}$ of capacity, the charge of this capacitor is monitored using an ADC input of the micro-controller. There is an output of the micro-controller connected to a mosfet transistor, which excites the primary of the transducer drive transformer at the frequency and duty cycle programmed in the micro-controller. The transformer converts from $5 \mathrm{~V}$ to approximately $200 \mathrm{Vpp}$ of signal for exciting the transducer through an inductor that reduce the capacitive impedance of the transducer. Directly from the transducer the board has a voltage limiter to limit the reception signal to $1.2 \mathrm{Vpp}$, then the signal is amplified with a gain of proximately of 4 . Additionally in the reception part the board has a trigger Smith too for converting the received signal to a square signal that could be detected and interpreted by the micro-controller (for example, it could provide time of reception directly if wanted). The micro-controller has the code for the emission of the signal and has a level adapter (SP233) for establishing the communication with the computer in the standard RS232 protocol, which can be used to configure the frequency, duty cycle and length of the signal, or directly the samples of the emitting signal. This micro-controller has the option to be triggered by a TTL signal, which is used to improve time synchronization.

\section{Prototype tests}

Several tests have been made or are under way to both the transducers and the electronics [4]. Next, we summarize the status and plans.

- Transmitting and receiving voltage response of the transducers: the measurements of these parameters have been done by comparison with a reference hydrophone in a relatively small $1.10 \times 0.85 \times 0.80 \mathrm{~m}^{3}$ tank. A well calibrated Reson TC4014 hydrophone was used as reference. In general, the results are in agreement with the specifications given by the supplier, although there are some little differences that are under study.

- Pressure tests to the transducers: The FFR transducers have been tested under pressure using the large hyperbaric tank laboratory at IFREMER Brest. An emitting-receiving system of short pulses with the FFR transducers was set, monitoring the transmission as a function of the pressure. Fig. 2 shows the 
relative acoustic power transmitted as a function of frequency and pressure for a couple of FFR transducers. Little variations with the pressure can be appreciated but no significant drifts on time were observed.

- Present and future tests: the integration of the electronics and transducers has started and tests are under way. Results in the lab and in shallow water will be soon available to demonstrate the feasibility of the system. Finally, the system will be tested in deep water in 2010 as part of a KM3NeT prototype.

\section{Acknowledgements}

This work was partially supported by the Spanish Ministerio de Ciencia e Innovación, ref. FPA2007-63729, and the European Frame- work Programme, Contract no. DS 011937 and Grant no. 212525. We acknowledge IFREMER Brest for both funding and technical support to perform the pressure tests. We thank G. Riccobene, V. Bertin and P. Keller for the fruitful discussions about the system.

\section{References}

[1] KM3NeT Consortium, Conceptual design report, see 〈http://www.km3net. org $>$.

[2] M. Ardid, Nucl. Instr. and Meth. A 602 (2009) 174.

[3] S. Toscano, et al., Nucl. Instr. and Meth. A 602 (2009) 183.

[4] M. Ardid, et al., R\&D towards the acoustic positioning system of KM3NeT, presented in VLVNT'09, Athens, 2009. 


\title{
R\&D for an innovative acoustic positioning system for the KM3NeT neutrino telescope
}

\author{
F. Ameli ${ }^{\mathrm{a}}$, M. Ardid ${ }^{\mathrm{b}}, \mathrm{V}$. Bertin ${ }^{\mathrm{c}}, \mathrm{M}$. Bonori ${ }^{\mathrm{a}}$, M. Bou-Cabo ${ }^{\mathrm{b}}$, C. Cali $^{\mathrm{d}}$, A. D’Amico $^{\mathrm{d}}$, G. Giovanetti $^{\mathrm{a}}$, \\ M. Imbesi ${ }^{\mathrm{d}}$, P. Keller ${ }^{\mathrm{c}}$, G. Larosa ${ }^{\mathrm{b}}$, C.D. Llorens ${ }^{\mathrm{b}}$, R. Masullo ${ }^{\mathrm{a}}$, N. Randazzo ${ }^{\mathrm{e}}$, G. Riccobene ${ }^{\mathrm{d}, *}$, \\ F. Speziale ${ }^{\mathrm{d}}$, S. Viola ${ }^{\mathrm{d}}$ \\ ${ }^{a}$ Università La Sapienza and INFN Roma 1, Piazzale A. Moro 2 I-00185, Rome, Italy \\ ${ }^{\mathrm{b}}$ Institut de Gestiò Integrada de Zones Costaneres-UPV, Cra. Nazaret-Oliva S/N E-46730 Gandia, Valencia, Spain \\ ' CPPM, CNRS/IN2P3 et Université de la Mediterranée, 163, Avenue de Luminy, Case 902, 13288 Marseille Cedex 9, France \\ d LNS-INFN, Via S. Sofia 62 I-95123, Catania, Italy \\ e Università di Catania and INFN Catania, Via S. Sofia 64 I-95123, Catania, Italy
}

\section{For the KM3NeT consortium}

\section{A R T I C L E I N F O}

Available online 5 May 2010

Keywords:

Underwater neutrino telescope

KM3NeT

Calibration

Acoustic positioning system

Transceiver

\section{Introduction}

The Acoustic Positioning System (APS) is a sub-system of the $\mathrm{km}^{3}$-scale neutrino detector that must provide mandatory information during the deployment and the operation phases of the telescope [1]. During the deployment phase, the APS must provide the position of telescope's mechanical structures, in a geo-referenced coordinate system, with an accuracy of about $1 \mathrm{~m}$. This is important both for a safe deployment of the mechanical structures and for the determination of the absolute position and pointing direction of the telescope (necessary for the localization of astrophysical sources). During the telescope operation phase, the APS data are used to recover the positions of optical modules (OMs) in deep sea. In fact, in order to effectively reconstruct the muon tracks via the optical Cherenkov technique, the OM coordinates must be known (in a geo- referenced system) with an accuracy of about $10 \mathrm{~cm}$, i.e. qualitatively speaking, about the length of the OM diameter. Moreover, in deep sea, the mechanical structures holding the optical modules move under the effect of currents and, therefore, their positions must be continuously monitored (e.g. about twice per minute under conditions of low sea currents, as measured in deep-sea sites candidates for KM3NeT

\footnotetext{
* Corresponding author.

E-mail address: riccobene@Ins.infn.it (G. Riccobene).
}

[1]). A deep-sea APS is composed by three main items: (1) a so called Long Base-Line (LBL) of acoustic transceivers, anchored on the seabed in known positions; (2) an array of acoustic receivers (hydrophones) rigidly connected to the telescope mechanical structures; (3) a PC farm for the APS data analysis, on shore. The hydrophones' positions are recovered by measuring the Acoustic Transit Time (ATT) of the LBL transceivers signals on the hydrophones, thus determining via triangulation, the position of the hydrophones with respect to the geo-referenced LBL. This innovative APS has been designed to accomplish full integration with the electronics and mechanical design proposed by for the KM3NeT telescope [1]. In particular, this new APS upgrades the systems developed for NEMO Phase 1 [2] and ANTARES [3]. It provides a better accuracy in the TOA measurement (thus a better position accuracy), thanks to absolute time synchronization between transceivers and hydrophones. It is also scalable to a $\mathrm{km}^{3}$ detector and all the components have been tested for long term installation at $3500 \mathrm{~m}$ depth. Eventually, it uses commercial audio electronics components and technology, so that costs of the electronics and data acquisition chain have been strongly reduced.

\section{Proposal for the KM3NeT APS}

The general scheme of the proposed APS is sketched in Fig. 1. Two hydrophones are installed on each storey of the detector. 


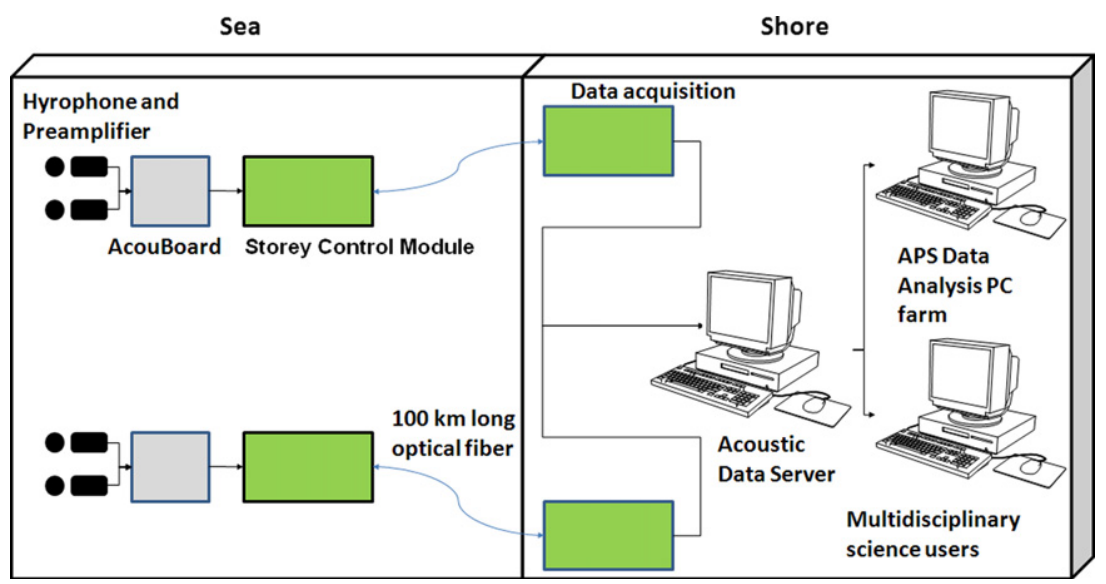

Fig. 1. Scheme of the APS data acquisition chain.

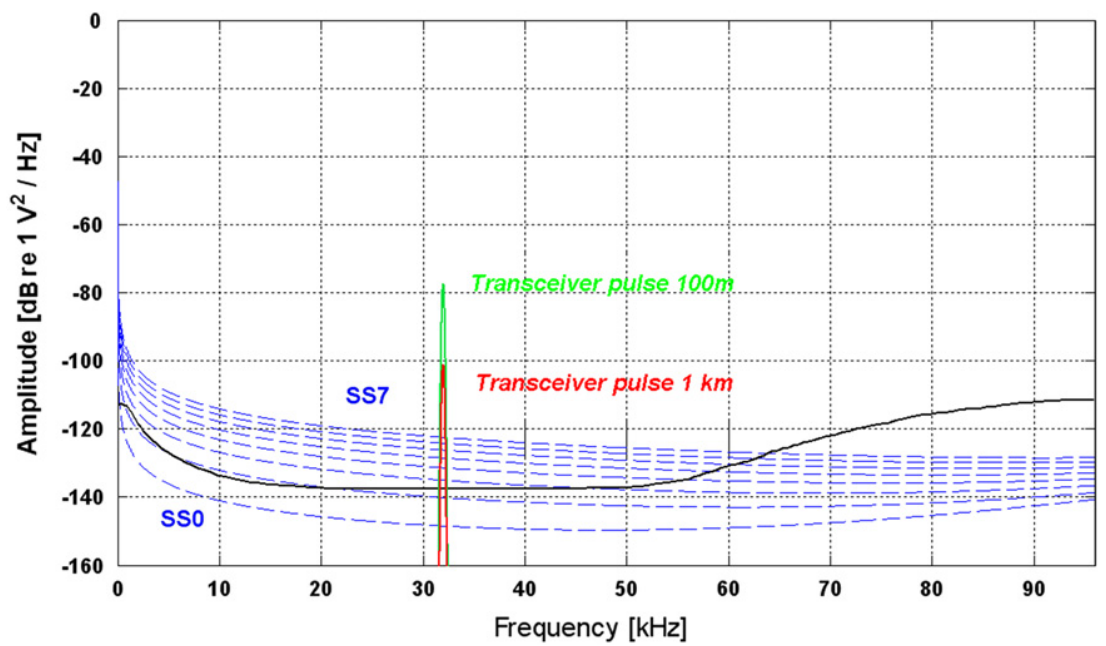

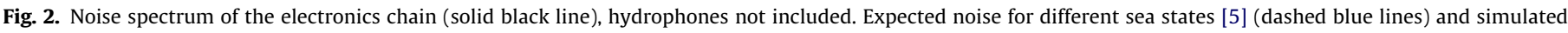

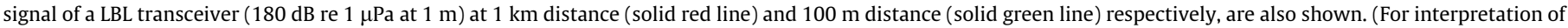
the references to colour in this figure legend, the reader is referred to the web version of this article.)

The hydrophones analogue signals are sampled by an ADCs hosted on a proprietary board called AcouBoard, encoded using the EBU/AES-3 standard [4], and then sent to the detector Storey Control Module (SCM) board. As described in ref. [1], all SCMs in the detector are synchronous and phased with respect to the GPS time signal transmitted from shore. This means that also the whole hydrophone array is synchronised and phased to GPS. The SCM sends to the shore station, via optical fibre, the APS data, embedded in the main data stream, containing also data from optical modules and environmental probes. In the shore laboratory, a dedicated board receives the main data stream, parses the audio data and reconverts them into electrical digital signals and transmit them to an audio data acquisition board called Acoustic Data Server (ADS). The ADS redirects data to a farm of PCs that performs APS data analysis. In fact, contrary to the previous ANTARES and NEMO experiences, the proposed APS relies on "all data to shore" philosophy. This means that data recorded by the hydrophones are continuously sent to shore to be analysed. This choice avoids the use of off-shore electronics dedicated to signal identification, reducing power consumption and costs and improving the system reliability and speed.

One of the main tasks of this R\&D activity has been addressed to the selection and characterization of hydrophones suitable for very deep sea installation. A new hydrophone, the SMID TR-401, and a preamplifier, SMID AM-401, have been developed by SMID. A pre-production of 40 hydrophones and preamplifiers has been acquired and tested at the NATO Undersea Research Centre of La Spezia (Italy). The hydrophones calibration curves were measured at 1 bar pressure, showing that the average sensitivity is about $-172 \pm 3 \mathrm{~dB}$ in the frequency range $(1 \mathrm{kHz} \div 70 \mathrm{kHz})$, using the SMID AM-401 preamplifier, $+38 \mathrm{~dB}$ gain. The directivity pattern of the hydrophone is omnidirectional. The relative change of hydrophones sensitivity as a function of pressure was also measured. The change of sensitivity, as a function of pressure, is less than $\pm 1 \mathrm{~dB}$ and it is therefore negligible for our purposes. The preamplifier output differential signal is sent to the AcouBoard that performs digitization of the signals coming from the two hydrophones of the floor, using a Sigma-Delta $192 \mathrm{kHz} / 24$ bit stereo ADC. This board was designed and constructed in collaboration with AGE Scientific (Lucca, Italy). The data transmission rate per hydrophone is $6.2 \mathrm{Mbps}$, fully sustainable by the proposed KM3NeT electronics and data transmission system [1]. Digitized data are then transmitted to the SCM, which adds the absolute GPS time to the audio stream. The whole data stream is transmitted, via optical fibre, from each SCM to shore, using a point-to-point connection. On shore the AES-3 acoustic data are parsed from the main data stream, and addressed to the APS data analysis system. As an example, Fig. 2 shows the measured 
electronics noise spectrum of the chain compared to the expected acoustic noise in deep sea [5] and to the signal emitted by an LBL transceiver at $100 \mathrm{~m}$ and $1 \mathrm{~km}$ distance from the hydrophone. The SSO curve indicates the expected background noise spectrum in condition of calm sea and absence of impulsive acoustic sources.

The LBL is composed by a field of acoustic transceivers, whose positions must be geo-referenced during the deployment operation using GPS signal, available on the ship that performs the deployment. Based on the ANTARES and NEMO Phase 1 experience, this positioning procedure has an accuracy of few metres. Each transceiver of the LBL will be hosted in a dedicated vessel anchored on the seabed, e.g. a Secondary Junction Box of the telescope. Each transceiver is connected to a Signal Generator Board, used when it acts as a beacon, as described in Ref. [6], and to an AcouBoard, used when it acts as a receiver. Since the whole array (LBL transceivers and hydrophones) is phased and synchronous with the GPS time, the proposed APS can perform precise ATT measurements. Preliminary tests show that the time accuracy of this system is about $1 \mu \mathrm{s}$. ATT measurements between different LBL transceivers are used to perform LBL auto-calibration in deep sea: this means that transceivers will determine and monitor their relative distance. As shown by the ANTARES results [7], after LBL calibration, the proposed system is expected to reach accuracy of the order of $1 \mathrm{~m}$ for absolute detector positioning. ATT measurements will be used to reconstruct the hydrophones positions, via triangulation. The accuracy in the determination of the hydrophones position with respect to the LBL reference system is expected to be less than $10 \mathrm{~cm}$. The APS data analysis is performed by a farm of PCs that analyses the data stream and recognises the pulses emitted by the LBL transceivers, through digital signal processing techniques. A chain of software tools measure the signal ATT - i.e. the difference between the acoustic pulse emitted by a transceiver and the TOA - and determine, via triangulation, the position of each acoustic receiver.

On shore, acoustic data will be distributed and available also for other applications, among which the real-time acoustic monitoring of the installation site in a range of several tens of $\mathrm{km}$. Sources of possible noise for the telescope operation, such as passage and operation of marine vessels, will be detected and tracked. Moreover hydrophones data will be an excellent tool for passive detection and tracking of cetaceans [8]. This APS will also provide a first tool to study the feasibility of a neutrino acoustic detector and a possible correlation between acoustic and optical signals [9].

\section{References}

[1] KM3NeT Consortium, Conceptual Design Report, 2008, ISBN: 978-90-6488031-5, 〈http://www.km3net.org $\rangle$.

[2] E. Migneco, et al., Nucl. Instr. and Meth. A588 (2008) 111

[3] M. Ardid, et al., Nucl. Instr. and Meth. A 602 (2009) 174.

[4] Available at 〈http://www.ebu.ch $\rangle$.

[5] R.J. Urick, in: Sound Propagation in the Sea, Peninsula Publishing, ISBN 0-932146-08-2, 1982.

[6] M. Ardid, et al., R\&D towards the acoustic positioning system of KM3NeT, this issue.

[7] V. Bertin, et al., Nucl. Instr. and Meth. A604 (2009) 136.

[8] N. Nosengo, Nature 426 (2009) 560.

[9] G. Riccobene, J. Phys.: Conf. Ser. 136 (2008) 022053. 


\title{
Calibration of sensors for acoustic detection of neutrinos
}

\author{
M Ardid, M Bou-Cabo, V Espinosa, J Martínez-Mora, F Camarena and J Alba \\ Departament de Física Aplicada, E.P.S. Gandia, Universitat Politècnica de València, \\ Cra. Nazaret/Oliva S/N, E-46730 Gandia, Spain. \\ mardid@fis.upv.es
}

\begin{abstract}
Calibration of sensors is an important task for the acoustic detection of neutrinos. Different approaches have been tried and used (calibrated hydrophones, resistors, powerful lasers, light bulbs explosion, etc.) We propose some methods for calibration that can be used in both the lab and the telescope ("in situ"). In this paper, different studies following these methods and their results are reported. First, we describe the reciprocity calibration method for acoustic sensors. Since it is a simple method and calibrated hydrophones are not needed, this technique is accessible for any lab. Moreover, the technique could be used to calibrate the sensors of a neutrino telescope just by using themselves (reciprocally). A comparison of this technique using different kind of signals (MLS, TSP, tone bursts, white noise), and in different propagation conditions is presented. The limitations of the technique are shown, as well as some possibilities to overcome them. The second aspect treated is the obtaining of neutrinolike signals for calibration. Probably, the most convenient way to do it would be to generate these signals from transducers directly. Since transducers do not usually have a flat frequency response, distortion is produced, and neutrino-like signals could be difficult to achieve. We present some equalization techniques to offset this effect. In this sense, the use of inverse filter based in Mourjopoulos theory seems to be quite convenient.
\end{abstract}

\section{Introduction}

Although acoustic detection of neutrinos has been proposed long time ago [1], it is just recently when science community show an increasing interest, and a major effort has been made for achieving this objective. Some experiments and test facilities have been appeared in water $[2,3,4,5,6]$ and in ice [7]. It is also worthwhile to mention the efforts made in simulations [8] and in R\&D for acoustic telescopes $[9,10]$. Calibration of acoustic sensors of the telescope, both in the lab and "in situ", is also a clue aspect on this task, and different approaches have been proposed [2,11,12]. In this paper, two studies related to calibration are presented: calibration of the sensitivity of acoustic sensors using the reciprocity method, and generation of neutrino-like signals using transducers.

\section{Calibration of the sensitivity of acoustic sensors using the reciprocity method}

One of the more common methods for calibration of the sensitivity of acoustic transducers is the reciprocity technique. A detailed description of the method is usually present in basic books of acoustics and transduction; see for example $[13,14]$, and it is not included here. The procedure is quite simple and allows to calibrate hydrophones with non-calibrated ones. No sophisticated acoustic equipment is needed, which could be very convenient for the application in particle physics labs. However, it usually requires free field configuration, which is not always an easy configuration for 
this kind of labs. In this work we study the use of different calibration signals and configurations in order to overcome the limitations mentioned. On the other hand, the reciprocity technique could, under certain circumstances, be also used to calibrate the sensors of neutrino telescopes just by using themselves reciprocally.

Using three non-calibrated hydrophones (designated by letters $a, b, c$ ), the sensitivity of transducer $c$ can be obtained in just three steps involving four measurements: $\mathrm{V}_{b}, \mathrm{~V}_{c}, \mathrm{~V}_{c}{ }^{\prime}$ and $\mathrm{I}_{b}$ (voltages and current in the transducers $b$ and $c$ ) with the expression

$$
S=\left(J \frac{\left|V_{c} \| V_{c}\right|}{\left|V_{b}\right|\left|I_{b}\right|}\right)^{1 / 2}
$$

where $J$ is the reciprocity parameter, which depends on the acoustic propagation conditions. The expression of this parameter is given in [15] for different cases. Thus, $J=2 d /(\rho f)$ for the spherical free field case, $J=2 A /(\rho c)$ for a tube assuming plane waves and $J=2 \pi f V /\left(\rho c^{2}\right)$, for a coupler, which consists in a small volume and assumes that the pressure is the same at any point, where $d$ is the distance between the transducers, $\rho$ is the density of the medium, $f$ is the frequency, $A$ is the area of the tube, $c$ the speed of the wave, and $V$ is the volume of the coupler. Notice the different frequency dependence of $J$ for every configuration.

Our studies have been done using Airmar Tech. P319 transducers $a$ and $b$, and a Reson TC4034 hydrophone as transducer $c$.

\subsection{Studies using different kind of signals}

The use of different kind of signals implemented in Cool Edit and Aurora [16] (MLS, sine sweep, tone bursts and white noise) has been studied for reciprocity calibration of the sensitivity of acoustic sensors in a $1.10 \times 0.85 \times 0.80 \mathrm{~m}^{3}$ tank. In figure 1 , the results of the calibration of the sensitivity of transducer $c$ for different signals are presented, and compared to the reference calibration provided from the manufacturer. Despite the limitations of the configuration, that is, the reflections in the small tank, the results are in a rough agreement with the reference calibration. However, it is also true that this technique must be refined before being able to use it for precise calibration of transducers. Another interesting aspect is that there are observable differences depending on the signal used. This can be explained in terms that the effects of the limitations in the method, such as the reflections in the walls, are sensitive to the signal used.
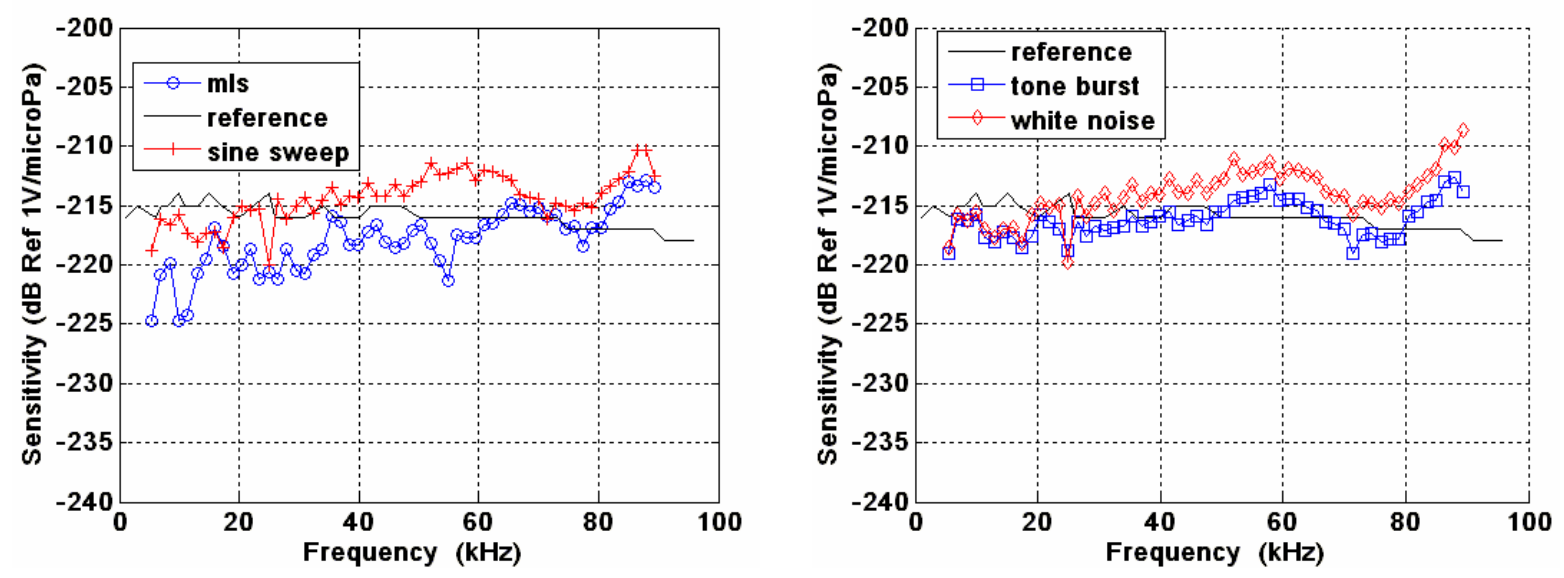

Figure 1. Results of the calibration of the sensitivity of transducer $\mathrm{c}$ for different signals

\subsection{Studies using different propagation conditions}

Additional to the tank study, in which we assumed a spherical free field wave, we have studied two more cases. The first one is a cylindrical $170 \mathrm{~cm}$-length tube with a diameter of $8 \mathrm{~cm}$, in which plane 
waves are assumed. The second configuration is a coupler consisting on a small $25 \mathrm{~cm}$-length tube and a diameter of $8 \mathrm{~cm}$ with methacrylate walls. The results of the calibration of the sensitivity of transducer $c$ in these two configurations are presented in figure 2 and compared to the reference calibration for both, using MLS and sine sweep signals. Again, a rough estimation of the sensitivity of the transducer is achieved, and the results are even more dependent of the signal used. According to the results, the coupler with MLS signal choice seems to be very promising, moreover, considering the limitations of the coupler used, which was a self-made prototype not optimised in materials nor in geometry. Therefore, this method could be proposed as a standard rough calibration of hydrophones in small labs working in collaboration for the development of an acoustic neutrino telescope in water. In addition, it has even more advantages for calibration of hydrophones for ice because of the small volume needed.
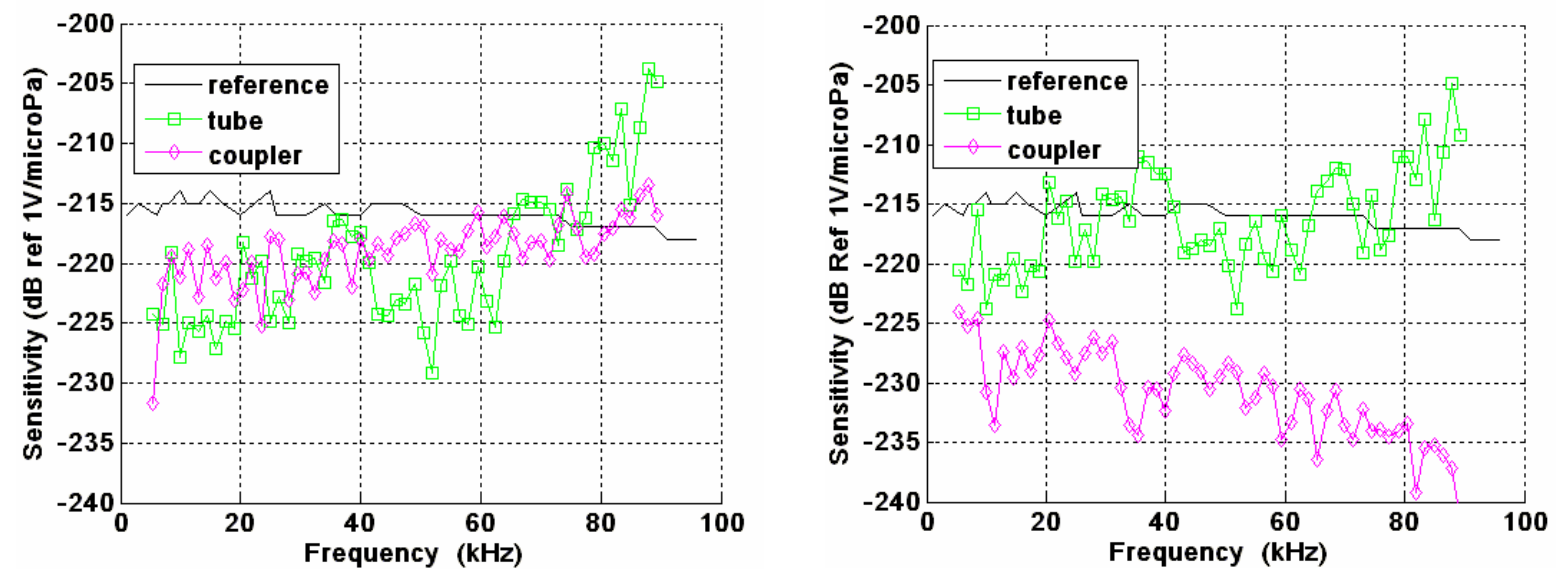

Figure 2. Results of the calibration of the sensitivity of transducer $\mathrm{c}$ using the tube and the coupler configurations using MLS signals (left) or sine sweep (right)

\section{Generation of neutrino-like signals using transducers}

Generation of neutrino-like signals is necessary to calibrate acoustic sensors for neutrino detection, as well as for the calibration of the acoustic neutrino telescope itself. Probably, the easiest and most convenient way to generate these signals is from transducers directly. However, since powerful transducers do not usually have a flat frequency response, distortion is produced, and it could be difficult to achieve. In this section we present some equalization techniques to offset this effect.

This study has been done in a $1.10 \times 0.85 \times 0.80 \mathrm{~m}^{3}$ tank using the Airmar Tech. P319 transducer as emitter and the Reson TC4034 hydrophone as receiver. This hydrophone has a flat frequency response below $100 \mathrm{kHz}$, whereas the emitter has a resonance at $50 \mathrm{kHz}$ with a quality factor $\mathrm{Q}=28$. Both transducers are controlled by a computer with a HDSP9632 soundcard working at $192 \mathrm{kHz}$ sampling frequency. Cool Edit and Aurora software are used for the data acquisition and analysis.

The neutrino-like signal used for generation is the pressure pulse due to a $1.2 \times 10^{11} \mathrm{GeV}$ shower in sea water at a distance of $1 \mathrm{~km}$ with a zero degree angle with respect to the plane transverse, according to simulations of the ACORNE collaboration [3].

\subsection{Without equalisation}

Certainly, the first attempt to generate neutrino-like signals from transducers is to feed it with an electric signal of the same shape. The results of this rough attempt are presented in figure 3 , where the neutrino-like signal labelled as reference, which is used for feeding the emitter, is compared to what is directly observed in the receiver. It is clear that the received signal is highly distorted compared to the emission signal. There is a kind of inertia, in which the $50 \mathrm{kHz}$ resonance has a notorious effect. 


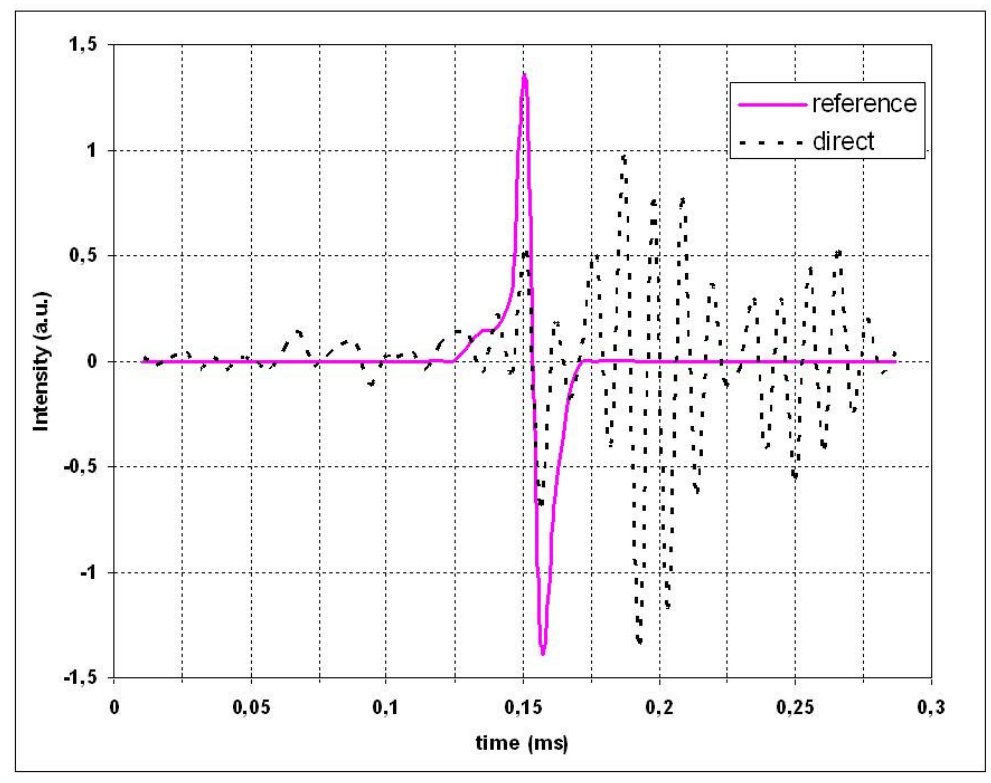

Figure 3. Received signal by feeding directly with the neutrino-like signal (reference).

\subsection{Equalisation}

After the first attempt, a question arises: if feeding with the original signal, this is not received. Could we feed with another signal in order to obtain the original signal in the receiver position? This is an inverse problem. To solve it, the first step is to know the transfer function of the system. Using a MLS signal, which is quite convenient due to their properties [16,12], we could obtain the impulse response, and therefore the transfer function. Afterwards, we could apply two equalisation techniques implemented in the Aurora software. Flatten spectrum is the name of the first technique that creates an inverse filter inverting only the minimum phase component of it, that is the magnitude of the transfer function is inverted. The second technique, named inverse filter, inverts mixed-phase impulse response following the Mourjopoulos least-squares technique [17]. Finally, once the filter is obtained, the original signal is convolved with the filter in order to obtain the signal that should be used for feeding the transducer. In figure 4 different steps of these procedures are presented. On top, the impulse response is shown: a) extended spectrum, b) zoom at the peak. c) and d) show the filters obtained using the inverse and flatten spectrum techniques respectively. Finally, e) and f) show the feeding signals obtained in both techniques.

The final result of the method is shown in figure 5, which shows the received signals applying both techniques in comparison with the neutrino-like signal reference. The flatten spectrum technique improves a little with respect to the case of non equalisation. However, it is still far from being good. Much better results are observed in the inverse filter based in the Morjopoulos technique, which reproduces the neutrino-like signal shape with large accuracy. 

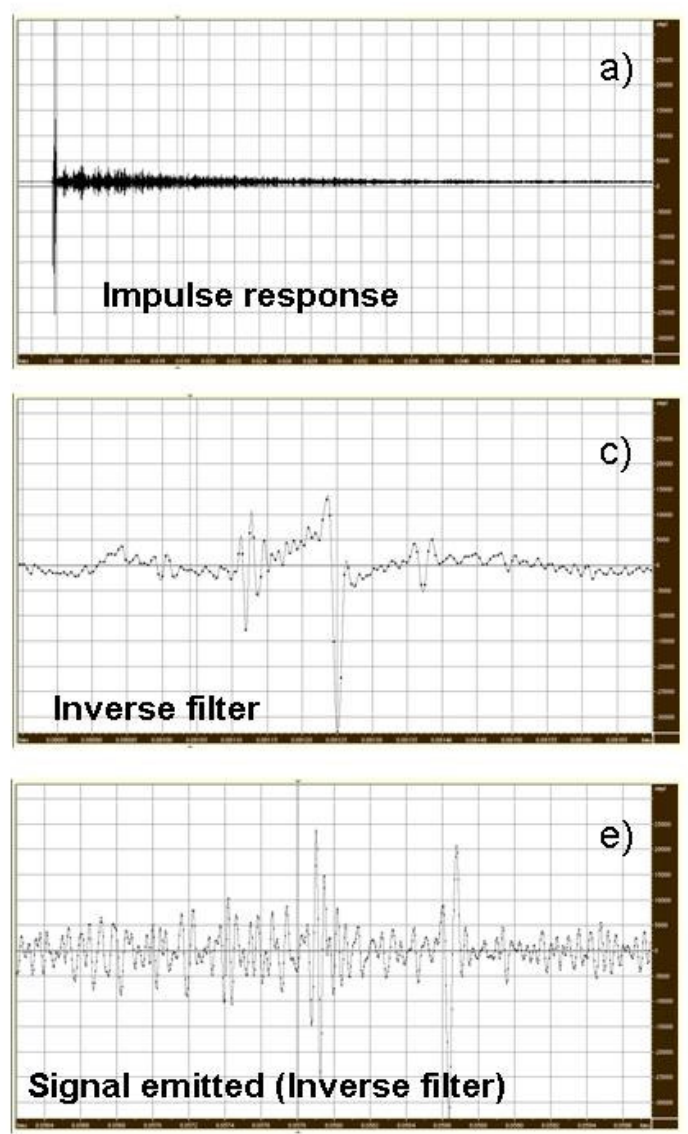

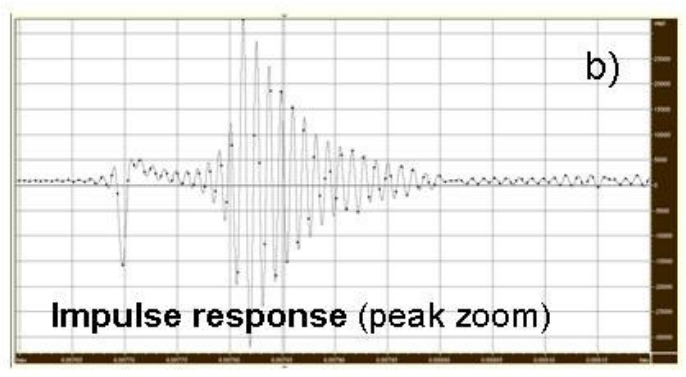

d)
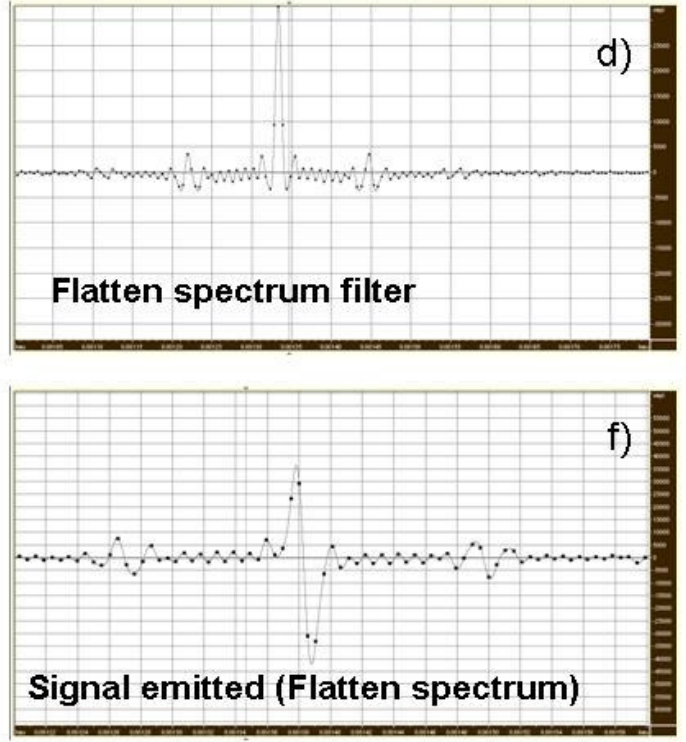

Figure 4. a) Impulse response of the system, extended spectrum, b) zoom at the peak of the impulse response. c) and d) show the filters obtained using the inverse and flatten spectrum techniques, respectively. e) and f) show the feeding signals obtained in these techniques.

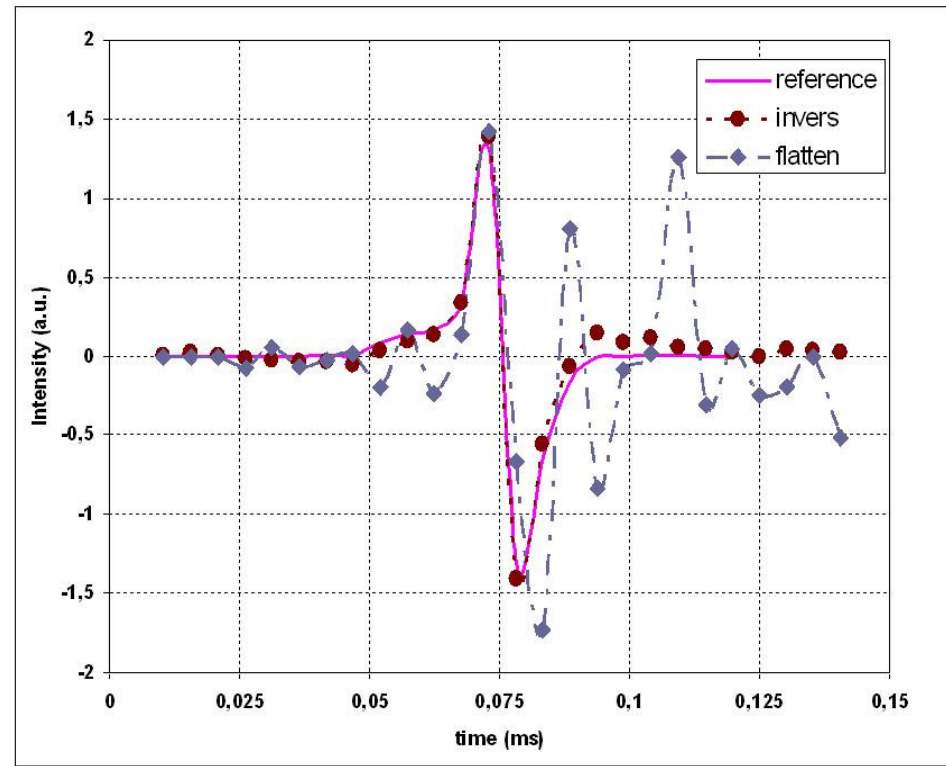

Figure 5. Received signals applying inverse filter and flatten spectrum techniques in comparison with the neutrino-like signal reference 
3.3. Convolution with MLS plus Inverse filter

Finally, we would like to propose a technique for the calibration with neutrino-like signals using transducers: instead of using the original neutrino-like signal for feeding, our proposal is to use this signal convolved with a MLS signal and apply the inverse filter. The emitted and received signals are, therefore, long signals, which only recover into neutrino-like signals after MLS deconvolution. This technique of calibration could have a series of advantages in a telescope: better signal to noise ratio, because of the large average in which the MLS results. Therefore, less amplification would be needed, or in other point of view, it could be used for larger distances. On the other hand, it would be possible to calibrate at the same time as measuring because the signal appears only after deconvolution with the MLS with the only effect of a little increase of the noise, but normally negligible. Moreover, in some cases the same sensors for detection could be used also for calibration, generating this kind of signals.

\section{Acknowledgements}

We would like to thank professors and colleagues J. Ramis, J.Redondo, V. Sánchez and L. Thompson for the fruitful discussions we have had on the topics presented in this paper.

\section{References}

[1] Askariyan G A, Dolgoshein B A, Kalinovsky A N, Mokhov N V 1979 Nucl. Instr. Meth. 164 267

[2] Vandenbroucke J, Gratta G and Lehtinen N G 2005 Astrophys. J. 621301

[3] The ACoRNE Collaboration 2005 PPARCPP/C504019 accessible at http://www.shef.ac.uk/physics/research/pppa/research/acorne.php

[4] Riccobene $\mathrm{G}$ et al. 2004 Nucl. Instr. Meth. A $\mathbf{5 1 8} 220$

[5] Lahmann R et al. 2006 Int. J. Mod. Phys. A 21 supp01 227

[6] Balkanov V et al. 2003 Nucl. Phys. B (Proc. Suppl.) 118363

[7] Böser $\mathrm{S}$ et al. 2006 Int. J. Mod. Phys. A 21 supp01 221

[8] Niess V and Bertin V 2006 Underwater acoustic detection of ultra high energy neutrinos, Astropart. Phys. (in press doi:10.1016/j.astropartphys.2006.06.005.)

[9] Naumann C et al. 2006 Int. J. Mod. Phys. A 21 supp01 92

[10] Anton G et al. 2006 Study of piezo based sensors for acoustic particle detection Astropart. Phys. (in press doi:10.1016/j.astropartphys.2006.07.001.)

[11] Capone A and De Bonis G 2006 Int. J. Mod. Phys. A 21 supp01 112

[12] Ardid M et al. 2006 Int. J. Mod. Phys. A 21 supp01 137

[13] Kinsler L E et al. 2000 Fundamentals of acoustics (NewYork: John Wiley \& Sons)

[14] Urick J 1983 Principles of underwater sound (Los Altos: Peninsula Publishing)

[15] Bobber R J 1966 J. Acoust. Soc. Am. 39680

[16] Farina A and Righini F 1997 Software implementation of an MLS analyzer, with tools for convolution, auralization and inverse filtering 103rd AES Convention (New York)

[17] Mourjopoulos J N 1994 J. Audio Eng. Soc. 42884 


\title{
Use of parametric acoustic sources to generate neutrino-like signals
}

\author{
M. Ardid *, M. Bou-Cabo, F. Camarena, V. Espinosa, G. Larosa, J.A. Martínez-Mora, M. Ferri \\ Institut de Investigació per a la Gestió Integrada de les Zones Costaneres, Universitat Politècnica de València, Cra. Nazaret-Oliva S/N, 46730 Gandia, Spain
}

\section{A R T I C L E I N F O}

Available online 31 March 2009

Keywords:

Acoustic neutrino transmitter

Acoustic detection

Calibration

Parametric array

\begin{abstract}
A B S T R A C T
It is not easy to design a calibrator system able to reproduce the time and directivity patterns of the acoustic pulse produced in an ultra high energy neutrino interaction. Linear arrays of acoustic transducers with coherent emission have been proposed, but it might result in a long array with many elements, increasing the cost and making the deployment and operation much more complex. In this paper, we evaluate the possibility of using an alternative approach using parametric acoustic sources to generate neutrino-like signals. This non-linear acoustic effect can also be applied to transient signals allowing to generate them by a "special modulation" at a larger frequency. The technique has the advantage of being much more directive since the directivity of the parametric source is similar to that of the large frequency used, and therefore it will result in a much more compact design with fewer sources. Here, we present the studies performed with planar transducers in a tank to evaluate the possibilities of the technique, which seems very promising according to our results.
\end{abstract}

(c) 2009 Elsevier B.V. All rights reserved.

\section{Introduction}

The possibility of calibrating and testing acoustic neutrino telescopes with neutrino-like signals is an essential aspect not only to check and monitor the sensitivity of the different acoustic sensors, but also to train and tune the detector, and to test the system and its reliability [1]. In this sense, the use of acoustic transmitters is foreseen in every experiment of this kind. However, due to the nature of the acoustic pulse produced in an ultra high energy neutrino interaction (i.e., a very directive 'pancake' short bipolar pulse), it is not easy to design a system able to reproduce the time and directivity patterns whilst bearing in mind practical issues such as ease of deployment and operation.

Different solutions have been proposed to have acoustic sources from transducers able to reproduce the time pattern, i.e., the bipolar signal [2-5]. However, much difficulty seems to appear when dealing with the directivity pattern. The simplest approximation to do it could be to build a linear array of acoustic transducers with coherent emission [2]. This approach will result in a long array with many elements, increasing the cost of the acoustic transmitter and complicating the deployment and operation of it, and consequently limiting its use. In this paper, we evaluate the possibility of using an alternative approach using parametric acoustic sources to generate neutrino-like signals. This technique would have the advantage of being much more directive since the directivity of the parametric source is

\footnotetext{
* Corresponding author. Tel.: +34 962849314; fax: +34962849309.

E-mail address: mardid@fis.upv.es (M. Ardid).
}

similar to that of the large frequency used, and therefore, it will result in a much more compact design with fewer sources, allowing compact designs with ease of deployment and operation.

In this paper the basics of the parametric acoustic source and how this effect could be used for the emission of neutrino-like signals in underwater neutrino telescopes are described. Afterwards, we present some studies and measurements done to understand the emission of neutrino-like signals using acoustic parametric sources. These studies will help to evaluate the feasibility of the technique and will give us the necessary input for the final design of the acoustic transmitter to reproduce neutrino-like signals based on the parametric effect.

\section{Parametric acoustic sources for neutrino calibration}

Acoustic parametric generation is a well-known non-linear acoustic effect, which is quite extensively studied and it has important applications in underwater acoustics, especially to obtain directive acoustic sources. This effect appears, for example, when there are two intense monochromatic acoustic beams with close frequencies travelling together along the medium (water, for example). Under these circumstances, in the region of non-linear interaction, secondary beams with sum, difference, double frequencies and harmonics appear. The main application consists of producing a directive low-frequency beam by using the difference frequency generation from two close high-frequency beams. At high frequency it is easy to have directive beams, property which is maintained for the secondary beams. Moreover, since the high-frequency components are rapidly absorbed, for 

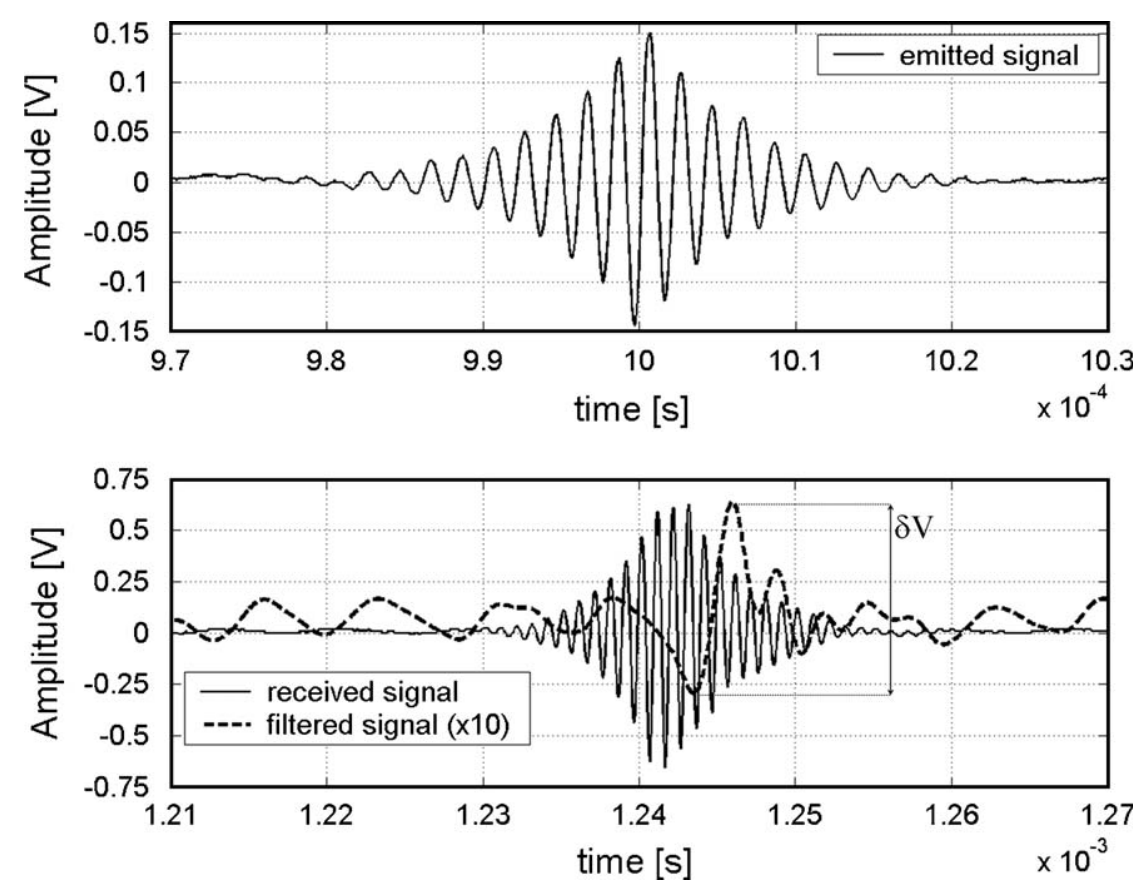

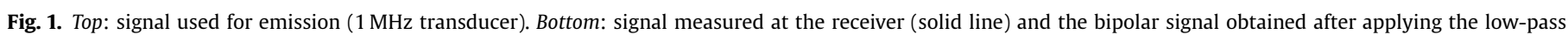
filter (dashed line).

large-range applications, just this secondary low-frequency component is available.

The parametric acoustic sources have some advantages with respect to traditional linear radiating systems, such as the opportunity of obtaining narrow directional patterns at small overall dimensions of primary transducer, the absence or low level of side-lobes in a directional pattern on a difference frequency, and a broad band of operating frequencies of radiated signals. For all these reasons, this kind of sources is widely used in underwater acoustics: sonar, communication, etc.

The same effect can be used for transient signals [6] as it is possible to generate a short signal by a "special modulation" at a larger frequency in such a way that the pulse interacts with itself in the medium providing the desired signal due to the sum (integral) of difference frequencies from the spectral content of the short modulated signal. Theoretical and experimental studies show that the shape of the secondary signal is basically the second derivative of the envelop of the primary signal, where the pressure amplitude is proportional to the square of the primary pressure amplitude, and depends on the non-linear acoustic parameter, besides other parameters of the medium. To determine the signal for the emission we have used the following expression:

$p(x, t)=\left(1+\frac{B}{2 A}\right) \frac{P^{2} S}{16 \pi \rho c^{4} \alpha x} \frac{\partial^{2}}{\partial t^{2}}\left[f\left(t-\frac{x}{c}\right)\right]^{2}$

where $P$ is the pressure amplitude of the primary beam pulse, $S$ the surface area of the transducer, $f(t-x / c)$ the envelop function of the signal, which is modulated at the primary beam frequency, $x$ the distance, $t$ the time, $B / A$ the non-linear parameter of the medium, $\rho$ the density, $c$ the sound speed and $\alpha$ the absorption coefficient. With this, $p(x, t)$ is the expected parametric signal. In our studies we would like to have for $p(x, t)$ a bipolar signal, and for this we have selected a first time derivative of a Gaussian function with a sigma of $5 \mu$ s. The envelope function $f(t-x / c)$ was calculated by integrating the expression.

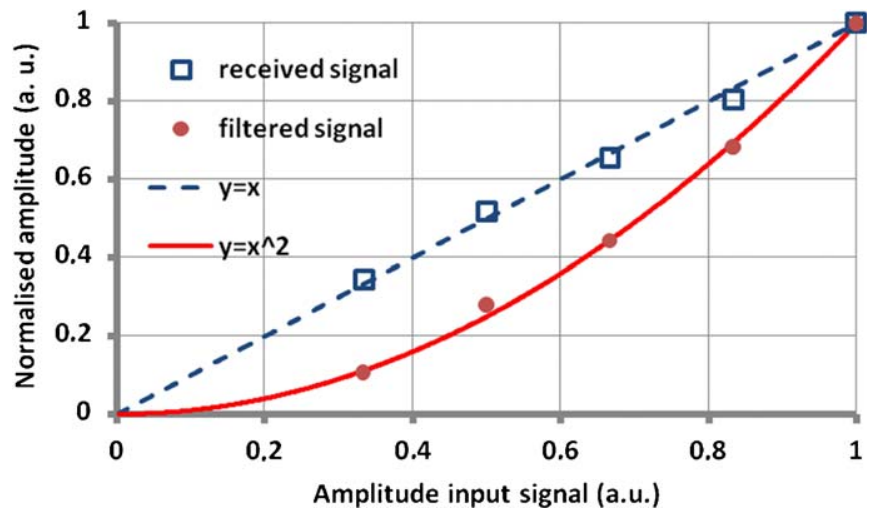

Fig. 2. Intensity of the received and bipolar (filtered) signal as a function of the primary beam intensity.

\section{Studies to evaluate the technique}

In this section, we present a study to obtain a neutrino acoustic signal from a planar transducer using the parametric effect in a small tank. Certainly, this lab study is still far from being an ideal calibrator for neutrino telescopes, but it can be very useful to evaluate the feasibility of the technique and set the basis for the final design of the calibrator using the parametric technique.

\subsection{Experimental setup}

The study of the generation of neutrino-like signals using parametric acoustic sources has been done in a $1.10 \times 0.85 \times$ $0.80 \mathrm{~m}^{3}$ tank. Two fixed planar transducers namely Reson TC3027 and Reson TC3021 were used as emitters, with 1 and $2 \mathrm{MHz}$ resonances, respectively. A Reson TC4014 hydrophone mounted on a mobile mechanical motor with a precision better than $0.1 \mathrm{~mm}$ was used as receiver. This hydrophone has a flat frequency 

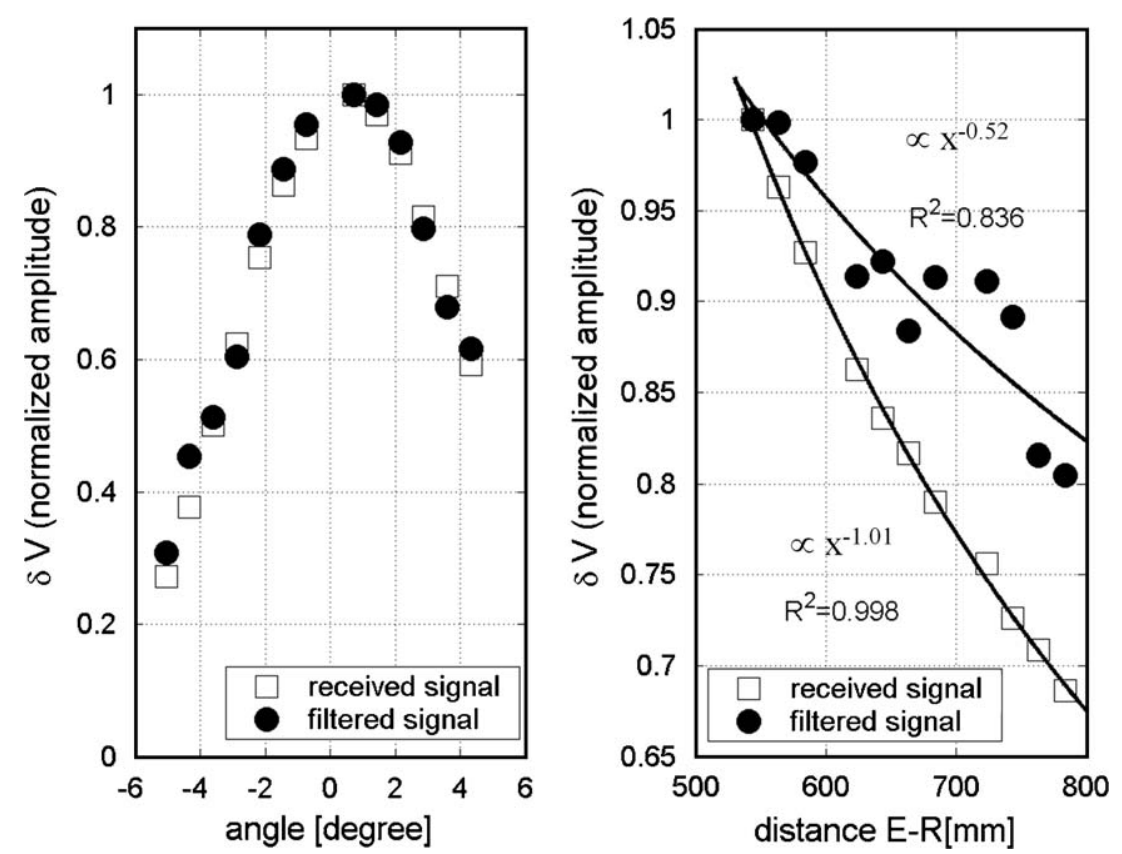

Fig. 3. Directivity pattern and distance dependence for the primary and parametric beams.

response below $400 \mathrm{kHz}$ with a sensitivity of around $-186 \mathrm{~dB}$ (ref $1 \mathrm{~V} / \mu \mathrm{Pa}$ ). Above $400 \mathrm{kHz}$, the sensitivity decreases with frequency, but at 1 and $2 \mathrm{MHz}$ it was still enough to detect the primary beams at these frequencies. The sensitivity pattern of the hydrophone was very convenient for our studies because it was sensitive enough to the primary frequencies allowing us to perform a fast alignment of the system, but the flat higher sensitivity at low frequency was very convenient to study the parametric signal. The movement of the receiver, as well as the emission and reception, was controlled by a computer with Labview. The emitter was feed with the NI PCI-5412 arbitrary waveform generator, whose signal was amplified using a 2100L RF Power Amplifier. The signal received was recorded using the NI PCI 5102 digitiser. The data was processed and analysed in MATLAB.

\subsection{Analysis and results}

The first study consisted in proving that it is possible to produce acoustic neutrino-like signals using the parametric effect. Applying the knowledge in transient parametric sources the signal for emission was calculated. For instance, Fig. 1 (top) shows the waveform used for the $1 \mathrm{MHz}$ primary beam before amplification (after amplification the peak amplitude used was around $120 \mathrm{~V}$ ). In Fig. 1 (bottom) the signal from the receiver with this signal is presented as a solid line. The primary signal is clearly visible, but a lower frequency component is also seen. To distinguish better the parametric signal a low-pass Butterworth filter with $200 \mathrm{kHz}$ (10th-order) was applied, and the result is given by the dashed line, where the bipolar signal is clearly seen. Considering that the sensitivity of the receiver at $1 \mathrm{MHz}$ is $29 \mathrm{~dB}$ less than the sensitivity for low frequency, the amplitude of the bipolar pressure signal in the tank experiment was usually in the [0.1-1\%] range of the amplitude of the received signal. As expected, the shape of the bipolar signal was following approximately the second derivative of the envelope of the $1 \mathrm{MHz}$ modulated signal. This aspect was confirmed increasing and decreasing the width of the signal, and using other signal shapes.

In the second study, the intensity of the parametric signal as a function of the primary beam intensity was measured. Fig. 2 shows the behaviour of the amplitude of the signal in the receiver, without filtering (main component is the $1 \mathrm{MHz}$ primary beam) and with the low-pass filter (basically the parametric bipolar signal). There is a linear relationship for the received signal whereas the bipolar signal is proportional to the square of the input signal, showing the non-linearity of the effect.

In the third study the directivity of the parametric source was measured and compared to the directivity of the transducer for the primary beam. The directivity patterns measured with a distance between emitter and receiver of about $80 \mathrm{~cm}$ are shown in Fig. 3 (left). In absolute numbers the received pressure is approximately 300 times larger than the filtered signal. Notice that although the spectral content of the parametric signal is completely different from that of the primary $1 \mathrm{MHz}$ beam, there is a similar directivity pattern for both cases.

Finally, the dependence of the primary $1 \mathrm{MHz}$ beam and the parametric signal with the distance between the emitter and the receiver at $0^{\circ}$ is shown in Fig. 3 (right). As expected, the pressure amplitude of the primary beam decreases with the inverse of the distance. However, there is a softer decrease in the case of the parametric signal. Our measurements are compatible with a decrease with the inverse of the square root of the distance.

\section{Conclusions and future}

From the measurements presented in the paper we can conclude that it is possible to generate neutrino-like acoustic signal using the parametric technique. With respect to other acoustic sources the parametric ones have shown high directivity, which could be very convenient to reproduce the pancake directivity with fewer sources in a more compact design.

After this first evaluation of the technique we have started to design an acoustic neutrino-calibrator using a cylindrical parametric array with piezoelectric tube ceramics. 


\section{Acknowledgments}

This work has been supported by the Ministerio de Ciencia e Innovación (Spain), project reference FPA2007-63729. We would like to thank V. Sánchez-Morcillo and I. Pérez-Arjona for fruitful discussions on parametric acoustic sources, as well as E. Soliveres, F. Hernández and M. Fuster for the help in some technical aspects of the work.

\section{References}

[1] M. Ardid, Calibration in acoustic detection of neutrinos, Nucl. Instr. and Meth. A (2009), this issue, doi:10.1016/j.nima.2009.03.071.
[2] G. Anton, et al., Astropart. Phys. 26 (2006) 301.

[3] O. Veledar, Hydrophone based calibrator for seawater acoustic detection of UHE neutrinos, Nucl. Instr. and Meth. A (2009), this issue, doi:10.1016/ j.nima.2009.03.070.

[4] M. Ardid, et al., Int. J. Mod. Phys. A 21 (Suppl. 1) (2006) 137.

[5] M. Ardid, et al., J. Phys. Conf. Ser. 81 (2007) 012015.

[6] M.B. Moffett, P. Mello, J. Acoust. Soc. Am. 66 (1979) 1. 